MALTIN MARUETTA

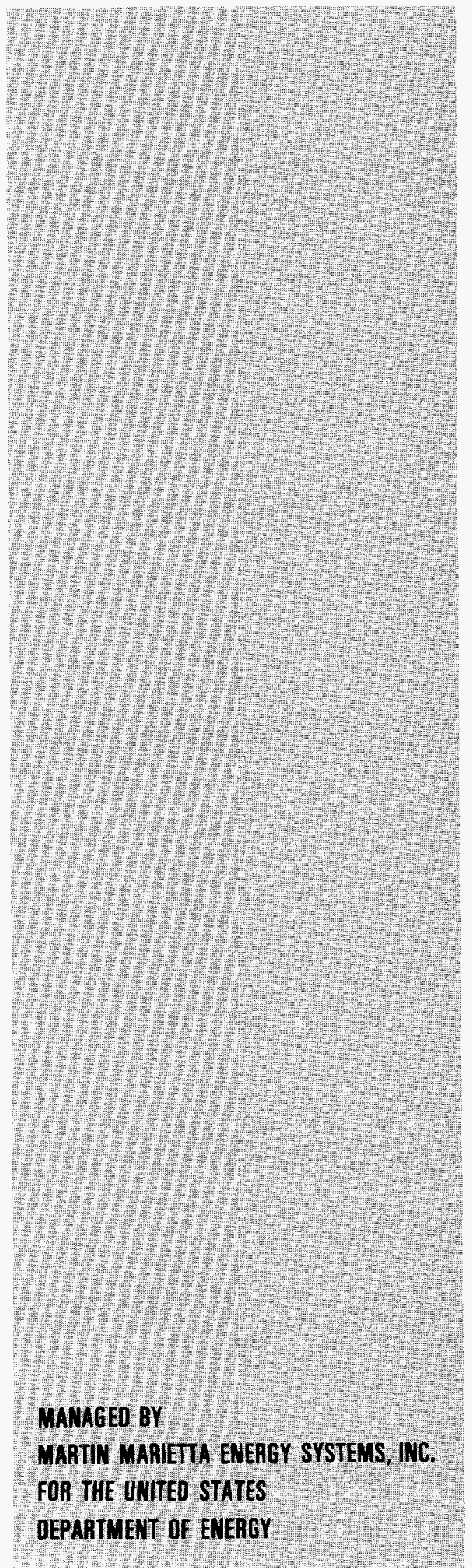

RESOURCE CONSERVATION AND RECOVERY ACT (RCRA) PART B PERMIT APPLICATION FOR TANK STORAGE UNITS AT THE OAK RIDGE Y-12 PLANT

Building 9811-1 RCRA Tank Storage Unit (OD-7)

Waste Oil/Solvent Storage Unit (OD-9)

Liquid Organic Solvent Storage Unit (OD-10)

Environmental Management Department

Health, Safety, Environment, and Accountability Organization

May 1994

Prepared by the

Oak Ridge Y-12 Plant

Oak Ridge, Tennessee 37831

Managed by

MARTIN MARIETTA ENERGY SYSTEMS, INC. for the

U.S. DEPARTMENT OF ENERGY

under contract DE-AC05-84OR21400

\section{MASTER}




\section{DISCLAIMER}

This report was prepared as an account of work sponsored by an agency of the United States Government. Neither the United States Government nor any agency thereof, nor any of their employees, make any warranty, express or implied, or assumes any legal liability or responsibility for the accuracy, completeness, or usefulness of any information, apparatus, product, or process disclosed, or represents that its use would not infringe privately owned rights. Reference herein to any specific commercial product, process, or service by trade name, trademark, manufacturer, or otherwise does not necessarily constitute or imply its endorsement, recommendation, or favoring by the United States Government or any agency thereof. The views and opinions of authors expressed herein do not necessarily state or reflect those of the United States Government or any agency thereof. 


\section{DISCLAIMER}

Portions of this document may be illegible in electronic image products. Images are produced from the best available original document. 
May 6, 1994

Mr. L. L. Radcliffe, Director

Waste Management and Technology

Development Division

Department of Energy, Oak Ridge Operations

Post Office Box 2001

Oak Ridge, Tennessee 37831

Dear Mr. Radcliffe:

Notice of Deficiency Response-Resource Conservation and Recovery Act (RCRA)

Part B Permit Application for the Container Storage Areas at the Oak Ridge Y-12 Plant

In reference to the letter dated March 30,1994, "Notice of Deficiency (NOD), RCRA Part B Permit Application-Tank Storage Areas," from the Tennessee Department of Environment and Conservation (TDEC) personnel, Enclosure 1 is a summary of the responses of the Y-12 Plant personnel to each of the TDEC comments listed in the subject NOD.

Due to the initial review cycle taking approximately 29 months, several items in the application are now obsolete. Therefore, a revised and complete permit application, entitled "Resource Conservation and Recovery Act (RCRA) Part B Permit Application for Tank Storage Units at the Oak Ridge Y-12 Plant," Document Y/TS-769/R3, is being submitted as Enclosure 2. Please note that changes made to the application are indicated in the right margin, except for the appendices which have been modified extensively.

As required in the NOD, please transmit four copies of Enclosures 1 and 2, and nine copies of each drawing, to the TDEC staff on or before May 16, 1994. Enclosure 3 is a computer disk containing the permit application, as requested in the NOD. This application was created using WordPerfect 5.1 software.

I certify that this document and all enclosures were prepared under my direction or supervision in accordance with a system designed to ensure that qualified personnel properly gathered and evaluated the information submitted. Based on my inquiry of the person or persons directly responsible for gathering information, the information submitted is, to the best of my knowledge and belief, true, accurate, and complete.

Note that the required permit certification has been signed and is included in Section $\mathrm{N}$ of the enclosed application. 
Mr. L. L. Radcliffe, DOE-ORO

Page 2

May 6, 1994

Please direct any questions or comments to B. E. Skaggs at (615) 241-2582.

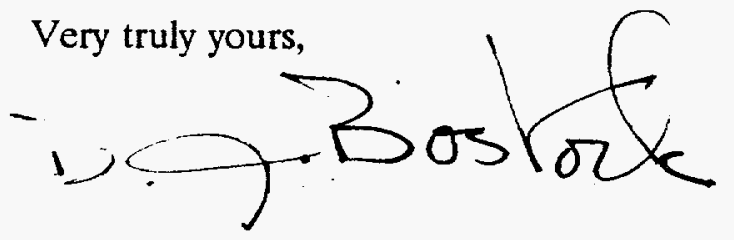

D. J. Bostock

Vice President and

Y-12 Plant Manager

Enclosures: As Stated

DJB:BESkaggs:krl

cc/encs 1 \& 2: R. D. Bagguley

L. Chi

C. H. Estes III

J. T. Foust

A. K. Lee, DOE-OSTI (2)

T. P. A. Perry

J. L. Sager, DOE-ORO

B. E. Skaggs

Y-12 Central Files

File-EMD-RC

cc: D. J. Bostock

T. R. Butz/R. M. Keyser/J. E. Powell

B. C. DeMonia, DOE-ORO

C. H. Fritts

J. S. Gilford

J. E. Heiskell/J. E. Stone

C. C. Hill

C. M. LaBorde

M. E. Mitchell 
Enclosure 1

Letter, Bostock to Radcliffe

Dated: May 6, 1994

Notice of Deficiency Response-Resource Conservation and Recovery Act (RCRA) Part B Permit Application for the Container Storage Areas at the Oak Ridge Y-12 Plant 


\author{
Notice of Deficiency \\ U.S. DOE Y-12 Plant \\ Tank Storage Areas \\ EPA ID: TN3 890090001 \\ Part B Permit Application \\ Dated, November 1991
}

1. "Rule 1200-1-11.06(9) requires the markings and labels to be placed on containers and it should be stated under Process Information (Part D) of the application."

Response: Marking and labeling requirements have been added to Sections $C$ and $D$ of the revised application.

2. "Under the Inspection Logs (in Appendix F-2), an inspection log should be provided for the General Inspection Schedule. All items listed in the Inspection Schedule should be included in the inspection logs."

Response: The inspection log in Appendix F-2 has been revised to include all items listed in the inspection schedule.

3. "Provide 9 copies of all drawings, folded, and placed in three-ring plastic sheets. Labels shall be provided separately."

Response: Nine copies of each drawing in the revised permit application have been included as instructed. 
Enclosure 2

Letter, Bostock to Radcliffe

Dated: May 6, 1994

Notice of Deficiency Response-Resource Conservation and Recovery Act (RCRA) Part B Permit Application for the Container Storage Areas at the Oak Ridge Y-12 Plant 


\title{
RESOURCE CONSERVATION AND RECOVERY ACT (RCRA) PART B PERMIT APPLICATION FOR TANK STORAGE UNITS AT THE OAK RIDGE Y-12 PLANT
}

\author{
Building 9811-1 RCRA Tank Storage Unit (OD-7) \\ Waste Oil/Solvent Storage Unit (OD-9) \\ Liquid Organic Solvent Storage Unit (OD-10)
}

Environmental Management Department

Health, Safety, Environment, and Accountability Organization

Prepared by the

Oak Ridge Y-12 Plant

Oak Ridge, Tennessee 37831

Managed by

MARTIN MARIETTA ENERGY SYSTEMS, INC.

for the

U.S. DEPARTMENT OF ENERGY

under contract DE-AC05-84OR21400 


\section{TABLE OF CONTENTS}

$\underline{\text { Page No. }}$

SECTION B - FACILITY DESCRIPTION $\ldots \ldots \ldots \ldots \ldots \ldots \ldots \ldots$ B-1

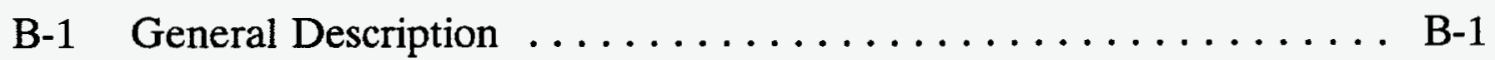

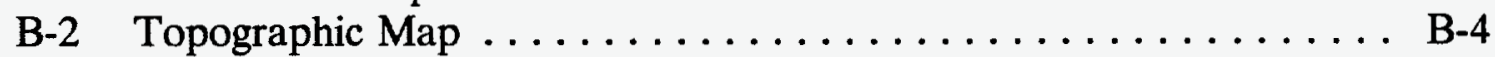

B-3 Location Information $\ldots \ldots \ldots \ldots \ldots \ldots \ldots \ldots \ldots \ldots \ldots \ldots \ldots$

B-4 Traffic Information $\ldots \ldots \ldots \ldots \ldots \ldots \ldots \ldots \ldots \ldots \ldots \ldots \ldots$

SECTION C - WASTE CHARACTERISTICS $\ldots \ldots \ldots \ldots \ldots \ldots \ldots \ldots$ C-1

C-1 Chemical and Physical Analyses $\ldots \ldots \ldots \ldots \ldots \ldots \ldots \ldots \ldots$ C-1

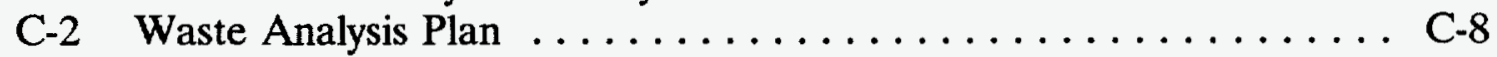

C-3 Land Disposal Restrictions $\ldots \ldots \ldots \ldots \ldots \ldots \ldots \ldots \ldots \ldots \ldots \ldots \ldots \ldots \ldots$

SECTION D - PROCESS INFORMATION $\ldots \ldots \ldots \ldots \ldots \ldots \ldots \ldots \ldots$ D-1

D-1 Container Systems . . . . . . . . . . . . . . . . . D-1

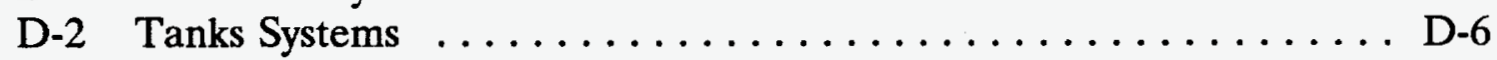

SECTION E - GROUNDWATER MONITORING $\ldots \ldots \ldots \ldots \ldots \ldots$ E-1

SECTION F - PROCEDURES TO PREVENT HAZARDS $\ldots \ldots \ldots \ldots \ldots$ F-1

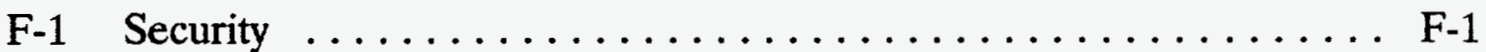

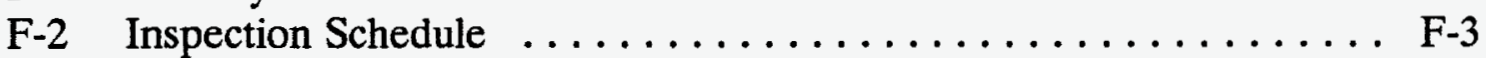

F-3 Waiver of Preparedness and Prevention Requirements .......... F-6

F-4 Preventative Procedures, Structures and Equipment . . . . . . . . F-7

F-5 Prevention of Reaction of Ignitable, Reactive, and

Incompatible Wastes $\ldots \ldots \ldots \ldots \ldots \ldots \ldots \ldots \ldots \ldots \ldots \ldots \ldots$

SECTION G - CONTINGENCY PLAN $\ldots \ldots \ldots \ldots \ldots \ldots \ldots \ldots \ldots$ G-1

G-1 General Information . ....................... G-1

G-2 Emergency Coordinators $\ldots \ldots \ldots \ldots \ldots \ldots \ldots \ldots \ldots \ldots \ldots \ldots \ldots \ldots \ldots \ldots$

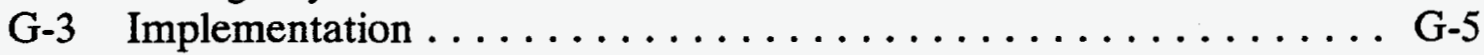

G-4 Control Procedures $\ldots \ldots \ldots \ldots \ldots \ldots \ldots \ldots \ldots \ldots \ldots \ldots \ldots \ldots \ldots \ldots$

G-5 Emergency Response Procedures $\ldots \ldots \ldots \ldots \ldots \ldots \ldots \ldots$ G-7

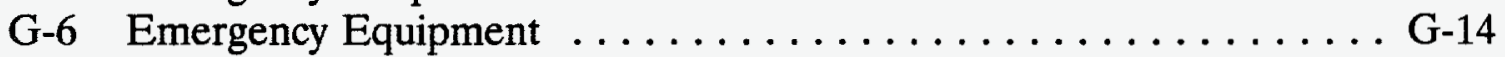

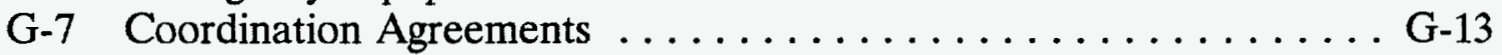

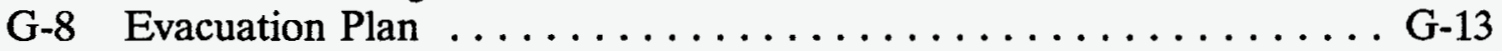

G-9 Required Reports $\ldots \ldots \ldots \ldots \ldots \ldots \ldots \ldots \ldots \ldots \ldots \ldots \ldots \ldots$ 
TABLE OF CONTENTS

(Continued)

Page No.

SECTION H - PERSONNEL TRAINING $\ldots \ldots \ldots \ldots \ldots \ldots \ldots \ldots \ldots$ H-1

H-1 Outline of Training Program $\ldots \ldots \ldots \ldots \ldots \ldots \ldots \ldots \ldots . . . . .1$

H-2 Implementation and Documentation of Training Program $\ldots . . . \mathrm{H}-7$

SECTION I - CLOSURE PLAN, POST CLOSURE PLAN, AND FINANCIAL REQUIREMENTS $\ldots \ldots \ldots \ldots \ldots \ldots \ldots$ I-1

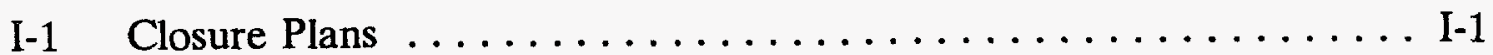

I-2 Post-Closure Plan . . . . . . . . . . . . . . . . . . . I

I-3 Certifications and Notices Required For Closure $\ldots \ldots \ldots \ldots \ldots$. I-9

I-4 Closure Cost Estimate . . . . . . . . . . . . . . . . . I I-10

I-5 Financial Assurance Mechanism For Closure $\ldots \ldots \ldots \ldots \ldots \ldots$ I-10

I-6 Post-Closure Cost Estimate . . . . . . . . . . . . . . . I-10

I-7 Financial Assurance Mechanism For Post-Closure . . . . . . . I-10

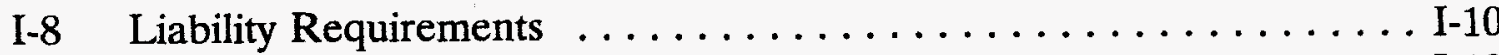

I-9 State Financial Mechanisms . . . . . . . . . . . . . . I-10

SECTION J - RECORD KEEPING $\ldots \ldots \ldots \ldots \ldots \ldots \ldots \ldots \ldots \ldots \ldots$ J-1

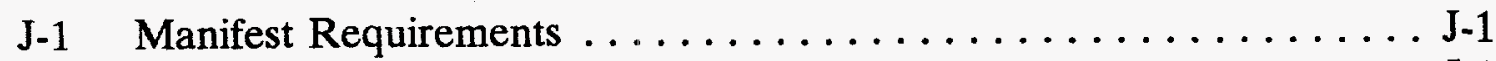

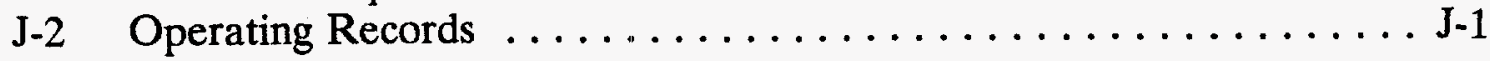

SECTION K - OTHER FEDERAL LAWS $\ldots \ldots \ldots \ldots \ldots \ldots \ldots \ldots \ldots \ldots \ldots \ldots$

SECTION L - ORGANIC AIR EMISSIONS $\ldots \ldots \ldots \ldots \ldots \ldots \ldots \ldots$ L-1

L-1 Specific Part B Information Requirements For

Process Vents ........................ L-1

L-2 Specific Part B Information Requirements For

Equipment $\ldots \ldots \ldots \ldots \ldots \ldots \ldots \ldots \ldots \ldots \ldots \ldots \ldots \ldots \ldots \ldots \ldots$

SECTION M - SOLID WASTE MANAGEMENT UNITS $\ldots \ldots \ldots \ldots \ldots$ M-1

SECTION N - CERTIFICATION $\ldots \ldots \ldots \ldots \ldots \ldots \ldots \ldots \ldots \ldots \ldots \ldots \ldots \ldots \ldots$ 


\section{LIST OF FIGURES}

Figure No.

Page No.

B-1 Wind Rose from the West Meteorological Tower (60 meters), Y-12 Plant Site . . . . . . . . . . . . . . . B-6

D-1 Building 9811-8 Waste/Oil Solvent Storage Tank

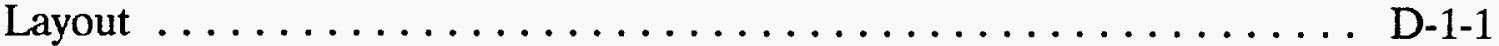

D-2 Oil Dike - 10 Storage Unit Plan View $\ldots \ldots \ldots \ldots \ldots \ldots \ldots \ldots \ldots$ D-1-2

D-3 Building 9811-1 Storage Tank Unit Layout $\ldots \ldots \ldots \ldots \ldots \ldots \ldots$ D-1-3

D-4 Building 9811-1 Process Flow Diagram (OD-7) $\ldots \ldots \ldots \ldots \ldots \ldots \ldots$ D-1-4

D-5 OD-9, Waste Oil/Solvent Storage Tank Process Flow Diagram ............................. D-1-5

D-6 Oil Dike - 10 Storage Tanks Process Flow Diagram ........... D-1-6

I-1 Building 9811-1 RCRA Tank Storage Unit (OD-7) $\ldots \ldots \ldots \ldots \ldots \ldots$ I-3

I-2 Waste Oil/Solvent Storage Unit (OD-9) $\ldots \ldots \ldots \ldots \ldots \ldots \ldots \ldots \ldots$ I-4

I-3 Liquid Organic Solvent Storage Unit (OD-10) $\ldots \ldots \ldots \ldots \ldots \ldots \ldots$ I-5 


\section{LIST OF TABLES}

Table No.

Page No.

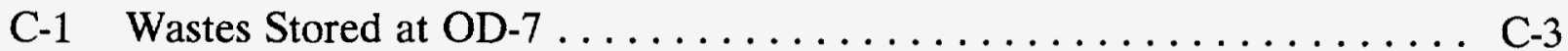

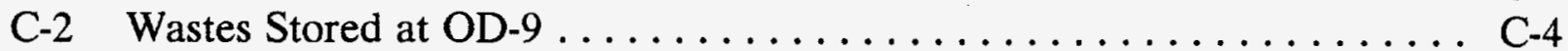

C-3 Waste Categories and Storage Arrangements at OD-10 ........ C-6

C-4 Waste Analysis Parameter and Rationale .................. C-9

C-5 Y-12 Storage Tank Waste Acceptance Criteria $\ldots \ldots \ldots \ldots \ldots \ldots \ldots$ C-11

C-6 Test Methods for Storage Tank Waste $\ldots \ldots \ldots \ldots \ldots \ldots \ldots \ldots$ C-12

F-1 General Inspection Schedule $\ldots \ldots \ldots \ldots \ldots \ldots \ldots \ldots \ldots \ldots \ldots \ldots \ldots \ldots \ldots \ldots \ldots \ldots .1-1$

F-2 Container Storage Area Inspection Schedule $\ldots \ldots \ldots \ldots \ldots \ldots \ldots \ldots$ F-1-2

F-3 Tank Storage Area Inspection Schedule $\ldots \ldots \ldots \ldots \ldots \ldots \ldots \ldots \ldots$ F-1-3

F-4 Daily Inspection Log Sheet for OD-7, OD-9, and OD-10 . . . . . . . F-2-1

F-5 Weekly Inspection Log Sheet for OD-7, OD-8, and OD-10 . . . . . F F-2-3 


\title{
LIST OF APPENDICES
}

\author{
B-1 Maps \\ B-2 Wind Rose \\ C-1 Waste Analyses \\ C-2 Waste Identification Forms \\ C-3 Potentially Incompatible Waste \\ D-1 Tank Storage Unit Figures \\ D-2 Secondary Containment Calculations \\ D-3 Tank Construction Details \\ D-4 Tank Certification \\ F-1 Inspection Schedule \\ F-2 Inspection Logs \\ G-1 Emergency Spill Equipment \\ G-2 Unit Specific Emergency \& Waste Descriptions \\ H-2 Job Descriptions \\ H-3 Training Requirements \\ L-1 Equipment Identification
}




\section{LIST OF ACRONYMS}

$\begin{array}{ll}\text { ANSI } & \text { American National Standards Institute } \\ \text { API } & \text { American Petroleum Institute } \\ \text { ASME } & \text { American Society of Mechanical Engineers } \\ \text { ASTM } & \text { American Society for Testing and Materials } \\ \text { BTU } & \text { British Thermal Unit } \\ \text { CFR } & \text { Code of Federal Regulations } \\ \text { DARA } & \text { Disposal Area Remedial Action } \\ \text { DOE } & \text { U.S. Department of Energy } \\ \text { DOT } & \text { U.S. Department of Transportation } \\ \text { EPA } & \text { U.S. Environmental Protection Agency } \\ \text { HSWA } & \text { Hazardous and Solid Waste Amendments } \\ \text { IH } & \text { Industrial Hygiene } \\ \text { IRWTA } & \text { Interim Reactive Waste Treatment Area } \\ \text { LDAR } & \text { Leak Detection and Repair } \\ \text { MMES } & \text { Martin Marietta Energy Systems (or Energy Systems) } \\ \text { NFPA } & \text { National Fire Protection Association } \\ \text { OJT } & \text { On-the-Job Training } \\ \text { OSHA } & \text { Occupational Safety and Health Act } \\ \text { PED } & \text { Plant Emergency Director } \\ \text { PCB } & \text { polychlorinated biphenyl } \\ \text { PSS } & \text { Plant Shift Superintendent } \\ \text { RCRA } & \text { Resource Conservation and Recovery Act } \\ \text { RP } & \text { Radiation Protection } \\ \text { SARA } & \text { Superfund Amendments Reauthorization Act } \\ \text { SID } & \text { Stream Identification } \\ \text { TCLP } & \text { Toxicity Characteristic Leaching Procedure } \\ \text { TDEC } & \text { Tennessee Department of Environment and Conservation } \\ \text { TMS } & \text { Training Management System } \\ \text { TSCA } & \text { Toxic Substances Control Act } \\ \text { UCN } & \text { Uniform Control Number } \\ \text { WTSD } & \text { Waste Transportation, Storage, and Disposal } \\ & \end{array}$




\section{SECTION B}

\section{FACILITY DESCRIPTION}

This section of the application provides a general description of the hazardous waste management facility as required by 40 CFR Part 270.14(b)(1) and Rules Governing Hazardous Waste Management in Tennessee, Rule 1200-1-11-.07(5)(a). This description is intended to provide guidance and facility orientation to the permit application reviewer and the permit writer for the Oak Ridge Y-12 Plant.

\section{B-1 GENERAL DESCRIPTION}

The Oak Ridge Y-12 Plant was built by the U.S. Army Corps of Engineers in 1943 as part of the Manhattan Project and given the original mission to separate the fissionable isotope of uranium by the electromagnetic process. After World War II, the electromagnetic separation process was discontinued in favor of the more economical gaseous diffusion process. In recent years, the Y-12 Plant staff has developed this facility into a highly sophisticated manufacturing and developmental engineering organization.

The U.S. Department of Energy (DOE) owns and operates the Y-12 Plant. Personnel from Martin Marietta Energy Systems, Inc., co-operate and manage the Y-12 Plant. Since 1984, the facility has been managed by Martin Marietta Energy Systems, Inc., personnel, under a prime contract with the U.S. DOE. The contract is administered by personnel at the DOE Oak Ridge Operations Office.

The Y-12 Plant occupies approximately 800 acres in Anderson County, Tennessee, and is located southwest of the city of Oak Ridge. The site employs approximately 5,000 people including employees of the Oak Ridge National Laboratory assigned to the Y-12 Plant. Two surface streams, East Fork Poplar Creek and Bear Creek, border the facility on the south, east, and southwest sides of the plant. There is access to the Y-12 Plant, controlled on Bear Creek Road, on the north side of the facility; indirect access from Scarboro Road on the east side of the facility; and indirect access to the facility on the south side via Bethel Valley Road. A controlled access road from Bethel Valley Road by way of Mt. Vernon Road is located on the southwest side of the site.

It is the mission of the Y-12 Plant to serve as a key manufacturing technology center for the development and demonstration of unique materials, components, and services of importance to the DOE and the nation. This is accomplished through the reclamation and 
storage of nuclear materials, manufacture of nuclear materials, manufacture of components for the defense capabilities of the nation, support to national security programs, and services provided to other customers as approved by DOE.

The Building 981-1 RCRA Tank Storage Unit, the Naste Oil/Solvent Storage Unit, and the Liquid Organic Solvent Storage Unit commonly referred to as OD-7, OD-9, and OD-10, respectively, are tank storage areas located at the Y-12 Plant. For the purposes of discussion throughout this application, each unit will be referred to by the OD-designation assigned to the unit.

\section{$\underline{\text { OD-7 }}$}

This unit is an interim status storage area and has been designated as the primary storage unit for nonignitible and nonreactive uranium-contaminated waste oils and solvents. The OD-7 is located southwest of Building 9204-4 at the intersection of West Second Street and K Road.

The storage tank area of the unit consists of a 50- $x$ 40-foot nominal concrete diked area. Positioned within the diked area are four, 30,000-gallon tanks (F-1, F-2, F-3, and F-4), and two, 10,000-gallon tanks (F-5 and F-6). The two, 10,000-gallon tanks are in place, but not in service.

Waste mixtures are usually transported to the facility in 55-gallon drums, steel or polyethylene portable tanks, or tanker trucks. The tanker truck loading/unloading station is at the southeast corner of the unit. Three sides of the loading/unloading station are diked, and the open entrance to the station is provided with a 3-inch high curb. Facility or portable pumps are used to transfer the waste oil/solvent/water mixture from the drums, portable tanks, or tanker trucks to one of the bulk storage tanks. Transfer may also take place to a tanker truck from a tank or drum.

The wastes stored at this unit typically consist of mixtures of oils and chlorinated organics. Some solvents may contain trace quantities of uranium and beryllium, as well as significant quantities of water. PCB-contaminated oils less than $50 \mathrm{ppm}$, as well as nonchlorinated solvents and some additional metals contaminated wastes, may also be accepted at the unit. 


\section{$\underline{\text { OD-9 }}$}

This unit typically receives and stores nonignitable and nonreactive waste oil/solvents that may contain water, may be contaminated with PCBs greater than $50 \mathrm{ppm}$ and uranium, and may contain chlorinated organic solvents. The liquid wastes are stored at OD-9 in tanks and drums until sufficient volume is accumulated for transportation to an outside facility for recovery or disposal.

This unit is an interim status storage area adjacent to Building 9811-8. OD-9 is located west of Building 9720-58, southwest of Building 9616-7 along Old Bear Creek Road.

The unit includes a concrete diked area with concrete pads to support six, 40,000-gallon storage tanks, associated process pumps, auxiliary piping, sump and sump pump, and instrumentation. The facility currently has five tanks (F1, F2, F3, F4, and F5) constructed with a base already in place for the sixth tank. The five tanks have dimensions of approximately 13.5 feet in diameter and 38 feet in height. These tanks are enclosed in a concrete retention basin with an internal width of 42 feet and an internal length of 73.5 feet. The approximate basin wall height of the basin is 5.6 feet.

This unit also includes a truck transfer station utilized for the loading and unloading of wastes. The transfer station is built on a concrete slab of approximately $73.5 \times 22$ feet that is sloped downward from both ends towards the center of the station. The containment structure has been constructed with a slope that diverts all spills into the diked area. The station loading platform is constructed of structural steel and is elevated into position on the concrete pad. Transfer pumps and auxiliary piping are positioned within the curbed transfer station. A container storage area within the truck transfer station has been provided for a RCRA capacity of 8,800 gallons. Polyethylene tanks containing free liquids may also be stored in this area.

\section{$\underline{\mathrm{OD}-10}$}

This unit is an interim status storage area which receives and stores liquid organic wastes generated in the Y-12 Plant. These wastes typically include waste oil and combustible and flammable waste liquids that may contain trace quantities of uranium. The OD-10 is located on the Y-12 Reservation northwest of the West End Treatment Facility, on the north side of Bear Creek Road, approximately 400 feet east of the western intersection of New and Old Bear Creek Roads (northwest corner of the new salvage yard). The entire unit, including the new salvage yard, is enclosed by a chain link fence. 
The Liquid Organic Solvent Storage Facility, OD-10, consists of a 4,500-square feet concrete slab and foundation of which half (2,250 sq. ft.) is contained by a 3-foot-high concrete dike for location of bulk storage tanks. Four 6,500-gallon carbon steel tanks (F-700A, F-700B, F-900A, and F-900B), and two 3,000-gallon stainless steel tanks (F-600A and F-600B) are located within the diked area, with space available for two additional tanks. The remaining 2,250 square feet of the unit is curbed and contained under a 14-foot-high canopy. This covered area houses the various pumping and piping systems, a tanker loading/unloading station, an electrical grounding grid, and approximately 2,100 square feet of storage and sampling area for received drums. Sumps with pumps are located in the diked and curbed areas for collection and transfer of collected material to the aqueous retention basin.

The 2,100 square feet of container storage is designed to handle additional container storage. The container storage area has been provided for a RCRA capacity of 10,560 gallons. Steel drums and polyethylene tanks that are used to transport the wastes to OD-10 may also be used for storage at the facility. The liquids received at this facility are pumped into the tanks for storage until sufficient quantity is accumulated for final disposal or recovery.

\section{B-2 TOPOGRAPHIC MAP}

\section{B-2a General Information}

This section discusses the maps which comply to the requirements of 40 CFR Part 270.14(b)(19) and Tennessee Rule 1200-1-11-.07(5)(a)17. Appendix B contains the maps that show the locations of these units as well as the solid waste management units, general site plan, facility property boundaries, locations of buildings, and the contour of the site to show surface water flow. Several maps have been utilized to give the permit reviewer and writer a clearer understanding of the location of these three facilities. The following maps are included in Appendix B-1 and have been provided to facilitate review:

Map 1: The Oak Ridge Y-12 Emergency Facilities Directory shows the general site plan. This map shows the locations of major plant buildings and other structures, the facility property boundaries, the legal boundaries of the site, the locations of portal controlled access roads, exclusion and protected areas of the plant, guard towers and vehicular check points. The plant access roads as well as internal roads are also shown on this map. (Scale: 1 inch $=400$ feet).

Map 2: The Oak Ridge Y-12 RCRA Waste Unit Map illustrates the hazardous waste management units at the Y-12 Plant and the surrounding topography and land uses 
around the units. The topography of this map includes a contour interval that clearly illustrates surface water flow patterns around the interim status units. The two major surface water streams are illustrated on this map as well as tributaries and intermittent streams feeding East Fork Poplar Creek and Bear Creek. (Scale: 1 inch = 1,280 feet).

Map 3: The Y-12 Plant Loading and Shipping Docks Map illustrates the loading and unloading docks and shipping docks around the plant. (Scale: 1 inch $=400$ feet).

Map 4: The Y-12 Floodplain map shows the East Fork Poplar Creek 100-year floodplain. The 500-year floodplain and maximum probable flood are also shown for the Y-12 Plant. The units in this package (OD-7, OD-9, and OD-10) are not located within the 100-year floodplain of either Bear Creek or East Fork Poplar Creek. Flood control and drainage barriers are, therefore, not necessary. (Scale: 1 inch $=600$ feet).

Maps 5 \& 6: Y-12 Sanitary Sewer System Master Plan and Y-12 Storm Sewer Master Plan Maps. These maps illustrate the sanitary sewer system and the detailed storm water drainage system for the Y-12 Plant. (Scale: Sanitary Sewers - 1 inch $=530$ feet, Storm Sewers -1 inch $=200$ feet).

A variance under Tennessee Rule 1200-1-11-.07(5) is necessary for the required map scale of one inch equals 200 feet for these maps. The size of the Y-12 Plant makes the use of the required scale difficult to utilize for review. A variance has been approved for alternate map scales to be used in the application.

Information required to be submitted in this section also includes the following areas:

- Wind rose - The wind rose shown in Figure B-1 indicates wind direction and wind speed taken from the 60 meter point on the west meteorological tower for 1990. This wind rose was chosen as typical for the facilities located on the west end of the plant included in this package. Appendix B-2 includes information provided by additional wind roses taken from the data gathered from the two meteorological towers located at the east and west end of the plant.

- Injection and withdrawal wells. Not applicable. There are no injection wells or withdrawal wells at the facility. Therefore, there are none shown on the permit maps. 


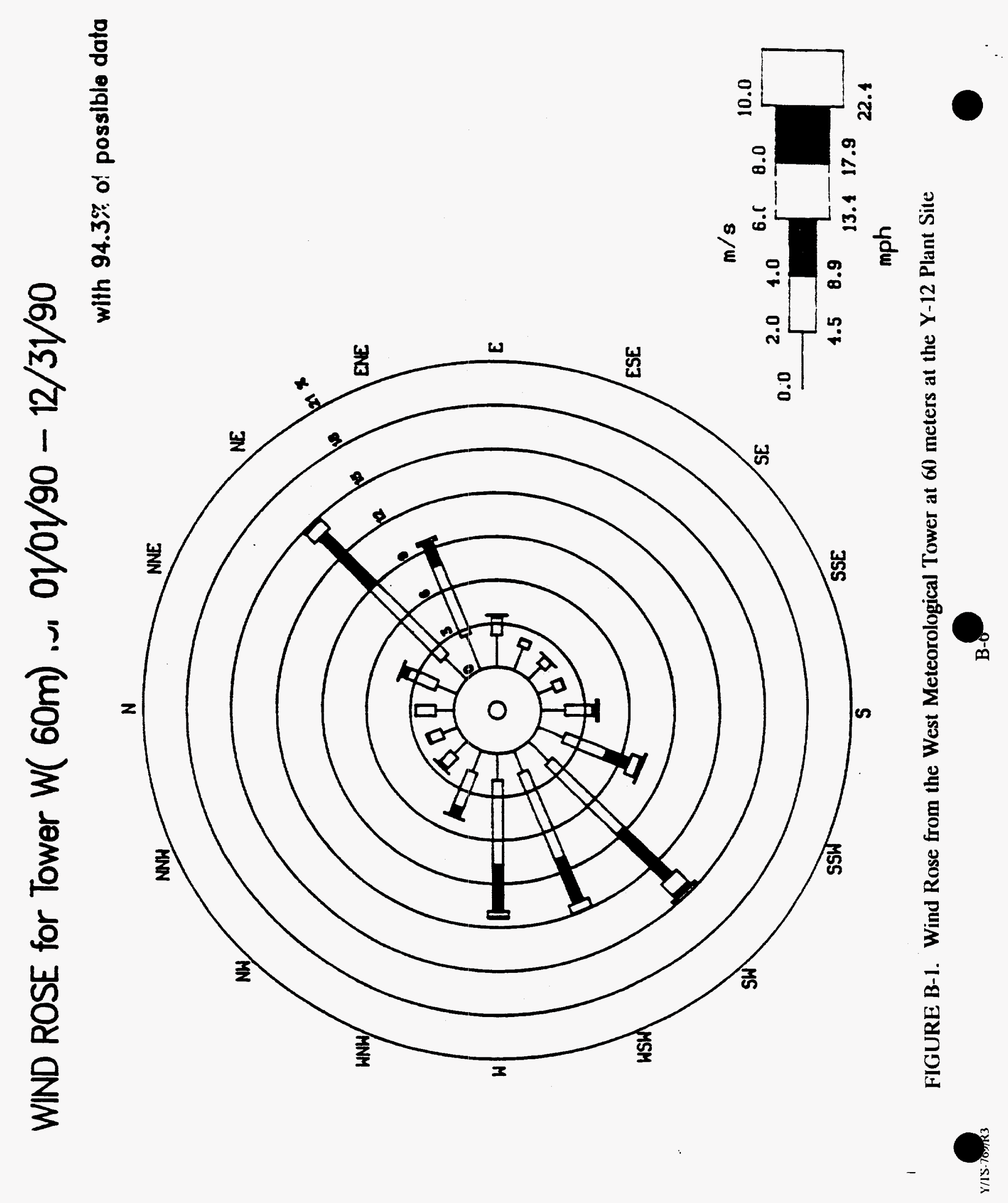


- Loading and unloading areas. The loading and unloading areas for OD-7, OD-9, and OD-10 are illustrated on Map 3 and also in the facility drawings referenced in Section D.

B-2b Additional Topographic Requirements for Land Storage, Treatment and Disposal Facilities and Post Closure Permits for Closed Land Units.

Not Applicable. None of these three units are hazardous waste land storage, treatment, or disposal units. Additional topographic information is not required of these hazardous waste management units in order to comply with the permit application regulations.

\section{B-3 LOCATION INFORMATION}

The locations of OD-7, OD-9, and OD-10 at the Y-12 Plant are illustrated in Map 2 of Appendix B-1.

\section{B-3a Seismic Considerations}

Not Applicable. Since the Y-12 Plant is an existing facility and is not located in a political jurisdiction as specified in 40 CFR Part 264, Appendix VI, seismic considerations need not be addressed.

\section{B-3b Floodplain Standard}

The floodplain map for the Y-12 Plant site is shown as Map 4. The Map illustrates the 100year, 500-year and maximum probable floor plain for East Fork Poplar Creek at the Y-12 plant site. The hazardous waste storage units (OD-7, OD-9, and OD-10) are not located within these floodplains. The Map was developed by the Tennessee Valley Authority (TVA). The techniques used to create the floodplain information for the Y-12 Plant Site are the same as those used by TVA for defining, developing and analyzing floodplains for the Federal Insurance Administration.

B-3b(1)(a) Flood Proofing and Flood Protection

Not applicable. None of the storage units are located within the floodplain.

B-3b(1)(b) Flood Plan

Not applicable. None of the storage units are located within the floodplain.

B-3b(2) Plan for Future Compliance with Floodplain Standard

Not applicable. None of the storage units are located within the floodplain. 


\section{B-3b(3) Waiver for Land Storage and Disposal Facilities}

Not applicable. None of the storage units are located within the floodplain.

\section{B-4 TRAFFIC INFORMATION}

The Y-12 Plant is a major in ustrial type facility operated under contract to the U.S. Department of Energy. The road system and its construction are typical of an industrial complex or military facility with numerous production, storage, administrative, maintenance, and utility buildings. These roads can easily bear the weight of the waste hauling vehicles used for each hazardous waste management unit. Roads are mostly two-way and built of black top to accommodate heavy and light traffic including automobiles, light trucks, armored security vehicles, heavy trucks, and tractor trailers (including those used to move nuclear material). There are also some constructed gravel roads capable of carrying the intended traffic. Entry and exit are controlled by guarded, locked gates. Internal traffic is controlled by marked lanes and stop signs at intersections typical of municipal or industrial complex surface streets. Hazardous wastes transported within the Plant or off-site generally consist of dump truck loads of soils and palletized drums, and may periodically include tanker loads of liquids such as oils.

The minimum requirement for construction of existing paved roads at $\mathrm{Y}-12$ is 1.5 to 14.0 inches of asphaltic concrete pavement overlaid on 6.0 to 18.0 inches of compacted aggregate base. All new paved roads are constructed with a minimum of 1.5 inches of asphaltic concrete pavement overlaid on 8.0 inches of stabilized aggregate base course. All paved roads to be used for access to and exit from hazardous waste management unit areas are capable of bearing loads up to allowable state highway limitations.

Other roads used for access to and exit from hazardous waste management unit areas are constructed of crushed stone surfaces and are designed to provide all-weather utilization throughout the Y-12 Plant. These gravell access roads are constructed with a minimum of 6.0 inches of crushed stone on a prepared subgrade and are useable on a year-round basis. These gravel roads are designed to support the anticipated traffic to and from the hazardous waste management unit areas.

The access roads to the units are useable on a year-round basis to authorized personnel only. The estimated traffic volume is twenty four vehicles per week. The types of vehicles typically used during operations are flatbed, pickup, and occasionally tanker trucks. The 
load bearing capacities of all access roads meet or exceed DOT, Bureau of Highways standards for these vehicles.

\section{$\underline{\mathrm{OD}-7}$}

Access to OD-7 is from West Second Street, which is south of the facility. This street is a typical paved street which meets the minimum requirements as specified for Y-12 Plant paved road. This road is capable of supporting the traffic associated with servicing of this facility.

\section{$\underline{\text { OD-9 }}$}

Access to OD-9 is from Old Bear Creek Road, which is south of the facility. A paved roadway, has been constructed according to $\mathrm{Y}-12$ roadway specifications between Old Bear Creek Road and OD-9 to provide access to and exit from the facility. This new roadway, as well as Old Bear Creek Road, are designed to be capable of handling the weight of loaded tanker trucks and drum transport vehicles destined for this facility.

\section{$\underline{\mathrm{OD}-10}$}

Access to OD-10 is from Bear Creek Road, which is south of the facility. Bear Creek Road is designed to meet the minimum construction requirements as specified. A gravel roadway provides entrance from Bear Creek Road to OD-10 to provide access to and exit from the facility. The gravel roadway and Bear Creek Road are capable of handling the weight of loaded tanker trucks and drum transport vehicles. 


\section{SECTION C \\ WASTE CHARACTERISTICS}

This section of the application describes the chemical and physical nature of the hazardous wastes handled and stored in each of the following storage units:

- $\quad$ Building 9811-1 RCRA Tank Storage Unit (OD-7);

- Waste Oil/Solvent Storage Unit (OD-9); and the

- Liquid Organic Solvent Storage Unit (OD-10).

This section also includes the waste analysis plan for sampling, testing, and evaluating the waste to assure that sufficient information is available for proper waste management. This information is submitted in response to the RCRA Part B Permit application requirements, as specified in 40 CFR Parts 270.14(b)(2) and (3); and in Rules Governing Hazardous Waste Management in Tennessee, Rules 1200-1-11-.07(5)(a)2 and 3.

\section{C-1 CHEMICAL AND PHYSICAL ANALYSIS}

\section{General Description}

The hazardous wastes normally stored at OD-7 and OD-9 can be described as waste oil mixed with organic solvents. Some of the solvents may contain trace quantities of metals, radioactive materials, $\mathrm{PCBs}$ (less than $50 \mathrm{ppm}$ at OD-7), as well as significant quantities of water.

The hazardous waste normally stored at OD-10 consists of various liquid organic solvents typically with a flash point less than $140^{\circ} \mathrm{F}$. Some may contain trace quantities of uranium and PCBs.

All wastes stored in these units have been generated at the Y-12 Plant and are primarily liquid except for some sludges/solids stored in drums at OD-9 and OD-10. The wastes stored at OD-7, OD-9, and OD-10 are generated from a variety of Y-12 Plant maintenance, process, and laboratory operations. Wastes are delivered to each of the storage units in drums, portable tanks, or tanker trucks. 


\section{Hazardous Characteristics}

The OD-7 storage unit receives and stores the following listed and characteristic wastes as defined in 40 CFR Part 261:

- F001, F002, F004 - F006, and nonreactive F007 - F010

- $\quad \mathrm{F} 011$ - F039

- D004 - D043

- All nonreactive and nonignitable U- and P-listed wastes

The primary purpose of the OD-7 unit is the storage of waste oils and solvents generally classified by the waste codes of F001 through F005 (the waste characteristic for F005 listing is only toxicity). A listing of the wastes stored at OD-7 is shown in Table C-1.

The OD-9 storage unit receives and stores the following listed and characteristic wastes as defined in 40 CFR Part 261:

- F001, F002, F004 - F006, and nonreactive F007 - F010

- F011 - F039

- D002, D004 - D043

- All nonreactive and nonignitable U- and P-listed wastes

The primary purpose of the OD-9 unit is the storage of waste oil contaminated with PCBs and/or chlorinated solvents generally classified by the waste codes F001 and F002. A listing of the wastes stored at OD-9 is shown in Table C-2.

The OD-10 storage unit receives and stores the following listed and characteristic wastes as defined in 40 CFR Part 261:

- F001 - F006, and nonreactive $\mathbb{F} 007$ - F010

- F011 - F039

- D001, D002, D004 - D043

- All nonreactive U- and F-listed wastes

A listing of waste stored at OD-10 is shown in Table C-3. 
TABLE C-1. Wastes Typically Stored at OD-7

$\mathrm{PCBs}^{\mathrm{a}}$

Nonchlorinated solvents

Acetone

Propanols

Cresols

Benzene

Toluene

Phenols

Xylenes

Ethoxyethanol

Butanol

Cyclohexanone

Methanol

Ethanol

Ethyl acetate

Ethyl benzene

Ethyl ether

Methyl ethyl ketone

Ethyl isobutyl ketone

Paint thinner (Varsol)

Mineral spirits

Dibutyl carbitol

Tributylphosphate

Hexane

Acetonitrile

Heptane

Pyridine

Waste oil contaminated with

Uranium

Waste oil contaminated with Beryllium
Chlorinated solvents

Chloromethane

Vinyl chloride

Methylene chloride

Trichlorofluoromethane

1,1-Dichloroethene

1,1-Dichloroethane

trans,1,2-Dichloroethene

Methyl Chloroform

1,2-Dichloroethane

1,1,1-Trichloroethane

Carbon tetrachloride

Bromodichloromethane

1,2-Dichloropropane trans-1,3-Dichloropropene

Trichloroethene

Dibromochloromethane

1,1,2-Trichloroethane cis-1,3-Dichloropropene

2-Chloroethylvinyl ether

Bromoform

1,1,2,2-Tetrachloroethane

Tetrachloroethene

Chlorobenzene

1,3-Dichlorobenzene

1,2-Dichlorobenzene

1,4-Dichlorobenzene

Freon-113

Chloroform

TCLP Metals and nickel

Metals (non-hazardous)

Cyanide

Sulfur

${ }^{2}$ PCB contaminated oils typically $<50 \mathrm{ppm}$. 
TABLE C-2. Wastes Typically Stored at OD-9

Waste oils contaminated with the following:

PCBs

Uranium

Chlorinated solvents

Perchloroethylene

Trichloroethylene

Freon 113

Methylene chloride

Nonchlorinated solvents ${ }^{\mathrm{a}}$

Xylenes

Toluene

Hexane

${ }^{2} \mathrm{Oil} /$ solvent mixtures have flash points above $140^{\circ} \mathrm{F}$ 
The primary purpose of the OD-10 unit is the storage of ignitable waste liquids. The majority of the incoming waste streams would be classified by the waste codes D001 and F003. A listing of the waste storage arrangements at OD-10 is shown in Table C-3.

$\mathrm{U}$ - and P-listed waste are generated occasionally from laboratory, maintenance, and process clean-up or clean-out operations. The quantity and number of shipments of $U$ - and P-listed wastes to each of these three storage areas is minimal and infrequent. No K-listed waste is accepted at any of these units.

\section{Basis for Hazardous Designation}

The hazard designation is based on process knowledge of the on-site generated liquid waste streams and analytical data. The information indicates the presence of F-listed solvents, TCLP criteria solvents and metals, and the possibility of liquid U- and P-listed wastes for materials stored at OD-7, OD-9, and OD-10.

\section{Laboratory Report on Analysis Results}

All liquid wastes stored in tanks are eventually shipped off-site for incineration. Examples of typical waste analyses is shown in Appendix C-1.

\section{C-1a Containers}

The specific parameters to be used for the proper management of the waste may include:

- Concentration of TCLP constituents

- Concentration of PCBs

- Concentration of radiological constituents

- The characteristic of ignitability

- The characteristic of corrosivity

- The characteristic of reactivity

- Waste compatibility with other wastes placed in the container

- Waste compatibility with the container 
Mixtures with varying compositions of the following materials:

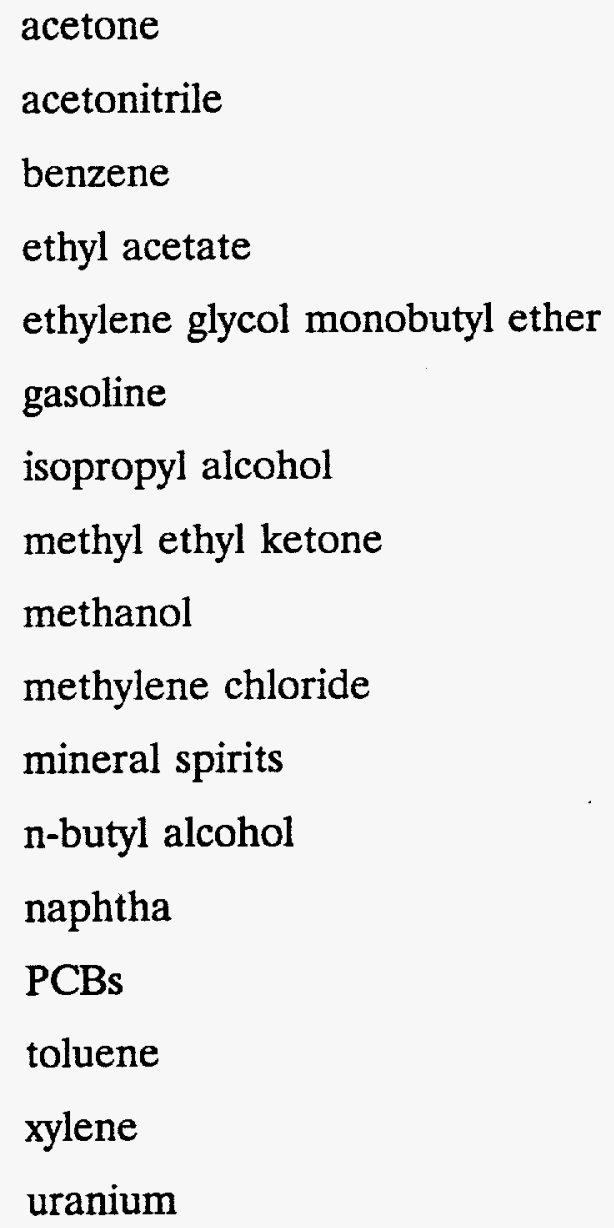

a Materials listed are typical and do not represent the only compounds/mixtures that may be placed in the tanks. 
The safe handling of the waste is of primary importance. Handling of waste will occur only when materials are being transferred to or removed from a tank. Any waste added to the tank must be compatible with existing tank contents. Compatibility of new wastes with existing inventory will be reviewed by Waste Management personnel. The Waste Transportation, Storage, and Disposal (WTSD) Department waste coordinator reviews the information provided by the waste generator on Request for Transfer, Storage and Disposal of Wastes Form (form UCN-2109). (see Appendix C-2) to determine the destination of the waste and its compatibility. Examples of incompatible waste are shown in Appendix C-3. A waste management facility engineer is consulted when questions arise concerning the compatibility of new material being added to existing tank contents. All equipment used to transfer waste is compatible with the waste. Special handling and storage precautions are required for the management of ignitable wastes.

Waste acceptance criteria will preclude the storage of reactive wastes (management of incompatible wastes and ignitable wastes in tanks are described in Sections F-5a and F-5e). Analysis for radiological characteristics will be performed on a case-by-case basis in accordance with DOE procedures.

The presence of radiological contaminants and PCBs must be known to ensure compliance with DOE Orders and Toxic Substances Control Act (TSCA) regulations. Certain information such as waste source, TCLP analysis, $\mathrm{pH}$, reactivity, and flash point must be known to assign the proper RCRA waste code designation. This information will be available through knowledge of the process generating the waste or by analysis.

The wastes must be compatible with the storage and transfer containers and transfer equipment. Waste will typically be handled in steel drums, steel or polyethylene portable containers, or tanker trucks used at the Y-12 facility. Engineering tests indicate polyethylene is resistant to attack by oils, chlorinated organics, and nonchlorinated organics at temperatures below $80^{\circ} \mathrm{C}$. The steel drums are constructed of either carbon or stainless steel. Polyethylene drum liners $(4 \mathrm{ml})$ are also available, if needed. The individual generators within the Y-12 Plant determine the compatibility of material to be stored.

\section{C-1b Tanks}

The waste specific parameters for management in tanks are the same as those described in Section C-1a, Containers. 
The tanks are constructed of carbon steel, fiberglass or stainless steel, or are epoxy-lined and are compatible with the wastes that will be stored in them. Various engineering references indicate that stainless steel is resistant to attack by oils, chlorinated hydrocarbons, and nonchlorinated hydrocarbons. Carbon steel, fiberglass and epoxy-lined tanks are compatible with petroleum derived oils. Tre specific gravity of $\ldots$ st of the waste material will be approximately 1.0 with the estimated range to be 0.8 tc 1.5 .

\section{C-1c Waste Piles}

Not applicable. The units covered in this permit application are not waste piles; therefore, the requirements of this section do not apply.

\section{C-1d Surface Impoundments}

Not applicable. The units covered in this permit application are not surface impoundments; therefore, the requirements of this section do not apply.

\section{C-1e Incinerators}

Not applicable. The units covered in this permit application are not incinerators; therefore, the requirements of this section do not apply.

\section{C-1f Landfills}

Not applicable. The units covered in this permit application are not landfills; therefore, the requirements of this section do not apply.

\section{C-1g Land Treatment}

Not applicable. The units covered in this permit application are not land treatment facilities; therefore, the requirements of this section do not apply.

C-1h Additional Requirements for Land Storage, Treatment, and Storage Facilities Not applicable. The units covered in this permit application are not land storage, treatment, or disposal facilities; therefore, the requirements of this section do not apply.

\section{C-2 WASTE ANALYSIS PLAN}

The waste analysis plan is included to describe the procedures for obtaining the chemical and physical characteristics of a waste. Characterization is necessary to ensure proper management of the tank and compliance with the EPA land disposal restrictions. Waste analysis parameters and rationale are summarized in Table C-4. 
TABLE C-4. Waste Analysis Parameters and Rationale

Rationale for

Testing

Equipment

Test

Parameter

Typically

Determined By

Handling and

Radiation

Analysis/Instrument

Segregation

Flash Point

Knowledge

Reactivity

Knowledge

Toxic Constituents

Knowledge

Compatibility

Knowledge

Off-Site

Chlorinated Solvents

PCBs

Thorium

Aqueous phase $\mathrm{pH}$

Beryllium

TCLP

Ash Content

Flash point

BTU

Total Uranium, U235\%

Analysis

Analysis

Analysis

Analysis

Analysis

Analysis

Analysis

Analysis

Analysis

Analysis 


\section{C-2a Parameters and Rationale}

A generator will request transfer of a hazardous waste using a Request for Transfer, Storage, and Disposal of Wastes Form (UCN-2109) or a waste stream identification number call-in form. A stream identification numbe: has been assigned to point sources of waste throughout the Y-12 Plant by Waste Management Operations. Normally, these waste streams are of uniform consistency. The WTSD Waste Coordinator reviews the information provided by the waste generator on form 2109 (see Appendix C-2) to determine the destination of the waste and its compatibility. Examples of incompatible waste are shown in Appendix C-3. A waste management facility engineer is consulted when questions arise concerning the compatibility of new material being added to existing tank contents. The container used to transport the waste will also be tagged (UCN-2114A for RCRA hazardous waste and UCN-2114B for nonhazardous waste). Containers of hazardous waste will be marked with the words "hazardous waste." Samples of these forms are presented in Appendix C-2.

Facility operators will review the generator's information to determine what additional characterization requirements are needed, and to verify that waste acceptance criteria are met. Table C-5 summarizes the waste acceptance criteria. The generator's knowledge of a waste will govern the required analyses to properly characterize a given waste. The generator will be required to document known information about the waste such as source, expected constituents, and expected handling or compatibility issues. The rationale behind the selection of the testing parameters is discussed in Sections C-1 and C-3. A copy of a Sample Requisition Request form is shown in Appendix C-2.

\section{C-2b Test Methods}

Waste characterization samples will be prepared according to the appropriate sample preparation protocol. The analytical protocols are specified in Table C-6.

Under the requirements of Tennessee Rule 1200-1-11-.06, adequate laboratory controls must be maintained to assure the proper operation of the facility. These techniques include the preparation and analysis of duplicate. blank, and spiked samples at s-eific intervals in the analytical operation. These techniques will be followed by Y-12 Plani personnel. 
TABLE C-5. Y-12 Storage Tank Waste Acceptance Criteria ${ }^{a}$

\section{CRITERIA}

- Storage of RCRA hazardous waste in these tanks will be limited to those RCRA waste codes described in Section C-1, Hazardous Characteristics.

- Storage of reactive materials will be prohibited.

- Storage of wastes with a flash point less than $140^{\circ} \mathrm{F}$ (Closed Cup) will be prohibited at OD-7 and OD-9.

- Wastes must be compatible with other wastes, stainless steel, carbon steel, or epoxy lined tanks, and transfer containers (polyethylene, stainless steel, or carbon steel).

${ }^{2}$ Facilities include OD-7, OD-9, and OD-10. 
TABLE C-6. Test Methods for Storage Tank Waste

Analyte or Group

Analytical

Method $^{2}$

Polychlorinated biphenyls

8750,8270

(PCBs)

Nonhalogenated volatile

5030,8740

organics

Nonhalogenated

8250,8270

semivolatile organics

Halogenated volatile

5030,8240

organics

Halogenated semivolatile

8250,8270

organics

Flash point

1010

Gross radiation scan, specific isotopes

Case Specific ${ }^{\mathfrak{c}}$

TCLP $^{\mathrm{b}}$

1311

BTU

Aqueous phase $\mathrm{pH}$

9040

Thorium

1635,134

Beryllium

7090

Uranium

2100

Ash Content

482

${ }^{a}$ Methods referenced from "Test Methods for Evaluating Solid Waste" (SW-846)

${ }^{b}$ Also refer to 40 CFR Part 261, Appendix II and III

' Testing and methods will be governed by DOE requirements 


\section{C-2c Sampling Methods}

\section{Sampling:}

The contents of each container of waste will be characterized by either process knowledge or analysis prior to transfer to the tanks. The characterization will remain valid until the process changes.

Waste sampling will be performed by two methods regardless of sampling frequency. A representative sample will be withdrawn from waste containers prior to transfer of the waste to a tank, and from a tank prior to treatment/disposal. Therefore, an approved sampling technique specific to container sampling, and a technique specific to tank sampling will be used.

Container sampling of liquids will be performed by use of an all glass Coliwasa drum sampler as described in SW-846. The use of the Coliwasa sampler will provide a representative vertical cross section of the contents of the drum or container and thereby address any anomalies that could develop due to vertical stratification. Sampling of containers with sludges or solids is infrequent but will be done using a thief or scoop.

Tank sampling involves either circulating the contents of the tank to obtain a representative composite sample or collecting samples from equally spaced side ports and then compositing them.

Samples will be collected from a sample port on the recirculating line. Circulation will be accomplished using the permanent tank pump or a portable pump. Sampling and field quality control procedures will follow methods that meet or exceed SW-846 quality requirements.

\section{Sample Handling:}

Once the sample is transferred to the sample container, the lid will be closed tightly and taped closed. The exterior of the sample container will be washed, dried, and a sample identification tag attached. At a minimum, the tag will identify the sample, the sample location, time of sample, sampler, preservatives, and a unique sample identification number. The sample containers will be placed in a plastic bag, tied closed, and placed in a sample ice chest with ice or equivalent. An analytical request form and chain-of-custody form will accompany the sample to the laboratory. The analytical request form will also identify the sample number with the tag that is affixed to the sample container(s). 
Splitting of concentrated samples for analytical purposes will be performed in the field. Transfer of samples to specified containers for analysis, such as $40 \mathrm{ml}$ septum vials for purge and trap analysis, will be performed in the laboratory.

\section{Reporting:}

All analytical results, generator information, and sample chain-of-custody documentation will be maintained in the tank operating record.

\section{C-2d Frequency of Analysis}

The contents of each unique batch of waste is characterized by either analysis or by process knowledge before transfer to the tanks. Characterization necessary to ensure safe handling, regulatory compliance, and compatibility will be required before a waste is transferred offsite. Characterization required for land disposal must be complete before the waste is removed from the tank. A waste characterization will remain valid until the generating process changes. Tank sampling will be done as necessary before waste is transferred offsite.

\section{C-2e Additional Requirements for Waste Generated Off-Site}

Not applicable. The units covered in this permit application are not receiving waste generated off-site. Therefore, the requirements for this section do not apply.

\section{C-2f Additional Requirements for Facilities Handling Ignitable, Reactive, or Incompatible} Waste

Waste $c$ aracteristics have been reviewed for compatibility using a Y-12 Plant hazardous waste compatibility table similar to the list in Tennessee Rule 1200-1-11-.06 Appendix .06/B, Examples of Potentially Incompatible Waste. See Appendix C-3 and Sections C-1, C-3, C-5 for additional information.

Based on a past waste handling history and on the review of incompatible groupings, wastes stored in tanks will be neither reactive nor incompatible.

Mixing of incompatible wastes wil also be prevented by requirements that the on-site generators provide information based on process knowledge or on testing describing the waste contents and characteristics. A compatibility review is an element of the waste acceptance criteria. Waste Management personnel will determine compatibility using waste handling history and other available literature data. 


\section{C-3 ADDITIONAL WASTE ANALYSIS REQUIREMENTS PERTAINING TO LAND DISPOSAL RESTRICTIONS}

\section{C-3a Waste Characteristics}

Specific data must be submitted by the generator to the owner/operator of a treatment or disposal facility to document whether the waste is restricted under the 40 CFR Part 268 requirements. This data will be obtained by analysis of tank contents and by knowledge of process. Waste determined to be restricted will be stored separately from non-restricted waste.

\section{C-3a(1) Waste Characteristics - Solvent Wastes and Dioxin-Containing Wastes}

The wastes generated at $\mathrm{Y}-12$ do not contain dioxin or dioxin-containing constituents based on knowledge of the process. The wastes could contain solvents in the F-listed solvent classification. Since the exact composition of the solvent constituents will vary, the wastes will be considered to be a F001, F002, F003, F004, and/or F005 waste. This classification is based on analytical data and on knowledge of current solvent use at Y-12. The wastes stored in each of the units meets the definition of a non-wastewater as defined in $40 \mathrm{CFR}$ Part 268.2.

\section{C-3a(2) Waste Characteristics - California List Wastes}

The California List places restrictions on liquid and solid hazardous wastes containing PCBs greater than or equal to $50 \mathrm{ppm}$, over $1,000 \mathrm{ppm}$ halogenated organic constituents, and liquids testing less than or equal to a $\mathrm{pH}$ of 2 . All of the wastes stored in tanks at OD-7, OD-9, and OD-10 could contain constituents exceeding the halogenated organic criteria. Based on knowledge of process, liquids testing less than or equal to $2 \mathrm{pH}$ will be stored in tanks. PCBs may be present in the waste, but testing will be conducted to ensure that if the regulatory limit for PCBs is exceeded, it will be handled as a TSCA waste. Wastes received in tanks will be limited to those waste codes listed in Section C-1.

\section{C-3a(3) Waste Characteristics - First-Second-and-Third-Third Waste}

Based on knowledge of the waste characteristics, the storage units may receive $\mathrm{P}$ - and $\mathrm{U}$ listed wastes, and TCLP and ignitable wastes, which are subject to land disposal restrictions under 40 CFR Part 268 (Tennessee Rule 1200-1-11-.10). Wastes received in these units will be limited to those waste codes listed in Section C-1. The wastes meet the definition of a wastewater or non-wastewater as defined in $40 \mathrm{CFR}$ Part 268.2. A summary of treatment codes is located in Appendix C-4. 
C-3b Additional Requirements for Treatment Facilities

Not applicable. The units covered in this permit application are not treatment facilities; therefore, the requirements for this section do not apply.

C-3c Additional Requirements for Disposal Facilities

Not applicable. The units covered in this permit application are not disposal facilities; therefore, the requirements for this section do not apply.

C-3d Additional Requirements for Surface Impoundments Exempted from Land Disposal Restrictions

Not applicable. The units covered in this permit application are not surface impoundments; therefore, the requirements for this section do not apply.

C-3e Requirements for Land Disposal Facilities With an Approved Exemption or Extension Not applicable. The units covered in this permit application are not land disposal facilities; therefore, the requirements for this section do not apply. 


\section{SECTION D \\ PROCESS INFORMATION}

This section discusses specific process information for the storage and handling of hazardous wastes at three separate tank storage areas at Y-12. These areas are OD-7, OD-9, and OD-10. OD-7 is the tank storage unit adjacent to Building 9811-1 (OD-8), a container storage unit that will be addressed in a separate application. OD-9 is the Waste Oil/Solvent Storage Unit at Building 9811-8 and includes a truck transfer station with a container storage area. OD-10 is the Liquid Organic Solvent Storage Unit and also includes a truck transfer station with a container storage area.

As required by 40 CFR Parts 270.15 and 270.16 and Rules Governing Hazardous Waste Management in Tennessee Rules 1200-1-11-.07(5)(b)1. and 2., this section describes the hazardous waste management processes used at the three areas.

The six tanks at OD-7 are normally used to store waste oils and solvents and have a total capacity of 140,000 gallons. The two, 10,000-gallon tanks are in place, but not in service.

At OD-9, the tanks and containers are normally used to store waste oil which may contain water and which may be contaminated with PCBs, uranium, and solvents. These five tanks have a total capacity of 200,000 gallons. Space is available so a sixth tank may be installed in the future if needed. The maximum volume of liquid to be stored in containers at OD-9 is 8,800 gallons.

Liquid organic wastes are stored in the containers and tanks at OD-10. These tanks have a total capacity of 32,000 gallons. The maximum volume of liquid to be stored in containers at $\mathrm{OD}-10$ is 10,560 gallons.

\section{D-1 CONTAINER SYSTEMS \\ D-1a Containers with Free Liquids}

The wastes stored at OD-9 consist of waste oils mixed with organic solvents generally classified as waste codes F001 - F006. All listed and characteristic waste types are stored at OD-9 except reactive waste, ignitable waste, and $\mathrm{K}$-listed waste. The wastes stored at OD-10 consist of various liquid organic solvents typically with a flash point less than $140^{\circ} \mathrm{F}$ and primarily classified by waste codes D001 and F003. All listed and characteristic waste types can be stored at OD-10 except reactive waste and K-listed waste. 


\section{D-1a(1) Basic Design Parameters, Dimensions, and Materials of Construction OD-9}

The container storage area is covered with a metal roof, curbed and sloped to drain into the tank secondary containment area. A plan view of the OD-9 storage area is presented in Appendix D-1, Figure D-1.

The container storage pad, surface drains, and the tank secondary containment structures are made of concrete. The pad is sealed and coated with an ep xy coating that is compatible with the waste stored at the unit. These structures are free of cracks or gaps and are sufficiently impervious to contain leaks, spills, and accumulated precipitation until the collected material is detected and removed. Additional information on the secondary containment system is presented in Section D-2.

$\underline{\text { OD-10 }}$

The foundation of the facility is made of concrete. The drum storage area is curbed and contained under a 14-foot high canopy roof. The foundation, slab, and curbing are free of cracks or gaps and sufficiently impervious to contain leaks and spills until the collected material is detected and removed. The container pad is sealed with an acrylic-based polymer. The aqueous retention basin is sealed and coated with an epoxy coating. A plan view of the OD-10 storage area is shown in Appendix D-1, Figure D-2. Additional information on the secondary containment system is presented in Section D-2.

\section{D-1a(2) Description of How Design Promotes Drainage or How Containers are Kept from Contact with Standing Liquids in Containment System}

$\underline{\text { OD-9 }}$

The container storage area floor and surface drain have downward gradients of $1 / 8$ inch per foot. The slopes of these structures and the tank secondary containment area base are adequate to allow liquids resulting from leaks, spills, or rainwater to flow rapidly into the tank secondary containment area sump. This design of the drum storage facility ensures that the containers are protected from prolonged contact with accumulated liquid since contact prevention is provided by the existing slope gradient.

\section{$\underline{\text { OD-10 }}$}

The container storage area floor has a downward gradient of $1 / 8$ inch per foot. The slope of this structure is adequate to allow liquids resulting from leaks, spills, or precipitation to flow into the drum containment area sump. Liquids in the sump will be removed upon their 
discovery. This design of the drum storage facility ensures that the containers are protected from prolonged contact with accumulated liquids since contact prevention is provided by the existing slope gradient.

\section{D-1a(3) Capacity of the Containment System Relative to the Number and Volume of Containers to be Stored}

$\underline{\text { OD-9 }}$

Currently, the maximum volume of liquids to be stored in containers is 8,800 gallons based on 160,55-gallon drums double stacked on pallets. The secondary containment capacity is approximately 1,996 gallons. On occasion, a 5,000-gallon tanker truck will be present to transfer its contents into the tanks. If storage of the tanker is required, drain valves separating the container storage area dike and the tank storage area dike will be opened, increasing the secondary containment capacity to approximately 86,000 gallons. Calculations are presented in Appendix D-2. Refer to Appendix D-1, Figure D-1 and drawings in Appendix D-3 for additional information.

\section{$\underline{\mathrm{OD}-10}$}

Normally, the maximum volume of liquid to be stored in containers is 10,560 gallons based on 192, 55-gallon drums double stacked on pallets. Spills which occur in the drum storage area will flow down gradient into the sump. In the unlikely event that the sump would overflow, the drum storage area is completely enclosed by a 5-inch-high curb and will hold approximately 6,100 gallons. Calculations are presented in Appendix D-2. Refer to Appendix D-1, Figure D-2 and drawings in Appendix D-3 for additional information.

Rainfall of 5.5 inches is based on the 24-year, 24-hour storm event.

\section{D-1a(4) Provisions for Preventing or Managing Run-On}

$\underline{\text { OD-9 }}$

Run-on into the containment system is prevented by the curbs and dikes that are above the surrounding area which is sloped away. The container storage area has a metal roof to minimize collection of rainwater in the containment area. In addition, surface drains to the plant storm sewer covered with gratings are provided between the roads and the concrete floors of the facility to prevent run-on from the roads from flowing into the containment system. 
$\underline{\mathrm{OD}-10}$

Run-on into the containment system is prevented by the curbs constructed around the container storage area that are above the surrounding area. The container storage area has a metal roof to minimize the collection of rainwater in the containment area. In addition, the area surrounding the container storage area is sloped so water will flow away from it.

\section{D-1a(5) How Accumulated Liquids can be Analyzed and Removed to Prevent Overflow OD-9 and OD-10}

Accumulated liquids would be present only as a result of precipitation, a spill, or a leak from one or more containers within the diked areas.

If accumulated liquid is observed by the operator, a sample is collected for $\mathrm{pH}$ and conductivity. If the results indicate a spill or leak has occurred, a sample will be taken and analyzed to determine the waste identification before transfer to the appropriate tank. See Section $\mathrm{C}$ for sampling analysis methods.

Removal of spilled liquids will be accomplished by use of portable pumps or by the use of adsorbents depending on the quantity of material present. Accumulated liquids will be removed immediately after their discovery.

\section{D-1b Containers Without Free Liquids}

Some of the wastes stored in containers at OD-9 and OD-10 will be without free liquids. These wastes are generated infrequently from spill cleanup and normally consist of soil, discarded personnel protective equipment and other solid material contaminated with the same waste described in Sections C-1 and D-1a. They are stored in the same container storage areas described in Section D-1a(1).

\section{D-1c(1) Container Management}

OD-9 and OD-10

Most wastes at this facility are stored in DOT specification 55-gallon drums. Several steps have been taken to prevent hazards during loading/unloading operations. Drum handling operations typically take place en drums are placed into storage or during loading for shipments to off-site disposal faciities. To minimize the potential for accidents involving other vehicles and pedestrians, traffic flow is limited around the loading area during operations. All drum handling equipment used (carts, lifts, etc.) are specifically designed to transport or lift drums safely and without damage. Ramps have been constructed to allow 
wheeled vehicles (carts, forklifts, etc.) easy access to containers while still providing containment for spilled liquids.

All waste containers in storage are kept sealed at all times except during filling operations (for solvents and other liquids), packing for shipment, or for sampling purposes. Containers are handled (i.e., moved, loaded onto trucks, filled, etc.) only under the direction of the hazardous waste supervisor. All equipment used for opening drums or moving them are non-sparking bung wrenches, drum carts, socket sets, etc. Funnels appropriately designed and fabricated are used with $17 \mathrm{E}$ drums for pouring liquids. Solvent drums, or drums holding other volatile liquids, are always filled in such a manner that three to four inches headspace is kept (approximately five gallons or 10 percent of the drum volume) to allow for expansion.

Containers of hazardous waste will be marked with the words "Hazardous Waste" at OD-9 and OD-10. Containers used for hazardous waste (i.e., 55-gallon drums) are intended for "once through" use only. This means they are to be used only once for storage of hazardous waste and then discarded. They are usually shipped with the waste and disposed of at the final destination. Some may be emptied and discarded, as are solvent drums after a bulk shipment for disposal. Drums used for hazardous waste storage are either new, reconditioned, or cleaned (by rinsing or other appropriate measure) or contain new material that is known to be compatible with the waste to be added (i.e., solvent drums, drums containing oil or inert materials). 4-ml Polyethylene drum liners are used for wastes not compatible with steel drums. Drums containing incompatible wastes are generally segregated by DOT hazard class and whenever possible, drums containing wastes known to be incompatible are stored in the different areas or are kept separate via portable dikes.

All containers are observed during packing and loading operations. Also, all containers are inspected weekly on an individual basis for deterioration, corrosion, leakage, etc.; a listing illustrative of the inspection technique for this facility is given in Section F-2. Any container that does not pass inspection is replaced with one that meets the proper requirements.

The storage areas have aisles for the passage and maneuver of forklift trucks accessing the segregated waste storage area. This aisle is kept clear of drums or equipment; drums are sorted in the designated segregated areas. 
Aisle spacing is typically 3- to 5-feet wicle with a minimum of 28 inches. A summary of required aisle spacing is shown in Appendix D-1. Drums are stored on pallets. The maximum number of drums that could be stored in this facility is based on the holding capacity of the diked area.

\section{D-1c(2) Requirements for Ignitable or Reactive Wastes and Incompatible Wastes}

\section{OD-9}

The wastes to be stored in this unit are not ignitable, reactive, or incompatible (see Section C-1). On special occasions, incompatible wastes may be stored in areas separated by portable dikes. A compatibility review will be conducted by Waste Management personnel before pumping into any of the tanks.

$\underline{\mathrm{OD}-10}$

Ignitable wastes are stored at OD-10. The container storage area at OD-10 is located more than 50 feet from the property line. See Map 2 for exact location of the OD-10 storage unit. Reactive or incompatible wastes will not be stored in OD-10. On special occasions, incompatible wastes may be stored in areas separated by portable dikes. A compatibility review will be conducted by Waste Management personnel before pumping into any of the tanks.

\section{D-2 TANK SYSTEMS}

OD-7

This unit has been designated as the primary storage unit for uranium-contaminated RCRA waste oils and solvents. The diked tank pad supports four, 30,000-gallon tanks and two, 10,000-gallon tanks which are not yet in service.

All tanks are made of mild steel, with the minimum thickness of the walls being 3/16 inch. The level indicator system consists of pressure transducers which measure the pressure of the height of the liquid stored above a certain point in the tanks, with the level to be indicated on the remote panel or on the tank level gauge.

The steel tanks are vertical, cylindrical, and have flat bottoms and tops. A plan view of the tanks is shown as in Appendix D-1, Figure D-3. A process flow diagram is shown in Appendix D-1, Figure D-4. Additional construction details, specifications, and drawings are shown in Appendix D-3. 
All tanks are aboveground and operate at atmospheric pressure.

$\underline{\mathrm{OD}-9}$

Wastes received and stored at this unit are non-ignitable and nonreactive waste oil/solvents that may contain water, may be contaminated with PCBs and uranium, and may also contain chlorinated organic solvents.

The Waste Oil/Solvent Storage Unit consists of five, 40,000-gallon epoxy-lined, carbon steel tanks with a concrete pad installed in the containment area for an additional sixth tank if needed. Each tank is 13.5 feet in diameter and 38 feet high. The tanks have been designed to contain liquids with a maximum specific gravity of 1.62 and operate under atmospheric pressure. The tanks and appurtenances have been designed and constructed in accordance with the latest applicable requirements of API [at the Standard 650, the standard specifications and codes of ANSI, ASTM, ASME, NFPA, and other standards as listed in Appendix D-3 (Tank Data Sheet) time of construction].

The type of construction materials, design conditions, and other tank information are also presented in the Tank Data Sheet. Specifications for the epoxy lining is given in Appendix D-3. A plan of the tanks is given in Appendix D-1, Figure D-1 and a process flow diagram is included as Figure D-5 (see Appendix D-1).

One-foot-thick, 16.5-foot-diameter concrete pads constructed on top of a base slab will serve as the foundations for the tanks. The storage tank containment area has a sump located in the northeast corner. Dimensions are $4 \times 3 \times 3$ feet with a capacity of approximately 270 gallons.

$\underline{\text { OD-10 }}$

Wastes received and stored include waste oil and combustible and flammable waste liquids generated at the Y-12 plant. The Liquid Organic Solvent Storage Unit consists of four, 6,500-gallon carbon steel tanks and two, 3,000-gallon stainless steel tanks installed in the containment area. Two additional concrete pads are in place and available for future expansion.

All tanks are vertical and have side sampling ports at 3- to 5-foot intervals. The carbon steel tanks are 9 feet in diameter and 10.5 feet high. The stainless steel tanks are 6 feet in diameter and 8 feet high. All the tanks will provide internal access through a side manhole. 
The tanks are designed to contain liquids with a maximum specific gravity of 1.62 and are operating under atmospheric pressure. The tanks and appurtenances are designed and constructed in accordance with the latest applicable requirements at the time of construction of API Standard 650, the standard specifications and codes of ANSI, ASTM, ASME, NFPA, and other standards as listed in Appendix D-3 (Tank Data Sheet). The type construction materials, design conditions, and other tank information are also presented in the Tank Data Sheet. A plan view of the tanks is given in Figure D-2 and a process flow diagram is shown as Figure D-6 (see Appendix D-1).

Three pumps at the unit are installed for transferring liquid waste from drums or tankers to tanks, tank to tank, recirculation, and loading into a tanker truck. The waste transfer pumps are constructed of materials compatible with the solvents to be transferred. Spark proof motors are used when handling flammable solvents. A tanker loading station is provided. Each ignitable liquid tank is vented through a flame arrestor. Sump pumps are provided for the tank containment area and the loading/unloading area. Rainwater collected in sumps in the diked and curbed areas of the facility will be transported via pumps to the aqueous retention basin. The basin is 30 feet long, 10 feet wide, and 3 feet deep, with a total capacity of 900 cubic feet (6,700 gallons). The basin is not covered or under a roof. Tank seams are full penetration ASME code welds.

\section{D-2a Existing Tank System \\ D-2a(1) Assessment of Existing Tank System Integrity \\ OD-7}

Tank assessment reports are not required for existing tanks that have secondary containment meeting the requirements of 40 CFR Part 264.193. Since the existing tanks at OD-7 were installed and operational before July 14, 1986 and they meet the requirement, they do not need a tank assessment report. An assessment report for the new tanks is included in Appendix D-4.

\section{$\underline{\text { OD-9 }}$}

The tanks at OD-9 were installed and became operational in the fall of 1988. The tank assessment report is included in Appendix D-4.

$\underline{\mathrm{OD}-10}$

The tanks at OD-10 were installed and became operational in the fall of 1988. The tank assessment report for OD-10 is included in Appendix D-4. 


\section{D-2a(2) External Corrosion Protection}

All tank systems are above ground. Therefore, the external metal components of the tank systems are not in contact with the soil or with standing water. Standard procedures are in place to inspect and test the tanks periodically in order to maintain shell thickness. Tank construction materials are selected based on standard engineering practices to ensure compatibility with the wastes to be stored.

\section{D-2b New Tank Systems}

\section{OD-7}

Two, 10,000-gallon tanks are to be placed in service at this facility in the near future. The total capacity will be 140,000 gallons after the facility upgrade.

\section{$\underline{\text { OD-9 }}$}

A concrete pad exists for the installation of a sixth tank if needed.

\section{D-2b(1) Assessment of New Tank System Integrity}

OD-7

A tank assessment for these tanks to be installed is included in Appendix D-4. However, a new tank assessment will be provided prior to operation of the two additional 10,000 gallon tanks.

\section{D-2b(2) External Corrosion Protection}

All new tanks will be above ground, therefore, the external metal components of the tank systems will not be in contact with the soil or with standing water. Standard procedures are in place to inspect and test the tanks periodically in order to maintain their shell thickness. Tank construction materials are selected based on standard engineering practices to ensure compatibility with wastes to be stored.

\section{$\mathrm{D}-2 \mathrm{~b}(3)$ Description of Tank System Installation and Testing Plans and Procedures}

The tanks will be constructed and inspected according to the ASME Pressure Vessel Code. The tank systems will be inspected during installation for weld breaks, punctures, scrapes on the protective coatings, cracks, corrosion, or other structural damage or inadequate construction/installation. The system will be tested for leak tightness before it is placed in use. 
All discrepancies and leaks that are found will be remedied before the tank system is used. The inspection will be conducted by an independent, qualified Tennessee registered professional engineer who is trained and experienced in the proper installation of tank systems and components.

A written statement for each tank system certified by the inspector, attesting that the tank system was properly installed and all required repairs were properly made, will be kept on file at MMES. These inspections will be sufficient to verify that the integrity of the weld seams are adequate to last throughout the expected service life of each tank. All tanks will be inspected in accordance with the tank inspection procedures. External inspection will be performed to determine the shell thickness, deterioration rate, and the structural integrity of the tank.

D-2c Dimensions and Capacities of each Tank

\begin{tabular}{|c|c|c|c|}
\hline Quantity & Dimensions & $\begin{array}{c}\text { Minimum Shell } \\
\text { Thickness }\end{array}$ & Capacity \\
\hline \multicolumn{4}{|l|}{$\underline{\mathrm{OD}-7}$} \\
\hline $2^{a}$ & $10.5^{\prime} \times 16.6^{\prime} \mathrm{h}$ & $1 / 4^{\prime \prime}$ & $10,000 \mathrm{gal}$ \\
\hline 4 & $12^{\prime} \times 35^{\prime} \mathrm{h}$ & $3 / 16^{\prime \prime}$ & $30,000 \mathrm{gal}$ \\
\hline \multicolumn{4}{|l|}{ OD-9 } \\
\hline 5 & $13.5^{\prime} \times 38^{\prime} \mathrm{h}$ & $1 / 4^{\prime \prime}$ & $40,000 \mathrm{gal}$ \\
\hline \multicolumn{4}{|l|}{$\underline{\mathrm{OD}-10}$} \\
\hline 4 & $9^{\prime} \times 10.5^{\prime} \mathrm{h}$ & $3 / 16^{\prime \prime}$ & $6,500 \mathrm{gal}$ \\
\hline 2 & $6^{\prime} \times 8^{\prime} \mathrm{h}$ & $0.120^{\prime \prime}$ & $3,000 \mathrm{gal}$ \\
\hline
\end{tabular}

\section{D-2d Descriptions of Feed System, Safety Cutoff ypass System and Pressure Controls} All the tanks at each of the storage units are designed and operated under atmospheric conditions. 
$\underline{\text { OD-7 }}$

Liquid level is checked manually on all tanks or with a tank liquid level gauge, if available. After the OD-7 upgrade, all tanks will have liquid level gauges. Pressure gauges are not required for the tanks because they are designed to operate under atmospheric pressure.

OD-9

A mechanically linked float indicator has been installed in each tank. A tank level gauge, which is coupled to the float indicator, will be readable from a distance of approximately 40 feet. The maximum height of the liquid level from the bottom of the tank will be less than 38 feet. The floats are connected to an alarm which shuts the pumps down if activated.

A transfer pump with associated piping has been installed for each tank. Each pump is connected to the truck transfer station loading area for tanker discharge pumping. The pumps are valved and piped to allow any one of the three pumps for Tanks F-1, F-2, and F-3 to provide backup service for the other two, and for either one of the two pumps for Tanks F-4 and F-5 to provide backup for the other one. There is no cross-connection between Tanks F-1, F-2, and F-3, and Tanks F-4 and F-5, or interchange of pumps between the two groups of tanks.

The piping was designed to prevent hydraulic shock when the tanker unloading arm valves are closed while the transfer pump is running. Sample ports with valves are provided on pump discharges. Piping is constructed of carbon steel and is insulated and heated. A complete flow diagram, which also includes pumps, piping, and other instrumentation, is detailed in Appendix D-1, Figure D-5.

Two 100-gpm duplex sump pump units with discharge piping have been installed to pump the liquids collected in the sump. Piping is manifolded and valved to allow discharge into any of the five tanks or to the storm drain. Capability is also provided to discharge into a portable polytank. Pressure gauges are not required for the tanks because they are designed to operate under atmospheric pressure.

$\underline{\mathrm{OD}-10}$

A diked loading/unloading station is located adjacent to the diked tank area for unloading incoming drums and tankers into the storage tanks and for unloading the bulk storage tanks into tankers for transport of wastes to other management facilities. Three loading/unloading systems will comprise the loading/unloading station. Each system consists of a pump and 
associated piping for transference of astes from drums or tankers to tanks, tank to tank, recirculation, and loading into a tanier truck. Check valves are installed in the piping network to prevent backflow and cross-contamination of tanks.

Continuous liquid level probes in explosion-proof ho sings are installed on each of the six tanks. Digital readouts for each tank level are located outside the diked area. High level switches are integrated to the digital readouts to prow de signals to the annunciator and to shut down the air pumps. An annunciator is provided to high evel alarms for all six tanks. Pressure gauges with valves are provided to measure pump discharge pressure of each of three pumps. Gauges are provided for the strainer associated with each pump. Three local flow meters are provided to measure flow from each pump to its respective pair of storage tanks. All instrumentation within the diked area are contained in explosion-proof housings. A process block flow diagram is presented in Appendix D-1, Figure D-6.

All tanks have permanent tops, therefore, the minimum freeboard to prevent overtopping by wave or wind action or precipitation is not required.

Pressure gauges are not required for the tanks because they are designed to operate under atmospheric pressure.

Tank grounding is provided in accordance with applicable Engineering Standards.

D-2e Diagram of Piping, Instrumentation, and Process Flow

Piping and instrument diagrams and process flow diagrams are provided in Appendix D-3 and Figures D-4 through D-6 (See Appendix D-1).

\section{D-2f Containment and Detection of Releases}

D-2f(1) Plans and Description of the Design, Construction, and Operation of the Secondary Co ainment Systems

Each of the three facilities has a diked containment area surrounding the tanks and auxiliary equipment that will hold 100 percent of the largest tank volume within its boundary. Those containment areas not covered by a roof will also hold the precipitation from a 25-year, 24-hour rainfall (5.5") in addition to the volume of the largest tank. 
Tanks are situated on concrete pads, and are within concrete containment areas, therefore, there will be no migration of the wastes to the soil. The dike floors are epoxy-coated to prevent migration of waste through the cement base.

The containment dikes are hydrostatically tested once every three years to ensure dike integrity.

\section{$\underline{\mathrm{OD}-7}$}

The storage tank area consists of a 50- $\mathrm{x} 40$-foot nominal concrete diked area. The dike encircling the tank pad is approximately 4-feet high and has a capacity of approximately 37,700 gallons. The pad is sloped to a sump equipped with a sump pump.

\section{$\underline{\text { OD-9 }}$}

The tank containment structure has dimensions of 42 feet $\times 73.5$ feet $\times 5.6$ feet (less the drum transfer area of 12 feet $\times 18$ feet and the tank pads) and has a capacity of approximately 86,000 gallons. If there is a leak or spill from a tank, the waste will be contained and pumped into an appropriate spare tank immediately. The storage tank containment area has a sump located in the northeast corner. Dimensions are 4 feet $\times 3$ feet $x 3$ feet with a capacity of approximately 270 gallons. The specifications and standards of construction materials and the caulking, sealing, and coating specifications are given in Appendix D-1.

\section{$\underline{\mathrm{OD}-10}$}

Two sumps are provided within the tank containment area. The capacity of each sump is 27 cubic feet or 200 gallons. The tank containment structure has dimensions of $65 \times 30 \mathrm{x}$ 3 feet (less the 8- $\times 10$-foot tank pads) and has a capacity of approximately 41,600 gallons, including the sump.

Rainwater collected in sumps in the diked and curbed areas of the facility will be transported via pumps to the aqueous retention basin. The basin is 30 feet long, 10 feet wide, and 3 feet deep, with a total capacity of 900 cubic feet (6,700 gallons). The basin is not covered or under a roof.

The total capacity of the tank containment basin, the aqueous retention basin, and the drum storage area is 54,400 gallons. If there is a tank leak or spill, the waste will be contained and immediately pumped into an appropriate tank. 


\section{D-2f(1)a Description of Leak Detection System}

The storage facilities are inspected daily, weekly, and annually for signs of leaks or discharges. Accumulated liquid in the secondary containment system will be removed using the emergency sump pump, portable pump, and/or a vacuum truck. The recovered liquid will be managed in accordance with the Waste Analysis Plan presented in Section C-2. Procedures for ensuring that accumulated liquid is promptly detected and removed within 24-hours (or at the earliest time possible) are discussed in Sections F-2 and G-5. See Appendix F-2, Table F-4 for the sample Daily Tank Storage Area Log Sheet.

\section{D-2f(1)b Requirements for External Liner, Vault, Double-Walled Tank or Equivalent Device}

Waste infiltration is prevented by use of external waterproofing and chemical resistant water stops at any joints of the dike construction. The dike and curb exterior are coated with waterproofing to prevent the infiltration of water. The waterproofing consists of a primer coat to act as a masonry and concrete filler-sealer followed by an intermediate cost of vinyl ester, heavy-duty, thick film, high resistant coating and a top coat of chemical resistant, laminated, monolithic floor topping. As described in Sections D-1a and D-2f(1), each of the containment systems can hold over 100 percent of the volume of the largest tank. The formation and ignition of vapors at OD-10 are prevented by outdoor storage and by use of spark-proof and explosion-proof equipment.

\section{D-2f(1)c Secondary Containment and Leak Detection Requirement of Auxiliary Equipment} All auxiliary equipment is located inside the diked containment area for the tank storage. Any spills or leaks will be handled as specified under the tank storage containment sections. Auxiliary equipment will be inspected daily. Refer to Section F-2, Inspection Schedule, for additional information.

\section{D-2f(2) Requirement for Tank Systems Until Secondary Containment is Implemented} Not applicable. All secondary containment areas are in place, therefore, this section does not apply.

\section{D-2f(3) Variance from Secondary Containment}

Not applicable. There will be no variance from the secondary containment, therefore, this section does not apply. 


\section{D-2g Controls and Practices to Prevent Spills and Overflows}

Information on spill prevention is presented in Section $\mathrm{F}$.

D-2h Storage and Treatment of Incompatible, Ignitable, and Reactives

The wastes stored at OD-7 and OD-9 are not ignitable, reactive or incompatible. The wastes stored at OD-10 are not reactive or incompatible, but are ignitable. Standard operating procedures for managing ignitable wastes are in place to prevent any releases.

On special occasions, incompatible wastes may be stored in areas separated by portable dikes. A compatibility review will be conducted by Waste Management personnel before pumping into any of the tanks.

D-2i Requirements for Leaks/Spills from Tanks

All information is included in the Contingency Plan, Section G-5. 


\section{SECTION E \\ GROUNDWATER MONITORING}

Groundwater monitoring is not required for OD-7, OD-9, and OD-10 as per the requirement of Subpart F of 40 CFR Part 264 and Tennessee Rule 1200-1-11-.07(5)(c). Because they are container and tank storage units, they are exempt from groundwater monitoring requirements. 


\section{SECTION F \\ PROCEDURES TO PREVENT HAZARDS}

This section of the application provides information concerning procedures to prevent hazards required by 40 CFR Part 270.14 and Rules Governing Hazardous Waste Management in Tennessee, Rule 1200-1-11-.07(5)(a). The following subject areas are addressed in this section: general security provisions, inspection schedules and requirements, preparedness and prevention requirements, and prevention of accidental ignition or reaction of ignitable, reactive, or incompatible wastes at OD-7, OD-9, and OD-10.

\section{F-1 SECURITY}

\section{F-1a Security Procedures and Equipment}

The Y-12 Plant maintains security procedures and equipment that prevent the unknowing entry of persons or livestock onto the active portion of the facility which minimizes the possibility for unauthorized entry. The 24 hours per day, 7 days per week surveillance system is utilized at the Y-12 Plant, and one or more barriers are present to control entry.

\section{F-1a(1) 24-Hour Surveillance System}

The Oak Ridge Y-12 Plant is a U.S. Department of Energy facility which produces and handles nuclear materials. It is a fully secure facility completely surrounded by a barbed wire-topped chain linked fence eight feet in height. A large security force and centralized security operations oversee the entire Y-12 Plant. The facility is continuously manned 24 hours per day, 7 days per week by armed guards from the Y-12 Plant Security Department. The perimeter of the facility is patrolled at intervals day and night via a system of patrol roads.

Most gates for pedestrian and vehicular access are manned by armed guards and only authorized personnel are admitted. All authorized visitors receive visitor badges at the gate and must be accompanied by authorized Y-12 Plant personnel or authorized contractors while on the plant grounds. All individuals entering Y-12 Plant must be authorized by the Y-12 Plant Security Department.

OD-7 is located within the fully secured perimeter. OD-9 and OD-10 are outside of this fully secure area. 
OD-9 is on Old Bear Creek Road and is located within the barbed wire-topped chain linked fence which is eight feet in height and surrounds several Waste Management facilities located at the west end of the Y-12 Plant. Access to this area is provided by four fenced gates. Two of the fenced gates are southeast and southwest of OD-9 where the fence crosses Old Bear Creek Road. The other two fenced gates are northeast of OD-9 near the West End Treatment Facility which is also located within this fenced area. The fenced gate located west of OD-9 is locked at all times and has a concrete barrier immediately west of it to further discourage entrance. The other three entrances are beyond a guard portal on Bear Creek Road which requires one person in each vehicle to possess a permanent badge in order to obtain access beyond that point.

OD-10 is located north of Bear Creek Road and is west of the Y-12 Plant. This facility is within the barbed wire-topped chain linked fence which is eight feet in height and which surrounds Waste Management facilities located in this area. Access to this area is provided by two fenced gates. One gate which normally remains in the closed and locked position is located southwest of OD-10 and also has a cross bar gate immediately west of the gate to further restrict access. The other gate which is used as the primary access to this area is located southeast of OD-10. An additional cross bar gate is also located on the access road between the fenced gate and Bear Creek Road in order to further restrict access. This primary gate is opened during normal business hours from approximately 8 a.m. to 4 p.m. during week days. At 4 p.m., the responsible WTSD supervisor locks the gate. The gate may be opened on off-shifts and weekends to allow overtime work.

\section{F-1a(2) Barrier and Means to Control Entry}

See F-1a(1) for information.

F-1a(2)(a) Barrier

See F-1a(1) for information.

\section{F-1a(2)(b) Means to Control Entry}

See F-1a(1) for information.

\section{F-1a(3) Warning Signs}

Incividual RCRA facilities on the Y-12 Plant site are posted with signs stating:

"Danger -- Authorized Personnei Only" 
or a similar message which indicates that only authorized personnel are allowed to enter and that entry onto the active portion can be dangerous. No languages other than English are necessary for the signs at this plant. All signs are located at each entrance and are legible from a distance of at least 25 feet and are visible from all angles of approach.

Signs are located on the north, south, east, and west sides of each unit and are either mounted on the unit or on boundary control devices at the edge of each unit.

\section{F-1b Waiver}

Not applicable. The Y-12 Plant does not request a waiver of the regulations stated in 40 CFR Part 264.14(a) and Tennessee Rule 1200-1-11.06(2)(e) concerning security of these units.

\section{$\mathrm{F}-1 \mathrm{~b}(1)$ Injury to Intruder}

Not applicable. A waiver is not required; therefore, this section is not applicable.

\section{F-1b(2) Violation Caused by Intruder}

Not applicable. A waiver is not required; therefore, this section is not applicable.

\section{F-2 INSPECTION SCHEDULE}

\section{F-2a General Inspection Requirements}

Because of the diverse activities and the specialized nature of activities at the Y-12 Plant, authority and responsibility for inspections, record-keeping, and remedial actions are delegated among various groups and operating facilities. Inspection activities include coverage of the areas of fire control, emergency and spill response, health and safety, radiological safety, and specialized equipment unique to operations within the Y-12 Plant.

For the purposes of this application, the general inspection schedule for areas and/or equipment related to hazardous waste regulations is given in Table F-1 in Appendix F-1. The schedule identifies the types and frequencies of inspections required by RCRA regulations, including monitoring equipment, safety and emergency equipment, security devices, and operating and structural equipment. The WTSD Department Manager maintains the schedules listed in Tables F-1, F-2, and F-3 (Appendix F-1) and is responsible for ensuring that inspections are completed for their specific facilities. 


\section{F-2a(1) Types of Problems}

Types of problems to be looked for when inspecting monitoring equipment, safety and emergency equipment, security devices, operating and structural equipment, and areas subject to spills are listed in Tables F-1, F-2, and F-3 in Appendix F-1.

\section{F-2a(2) Frequency of Inspection}

Inspection frequencies for plant-wide equipment and supplies are included in Tables F-1, F2, and F-3 in Appendix F-1.

\section{F-2b Specific Process Inspection Requirements}

Inspection of each unit is conducted according to the inspection schedules in Appendix F-1. Results of each inspection are recorded on inspection log sheets. Sample inspection log sheets are included in Appendix F-2. Information requested on the log sheets includes the inspector's name, date and time of inspection, items of inspection, types of problems encountered, status of the items, observations, and the date and nature of repairs and remedial actions. Typical problems encountered with each item on the inspection schedule are listed on the log sheet and serve as a reminder to the inspector to ensure a complete inspection. The inspector is required to check the status of each item and to indicate whether its condition is acceptable or unacceptable. If the status of a particular item is unacceptable, appropriate and complete information is recorded, including date and nature of repairs and remedial action. Evaluation and/or correction of unacceptable items will be initiated within 24 hours of the inspection.

\section{F-2b(1) Container Inspection}

Inspections of the container storage areas at OD-9 and OD-10 are conducted according to the general description in Section F-2b and the inspection schedule in Table F-2 in Appendix F-1. Table F-2 also includes the daily inspection requirement for loading and unloading areas when in use. The container storage areas are inspected on a weekly basis and recorded on the container storage area and tank supports inspection log in Appendix F-2. OD-7 does not have a container storage area.

\section{F-2b(2) Tank System Inspection}

As applicable, the tanks are inspected daily for signs of corrosion, erosion, exterior damage, or other deterioration of the materials from which they are constructed. The area surrounding the tanks are also inspected daily for signs of spills, dike failure, and accumulation of precipitation. 
The inspection schedule in Table F-3 in Appendix F-1 indicates the types of problems to be looked for during tank inspections. In addition to the information included in $F-2 b$, other items are included such as tank valve leaks, tank deterioration, tank damage, accumulation of runoff within the dike, dike failure or leakage, dike drainage valve malfunction, and accumulation of spilled hazardous waste within the dike. Also, a check of the tank ladders and structural supports are made for damage, structural stability, and general condition. The results of each inspection are recorded on the inspection log entitled "Daily Inspection Log Sheet for OD-7, OD-9, and OD-10" and is presented in Table F-4 in Appendix F-2.

\section{F-2b(3) Waste Pile Inspection}

Not applicable. The units covered in this permit application are not waste piles; therefore, the requirements for this section do not apply.

\section{F-2b(4) Surface Impoundment Inspection}

Not applicable. The units covered in this permit application are not surface impoundments; therefore, the requirements for this section do not apply.

\section{F-2b(5) Incinerator Inspection}

Not applicable. The units covered in this permit application are not incinerators; therefore, the requirements for this section do not apply.

\section{F-2b(6) Landfill Inspection}

Not applicable. The units covered in this permit application are not landfills; therefore, the requirements for this section do not apply.

\section{F-2b(7) Land Treatment Inspection}

Not applicable. The units covered in this permit application are not land treatment units; therefore, the requirements for this section do not apply.

\section{F-2b(8) Miscellaneous Unit Inspections}

Not applicable. The units covered in this permit application are not miscellaneous units; therefore, the requirements for this section do not apply.

F-2b(9) Subpart AA - Inspection Requirements (Organic Emissions from Process Vents) Not applicable. Subpart AA inspection requirements do not apply to units OD-7, OD-9, and OD-10. 
F-2b(10) Subpart BB - Inspection Requirements (Organic Emissions from Equipment Leaks at RCRA Units)

Applicable inspection requirements are included in Section L. Inspection forms are included in existing plant procedures.

\section{F-2c Remedial Action}

The WTSD Department is responsible for OD-7, OD-9, and OD-10. Operational supervisors and responsible technicians are responsible for initiating requests for required maintenance activities when unacceptable conditions or problems are discovered during inspections of these facilities. If inspections reveal that non-emergency maintenance is needed, it will be completed as soon as possible in accordance with a schedule noted in the $\log$, to preclude further damage and reduce the need for emergency repairs. The inspector instructs the responsible maintenance organization on the remedial actions to be taken to correct these deficiencies.

If a problem is imminent or has already occurred during the course of an inspection or any time between inspections, remedial actions will be taken immediately. In the event of an emergency involving the release of hazardous constituents to the environment, efforts will be directed toward activating the contingency plan, containing the hazard, removing it, and subsequently decontaminating the affected area. Refer to Section $G$ for further details.

\section{F-2d Inspection Log}

Sample inspection logs for the tank storage areas are given in Table F-4 in Appendix F-2. Sample inspection logs for the container storage areas are given in Table F-5 in Appendix F-2. inspected and information is recorded on the log sheets shown in Appendix F-2, Table F-5. The inspection logs will contain, at a minimum, the information presented in Appendix F-2. The log includes spaces for the date of the inspection, and the specific items to be inspected and provides for records of remedial action.

After an inspection, each log sheet is filed at the responsible WTSD Department Manager's office, and these records are kept in accordance with Recordkeeping, Section J.

\section{F-3 WAIVER OF PREPAREDNESS AND PREVENTION REQUIREMENTS}

The Y-12 Plant staff does not request a waiver of the preparedness and prevention requirements. Requirements of this subpart are primarily addressed in Sections D, F, and $\mathrm{G}$ of this application. 


\section{F-3a Equipment Requirements}

Additional internal and external communication systems, emergency equipment, and fire control equipment are discussed in Section G, Contingency Plan.

F-3a(1) Internal Communications

The Y-12 Plant staff does not request a waiver of the preparedness and prevention requirements. Requirements of this subpart are primarily addressed in Sections D, F, and $\mathrm{G}$ of this application.

\section{F-3a(2) External Communications}

The Y-12 Plant staff does not request a waiver of the preparedness and prevention requirements. Requirements of this subpart are primarily addressed in Sections D, F, and $\mathrm{G}$ of this application.

\section{F-3a(3) Emergency Equipment}

The Y-12 Plant staff does not request a waiver of the preparedness and prevention requirements. Requirements of this subpart are primarily addressed in Sections D, F, and $\mathrm{G}$ of this application.

\section{F-3a(4) Water for Fire Control}

The Y-12 Plant staff does not request a waiver of the preparedness and prevention requirements. Requirements of this subpart are primarily addressed in Sections D, F, and $\mathrm{G}$ of this application.

\section{F-3b Aisle Space Requirement}

The Y-12 Plant staff does not request a waiver of the preparedness and prevention requirements. Requirements of this subpart are primarily addressed in Sections D, F, and $\mathrm{G}$ of this application.

\section{F-4 PREVENTATIVE PROCEDURES, STRUCTURES, AND EQUIPMENT \\ F-4a Unloading Operations}

Wastes received at OD-7, OD-9, and OD-10 are received in drums, bulk tanker trucks, or steel or polyethylene portable tanks. Drums will normally be on pallets and are unloaded with a forklift. Ramps are provided to facilitate safe movement of containers from the transport vehicle to the appropriate storage space. In addition, adequate aisle space is maintained at all times. Facility pumps are used to transfer waste from tankers or drums I 
to one of the storage tanks, or from tank to tanker. An elevated loading platform has been constructed within the truck transfer station at OD-9 and OD-10 to facilitate efficient tanker loading procedures. Before each transfer, valves are checked and closed, and the tank level is checked to ensure that the tank designated to receive liquid waste has sufficient empty capacity available to accept the waste. These unloading operations are conducted by trained facility personnel. The tanks at these three facilities are located in containment basins. Additionally, the entire truck transfer station and drum storage and transfer areas have curbed sides and slopes to facilitate the drainage of any spills into the containment basin at each of these locations. Further information concerning spill or rupture or other emergency siruations is found in Section $\mathrm{G}$.

\section{F-4b Run-Off}

Run-off from OD-7, OD-9, and OD-10 is unlikely since the storage tanks are enclosed in a containment basin. In addition, the entire truck transfer station and drum storage area have curbed sides or slopes to facilitate the drainage of any spills into the containment basin at each of these locations. Leak tests are performed annually on the dikes at each facility. All water, such as precipitation, collected in the diked areas is analyzed before discharge.

\section{F-4c Water Supplies}

By preventing run-off as described in Section F-4b, water supply contamination is prevented. Groundwater contamination is prevented by eliminating the discharge of hazardous materials onto the unprotected ground. Additionally, any spills or leaks would be contained by the design described in Section F-4b. If process water is ever used at any of these facilities, protection devices such as backflow preventors and air gaps would be used.

\section{F-4d Equipment and Power Failure}

Operations at OD-7, OD-9, and OD-10 that will be affected if a facility power outage occurs are the lighting, pumps, and piping freeze protection. If the lights, pumps, or the freeze protection system should fail, personnel would cease loading, unloading, or transferring waste. The activities can be resumed when power is restored. No problems are anticipated from such a power interruption.

In the event of equipment failure such as truck or forklift breakdown, handling equipment breakage, or pump failure, operations will be halted until a replacement is secured or repairs are effected. The majority of the operation is passive storage and containment. The only items for which equipment failure could be a problem are the heat tracing cables in the 
piping network. In the event of failure of the heat tracing cables, pumping operations through the affected conduit would be halted until a replacement is secured or repairs are effected. A central freeze protection control panel is installed for OD-9 which allows the operator to immediately identify problems with the piping heat tracing cables, so that appropriate action can be taken in a timely fashion.

All plant-wide emergency alarms have backup power generators to insure continual availability.

\section{F-4e Personal Protection Equipment}

The equipment appropriate for employees at specific facilities and areas of the plant is specified by the Plant Industrial Hygiene (IH) and Radiation Protection (RP) personnel. The plant IH and RP personnel utilize hazardous chemical data, material safety data sheets, and radiological information necessary to determine the appropriate type of personal protection equipment needed. They also consider the characteristics of the waste types to be handled, including toxicity, ignitability, reactivity, corrosivity, routes of exposure, and other information. Industrial Hygiene and Industrial Safety personnel report to the Plant Shift Superintendent whenever the Contingency Plan is implemented, and they assist him in specifying the protective equipment for affected personnel such as fire fighters, rescue teams, spill cleanup personnel, and equipment decontaminators. Available equipment is listed in Appendix G-1. See Section H for a description of employee training in this subject area.

Personnel exposure to hazardous waste is minimized through the use of protective equipment as well as by safe handling practices. At a minimum, personnel in the storage areas wear safety glasses, and safety shoes. If actual handling of hazardous waste is necessary, personnel will wear the above items plus gloves of the appropriate type such as cotton, nitrile rubber, or latex rubber, as specified by the Industrial Hygiene Department for the specific chemical or chemical class being handled as well as work boots with steel inserts and, when needed, respirators. Whenever required, other protective equipment is available, including but not limited to, hard hats with face shields, impermeable coveralls, selfcontained breathing apparatuses, and acid suits. However, the actual requirement for specific safety equipment for the protection of personnel in the event of a spill or leak is determined on a case-by-case basis.

Good handling practices to prevent worker exposure include transferring hazardous wastes carefully, using proper equipment such as drum lifts, funnels, pumps, and pump adapters as 
well as sealing all containers before moving them. All operations are performed by fully trained laborers under the direction of the operating supervisor or the technician, who are familiar with the personnel protection procedures to be followed for the material being handled.

\section{F-5 PREVENTION OF REACTION OF IGNITABLE, REACTIVE, AND INCOMPATIBLE WASTES}

\section{F-5a Precautions to Prevent 1 aition or Reaction of Ignitable or Reactive Wastes} The wastes stored in OD-7 and OD-9 are neither reactive nor ignitable.

The wastes stored in OD-10 are not reactive, but they are ignitable. OD-10 receives wastes from all areas of the Y-12 Plant. Although ignitable wastes may not be present at all times, standard operational procedures are appropriate for the management of ignitable wastes. Accurate identification of wastes at the source of generation will ensure that wastes are managed so as to prevent reactions, fires, or releases of waste constituents.

Only wastes compatible with the containers and tanks are stored. Therefore, no reactions will occur and the only source of ignition will be external to the containers or tanks.

Nonsparking tools and equipment are used in the building. Sources of ignition including open flames, smoking, cutting and welding, hot surfaces, frictional heat, and sparks (static, electrical, or mechanical), are controlled at OD-10. Signs stating "Danger--No Smoking Matches or Open Lights" and "Danger -- Authorized Personnel Only" are posted conspicuously on the north, south, east, and west sides of OD-10. Cutting, welding, or other operations in which a potential hazard exists will only be permitted in this area if a special work permit has been issued. The special work permit will list all precautions necessary to prevent ignition of the waste.

Ventilation of the facility is provided by the open design. This design prevents the accumulation of hazardous or ignitable vapors which could result from facility operations or from accidental spills or leaks.

The facility is equipped with explosion-proof lights and other fixtures. All electrical equipment is UL rated for hazardous environments. Safety shower/eyewash assemblies are located at the facility. Water collected from the safety shower/eyewash assemblies is handled and disposed of as necessary. 


\section{F-5b General Precautions for Handling Ignitable or Reactive Waste and Mixing of Incompatible Waste}

There are no ignitable, reactive, or incompatible wastes accepted at OD-7 and OD-9.

There are no reactive or incompatible wastes accepted at OD-10. However, ignitable wastes are accepted. On special occasions incompatible wastes may be stored in areas separated by portable dikes. A compatibility review will be conducted by Waste Management personnel before pumping into any of the tanks. Section F-5a discusses the precautions taken to prevent reactions which:

1. Generate extreme heat or pressure, fire or explosions, or violent reactions;

2. Produce uncontrolled toxic mists, fumes, dusts, or gases in sufficient quantities to threaten human health or the environment;

3. Produce uncontrolled flammable fumes, dusts, or gases in sufficient quantities to pose a risk or fire or explosions;

4. Damage the structural integrity of the device or facility; or

5. Through other like means, threaten human health or the environment.

The use of generator information provided on Form 2109 (see Appendix C-2) minimizes placement of incompatible wastes in the same storage or staging area, and thereby minimizes reactions which may generate heat or pressure or cause violent reactions or other uncontrolled releases to the environment. All containers are stored closed so that fumes, dusts, or gases are not released. Wastes are characterized in accordance with the waste analysis plan in Section $\mathrm{C}$.

F-5c Management of Ignitable or Reactive Wastes in Containers

The wastes stored at OD-7 and OD-9 are neither reactive nor ignitable.

The wastes stored in OD-10 are not reactive, but they are ignitable. Section F-5a discusses how ignitable waste containers at this facility are protected from materials or conditions which could cause them to ignite. Wastes are characterized in accordance with the waste analysis plan in Section C. Also, see Section D-1(c)(2). 
Map 2 in Appendix B-1, Topographic Map, demonstrates that OD-10 is located at least 15 meters ( 50 feet) from the site property line.

\section{F-5d Management of Incompatible Waste in Containers}

OD-7 does not have a container storage area, but containers are managed at OD-9 and OD-10. It is the responsibility of the generator to insure that incompatible wastes are not initially placed in the same container. Before any waste is poured into an empty container, the container is examined carefully. Usually, the drummed waste is held only temporarily in the container storage area before being unloaded into one of the bulk storage tanks. A hazardous waste container label is properly filled out and applied to the container as applicable. Adequate aisle space is maintained on each side of the container storage to allow access for inspection. The partially filled containers are opened only when additional waste is added or samples are taken, and they are closed immediately afterward. The unit operators are trained in the proper handling of hazardous waste, including the importance of not adding an incompatible waste to a partially filled container. Wastes are mixed only if it is known from experience that they are compatible and after the contents of each drum are verified. Hazardous wastes will not be placed into any unwashed container that previously held an incompatible waste or material. The use of properly washed containers, appropriate information and identification of the waste applied to the label, and knowledge of waste compatibilities will prevent an operator from placing waste into a container that previously held an incompatible waste. Segregation of wastes is not needed at units OD-9 and OD-10 because incompatible wastes are not stored at these units. If incompatibles need to be stored, temporary dikes, birms, walls, etc., will be used to properly segregate the wastes. Wastes are characterized in accordance with the waste analysis plan in Section C.

\section{F-5e Management of Ignitable or Reactive Wastes in Tanks}

The wastes stored at OD-7 and OD-9 are neither reactive nor ignitable. The wastes stored in OD-10 are not reactive, but they are ignitable. Section F-5a describes how ignitable wastes stored in tanks at OD-10 are protected from any materials or conditions which could cause them to ignite.

Map 2, Appendix B-1, Topographic Map, demonstrates that OD-10 is located more than 15 meters ( 50 feet) from the boundary of the site property line as per the buffer zone requirements for stable liquid as stated in the National Fire Protection Association's 1987 "Flammable and Combustible Liquid Code" for tanks with emergency relief venting. Wastes are characterized in accordance with the waste analysis plan in Section C. 


\section{F-5f Incompatible Wastes in Tanks}

Wastes for OD-7, OD-9, and OD-10 are received in drums and steel or polyethylene portable tanks, or in bulk tanker trucks. The contents of each tanker truck or drum are checked against its internal shipping document and against available analytical data to determine its compatibility with the contents of the appropriate storage tank. Facility pumps are used to unload waste liquids from tanker trucks, portable tanks, or drums, and to transfer them to the appropriate storage tank. All tank construction materials are compatible with the waste material liquids and vapors, and no incompatible wastes and/or materials are stored in the same tank or in an unwashed tank that previously held an incompatible waste and/or material. Wastes are characterized in accordance with the waste analysis plan in Section C.

\section{F-5g Ignitable or Reactive Wastes in Waste Piles}

Not applicable. The units covered in this permit application are not waste piles; therefore, the requirements for this section do not apply.

\section{F-5h Incompatible Wastes in Waste Piles}

Not applicable. The units covered in this permit application are not waste piles; therefore, the requirements for this section do not apply.

\section{F-5i Ignitable or Reactive Wastes in Surface Impoundments}

Not applicable. The units covered in this permit application are not surface impoundments; therefore, the requirements for this section do not apply.

\section{F-5j Incompatible Wastes in Surface Impoundments}

Not applicable. The units covered in this permit application are not surface impoundments; therefore, the requirements for this section do not apply.

\section{F-5k Ignitable or Reactive Wastes in Landfills}

Not applicable. The units covered in this permit application are not hazardous waste landfills; therefore, the requirements for this section do not apply.

\section{F-51 Incompatible Wastes in Landfills}

Not applicable. The units covered in this permit application are not hazardous waste landfills; therefore, the requirements for this section do not apply. 


\section{F-5m Ignitable or Reactive Wastes in Land Treatment}

Not applicable. The units covered in this permit application are not land treatment units; therefore, the requirements for this section do not apply.

F-5n Incompatible Wastes in Land Treatment

Not applicable. The units covered in this permit application are not land treatment units; therefore, the requirements for this section do not apply. 


\section{SECTION G CONTINGENCY PLAN}

\section{GENERAL FACILITY DESCRIPTION}

The Oak Ridge Y-12 Plant was built by the U.S. Army Corps of Engineers in 1943 as part of the Manhattan Project, and given the original mission of separating the fissionable isotope of uranium by the electromagnetic process. After World War II, the electromagnetic process was discontinued in favor of the more economical gaseous diffusion process. In recent years, the Y-12 Plant staff has developed this facility into a highly sophisticated manufacturing and developmental engineering organization.

The U.S. DOE owns and operates the Y-12 Plant. Personnel from Martin Marietta Energy Systems, Inc., co-operate and manage the Y-12 Plant. Since 1984, the facility has been managed by Martin Marietta Energy Systems, Inc., personnel, under a prime contract with the U.S. DOE. The contract is administered by personnel at DOE, Oak Ridge Operations.

The Y-12 Plant occupies approximately 800 acres in Anderson County, Tennessee, and is located southwest of the city of Oak Ridge. The site employs approximately 5,000 people, including employees of the Oak Ridge National Laboratory assigned to the Y-12 Plant. Two surface streams, East Fork Poplar Creek and Bear Creek, border the facility on the south, east, and southwest sides of the plant. There is access to the Y-12 Plant, controlled on Bear Creek Road, on the north side of the facility; indirect access from Scarboro Road on the east side of the facility; and indirect access to the facility on the south side via Bethel Valley Road. A controlled access road from Bethel Valley Road by way of Mt. Vernon Road is located on the southwest side of the site.

It is the mission of the Y-12 Plant to serve as a key manufacturing technology center for the development and demonstration of unique materials, components, and services of importance to the DOE and the nation. This is accomplished through the reclamation and storage of nuclear materials, manufacture of nuclear materials, manufacture of components for the defense capabilities of the nation, support to national security programs, and services provided to other customers as approved by DOE.

\section{G-1 GENERAL INFORMATION}

The Y-12 RCRA Contingency Plan will be continually reviewed and revised if any of the following occur: the facility permit is revised, the plan is inadequate in an emergency, the 
procedures herein can be improved, the operations of the facility change in a way that alters the plan, the emergency coordinator changes, or the emergency equipment list changes. Copies of the Y-12 Emergency Management Plan are available at the Plant Shift Superintendent's Office and the Emergency Management Office. This document serves to supplement the Y-12 En rency Management Plan to be appropriate for all RCRA hazardous waste treatment, storage, or disposal units. The 90-day accumulation areas at the Y-12 Plant have a separate contingency supplement as required by RCRA and are separate from this supplement.

The facility name, address, identification number, and owner/operator name are provided below:

U.S. Department of Energy, Oak Ridge Y-12 Plant

Bear Creek Road

Post Office Box 2001

Oak Ridge, Tennessee 37831-8555

EPA ID TN3890090001

Owned and operated by U.S. Department of Energy

Managed and co-operated by Martin Marietta Energy Systems, Inc.

The overall layout of the Y-12 Plant and the location of RCRA units are shown in Map 2, "Y-12 Plant RCRA Waste Unit Locations." Map 1, "Y-12 Plant Emergency Facilities Directory," shows the locations of assembly stations, boundaries, and access controls to the plant. In the event of an emergency, the Plant Emergency Director (PED) will direct and inform all personnel of the evacuation routes.

\section{G-2 EMERGENCY COORDINATORS}

The emergency coordinator at the Y-12 Plant is the PED. The Y-12 Plant has several Plant Shift Superintendents (PSS) who share the responsibilities of the PED. At least one PSS is on duty 24 hours per day, every day of the year, and can be reached at (615) 574-7172 at the Emergency Operations Center (EOC) in Building 9706-2. The alternate EOC is located in Building 9709 and the phones are transferred if the operations are being conducted at this building. The PSS on duty is responsible for providing continuous plant-wide emergency direction as the PED. If the PED is incapacitated during an emergency, the Site Security Commander on duty is his alternate until another PSS can report to the scene. The PSS, or alternate, has access to names, telephone numbers, and addresses of all emergency 
personnel and will determine who must be contacted to provide emergency activity support.

The duties of the PED as the Emergency Coordinator include:

- Receiving notice that an incident has occurred;

- Evaluating the threat;

- Activating internal alarm systems to notify or evacuate personnel, if appropriate;

- Proceeding immediately to obtain information concerning released materials and initiating appropriate activities for characterizing and abating the release;

- Ensuring that necessary on-site notifications are made;

- Performing an assessment of the potential for off-site effects upon the public health and environment and notifying DOE Oak Ridge EOC of the same;

- Initiating and directing a plan of action;

- Mobilizing sufficient forces, including technical assistance, to respond to the emergency at hand;

- Directing the overall effort to respond to plant emergencies in such a way as to ensure that all emergency groups, both local and plantwide, function as a team.

- Delegating authority in any capacity necessary if the need arises during an emergency;

- Authorizing all rescue efforts requiring any employee experiencing illness or injury;

- Seeing that off-site medical facilities are notified immediately when a seriously ill or injured patient is en route, and provide the nature of the injury or illness;

- Ensuring that a medical department staff member, a supervisor, or someone knowledgeable as to the circumstances or acquainted with the details of any serious accident or illness accompanies the patient to the emergency room; 
- Determining the accessibility of plant areas after an accident and authorizing reentry of evacuated areas;

- Under special conditions, requesting the designation of a technical group to assist in evaluating the advisability of reentry;

- Terminating emergency status when the threat is entirely gone;

- Authorizing, when applicable, the sounding of the "all clear" signal at the termination of an emergency; and

- Restoring the plant to normal operations.

The names and work numbers of the PSSs are provided below:

\begin{tabular}{lcc}
\multicolumn{1}{c}{ Name } & Building Location & Work Phone \\
W. M. Bradley & $9706-2$ & (615) $574-7172$ \\
L. K. Brooks & $9706-2$ & $(615) 574-7172$ \\
J. D. Chapman & $9706-2$ & $(615) 574-7172$ \\
E. Manis & $9706-2$ & $(615) 574-7172$ \\
P. C. Norris & $9706-2$ & $(615) 574-7172$ \\
C. L. Beeler & $9706-2$ & $(615) 574-7172$ \\
G. L. Calvert & $9706-2$ & $(615) 574-7172$
\end{tabular}

Emergency resource books containing lists of emergency response telephone numbers (Emergency Response Organization personnel, facilities, off-site agencies, outside support organizations, etc.) are readily available to the PED in the EOC and alternate EOC. Telephone listings are revised as changes occur. In addition, a quarterly review is conducted by the Emergency Preparedness Operations Department Manager. 


\section{G-3 IMPLEMENTATION}

The decision to implement this contingency plan, as part of the Emergency Management Plan, depends upon whether an imminent or actual incident could threaten human health or the environment.

The contingency plan will be implemented by the PED in the following situations:

- A fire and/or explosion occurs, such that:

- The potential for human injury exists;

- Toxic fumes that could endanger human health or the environment are released;

- The fire could spread on site or off site and possibly ignite other flammable materials or cause heat-induced explosions;

- The use of water and/or chemical fire suppressants could result in contaminated runoff that could endanger human health or the environment; and/or

- An imminent danger exists that an explosion could ignite other hazardous wastes at the facility and possibly result in the release of toxic materials.

- A spill or release of a hazardous material occurs such that:

- The spill could result in release of flammable liquids or vapors, thus causing a fire or gas explosion hazard;

- The spill could cause the release of toxic liquids or fumes that could endanger human health or the environment; and/or

- The spill cannot be contained on site, resulting in off-site soil contamination and/or ground or surface water pollution that could endanger human health or the environment.

Many ways of discovering a spill or release of chemicals are possible. These include: routine and scheduled inspections of process equipment and material storage areas; unusual or strong chemical odors which may indicate a leak; and instrumentation such as level alarms, automatic sump pumps, and $\mathrm{pH}$ meters which may also reveal chemical spills or system malfunctions.

\section{G-4 CONTROL PROCEDURES - INCIDENT COMMANDER}

The incident commander is defined as the person assuming command and control of emergency response at the scene of the incident. The incident commander will be the operations supervisor on duty for a specific unit or, in the absence of a supervisor, the first 
arriving emergency response officer designated by the PED. The incident commander will be responsible for the following:

- Initial assessment of the incident scene to the PED;

- Establishing control and setting up the command post for emergency response;

- Initial evaluation of the magnitude of the problem;

- Evacuation of personnel from immediate danger;

- Arranging for assembly, organization, and briefing of emergency response personnel who have been summoned;

- Providing updated information on conditions, progress of response, and additional manpower or equipment needs to the PED;

- Directing operational changes needed (e.g., shutting off process flows);

- Implementing applicable prearranged plans and procedures; and

- Continuing to provide incident control until relieved by an alternate incident commander.

The following actions will be taken in areas affected by a fire or explosion:

1. Work in the affected areas will be shut down immediately.

2. Feedlines and additional equipment will be shut down, as necessary and practical.

3. The PED will be contacted.

4. The area will be cleared of all personnel not actively involved in fighting the fire. These persons are to report to the designated assembly points for accountability. 
5. All injured persons will be removed, and medical treatment will be administered by Medical Department personnel with outside assistance, as required.

\section{G-5 EMERGENCY RESPONSE PROCEDURES -- EMERGENCY COORDINATOR}

The PED is responsible for the overall direction of emergency response efforts as follows:

- Directs emergency service units and local emergency squads.

- Ensures that the incident commander at the scene of the emergency, evaluates:

- Radiation and general safety situations as they affect the immediate and adjacent areas,

- Need for interrupting utility services such as process water, ventilation, oxygen, natural gas, and electricity, and

- Need for operational changes.

- Considers the need for and arranges for any large-scale alert, evacuation, general alert, invocation of mutual assistance agreements, and procurement of additional emergency personnel or emergency equipment.

- Keeps Y-12 Plant management and appropriate staff groups informed.

- Determines when the emergency is over, and orders the "all clear" signal.

The Emergency Management Department staff is responsible for:

- Y-12 Plant-wide emergency planning.

- Updating the Emergency Management Plan.

- Planning for practice exercises.

- Coordinating the organization and training of emergency service units and local emergency organizations.

- Ensuring that plans are in place for receiving and evaluating emergencies. 
- Ensuring that plans are in place for activating internal alarm systems to alert/evacuate personn.1.

- Planning coordination for the emergency response team; determine if outside assistance is required.

- Ensuring that plans are in place to report incidents to personnel at the DOE, Oak Ridge Operations, staff in accordance with DOE Order 5000.3A "Occurrence and Processing of Operations Information."

\section{G-5a Notification}

The employee discovering a potential emergency incident will notify his immediate supervisor and/or the PED. The PED will immediately activate the internal alarm system to notify or evacuate personnel, if appropriate. The PED will also notify the Plant Manager, the Production Manager, the Environmental Coordinator, and Organization Managers of the operations involved. In the event that outside assistance is required, the PED will notify appropriate state and/or emergency response agencies.

\section{G-5b Identification of Hazardous Materials}

The incident commander will immediately attempt to identify the character, exact source, amount, and aerial extent of the material involved in the fire or release. The initial identification method will be by visual analysis of the material and location of the release. Plant records, including inventories and process and waste log sheets, are available at the operating department offices of the RCRA units to aid in estimating the composition and quantity of released material. In the event of a spill, a sample of the spilled material is taken if the material enters a storm drain, there is some question as to the identity of the material, or the material is suspected to contain PCBs. The Health, Safety, Environment, and Accountability Organization staff will sample to verify hazardous material identification, determine boundaries of contaminated areas and contaminant concentrations, and verify proper cleanup after cleanup activities are completed.

Information such as storm sewer locations and topographic information is available to support the PED in the process of identifying potential flow/contamination paths and determine appropriate control actions. 
G-5c Hazard Assessment

Assessment of possible hazards to human health or the environment will be made using the following methods:

1. Process knowledge (i.e., knowledge of the nature of waste materials released);

2. Review of Material Safety Data Sheets, if available;

3. Chemical analysis/monitoring data;

4. Results of modeling for releases to air, surface water, or groundwater; and

5. Specific health-based and environmental criteria or limits which may be exceeded.

Based on the hazard assessment, evacuation of the immediate unit area, entire facility, or local areas outside the facility may be necessary.

\section{G-5d Off-Site Notification/Evacuation}

The Y-12 Emergency Management Plan describes the methods used for notification of Y-12 emergency response personnel and appropriate federal, state, and local emergency response centers. Individuals or groups that may be notified include, but are not limited to, the following:

- DOE Oak Ridge Operations EOC,

- DOE Headquarters EOC (through the Oak Ridge Operations EOC voice bridge),

- Tennessee Emergency Management Agency,

- National Response Center,

- Local Emergency Planning Councils,

- Affected county notification points,

- City of Oak Ridge (Anderson County),

- Regional U.S. Environmental Protection Agency, and

- Other agencies as required by regulatory guidance.

Evacuation of nonessential personnel is ordered by the PED if it is determined that a threat to the safety of plant personnel exists. Evacuation routes will be determined by the PED.

\section{G-5e Prevention of Recurrence or Spread}

After incident mitigation, a recovery manager will be appointed to return the incident scene to preincident conditions and analyze the root cause of the incident. 


\section{G-5f Storage and Treatment of Released Material}

Any hazardous materials that result from a release, fire, or explosion at the Y-12 Plant will be contained, removed, and placed a 55-gallon drums (or smaller containers if appropriate). Leaking or damaged containers $\mathrm{v}$ be placed in 85 -gallon overpack drums so they can be stored until treatment or dispos arrangements are finalized.

Contaminated absorbent materials, protective clothing, and other disposable material used in remediation of the emergency and subsequent decontamination activities will be placed in 55-gallon drums and stored at a RCRA storage unit pending treatment or disposal. These items will be handled with the same degree of caution as the wastes themselves so that public health and the environment are not further threatened.

Immediately after an emergency, the emergency coordinator will make arrangements for treatment, storage, or disposal of recovered waste, contaminated soil, surface water, or any other contaminated material. Emergency and spill response equipment available for cleanup, storage, and treatment are identified in the Y-12 Emergency Management Plan.

\section{G-5g Incompatible Waste}

In order to prevent reactions caused by proximity of incompatible substances, wastes which have been spilled or released must be segregated from other wastes or materials which are incompatible. It is a duty of the Spill Response Coordinator to ensure that wastes which may be incompatible with the released material are not treated, stored, or disposed of in the vicinity of the spill or fire until cleanup procedures are completed.

Incompatible wastes are unlikely to be treated, stored, or located in the affected areas until cleanup is completed because of the waste segregation practices used at the facility. If possible, no additional wastes will be stored in the affected area until the cleanup is completed. If waste storage there is necessary, wastes will be placed only in those areas where no incompatible wastes are present.

\section{G-5h Postemergency Equipment Maintenance}

All emergency response elements will ensure that team equipment is properly decontaminated, supplies are restocked, and the team is returned to preemergency readiness. 


\section{G-5i Container Spills and Leakage}

In the event of a hazardous material spill or release, the following general procedures will be used for rapid and safe response and control of the situation. Spills or releases and impending spills or releases discovered during routine inspections will be handled in the same manner as described below for spill and release emergencies. These are general guidelines, and circumstances may dictate some alterations to these procedures.

If an employee discovers a chemical spill or process upset resulting in a hazardous material release, he or she will immediately report it to the area supervisor. The area supervisor or the employee will contact the PED. When contacted, the PED will obtain information pertaining to the following:

1. The material spilled or released;

2. Location and source of the release or spillage of hazardous material;

3. An estimate of the quantity released and the rate at which it is being released;

4. The direction in which the spill, vapor, or smoke release is heading;

5. Any injuries involved; and

6. Fire and/or explosion or possibility of these events.

This information will help the PED to assess the magnitude and potential seriousness of the spill or release. The PED will contact and deploy the necessary in-plant personnel. If additional assistance is required, the PED will also contact personnel at the other Oak Ridge plants that have agreed to provide assistance and the agencies discussed in the Coordination Agreements section of this plan.

The initial response to any emergency will be to protect human health and safety, and then the environment. Identification, containment, treatment, and disposal assessment will be the secondary responses.

Medical assistance for injured persons will be obtained from the Y-12 Health Services staff.

Cleanup personnel summoned by the PED will don protective clothing and equipment, as specified by the Health, Safety, Environment, and Accountability Organization staff. If a flammable waste is involved, all ignition sources will be removed, and spark and explosionproof equipment and clothing will be used for containment and cleanup activities. If possible, cleanup personnel will try to stop the leak. Special materials, such as tank patch 
kits, will be kept on hand for temporary repairs. All surrounding materials that could be reactive with the waste materials will be removed. The major components of the waste will be determined.

Absorbent pads, booms, earth, sandbags, sand, and other inert materials will be use to contain, divert, and cleanup a spill if it has not been contained oy a dike or sump. Sewer plugs are available, if required, to isolate a spill. Spills contained within a dike or sump may . pumped back into the appropriate storage tank or drum, if it is structurally sound. All containment and cleanup materials will be placed in drums for proper disposal. Some items, such as absorbent rags or booms, may have to be cut up. All recovered liquid wastes and contaminated soil that cannot be returned to their original storage tanks or containers will be placed in drums for removal to an approved storage or disposal site.

Most tank and container spills and leaks are contained within the dikes and sumps provided in the tank and container areas. Small spills occurring in a diked area are directed to the sump provided in that area. Immediately after the spill is detected, the Waste Management Organization staff will be summoned to remove any standing liquids (as described above) and arrange to have the spilled material taken to a unit approved to handle that particular waste. If necessary, a portable sump pump will be used to pump the diluted waste material into 55-gallon drums. The transfer of the spilled material will be performed within 24 hours or at the earliest practical time if it is demonstrated that the material cannot be transferred within 24 hours.

If, for some reason, a chemical spill is not contained within a dike or sump area, an appropriately sized area of isolation will be established around the spill. The size of the area will generally depend on the size of the spill and the materials involved. An area at least 50 feet in all directions will be isolated. For large spills, an area at least 100 feet in all directions will be isolated. When any spill occurs, only those persons involved in overseeing or performing emergency operations will be allowed within the designated hazard area. If possible, the area will be roped or otherwise blocked off. All persons not actively involved in managing the spill will be kept upwind.

If the PED determines that Y-12 and the other DOE plants are unable to handle the emergency, then local, state, and federal authorities will be notified of the situation. When necessary, evacuation of all potentially affected plant areas will begin as soon as possible. 
All emergency equipment used for spill management must be cleaned by the responsible personnel so that it is fit for use prior to resumption of plant operations in the affected areas.

\section{G-5j Tank Spills and Leakage}

In the event of a hazardous material spill or release, the procedures described for container spills and leakage apply for tank releases.

\section{G-6 EMERGENCY EQUIPMENT}

A listing of the emergency and spill response equipment is provided in the $\mathrm{Y}-12$ Emergency Management Plan. In addition, emergency equipment is maintained at the units in this plan for minor releases which include, but is not limited to, absorbent material, fire extinguishers, shovels, shoe scuffs, gloves, eye protection, and protective clothing. The inspection lists and frequency for inspection of the spill response equipment at the units are presented in the Y-12 Emergency Management Plan.

\section{G-7 COORDINATION AGREEMENTS}

The Y-12 Emergency Management Plan details all coordination agreements currently held with local agencies. A copy of this plan has been provided to all mutual aid organizations. Designated emergency coordinators will commit the necessary resources to implement the contingency plan.

\section{G-8 EVACUATION PLAN}

All emergencies at the Y-12 Plant warrant prompt and deliberate action. Criteria for evacuation have been established. The PED is responsible for determining whether evacuation is necessary. The Y-12 Emergency Management Plan contains details of this criteria.

\section{G-9 REQUIRED REPORTS}

The PED will note in the operating record the time, date, and details of any incident which required implementation of the Contingency Plan. Internal reports will be filed as required by DOE and Martin Marietta Energy Systems, Inc., personnel.

Within 15 days after the incident, personnel from the Y-12 Plant will submit a written report on the incident which required implementation of the Contingency Plan to the DOE staff for review and transmittal to the Commissioner of the Tennessee Department of 
Environment and Conservation, as required by Tennessee Rule 1200-1-11- .06(6)(g)(10). The report will include:

- Name, address, and telephone number of the owner or operator;

- Name, address, and telephone number of the facility;

- Date, time, and type of incident (e.g., fire, explosion);

- Name and quantity of material(s) involved;

- The extent of injuries, if any;

- An assessment of actual or potential hazards to public health or the environment, where this is applicable; and

- Estimated quantity and disposition of recovered material that resulted from the incident. 


\section{SECTION H \\ PERSONNEL TRAINING}

The information contained in this section of the permit application outlines the training programs for personnel at the Y-12 Plant who are directly involved with the operation of hazardous waste management units in accordance with the requirements of 40 CFR Parts 264 and 270, and Rules 1200-1-11-.07 and -.06 of the Rules Governing Hazardous Waste Management in Tennessee.

\section{H-1 OUTLINE OF TRAINING PROGRAM}

\section{H-1a Job Titles and Tasks}

The organization of personnel involved in operations connected with these facilities is presented in Appendix H-1, Figure H-1. Responsibility involving compliance with RCRA resides with the responsible department head and/or supervisor for each facility in the Waste Management Division, who oversees all aspects of the management of wastes in OD-7, OD-9, and OD-10. The Staff Engineer for each facility provides technical support and project management related to the physical aspects and compliance requirements of the facility. Sampling, verification of waste streams, documentation, and quality control regarding storage and management procedures is the responsibility of the WTSD Department. Actual handling of wastes and movement of wastes into and out of the building is performed by trained laborers working at the specific facilities. The job titles, tasks, and task descriptions for each position are presented in Appendix H-2. The minimum information provided in the job descriptions are as follows:

- Position title,

- Basic function of position,

- Major environmental duties and responsibilities, and

- Formal education required.

\section{H-1b Training Content, Frequency, and Techniques}

The workers receive documented performance-based training and job-specific training. Training techniques are patterned after the performance-based training and include, but are not limited to, classroom, on-the-job, and required reading materials. The Y-12 Plant Administrative Procedures exist which delineate training responsibilities and structures within the Y-12 Plant. All personnel who work at OD-7, OD-9, and OD-10 receive initial and annual refresher OSHA Hazard Communications Training, initial OSHA/SARA 24-hour 
training, 8-hour refresher OSHA/SARA training, annual respirator training, annual RCRA training, and biennial radiation protection and criticality training. The frequency of the course training is presented in Appendix H-3. Specific modules used are listed in the following paragraph.

Basic Training: The basic training program includes, but is not limited to, the following subject areas:

- 24-Hour OSHA/SARA Training: All personnel working at OD-7, OD-9, and OD-10 are sent to the 24-Hour Hazardous Waste Management Training and an annual 8-hour refresher as required by OSHA, per SARA. Supervisors receive an additional 8 hours of training as required.

- Hazard Communications Training: All personnel received the initial Hazard Communications training. Specific modules listed below are included as part of this training as applicable.

- Compliance Awareness: This module presents a general overview of the environmental regulations that impact the work of the Y-12 Plant facility.

- RCRA Annual Training: This module presents the basic requirements for compliance with RCRA and includes proper hazardous waste management and documentation. This module is updated annually as needed and presented to the applicable personnel.

Specifically, the following subjects will be covered in the annual RCRA refresher training:

1. All hazardous wastes currently being handled at the facilities, noting any changes in waste type, volume, source, characteristics, or location that have occurred during the past year.

2. The status of storage and operating conditions and procedures, noting any areas where there are problems or the potential for problems. Employees participate in developing effective solutions. 
3. The requirements contained in the RCRA permit of the facilities, noting any changes that have occurred during the past year. Areas where maintenance of compliance is a problem are identified and discussed, and effective solutions are sought.

4. Incidents that have occurred in the past year that warranted use of contingency plans and/or emergency action. This review focuses on the cause of the incident and identification of steps to be taken to prevent or to ensure better handling of such events in the future.

- Hazard Communication/Toxicology: This training program is designed to inform employees of the potential harmful effects of chemicals. The program examines the nature of toxic effects, the dose/response relationship, routes of entry of toxic substances, and various acute and chronic effects.

- Hazard Communication/Chemical Safety: Training will outline an overview of the health and safety hazards that chemicals pose and good chemical safety practices, thus motivating workers to take precautions to protect themselves. It describes the different forms of chemicals, routes of exposure, common signs and symptoms of exposure, and the effects of exposure. Materials described include carcinogens, corrosives, toxics, irritants, sensitizers, and chemicals that have target organ effects. The importance of using labels and material safety data sheets, as well as the measuring and monitoring of the job environment, will be detailed.

- Corrosives: This module presents the hazards that corrosives pose, describes the exposure symptoms, discusses containers and storage, outlines personal safety precautions, and explains what to do in the event of an emergency.

- Solvents: This module concentrates on the health and safety precautions when working with solvents.

- Poisons: This module discusses the different forms of poisons, safe handling procedures, and proper storage. It emphasizes personal protection as well as emergency methods and first aid. This module places emphasis on compressed gases because of their widespread use and the physical hazards that they pose. 
- Gases: This module discusses proper moving and storing of gas cylinders, the effect of different gases on the body, personal protection, what to do in an emergency, and special instructions for emergency and rescue personnel.

- Oxidizers: Thi nodule addresses the proper safety and health measures when handling oxidizers.

- Explosives: This module stresses the importance of using the correct tools and equipment, maintaining a proper work environment, checking labels and material safety data sheets, and checking process sheets for all operations or processes which involve potential explosion hazards.

- Carcinogens: This module describes protection which is dependent upon a system of safeguards--personal protective gear, engineering controls, administrative controls, or a combination of the three. It covers each control in addition to routes of entry, industrial hygiene, labels, warning signs and posters, material safety data sheets, and monitoring.

- Protective Clothing: In dealing with chemical hazards, the most important line of defense against personal contact and contamination is protective clothing. Training details the correct methods of selecting and wearing protective equipment including gloves, aprons, goggles, etc., as required.

- Respiratory Protection: In order to protect the respiratory tract against irritating and poisonous gases, fumes, smoke, and dusts, the worker must be knowledgeable in the proper $e$ of the respirator. Information on the various types of respirators, the requirements to ensure a good fit, and emergency actions are presented in this module. Workers will also be trained on the specific respiratory hazards, requirements, and issue procedures for their specific job.

- Radiological Protection: Informs workers about the hazards associated with radiation exposure and presents methods of controlling dose levels to within acceptable limits. Training will be presented in the Radiation Control module.

- Criticality Safety: The concepts and required safety controls related to criticality safety are explained in this module. 
Job Qualification: Currently, on-the-job training (OJT) of technicians and laborers is conducted under the direct supervision of the waste management supervisor. This training includes operational and job safety requirements. However, in order to improve, formalize, and document the required OJT, the job task analysis for each of these facilities has been completed. Based on this job task analysis and specific safety requirements for each facility, lesson plans for OJT will be completed and will be performed by supervisors who have successfully completed the Supervisors On-The-Job Training course. Comprehensive written exams will be required once a participant has completed training associated with his/her responsibilities per the operating procedures. In addition to the written examination, the technician or laborer will be required to demonstrate his proficiency in the required tasks. Failure of the test requires the technician/laborer to undergo further training. Though the lesson plans will be specifically directed at the proper operation of the facilities, general topics to be included as applicable are: (1) conducting routine checks and inspections, (2) job-specific personal protective equipment training, and (3) maintaining records and data. Annual refresher training will be provided as applicable and necessary.

Emergency Preparedness: The training program is designed to ensure that personnel not only handle hazardous wastes in a safe manner, but also properly respond to emergency situations. The program trains hazardous waste handling/management personnel to maintain compliance under both normal operating conditions and emergency conditions.

Training elements addressing non-routine and emergency situations (unscheduled shutdowns and startups related to storms, power outages, fires, explosions, spills) as applicable include:

1. Contingency Plan requirements and implementation,

2. Procedures for locating, using, inspecting, repairing, and replacing facility emergency and monitoring equipment, including personal safety, fire control, and spill control equipment and alarm and communication systems,

3. Response to fires or explosions,

4. Response to incidents and procedures for containing, controlling, and mitigating spills, and any surface or groundwater contamination, 
5. Shutdown of operations, power failure procedures and any other emergency operating procedures, and

6. Procedures for evacuation of nearby areas.

In addition to the hazardous waste management personnel, a plant emergency squad is on duty for response to all fires and other general plant emergencies. This emergency squad is tra ned with classroom training methods and fire drills. The classroom training is required for introductory training and as an annual review for each member of the squad.

Training records are being maintained by personnel in the Y-12 Training Records Center. The Training Management System (TMS), an electronic data base, is used by training personnel to track the status of training.

\section{H-1c Training Director}

The personnel training program is directed by a Waste Management Divisional Training Manager who is familiar with plant operations, facility design, and operating procedures. This manager is required to have a minimum of a bachelors degree and process knowledge, and demonstrated knowledge of instructional system design and technology. The Training Coordinators who perform the training must be reviewed and approved by the Training Manager. The qualifications required for these positions are included in the job descriptions found in Appendix H-2.

\section{H-1d Relevance of Training to Job Position}

The training program is tiered in some areas to provide training to personnel at levels that are relevant to their positions within the plant. For example, the personnel responsible for the completion of manifests receive additional training in recordkeeping required for compliance, whereas laborers do not. Laborers are more specifically trained to maintain proper and safe operating procedures and to respond effectively in the event of a spill or other emergency. The completed job task analysis for each of these three facilities will be utilized to update and improve the existing training as applicable in order to continue to make the training more relevant to the specific job position being trained. 


\section{H-2 IMPLEMENTATION AND DOCUMENTATION OF TRAINING PROGRAM}

H-2a Implementation

The Waste Management Organization Training Manager has been fully trained at the time of this submittal. All personnel must complete this training within six months from their date of assignment to a hazardous waste management job. No employee assigned to perform a hazardous waste management job works unsupervised prior to completion of the training program. The six month training completion period applies to all of the compliance related training. The OJT program is administered on a continual basis.

\section{H-2b Recordkeeping}

Please see Section J, Recordkeeping, for information. 


\section{SECTION I}

\section{CLOSURE PLAN, POST CLOSURE PLAN, AND FINANCIAL REQUIREMENTS}

\section{I-1 CLOSURE PLANS}

This closure plan has been prepared for the OD-7, OD-9, and OD-10 facilities located at the Oak Ridge Y-12 Plant. The units are used for tank storage of waste oils, solvents, and PCB containing wastes. Complete facility descriptions are provided in Section B, Facility Description.

The Oak Ridge Y-12 Plant is located in Anderson County and is co-operated and managed by personnel from Martin Marietta Energy Systems Inc., for the DOE. The EPA identification number for the Y-12 Plant is TN3 89-009-0001.

If changes occur in the operating plans or unit design that may affect the closure plan, it will be amended. Amendments to the closure plan may also be necessary if new technologies are developed, changes in operating requirements or contingencies, and changes of the landuse patterns around the site.

\section{I-1a Closure Performance Standard}

This closure plan is designed to ensure that, after closure, the facility will not require further maintenance and controls; to minimize or eliminate threats to human health or the environment; and to avoid the escape of hazardous wastes, hazardous waste constituents, leachate, contaminated rainfall, or waste decomposition products to ground or surface waters, or to the atmosphere.

This standard will be accomplished through the removal of all RCRA hazardous wastes stored in tanks or drums at the facility. These wastes will be transferred to an appropriately permitted facility for storage or treatment. In addition, to minimize residual contamination on-site, the tanks, containment basin, truck transfer station, process pumps, sumps and sump pumps, loading platform, and auxiliary piping will be cleaned until the facility has been satisfactorily decontaminated.

The following sections discuss, in detail, efforts to be made at the facilities to satisfy closure requirements. 


\section{I-1b Partial Closure and Final Closure Activities}

Partial closure for the units in this application is not anticipated. If it becomes necessary to partially close any of the units described in this permit application, the procedures described in Section I-1e, Closure Procedures, will be followed for the type of unit being closed.

Final closure of the units will consist of the removal of all hazardous wastes and hazardous waste residues remaining at the unit and the decontamination or disposal of the containment structure components and auxiliary equipment. All hazardous wastes and residues will be containerized and transported to an approved RCRA permitted facility for storage, treatment, or disposal.

\section{I-1c Maximum Waste Inventory}

The following table represents the maximum waste inventory that will be in storage at the units:

\begin{tabular}{ccc} 
& \multicolumn{2}{c}{ Maximum Waste Inventory (gallons) } \\
\cline { 2 - 3 } & Tanks & Containers \\
\hline OD-7 & 140,000 & N/A \\
OD-9 & 200,000 & 8,800 \\
OD-10 & 32,000 & 10,560 \\
\hline
\end{tabular}

All hazardous wastes remaining in these units at the time of closure will be transferred to a permitted facility for storage, treatment, or disposal. The procedures for removing, transporting, and/or storing the remaining hazardous waste and decontamination debris from the units are described in Section $\mathrm{I}-1 \mathrm{e}(1)$.

\section{I-1d Schedule for Closure}

The proposed schedule for final closure for units OD-7, OD-9, and OD-10 is 2020 . The proposed closure schedules are included in Figures I-1 through I-3. 


\section{Figure 1-1 \\ Schedule of Closure \\ Building 9811-1 RCRA Tank Storage Unit (OD-7)}

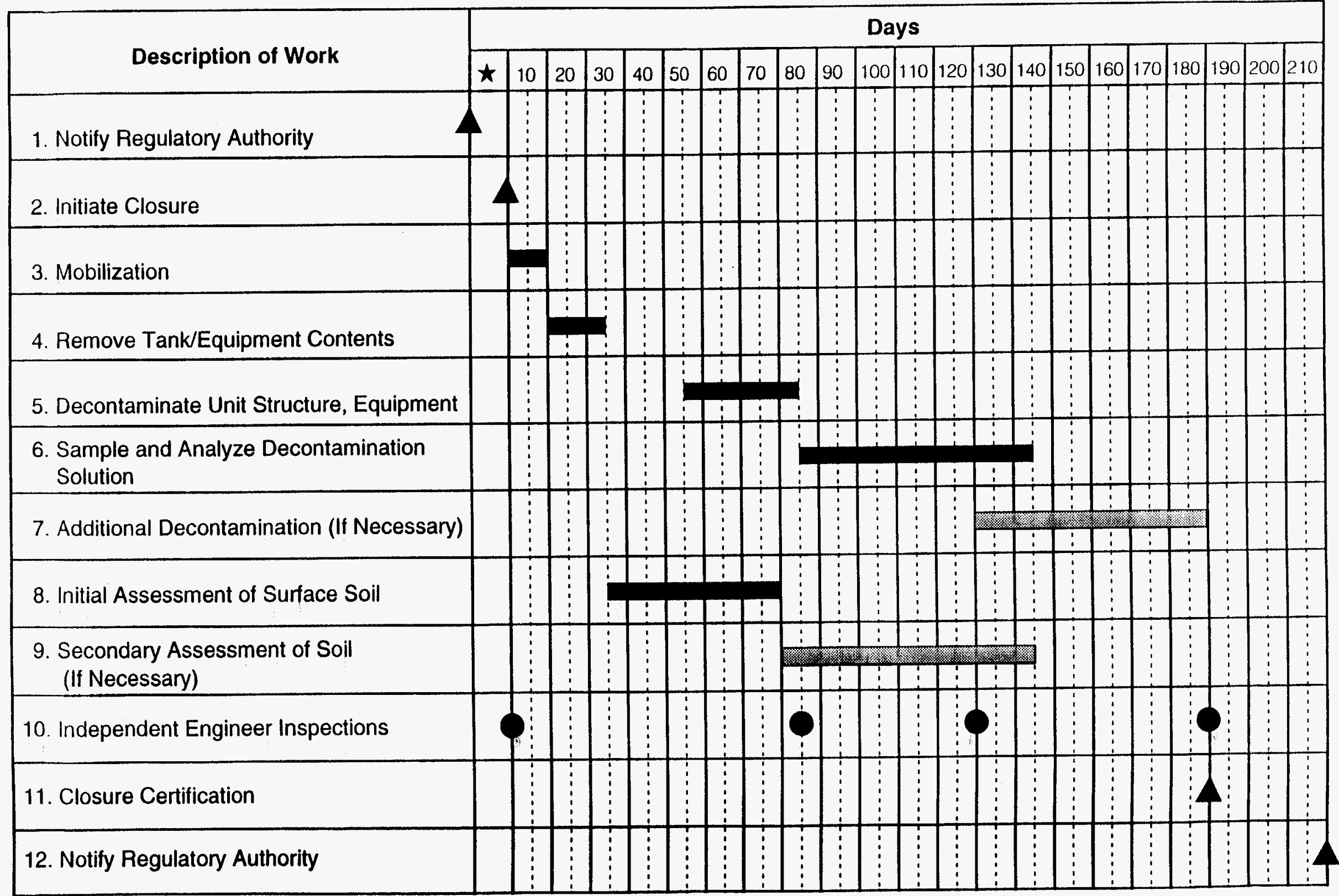

$\star$ Notification will be submitted prior to start of closure.

Y-GA 94-792 sh 


\section{Figure 1-2 \\ Schedule of Closure \\ Waste Oil/Solvent Storage Unit (OD-9)}

\begin{tabular}{|c|c|c|c|c|c|c|c|c|c|c|c|c|c|c|c|c|c|c|c|c|c|c|}
\hline \multirow{2}{*}{ Description of Work } & \multicolumn{22}{|c|}{ Days } \\
\hline & $\star$ & 10 & 20 & 30 & 40 & 50 & 60 & 70 & 80 & 90 & 100 & 110 & 120 & 130 & 140 & 150 & 160 & 170 & 180 & 190 & 200 & 210 \\
\hline 1. Notify Regulatory Authority & & & & $\vdots$ & $\begin{array}{l}\vdots \\
\vdots\end{array}$ & & : & & 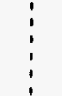 & $\vdots$ & & $\begin{array}{l}\vdots \\
\vdots \\
\end{array}$ & $\vdots$ & & $\vdots$ & & $\vdots$ & $\begin{array}{l}\vdots \\
\vdots\end{array}$ & & $i$ & & \\
\hline 2. Initiate Closure & & & & & $\vdots$ & & & & & & & $\vdots$ & $\begin{array}{ll}\vdots \\
\vdots\end{array}$ & & & & & : & & & & \\
\hline 3. Mobilization & & & $\vdots$ & & & $\vdots$ & $\vdots$ & & & & & $\vdots$ & $\vdots$ & & $\vdots$ & & & $\vdots$ & & & & \\
\hline 4. Remove Tank/Equipment Contents & & & $\vdots$ & & & $\vdots$ & $\vdots$ & & $\vdots$ & $\vdots$ & $\vdots$ & $\vdots$ & $\vdots$ & & & $\vdots$ & & $\vdots$ & & & & \\
\hline 5. Decontaminate Unit Structure, Equipment & & & $\vdots$ & $\vdots$ & & & $\vdots$ & & & & & $\vdots$ & $\vdots$ & & & & & $\vdots$ & & & $\vdots$ & \\
\hline $\begin{array}{l}\text { 6. Sample and Analyze Decontamination } \\
\text { Solution }\end{array}$ & & & $\vdots$ & $\vdots$ & $\vdots$ & $\vdots$ & 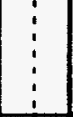 & & & & $\vdots$ & $\vdots$ & $\vdots$ & & & $\vdots$ & & $\vdots$ & & & $\vdots$ & \\
\hline 7. Additional Decontamination (If Necessary) & & & $\vdots$ & $\vdots$ & & $\vdots$ & $\vdots$ & $\vdots$ & $\vdots$ & & $\vdots$ & 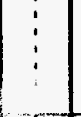 & $\vdots$ & & & & & & & : & $\vdots$ & \\
\hline 8. Initial Assessment of Surface Soil & & & & & & $\vdots$ & $\vdots$ & : & $\vdots$ & & 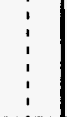 & 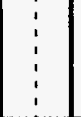 & $\vdots$ & & $\vdots$ & $\vdots$ & & $\vdots$ & $\vdots$ & & $\vdots$ & \\
\hline $\begin{array}{l}\text { 9. Secondary Assessment of Soil } \\
\text { (If Necessary) }\end{array}$ & & $\vdots$ & $\vdots$ & $\vdots$ & $\vdots$ & $\vdots$ & $\vdots$ & $\vdots$ & & $\vdots$ & $\vdots$ & $\vdots$ & $\vdots$ & $\begin{array}{l}: \\
\vdots \\
\end{array}$ & $\begin{array}{l}! \\
\vdots\end{array}$ & $\begin{array}{l}3 \\
\vdots \\
\vdots\end{array}$ & & $\vdots$ & $\vdots$ & & $\vdots$ & \\
\hline 10. Independent Engineer Inspections & & & & $\vdots$ & & & & & & & & & & & & $\vdots$ & & $\begin{array}{l}\vdots \\
\vdots\end{array}$ & & & & $\vdots$ \\
\hline 11. Closure Certification & & & $\vdots$ & $\vdots$ & & $\vdots$ & $\vdots$ & $\vdots$ & & & $\vdots$ & $\vdots$ & $\vdots$ & $\vdots$ & & & & & & & & $\vdots$ \\
\hline 12. Notify Regulato Authority & & & $\vdots$ & $\vdots$ & $\vdots$ & $\vdots$ & & $\vdots$ & 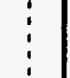 & 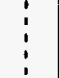 & $\vdots$ & $\vdots$ & $\vdots$ & $\vdots$ & $\vdots$ & $\vdots$ & & $\vdots$ & $\vdots$ & $\vdots$ & $\vdots$ & \\
\hline
\end{tabular}




\section{Figure 1-3 \\ Schedule of Closure \\ Liquid Organic Solvent Storage Unit (OD-10)}

\begin{tabular}{|c|c|c|c|c|c|c|c|c|c|c|c|c|c|c|c|c|c|c|c|c|c|c|}
\hline \multirow{2}{*}{ Description of Work } & \multicolumn{22}{|c|}{ Days } \\
\hline & $\star$ & 10 & 20 & 30 & 40 & 50 & 60 & 70 & 80 & 90 & 100 & 110 & 120 & 130 & 140 & 150 & 160 & 170 & 180 & 190 & 200 & 210 \\
\hline 1. Notify Regulatory Authority & & & & & & & & & & 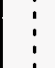 & & & & & & $\vdots$ & & 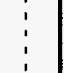 & & & & \\
\hline 2. Initiate Closure & & & & & : & & & & & 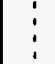 & & & & & & : & & $\vdots$ & & & $\vdots$ & \\
\hline 3. Mobilization & & & 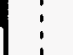 & $\vdots$ & $\vdots$ & : & : & & & : & & & $\vdots$ & & & 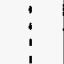 & & : & & & $\vdots$ & \\
\hline 4. Remove Tank/Equipment Contents & & & & & : & & & & & & : & & $\vdots$ & & & & & & & & & \\
\hline 5. Decontaminate Unit Structure, Equipment & & & & & & & & & & & & & & & & & : & & & & & \\
\hline $\begin{array}{l}\text { 6. Sample and Analyze Decontamination } \\
\text { Solution }\end{array}$ & & & & & : & & & & & & & & 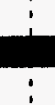 & & & & & & & & & \\
\hline 7. Additional Decontamination (If Necessary) & & & & & & & & & & & & & & & & & & & & & & \\
\hline 8. Initial Assessment of Surface Soil & & & & & & & & & & & & & & & $\vdots$ & & & & & & " & \\
\hline $\begin{array}{l}\text { 9. Secondary Assessment of Soil } \\
\text { (If Necessary) }\end{array}$ & & & & & & & & & & & & $\therefore$ & & 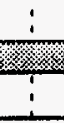 & í & & & $\vdots$ & & & $\vdots$ & \\
\hline 10. Independent Engineer Inspections & & & & & & & & & & & & & & & & & & & & & & \\
\hline 11. Closure Certification & & & & & & & & & & & & & & & & & & & & & & \\
\hline 12. Notify Regulatory Authority & & & & & & & & & & & & & & & & & & & & & & \\
\hline
\end{tabular}

$\star$ Notification will be submitted prior to start of closure. 


\section{I-1d(1) Time Allowed For Closure}

All hazardous wastes will be removed from the unit and will be treated or disposed of either on-site or off-site within 90 days from receipt of the final volume of hazardous waste. Closure activities will be completed within 180 days from the receipt of the final volume of hazardous waste. The actual times $f$ each step of the closure activities is shown in Figures I-1 through I-3.

\section{I-1d(1)(a) Extensions for Closure ime}

It is not anticipated that an extension for time for closure activities for the units will be require $\%$. However, if closure cannot be completed within the specified time, a request for an extension of closure time will be submitted to the Commissioner in accordance with Tennessee Rule 1200-1-11-.06(7)(d).

\section{I-1e Closure Procedures}

Before closure activities begin, the units will be surveyed by the Y-12 Health Physics Organization personnel and a safety plan will be prepared based on the site conditions. The plan will identify radiological and chemical hazards as well as controls to reduce worker risk.

\section{I-1e(1) Inventory Removal, Disposal and Decontamination of Equipment}

Closure activities for the units in this permit.application will be performed in a similar manner.

All hazardous wastes present at the time of closure will be removed and transferred, via a tank truck, to a permitted storage area, treated, or shipped off-site. Material will be removed from the tanks using pumps or other means that may be necessary. Sludges that may be present in the tanks will be removed using pumps or removed by manual means, such as shovels or scoops. Decontamination of equipment and structures, which includes, but is not limited to, tanks, containment basins, truck transfer station, process pumps, sumps and sump pumps, loading platform, and process piping, will be steamed cleaned. The rinse waters generated will be collected, drummed, and transferred to a permitted facility for storage, disposal, treatment, or appropriate management. Wastes generated from these activities will be collected, sampled for hazardous constituents, and managed in an appropriate manner based on the analytical results.

Wipe samples will be collected to verify if the decontamination efforts are complete. A wiping material (cotton swab or filter paper) will be used and random samples taken at the 
units. The wipe samples will be analyzed for the hazardous constituents which were managed at the unit using an EPA approved analytical procedure (e.g., TCLP).

If residual contamination exceeds the allowable limits, an additional washing will be performed. Areas that persist in retaining contamination after this washing will be sand blasted or physically removed from the area. The debris will be collected and managed as hazardous waste.

The equipment that may be used for the closure activities includes, but is not limited to, cleaning brushes, adsorbents, solvents, soap and alkaline cleaners, squeegees, pressure sprayers, water, water recovery drums, concrete removal equipment, forklift, plastic sheeting, and pumps. Equipment will be rinsed, if applicable, to remove any residual contamination that may have adhered to the cleaning apparatus. The rinse water will be collected, sampled, and managed accordingly. Debris from closure will be collected, sampled, and analyzed for hazardous contituents. If the tests indicate that the debris is hazardous waste, then it will be treated as such. If the debris is not deemed hazardous waste, it will be disposed of accordingly.

\section{$\underline{\text { Soil Assessment }}$}

If major cracks are discovered in the containment area at the time of closure, soil samples will be taken directly beneath the cracks. Corings will be made through the major cracks (excludes hairline fractures) if present, and a split-spoon sampler will be used to obtain a sample beneath the containment structure. It is very likely that major cracks will not be present since inspections and annual leak testing are performed. In this event, random soil samples will be taken from exposed areas adjacent to the units and analyzed for hazardous constituents that were managed at the unit. Soil cuttings and debris will be collected and stored at a permitted facility pending analytical results. If the analytical results exceed the desirable limits, the soil will be excavated, contained, and managed as hazardous waste. Decontamination of equipment used for soil sampling and soil excavation will be performed in the same manner described above.

Final closure of the units will be certified by the Department of Energy and an independent registered Professional Engineer.

\section{I-1e(2) Closure of Disposal Units}

Not applicable. Requirements of this section do not apply to the units in this permit 
application.

\section{I-1e(3) Closure of Containers}

All containers of hazardous waste at units OD-9 and OD-10 will be transferred to an approved facility for storage or treatment. Equipment to be used will be a, but not limited to, forklift, hand pallet jack, and/or hand dolly. Closure activities for the container storage areas will be performed as part of the overall closure activities of the units and similar procedures described in Section I-1e, Closure Procedures.

\section{I-1e(4) Closure of Tanks}

The closure procedures described in section I-1e (Closure Procedures), will be followed for the closure of the tanks.

\section{I-1e(5) Closure of Waste Piles}

Requirements of this section do not apply to the units in this permit application.

\section{I-1e(6) Closure of Surface Impoundments}

Requirements of this section do not apply to the units in this permit application.

\section{I-1e(7) Closure of Incinerators}

Requirements of this section do not apply to the units in this permit application.

\section{I-1e(8) Closure of Landfills}

Requirements of this section do not apply to the units in this permit application.

\section{I-1e(9) Closure of Land Treatment Units}

Requirements of this section do not apply to the units in this permit application.

\section{I-1e(10) Closure of Miscellaneous Units}

Requirements of this section do not apply to the units in this permit application.

\section{I-2 POST-CLOSURE PLAN}

Hazardous waste or hazardous waste residues will not remain at the units after closure; therefore, this section is not required. 


\section{I-2a Inspection Plan}

Hazardous waste or hazardous waste residues will not remain at the units after closure; therefore, this section is not required.

\section{I-2b Monitoring Plan}

Hazardous waste or hazardous waste residues will not remain at the units after closure; therefore, this section is not required.

\section{I-2c Maintenance Plan}

Hazardous waste or hazardous waste residues will not remain at the units after closure; therefore, this section is not required.

\section{I-2d Land Treatment}

Hazardous waste or hazardous waste residues will not remain at the units after closure; therefore, this section is not required.

\section{I-2e Post-Closure Care for Miscellaneous Units}

Hazardous waste or hazardous waste residues will not remain at the units after closure; therefore, this section is not required.

\section{I-2f Post-Closure Security}

Hazardous waste or hazardous waste residues will not remain at the units after closure; therefore, this section is not required.

\section{I-2g Post-Closure Contact}

Hazardous waste or hazardous waste residues will not remain at the units after closure; therefore, this section is not required.

\section{I-3 CERTIFICATION AND NOTICES REQUIRED FOR CLOSURES}

\section{I-3a Certification of Closure}

Within 60 days of completing final closure of the units, DOE will submit, in writing, a closure certification to the Commissioner. The certification will verify that the units were closed in accordance with the specifications of the approved closure plan. The certification will be signed by DOE and an independent registered professional engineer. 


\section{I-3b Survey Plat}

A survey plat is not required for the clean closure of a tank system.

I-3c Notice to Local Land Authority

This section is not required for the clean closure of a tank system.

\section{I-3d Post-Closure Certification}

This section is not required for the clean closure of a tank system.

\section{I-3e Notice in Deed to Property}

This section is not required for the clean closure of a tank system.

\section{I-4 CLOSURE COST ESTIMATE}

Under 40 CFR Part 264.140(c), federal facilities are exempt from the requirements of this section.

\section{I-5 FINANCIAL ASSURANCE MECHANISM FOR CLOSURE}

Under 40 CFR Part 264.140(c), federal facilities are exempt from the requirements of this section.

\section{I-6 POST-CLOSURE COST ESTIMATE}

Under 40 CFR Part 264.140(c), federal facilities are exempt from the requirements of this section.

\section{I-7 FINANCIAL ASSURANCE MECHANISM FOR POST-CLOSURE}

Under 40 CFR Part 264.140(c), federal facilities are exempt from the requirements of this section.

\section{I-8 LIABILITY REQUIREMENTS}

Under 40 CFR Part 264.140(c), federal facilities are exempt from the requirements of this section.

\section{I-9 STATE FINANCIAL MECHANISM}

Under $4:$ CFR Part 264.140(c), federal facilities are exempt from the requirements of this section. 


\section{SECTION J RECORDKEEPING}

This section of the application outlines the recordkeeping and reporting requirements for hazardous waste management units as required by 40 CFR Part 264 and Rule 1200-1-11-.06 of the Rules Governing Hazardous Waste Management in Tennessee.

\section{J-1 MANIFEST REQUIREMENTS}

OD-7, OD-9, and OD-10, do not receive hazardous wastes from off-site.

\section{J-2 OPERATING RECORD}

Records and results of waste analyses, as required in 40 CFR Part 264.73(b)(3) and Rules 1200-1-11-.02 and .06(5)(d)2(iii), are recorded and maintained in the operating files and databases in the Waste Management Division. The management, including storage and/or treatment, of hazardous wastes is tracked at all times.

For nonroutine wastes, the Y-12 Plant uses the "Request for Transfer, Storage or Disposal of Radioactive, Hazardous and Special Wastes" form (UCN-2109 form), which is located in Appendix C-2, for identification of waste materials. For routine wastes, the Y-12 Plant uses a "Blanket Request" process or "Stream Identification (SID) Number" process which assigns a specific waste stream a number to allow tracking of the waste. Upon generation of a routine or nonroutine waste, log sheets, completed forms, and generation records provided by the generator include the description and quantity of waste materials. These forms are assigned a unique number to facilitate entry into the waste tracking systems used by the WTSD Department. The completed forms are reviewed by a technician or engineer from WTSD to determine the appropriate storage, treatment, or disposal method which is recorded on the form and entered into the data base as applicable. After transporting the waste to the appropriate on-site storage or treatment unit or off-site disposal facility, the forms are signed by WTSD personnel and are maintained by the WTSD Department. Finally, operating logs are maintained which include the current quantity and type of wastes located at each facility.

The Y-12 Plant Waste Acceptance Plan, discussed in Section C, defines the information required to safely store wastes in these units in accordance with RCRA regulations.

An incident requiring implementation of the Contingency Plan would be reported per 
Section G. A detailed, written report would be submitted by the Y-12 Environmental Management Department to the TDEC within 15 days of the incident, and a file copy would be maintained by the Environmental Management Department. The report would include:

1. name, address, and telephone number of the owner or operator;

2. name, address, and telephone number of a contact at the unit;

3. date, time, and type of incident (e.g., fire, explosion);

4. name and quantity of material(s) involved;

5. extent of injuries, if any;

6. assessment of actual or potential hazards to public health or environment, if applicable; and

7. estimated quantity and disposition of recovered material that resulted from the incident.

Records of inspections of OD-7, OD-9, and OD-10 are maintained by the WTSD Department. Inspection logs are completed per Section F. Copies of example inspection log sheets are provided in Appendix F-2.

Groundwater monitoring data is not required for these facilities (Section E).

The DOE is the owner of the Y-12 Plant. The units addressed in this application only receive waste from the Y-12 Plant. Therefore, it is not required that off-site generators be notified of the status of the Y-12 Plant RCRA permits.

The closure and postclosure cost estimates are not required for federal facilities as indicated in Section I, Closure Plans.

The units addressed in this application are not surface impoundments, waste piles, land treatment units, or landfills. Therefore, no Land Disposal Restricted Certification Program is required.

The training records for personnel in the Waste Management Division are maintained by the training department. The training coordinator assigned to a designated operating or engineering department maintains these records for that specific department. Training information is discussed in Section $\mathrm{H}$. 
The hazardous waste storage tanks located in these units are contained within a secondary containment system. Therefore, the tank certification records and reports are not applicable. During any major repairs to a tank system, an independent qualified, registered, professional engineer would be engaged to assess the tank and the tank repairs. After the tank system has been adequately repaired, the engineer would provide a certification that the repaired system is capable of handling hazardous waste without unintentional releases for the intended life of the system. This certification would be submitted to the TDEC within 7 days after returning the tank system to use.

Preparation of the annual and biannual reports on the hazardous waste activities at the Y-12 Plant is coordinated and maintained by the Environmental Management Department with data supplied by the Waste Management Division and waste generating divisions. These reports address the amount of waste generated, the amount of waste shipped off-site, the amount received, and the amount of waste currently on site.

As part of the annual report on the hazardous waste activities at the Y-12 Plant, wastestream specific waste minimization information is submitted to the TDEC for the Y-12 Plant. This annual report certification is prepared and maintained on file by the Environmental Management Department. Additionally, the biannual Waste Minimization Report is submitted to the EPA which contains similar information. The Y-12 Waste Minimization Program is designed to reduce the volume and toxicity of hazardous wastes generated at the Y-12 Plant and provides information on the methods of reducing waste to minimize the threat to human health and the environment.

The operating records and reports are prepared, maintained, and available for inspection. Training records on current personnel are kept until closure of the hazardous waste management units. The training records of former employees are maintained for a minimum of 3 years from the date the employee last worked at the Y-12 Plant. Personnel training records accompany the employee during any transfer within the company. 


\section{SECTION K OTHER FEDERAL LAWS}

The Y-12 Plant has reviewed and considers to be in compliance with the following Federal Laws:

- $\quad$ Fish and Wildlife Coordination Act of 1934

- National Historic Preservation Act of 1966

- Wild and Scenic Rivers Act of 1968

- Coastal Zone Management Act of 1972

- Endangered Species Act of 1973

- Occupational Safety and Health Act of 1970

- National Environmental Policy Act, January 1, 1970

- Federal Water Pollution Control Act of 1977

- Clean Water Act

- National Emission Standards for Hazardous Air Pollutants, and

- Toxic Substances Control Act

- Clean Air Act

Information will be provided by $\mathrm{Y}-12$ at the request of the TDEC office. 


\section{SECTION L ORGANIC AIR EMISSIONS}

\section{L-1 SPECIFIC INFORMATION REQUIREMENTS FOR PROCESS VENTS}

The requirements of this section apply to those hazardous waste management facilities that are required to obtain a RCRA permit. Subpart AA of 40 CFR Part 264 applies to emissions from process vents associated with distillation, fractionation, thin-film evaporation, solvent extraction, or air or steam stripping operations which are used to manage hazardous wastes with organic concentrations of a least $10 \mathrm{ppm}$ by weight. Subpart AA also applies to vents on tanks such as distillate receivers, bottoms receivers, surge control tanks, separator tanks, and hot wells associated with these units, if emissions from these processes are vented through the tank. The units in this permit application are not subject to the 40 CFR Part 264, Subpart AA requirements for process vents.

\section{L-2 SPECIFIC INFORMATION REQUIREMENTS FOR EQUIPMENT}

Subpart BB of 40 CFR Part 264 are equipment leak standards that apply to emissions from equipment that contains or contacts hazardous wastes with organic concentrations of at least 10 percent by weight that are managed in units that are required to obtain a RCRA permit or hazardous waste recycling units that are located on hazardous waste management facilities. For the purpose of these regulations, equipment is defined to include each valve, pump, compressor, pressure relief device, sampling connection system, open-ended valve or line or flange, and any control devices or systems. Based on waste analyses and knowledge of the types of wastes stored, OD-7, OD-9, and OD-10 are required to be monitored in accordance with this standard. A leak detection and repair program has been implemented at OD-7, OD-9, and OD-10. This section describes the information requirements for facilities that have equipment to which Subpart BB of 40 CFR Part 264 applies.

\section{L-2a Equipment Identification}

The equipment at OD-7, OD-9, and OD-10 that is subject to the requirements of 40 CFR Parts 264.1050 through 264.1065 is listed in Appendix L-1. Information includes the equipment identification number and the type of equipment. The physical state of the hazardous waste at the equipment is liquid. The percent by weight of total organics in the waste streams at OD-7, OD-9, and OD-10 is approximately 100 percent at each item of equipment. The program plan followed at the units to remain in compliance with the standard is described in existing plant procedures. The approximate locations of the facilities 
within the Y-12 boundary can be seen in Map 2, The Y-12 Plant Waste Unit Identification Key.

\section{L-2b Implementation Schedule}

The installation of a closed-vent system or control device to comply with the provisions of 40 CFR Part 264, Subpart BB, is not required for these units.

\section{L-2c Other Control Devices}

The installation of these control devices to comply with the provisions of 40 CFR Part 264, Subpart BB, is not required for these units.

\section{L-2d Documentation of Compliance with Equipment Standards}

Existing procedures are used to comply with the equipment standards of 40 CFR Part 264, Subpart BB. Monitoring data is available to document compliance for these units. OD-7, OD-9, and OD-10 are operating under the alternative air emission monitoring methods described in 40 CFR Part 265.1062 which allow leak detection monitoring on an annual basis. The EPA was notified, pursuant to 40 CFR Part 265.1062, that the alternate standards would be used.

\section{L-2e Documentation of Compliance with Closed-Vent Systems and Control Device}

\section{Requirements}

Control devices are not required for these units; therefore, the requirements of this section do not apply. 


\section{SECTION M \\ SOLID WASTE MANAGEMENT UNITS}

Based on information from the State, material on solid waste management units at the Oak Ridge Y-12 Plant is not required for individual Part B permit applications because the entire ORR is covered by the ORNL Hazardous and Solid Waste Amendments Permit (HSWA TN001) for Building 7652 (a hazardous waste storage facility). The HSWA Permit was issued on September 26, 1986. 


\section{SECTION N}

\section{CERTIFICATION}

I certify under penalty of law that this document and all attachments were prepared under my direction and supervision in accordance with a system designed to ensure that qualified personnel properly gather and evaluate the information submitted. Based on my inquiny of the person or persons who manage the system and of those persons directly responsible for gathering the information, the information submitted is to the best of my knowledge and belief, true, accurate, and complete. I am aware that there are significant penalties for submitting false information, including the possibility of fine and imprisonment for knowing violations.
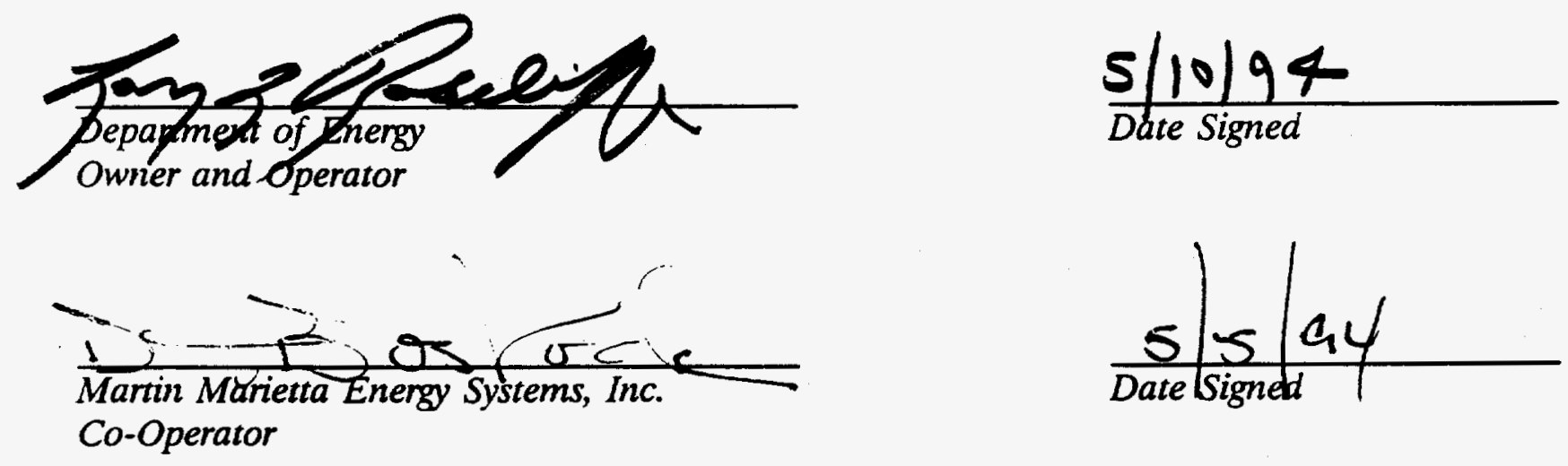

The Department of Energy and its operating contractor, Martin Marietta Energy Systems, Inc., have jointly signed this application as the operator of the permitted facility. The Department has determined that dual signatures best reflect the actual apportionment of responsibility under which the Department's RCRA responsibilities are for policy, programmatic, funding and scheduling decisions, as well as general oversight, and the contractor's $R C R A$ responsibilities are for day-to-day operations, including but not limited to, recordkeeping, reporting, and contingency planning. For purposes of the certification required by 40 CFR Section $270.11(d)$ and Tennessee Rule 1200-1-11-.07(2)(a)10, the Department's and Martin Marietta Energy Systems, Inc.'s, representatives certify, to the best of their knowledge and belief, the truth, accuracy and completeness of the application for their respective areas of responsibility. 
APPENDIX B-1

MAPS 


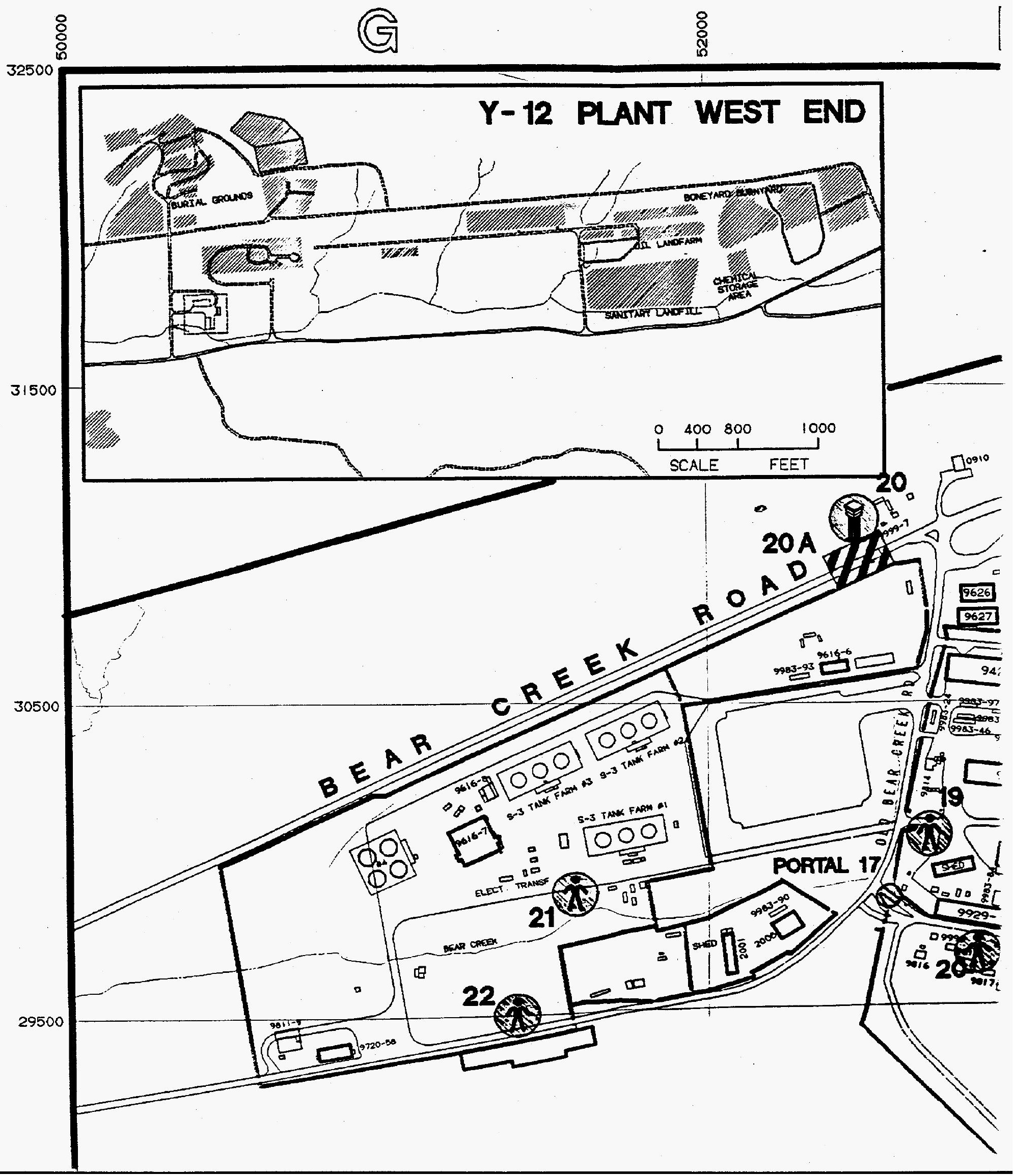


F告菩

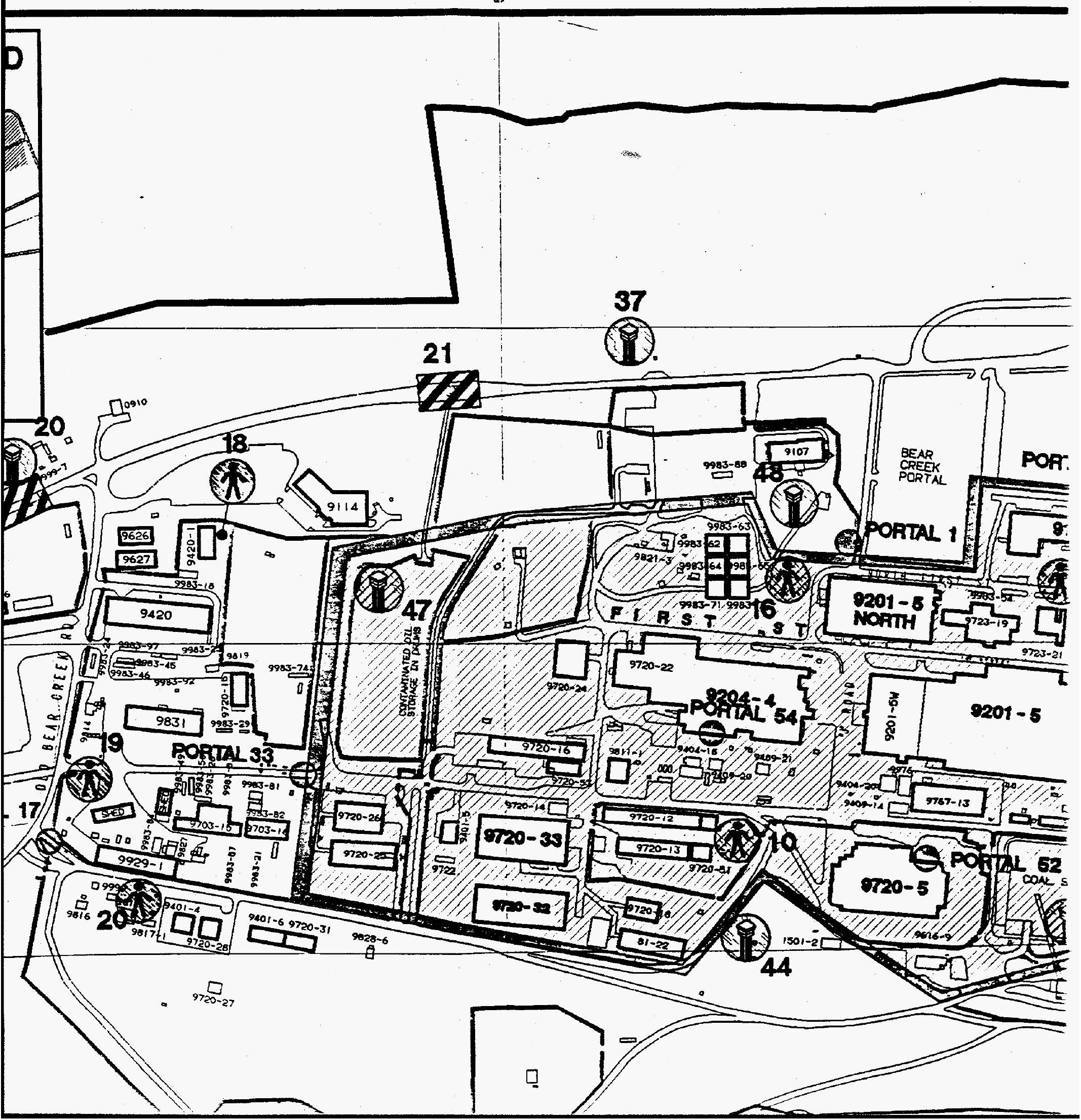



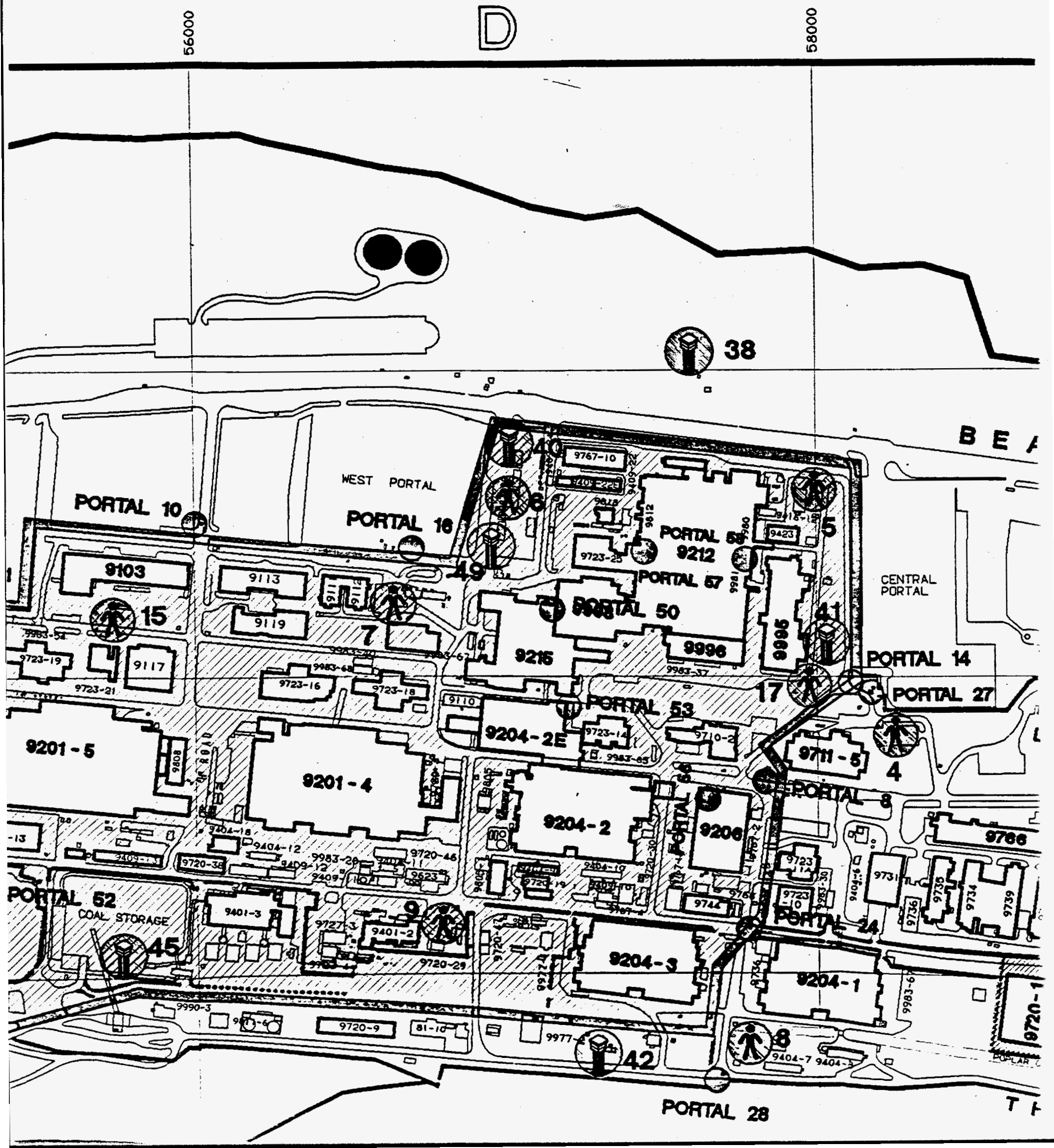
C

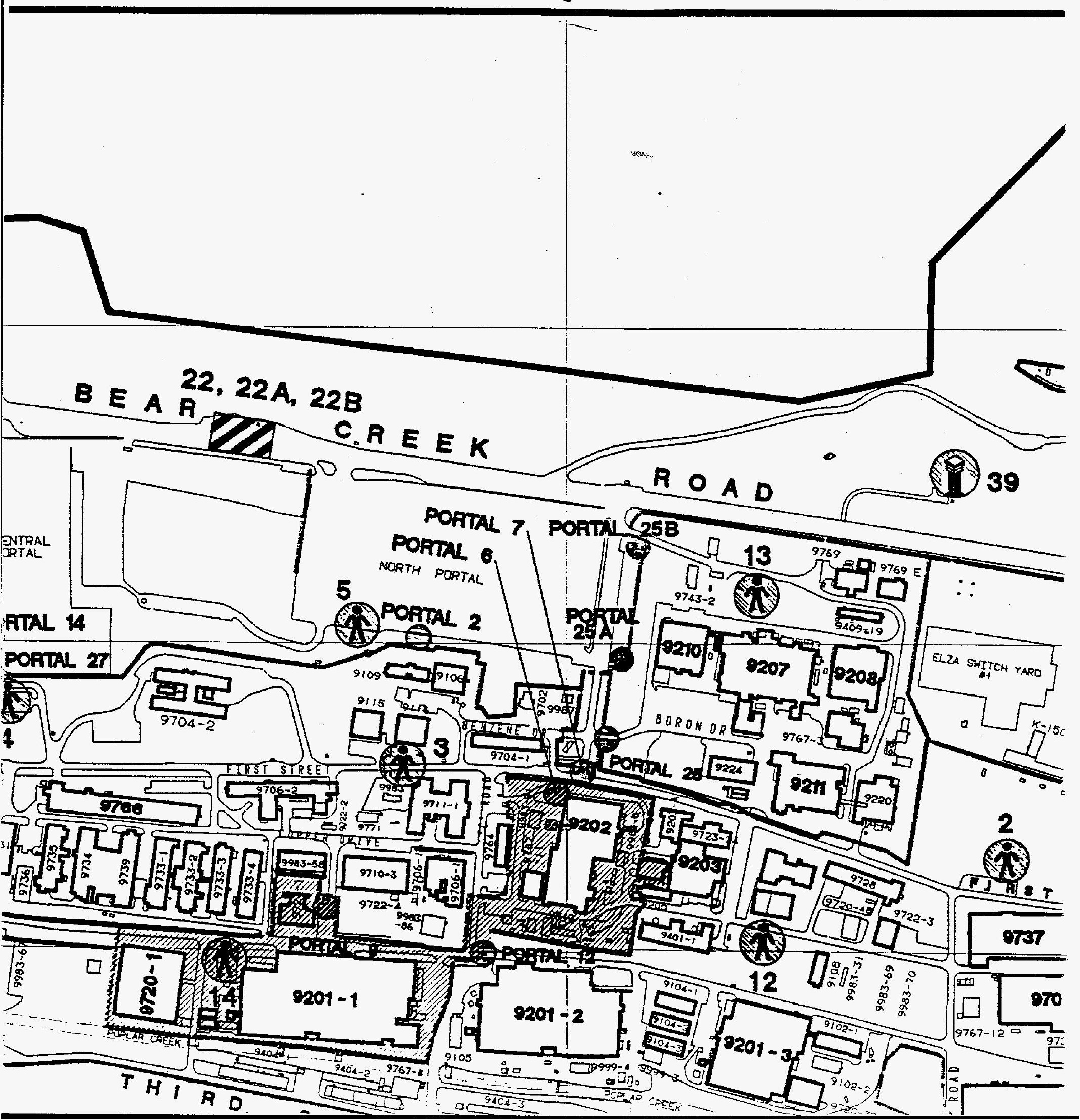




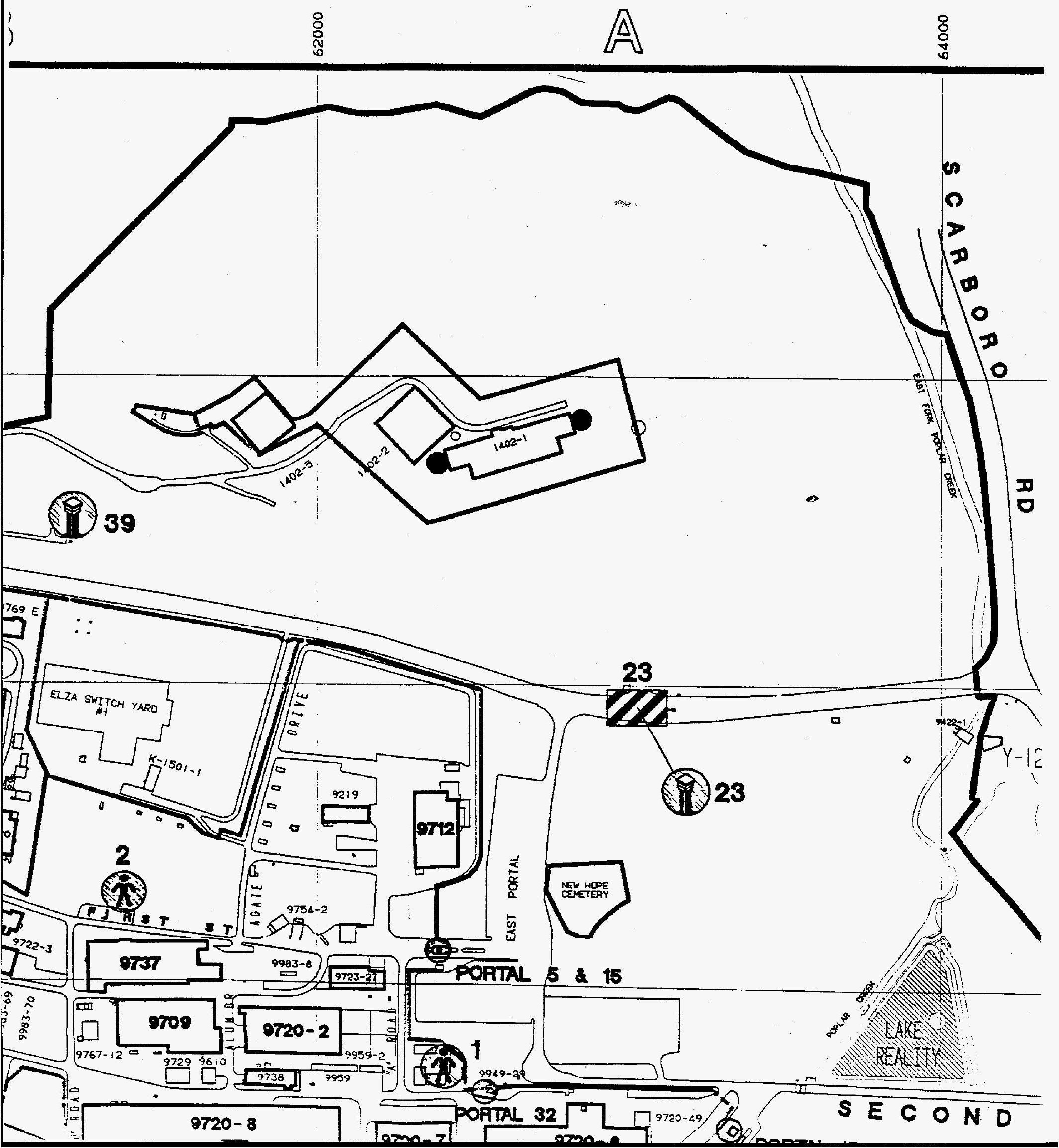




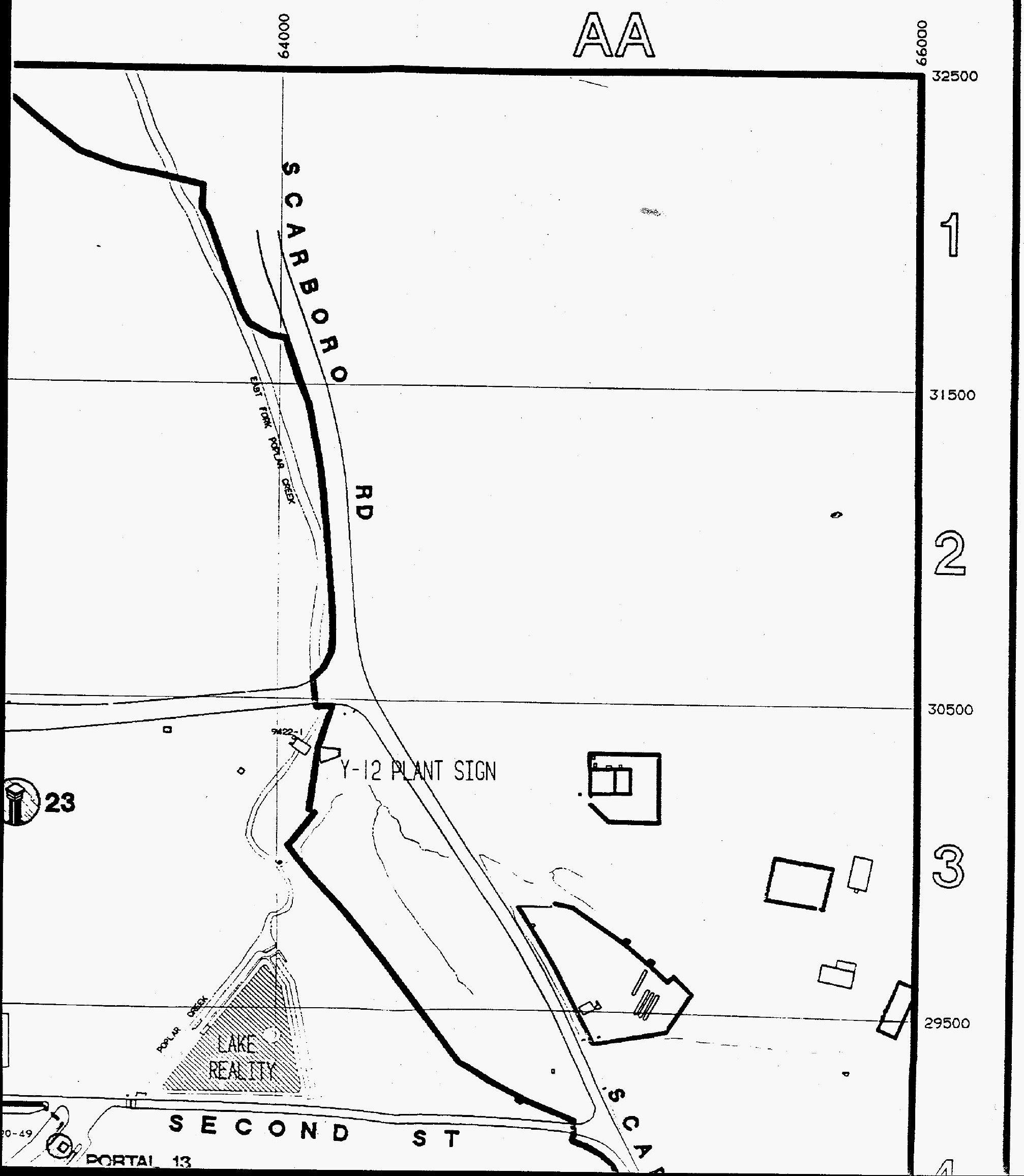




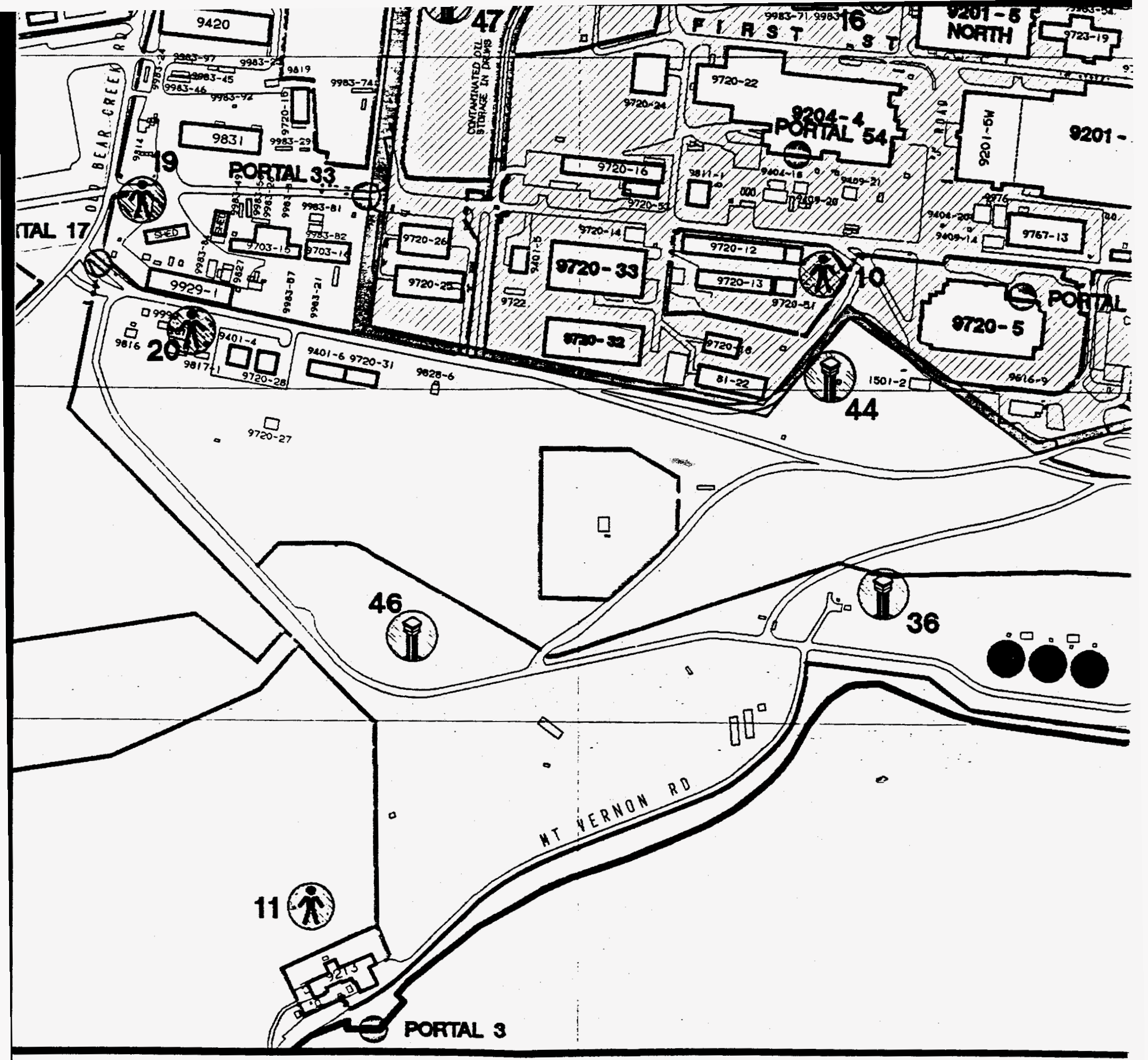




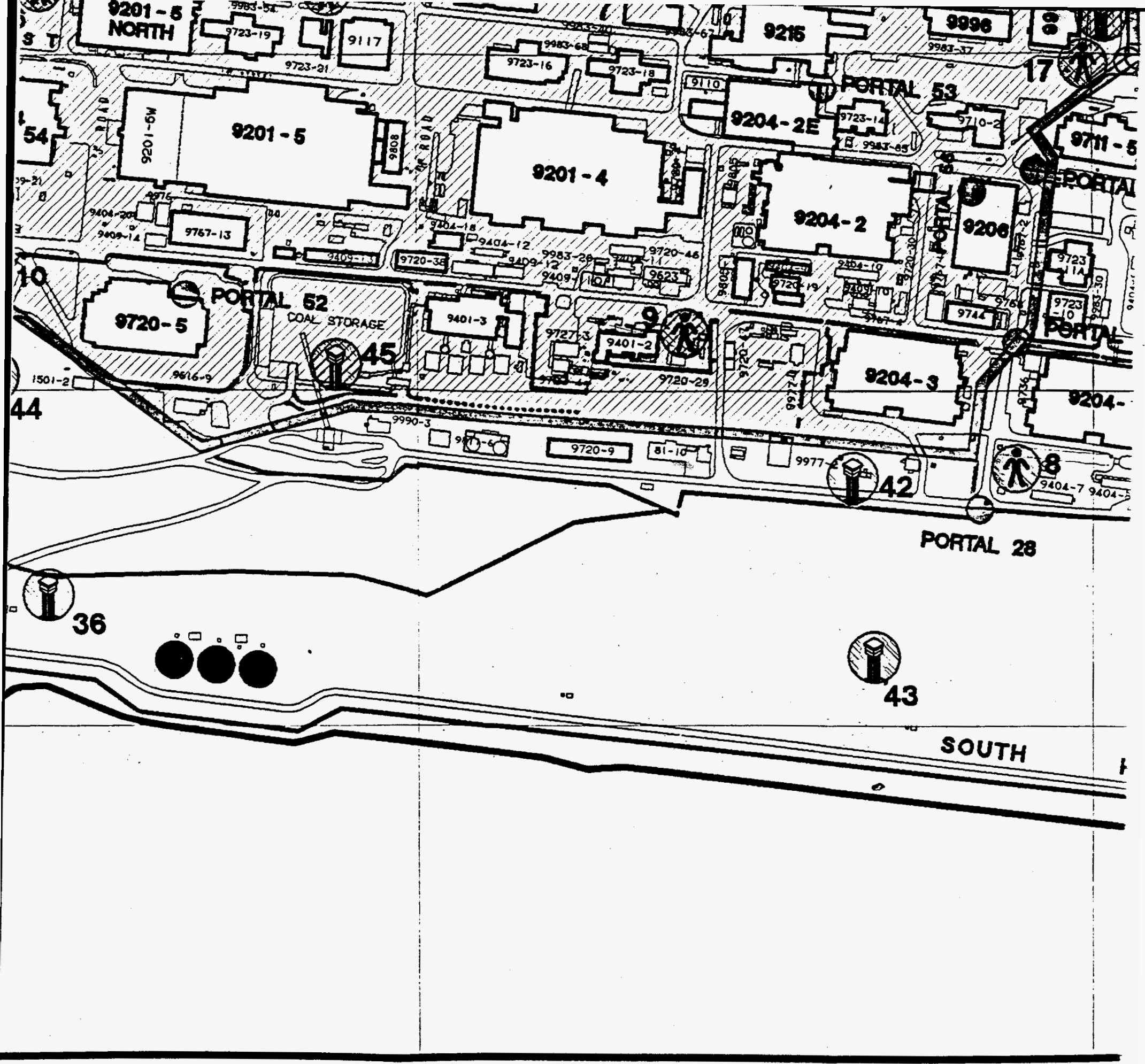




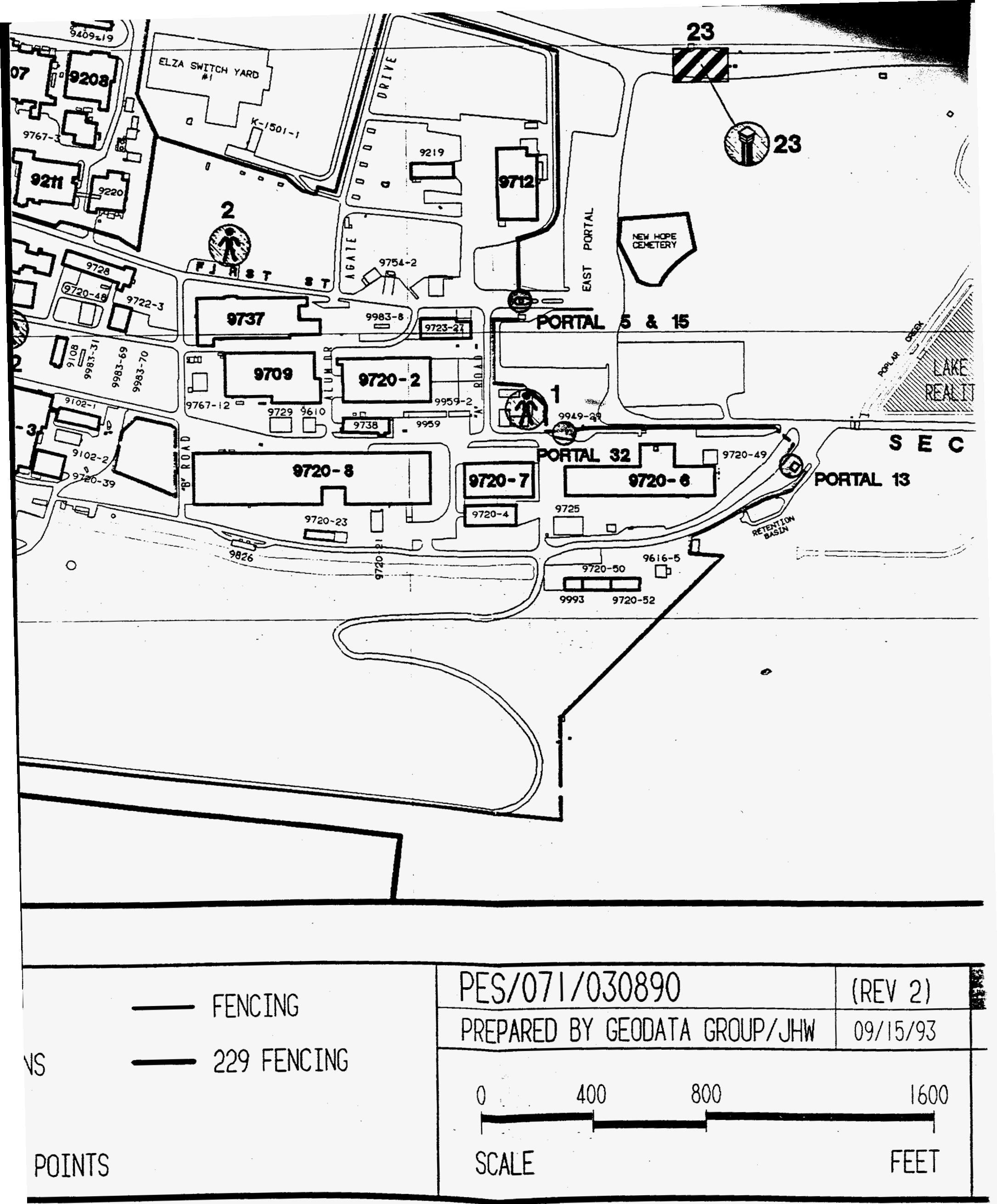




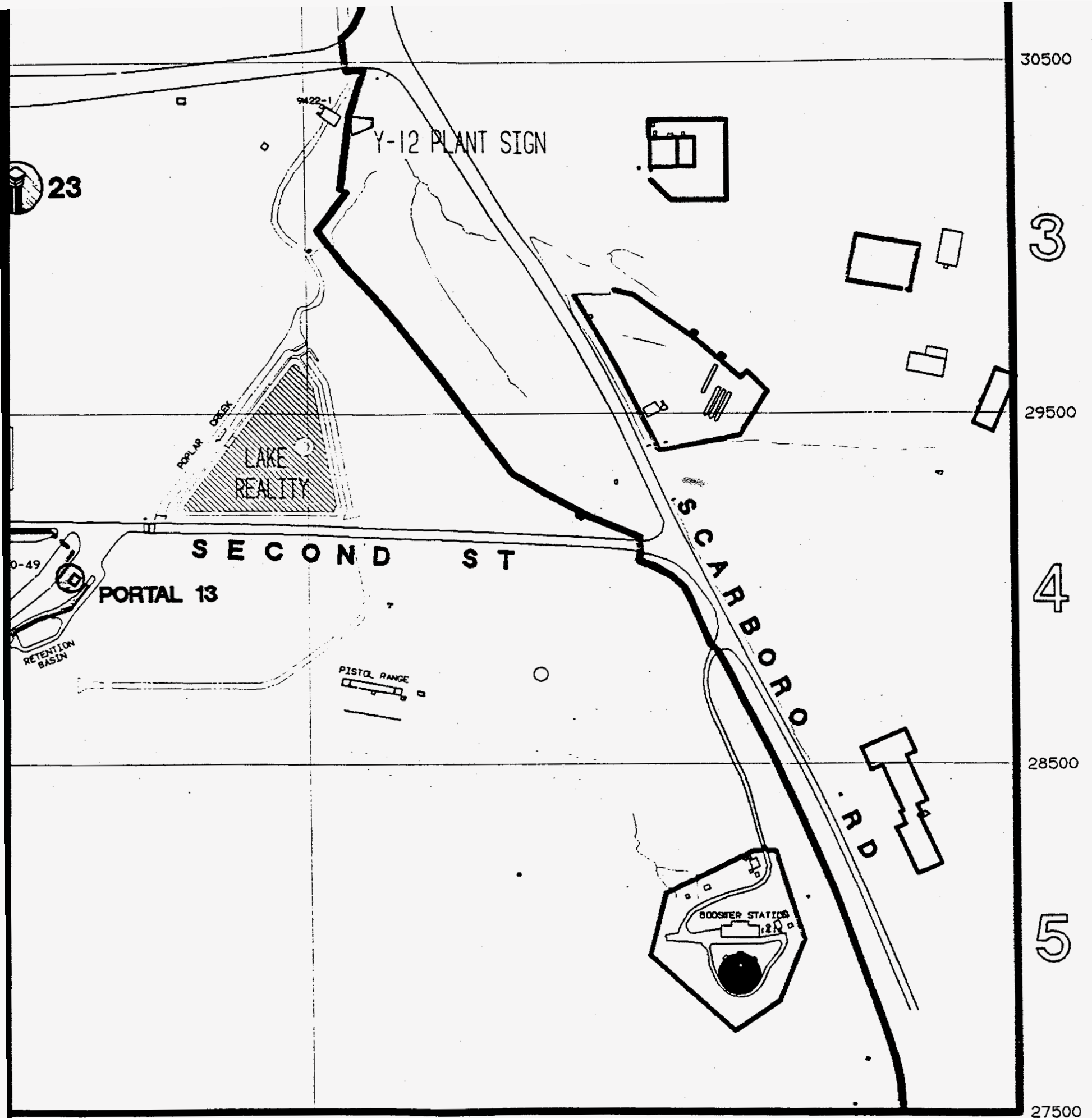

27500

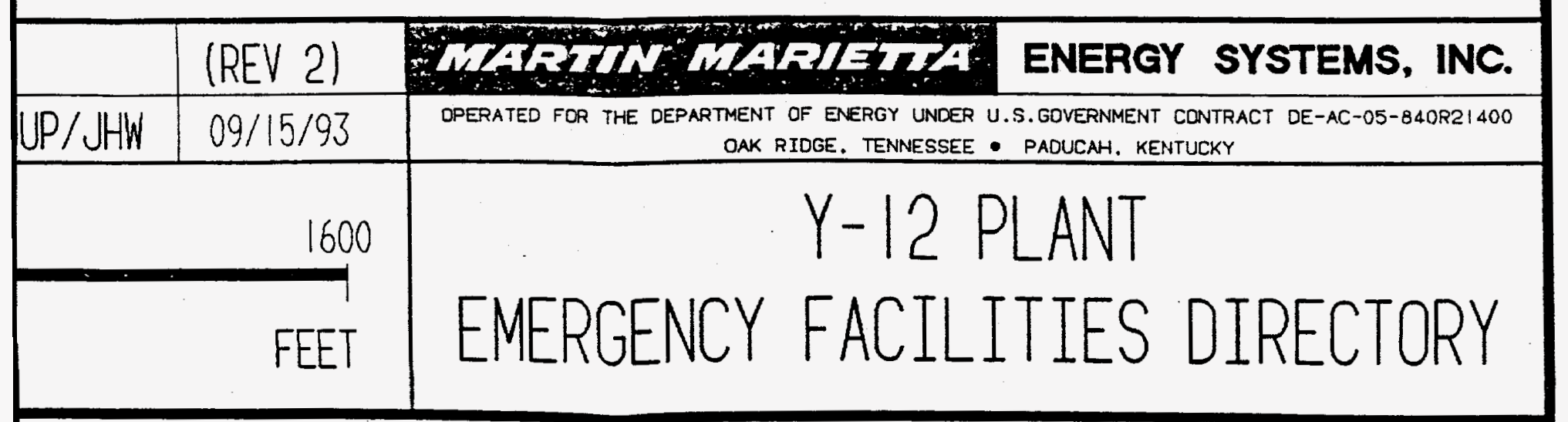




\section{OAK RIDGE Y-12 PLANT}

WASTE UNIT

QDENTIEICATION KEY

\section{APPLICATION EPA \\ LINE PROCESS COOE DESCRIPTION}

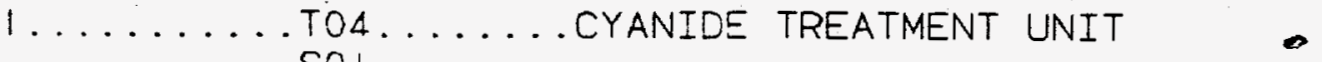
SO!

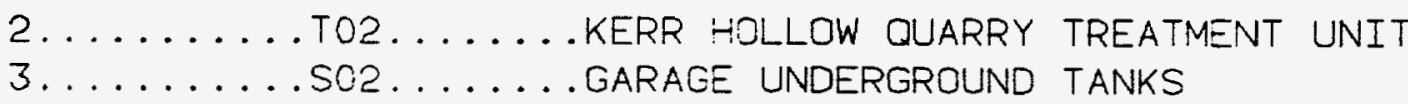

$4 \ldots \ldots \ldots$. . . . . . WALK-IN PITS

$5 \ldots \ldots . \ldots$.......... INTERIM DRUM YARD

$6 \ldots \ldots . . .501 \ldots . .$. BUILDING $9720-9$ STORAGE UNIT

$7 \ldots . \ldots . . . . . .$. RORA \& MIXED WASTE STORAGE \&

STAGING BUILDING 9720-31

$8 \ldots \ldots . . . .502 \ldots . .$. BUILDING $9811-1$ RCRA

TANK STORAGE UNIT

$9 \ldots \ldots . \ldots$.......... BUILDING $9811-1$ RCRA

CONTAINER STORAGE UNIT

$10 \ldots \ldots . . . . . .$. SOLSTE OIL/SOLVENT STORAGE UNIT SOI

$11 \ldots . \ldots . . . .502 \ldots . . .$. LIQ. ORGANIC SOLVENT STOR. UNIT SOI

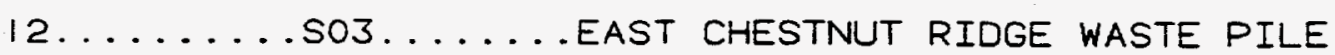

$13 \ldots \ldots \ldots$............ CONTAINERIZED WASTE STORAGE AREA

$14 \ldots \ldots \ldots$. . . . . . CLASSIFIED CONTAINER STORAGE UNIT

BUILDING 9720-25

$15 \ldots \ldots \ldots . . \ldots 503 \ldots . \ldots$ IL LANDFARM SOILS CONTAINMT. PAD

$16 \ldots . \ldots . . . . . . .503 \ldots$ DSPOSAL AREA REMEDIAL ACTION

(DARA) SOLIDS STORAGE UNIT

$17 \ldots \ldots \ldots$. . . . . . URANIUM TREATMENT UNIT

$18 \ldots \ldots \ldots$ TO ....... INTEREM REACTIVE WASTE TREATMT AREA

○................ 


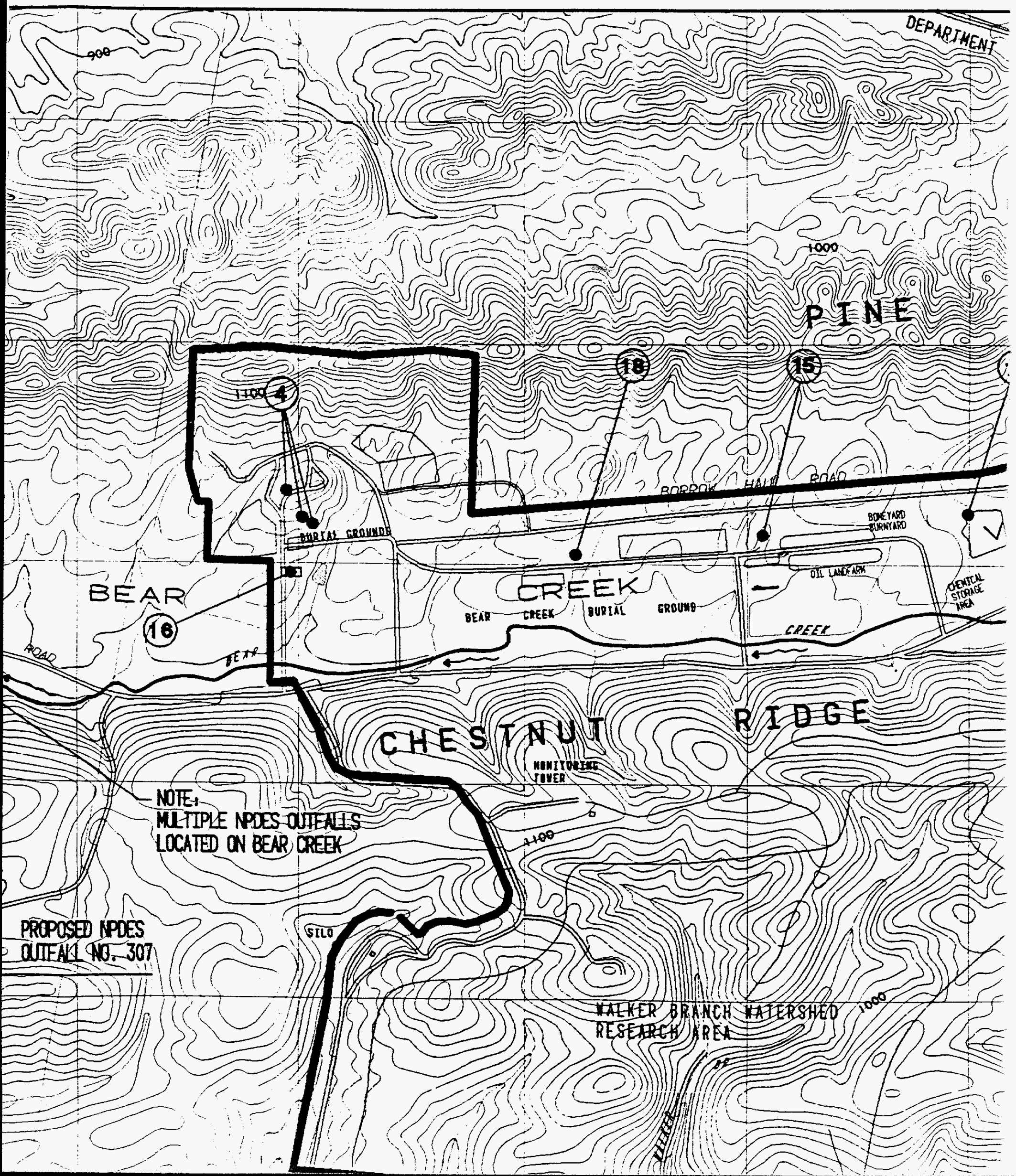




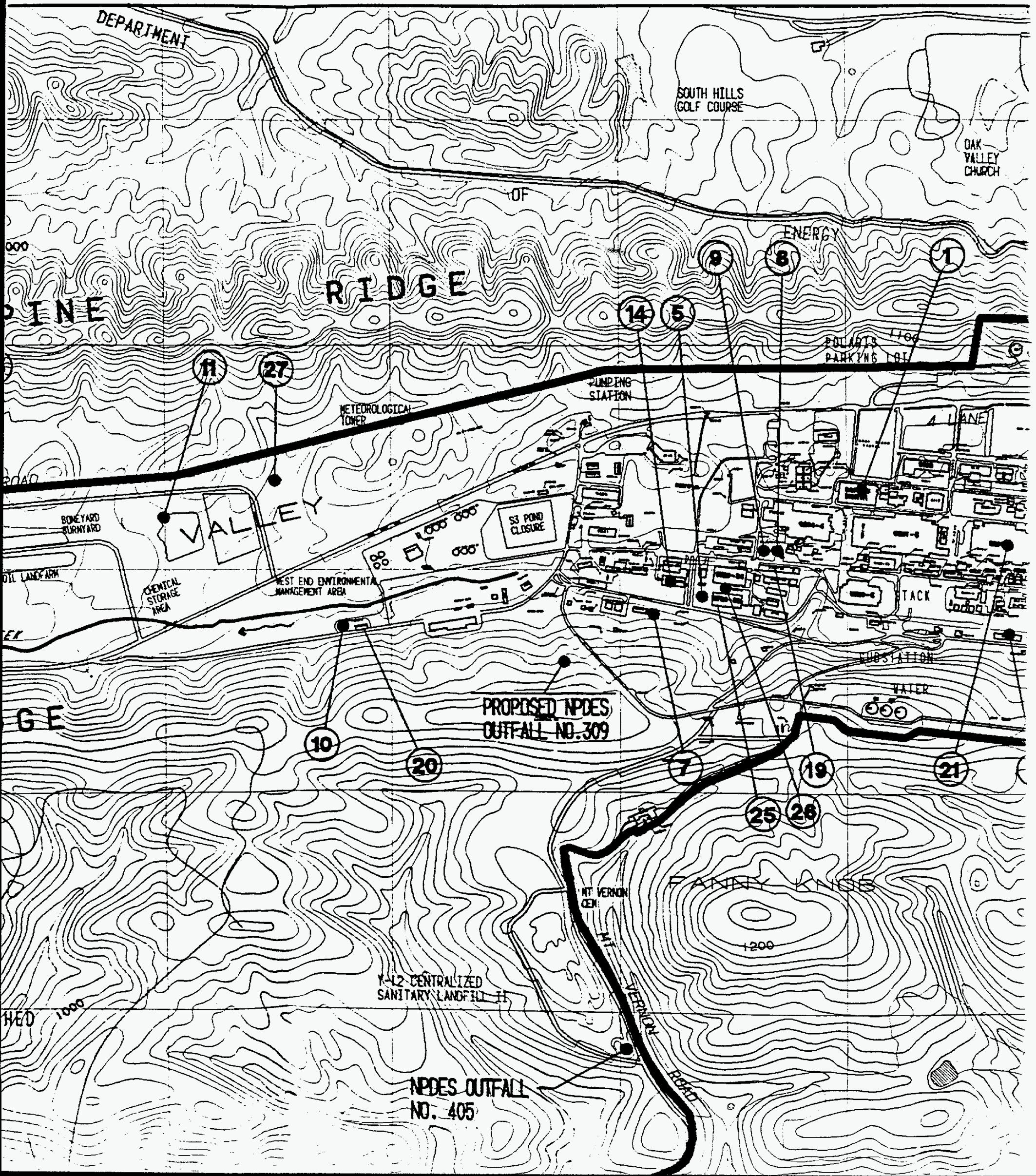




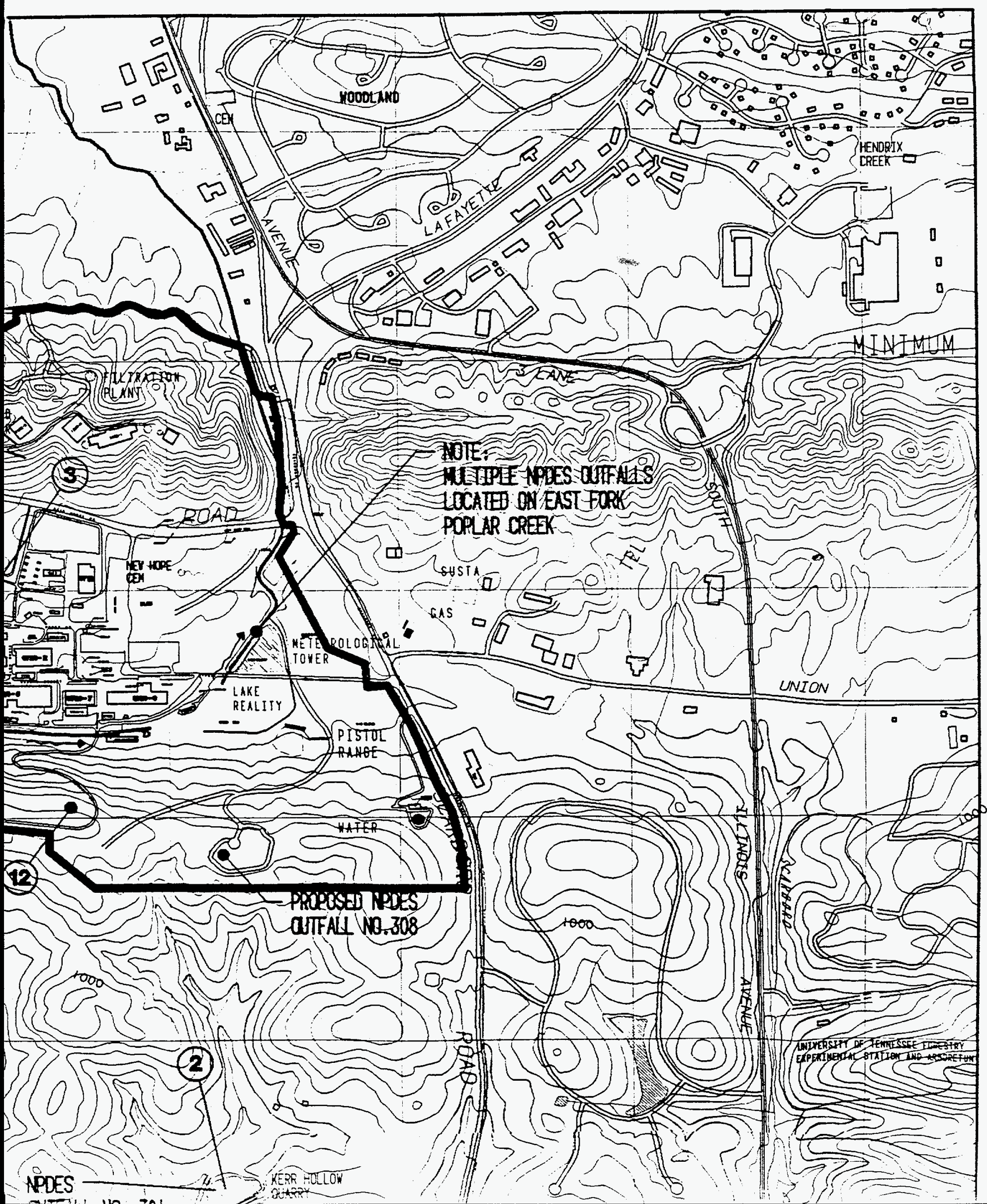


$6 \ldots \ldots \ldots$ SO $\ldots \ldots \ldots$ BUILDING $9720-9$ STORAGE UNIT

$7 \ldots \ldots \ldots . . .501 \ldots . .$. RCRA \& MIXED WASTE STORAGE \& STAGING BUILDING 9720-31

$8 \ldots \ldots \ldots$. . . . . . BUILDING 981।-1 RCRA

TANK STORAGE UNIT

$9 \ldots \ldots \ldots$........... BUILDING $9811-1$ RCRA

CONTAINER STORAGE UNIT

$10 \ldots \ldots \ldots$ SO2......WASTE OIL/SOLVENT STORAGE UNIT SOI

$11 \ldots \ldots \ldots$. . . . . . LIO. ORGANIC SOLVENT STOR. UNIT SOI

$12 \ldots \ldots \ldots$ SO $\ldots \ldots \ldots$ EAST CHESTNUT RIDGE WASTE PILE

$13 \ldots \ldots \ldots$. . . . . . CONTAINERIZED WASTE STORAGE AREA

$14 \ldots \ldots \ldots$ SO $1 \ldots \ldots \ldots$ CLASSIFIED CONTAINER STORAGE UNIT BUILDING 9720-25

$15 \ldots \ldots \ldots$ SO $\ldots \ldots$ OIL LANDFARM SOILS CONTAINMT. PAD

$16 \ldots \ldots \ldots$. . . . . . DISPOSAL AREA REMEDIAL ACTION

(DARA) SOLIDS STORAGE UNIT

$17 \ldots \ldots \ldots$ TO $\ldots \ldots$. URANIUM TREATMENT UNIT

Sol

$18 \ldots \ldots \ldots$ TO $4 \ldots \ldots$ INTERIM REACTIVE WASTE TREATMT AREA

$19 \ldots \ldots . . .501 \ldots \ldots$ BUILDING $9720-12$ CLASSIFIED

CONTAINER STORAGE AREA

$20 \ldots \ldots . . .501 \ldots \ldots$ RCRA AND PCB CONTAINER

STORAGE AREA. BUILDING 9720-58

$21 \ldots \ldots . . .501 \ldots .$. BUILDING $9201-4$ CONTAINER

STORAGE AREA

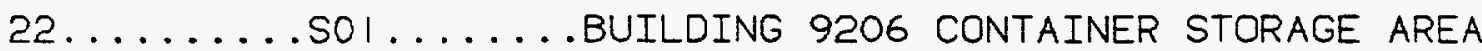

$23 \ldots \ldots \ldots . . . . . . . .801 \ldots$ BUILDING 9212 CONTAINER STORAGE AREA

$24 \ldots \ldots \ldots$. . . . . . .

$25 \ldots \ldots \ldots$ SO $\ldots \ldots$. . . .

STORAGE UNIT (FUTURE)

$26 \ldots \ldots \ldots$.......... BLDG 9720-59 CLASSIFIED WASTE STORAGE UNIT (FUTURE)

$27 \ldots \ldots \ldots$.......... OAK RIDGE RESERVATION STORAGE UNITS (FUTURE).

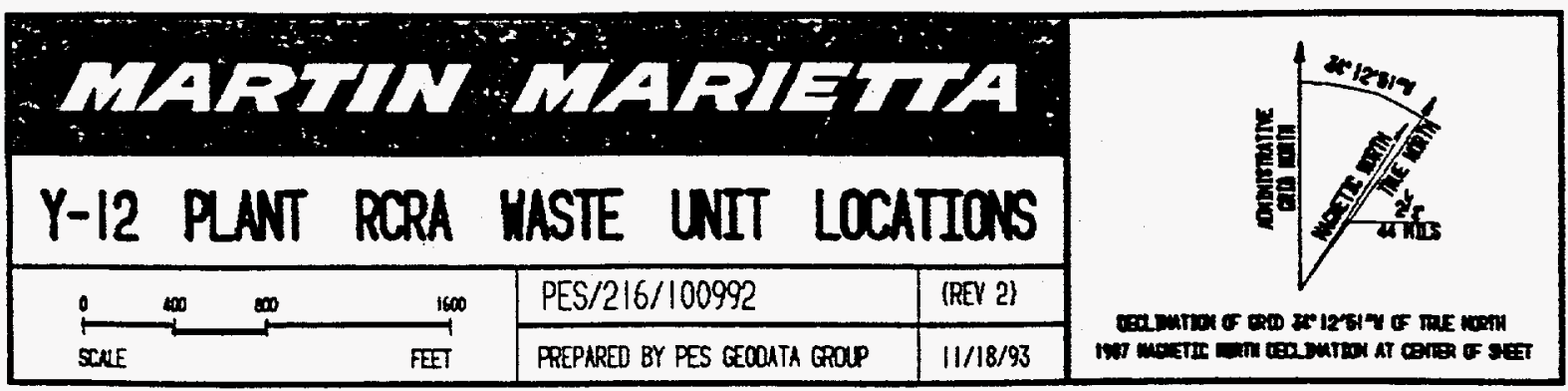

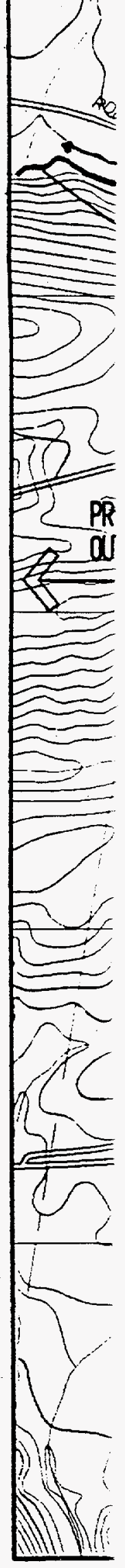




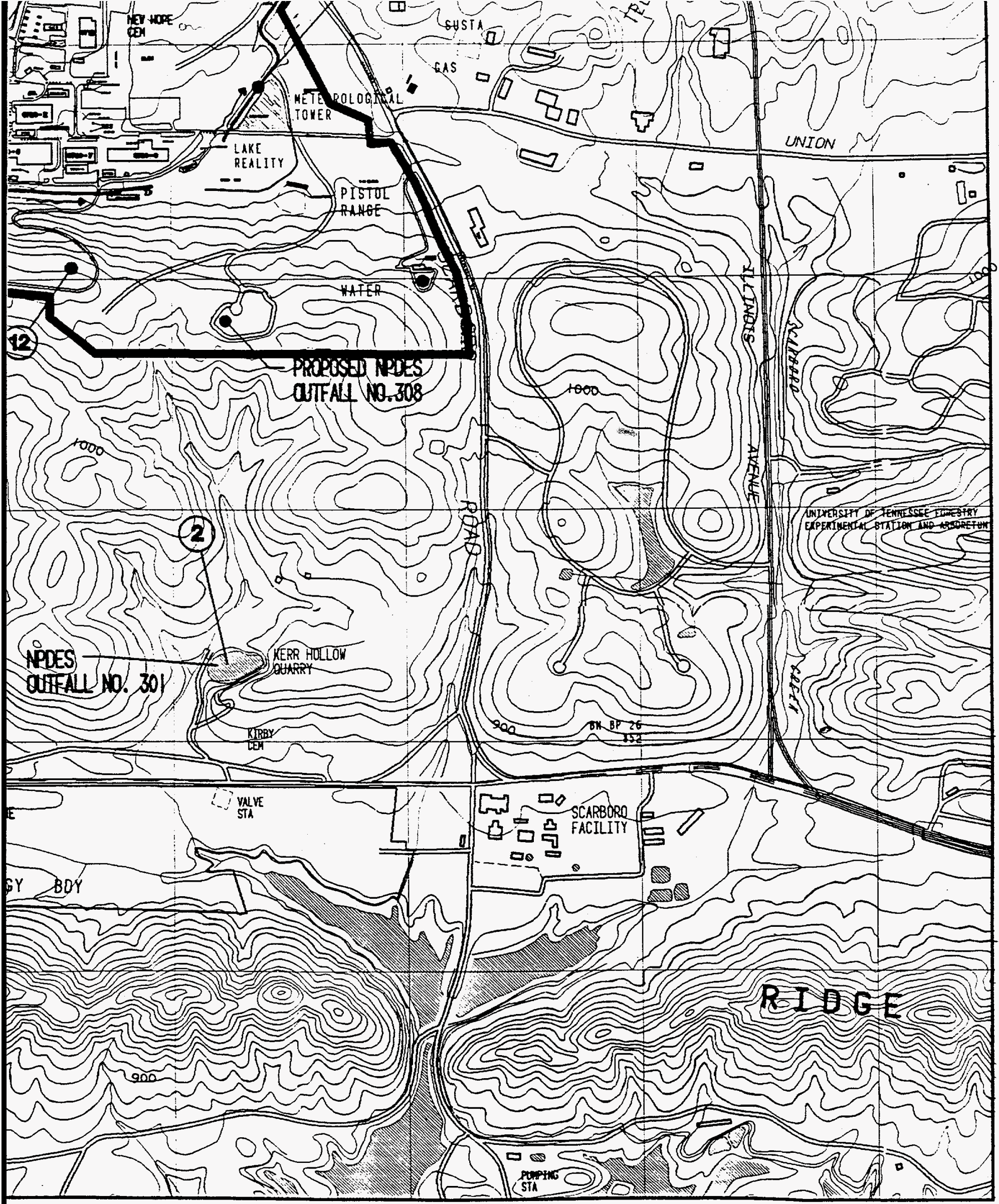


8

5

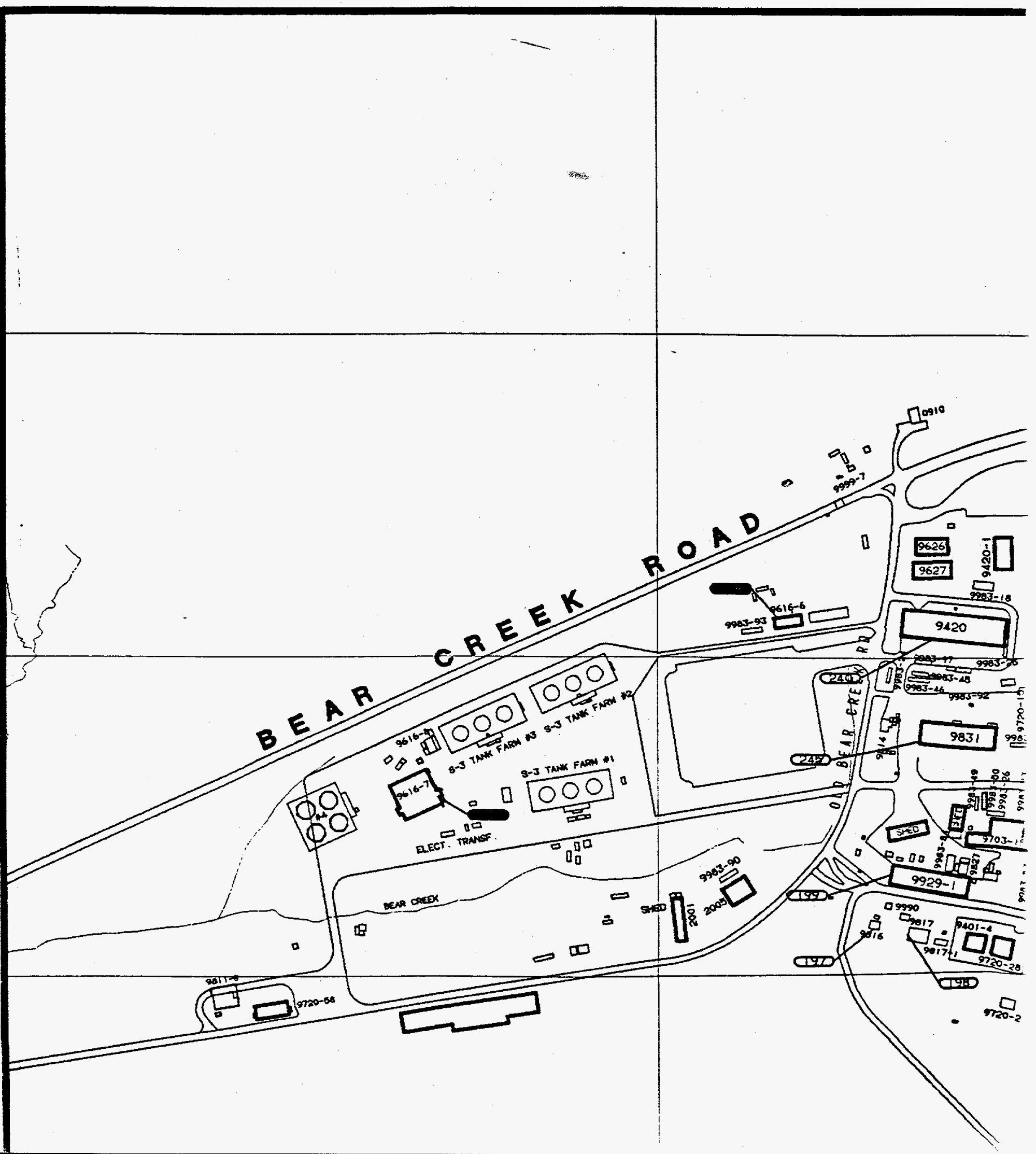



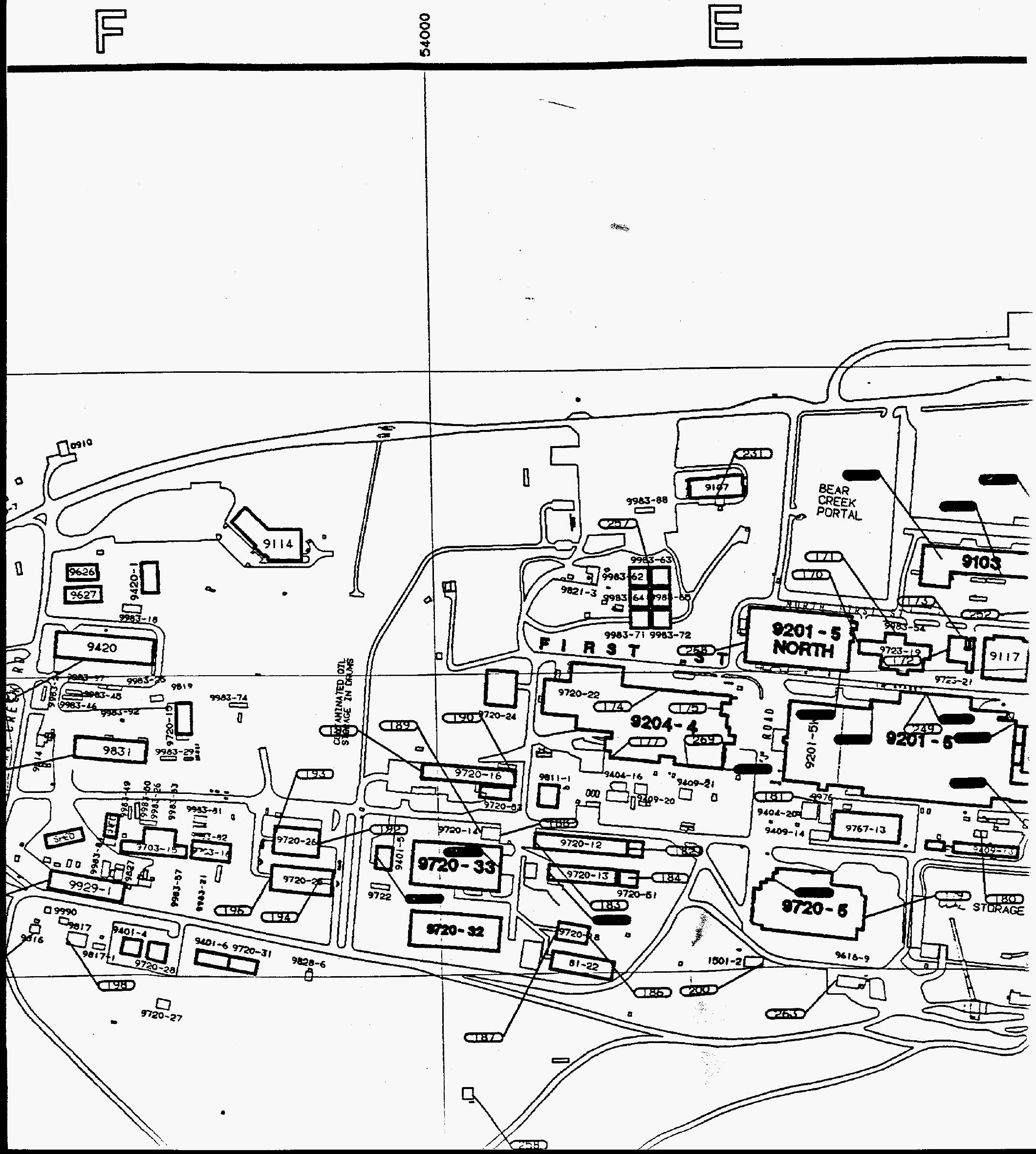


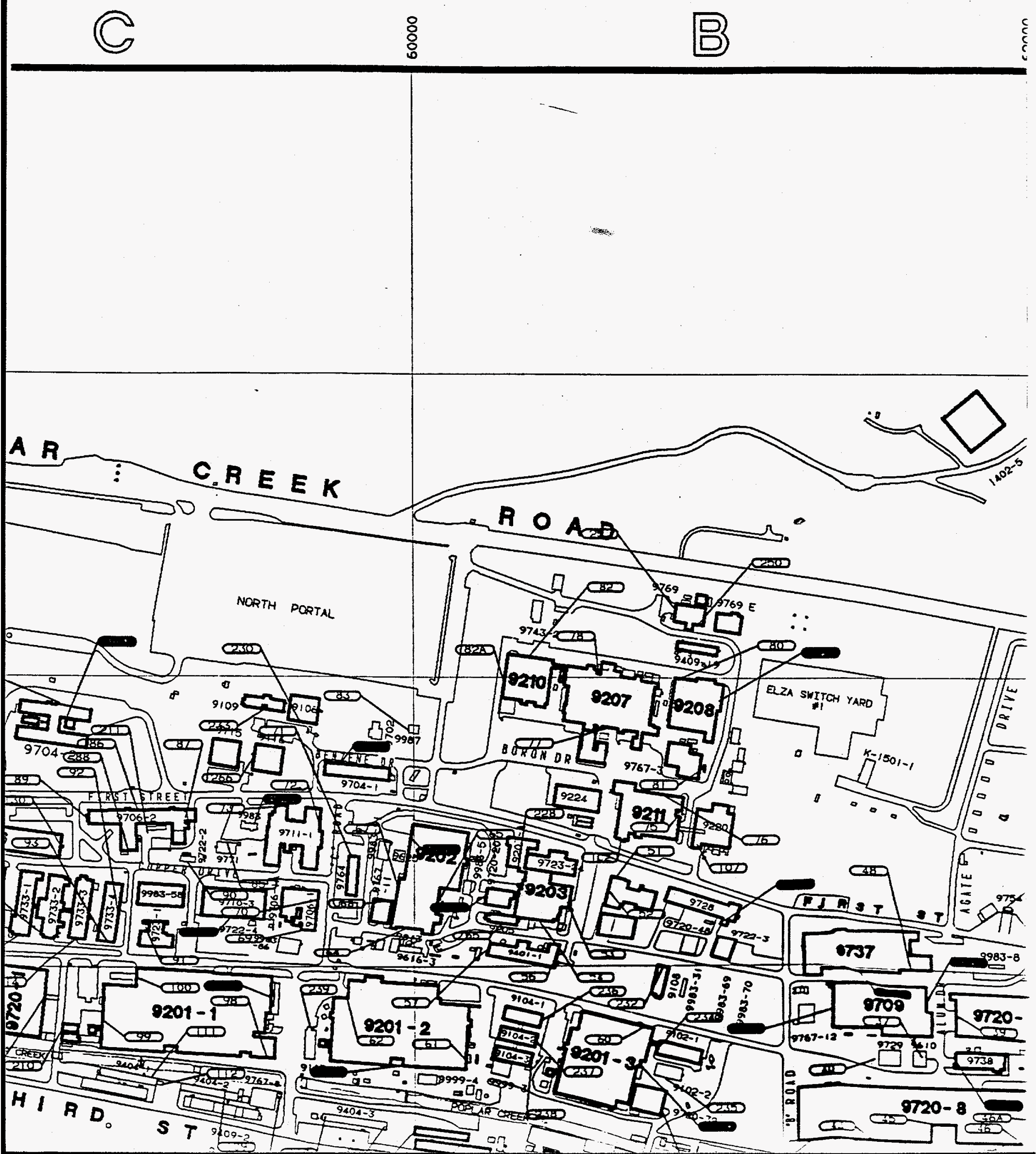




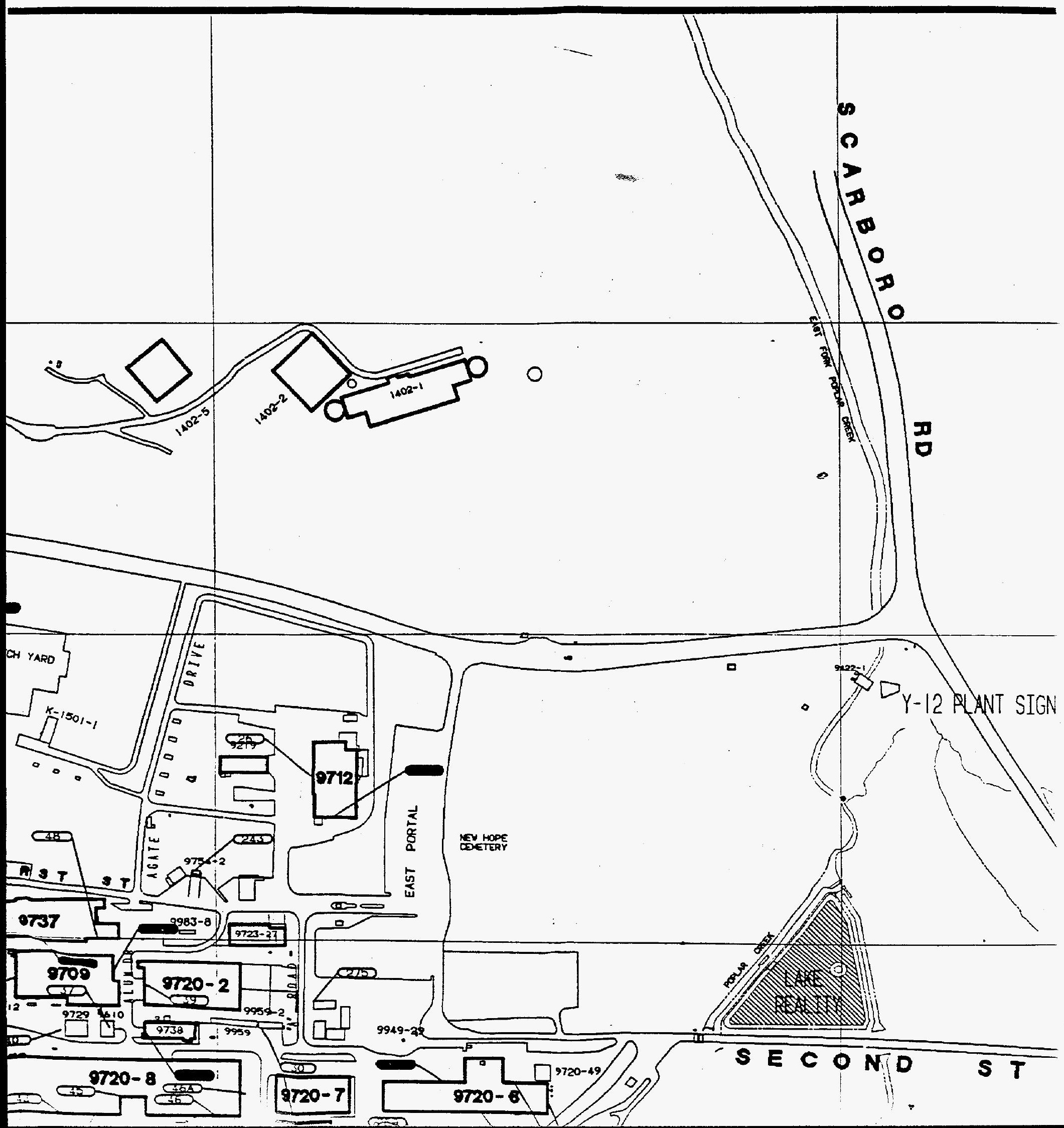




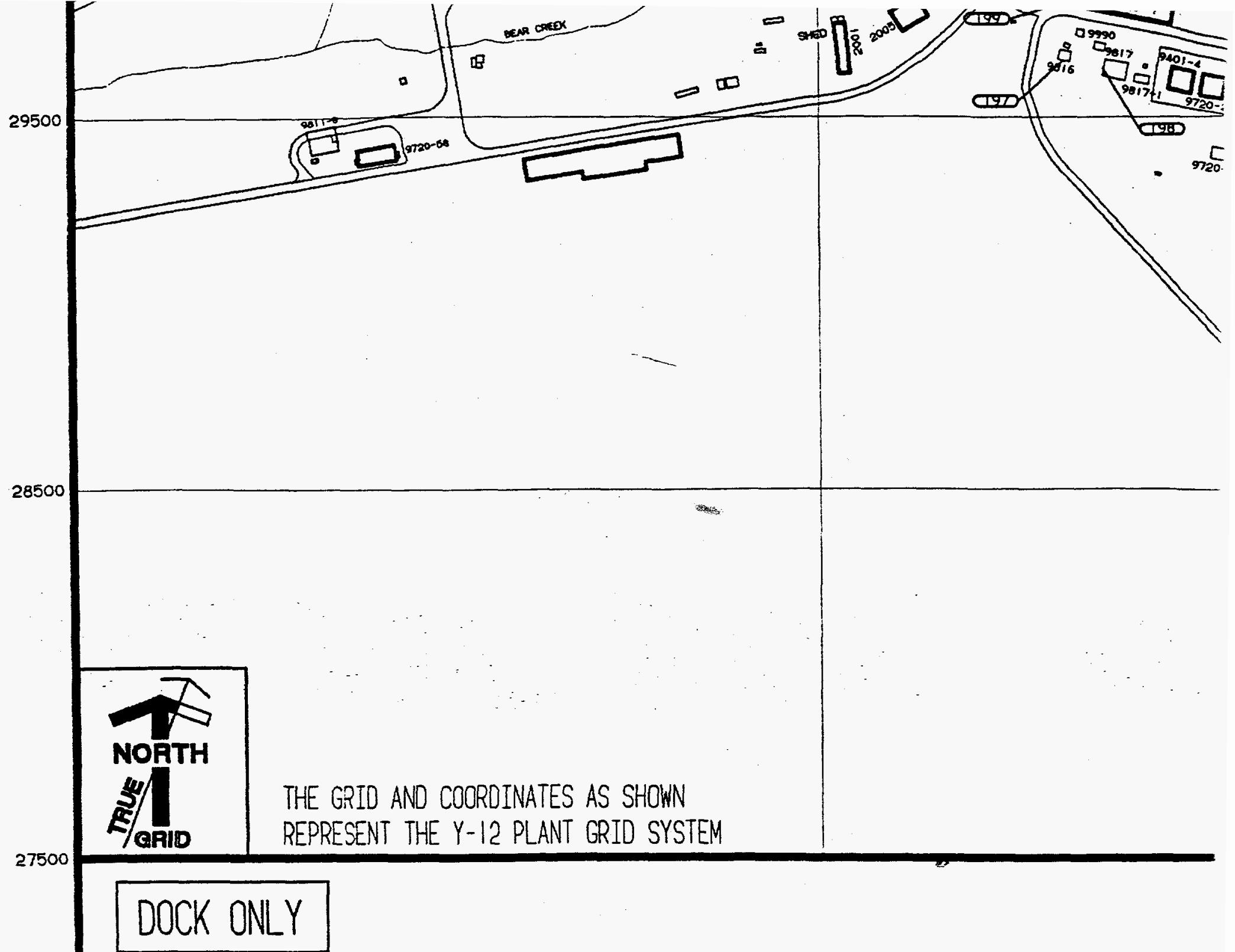

3 S.W. CORNER 9723-25....D-2

4 WEST SIDE $9723-25 \ldots \ldots . D-2$

5 N. SIDE $9723-25 \ldots \ldots \ldots . D-2$

7 N.E. CORNER $9212 \ldots \ldots \ldots$. .

8 N.E. CORNER $9212 \ldots \ldots$. . D-2

9 E. SIDE $9981 \ldots \ldots \ldots \ldots . .2$

$9 A$ E. SIDE $9212 \ldots \ldots \ldots \ldots$.

10 N. SIDE $9995 \ldots \ldots \ldots \ldots . . .2$

IOA S.W.CORNER SHED ......... D-2

11 N.E. CORNER $9995 \ldots . .$. . D-2

12 E. SIDE $9995 \ldots \ldots \ldots \ldots . . .2$

14 E. SIDE $9212 \ldots \ldots \ldots \ldots \ldots$.

15 N.E. SIDE $9996 \ldots \ldots \ldots . . .2-2$

I9A S.E.CORNER $9215 \ldots \ldots \ldots . .2-2$

$19 B$ S. SIDE $9215 \ldots \ldots \ldots \ldots . . .2$

I9C S.W. CORNER $9215 \ldots . . . . D-2$

190 W. SIDE $9215 \ldots \ldots \ldots \ldots . . .2$

I9E N.W. $9215 \ldots \ldots \ldots \ldots \ldots . . .2$

26 W. SIDE $9712 \ldots \ldots \ldots \ldots A-3$

30 S. SIDE $9959-2 \ldots \ldots \ldots . .4$

32 N.E. SIDE $9720-6 \ldots . . . A-4$

33 E. END $9720-6 \ldots \ldots \ldots . . .4$

34 S. SIDE $9720-6 \ldots \ldots \ldots A-4$

35 N.W. CORNER $9720-7 \ldots . . A-4$

37 E. SIDE $9610 \ldots \ldots \ldots . . .4$

$39 W$. SIDE $9720-2 \ldots \ldots \ldots .$.

$40 \quad W$. SIDE $9729 \ldots \ldots \ldots \ldots . . . .$.

41 S. SIDE $9720-8 \ldots \ldots \ldots .8-4$
42

43

44

45

46

$46 \mathrm{~A}$

48

58

52

53

54

55

56

57

60

61

62

64

65

67

68

69

70

71

72

73

75

76
S. SIDE $9720-8 \ldots \ldots \ldots .$.

S. SIDE $9720-8 \ldots \ldots \ldots . . .4$

S. SIDE 9720-8.......8-4

S. SIDE $9720-8 \ldots \ldots \ldots . . .18-4$

S. SIDE $9720-8 \ldots \ldots \ldots$.

E. SIDE $9720-8 \ldots \ldots \ldots . . .4$

S. SIDE E. END $9737 \ldots$. B-3

N. SIDE $9723-4 \ldots \ldots \ldots B-3$

W. SIDE $9723-4 \ldots \ldots \ldots . .3-3$

E. SIDE $9203 \ldots \ldots \ldots \ldots . . .3$

S. SIDE $9203 \ldots \ldots \ldots \ldots . . . . .3$

S. SIDE $9205 \ldots \ldots \ldots \ldots . . . .3$

E. SIDE $9401-1 \ldots \ldots \ldots . B-3$

W. END $9401-1 \ldots \ldots \ldots . . .3-3$

N.E. CORNER $9201-3 \ldots . . B-4$

S.E. CORNER $9201-2 \ldots . .8-4$

N.W. CORNER 9201-2....C-4

S. SIDE $9202 \ldots \ldots \ldots \ldots . . .3$

E. SIDE $9202 \ldots \ldots \ldots \ldots \ldots$. . .

W. SIDE $9202 \ldots \ldots \ldots \ldots . . .3$

W. SIDE $9202 \ldots \ldots \ldots \ldots \ldots$. . 3

S. SIDE $9706-i \ldots \ldots \ldots \ldots$. 3

$E$. SIDE 9706-1A......C-3

W. SIDE $9764 \ldots \ldots \ldots \ldots . . . .3$

E. SIDE $9711-1 \ldots \ldots \ldots . .3$

N.W. CORNER 97ii-i ...c-3

E. SIDE $9211 \ldots \ldots \ldots \ldots . . .3$

N. SIDE $9211 \ldots \ldots \ldots \ldots . . .3$
77

78

80

81

82

$82 \mathrm{~A}$

83

85

86

87

88

89

90

91

92

93

98

99

100

101

102

104

105

106

107

108

109

110
S.

N. S

N.W.

E. S

N.

W.

S.

N.

N.

$E$.

S.

W.

S.

W.

$E$

5 .

S.E

W.

N.W

$E$.

S.W

W.

E.

N.

5 .

$E$.

$N$.

W. 


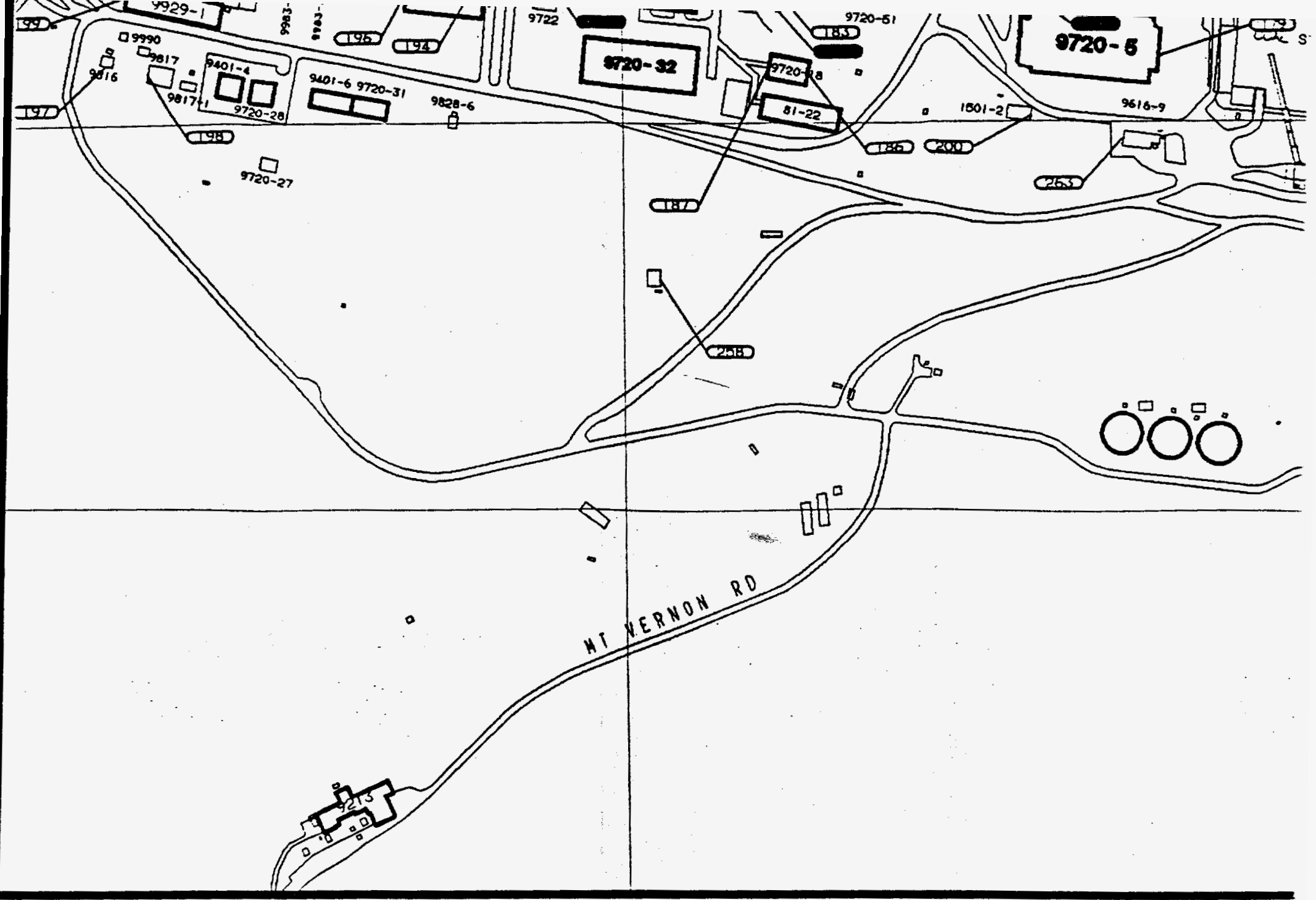

.B-4 77 S. SIDE $9207 \ldots \ldots \ldots . . . .3-3$

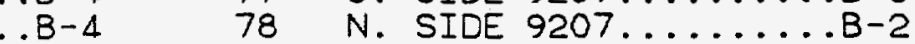
.8-4 80 N.W. CORNER $9208 \ldots \ldots . . .3-3$ .B-4 81 E. SIDE $9767-3 \ldots \ldots . .8-3$

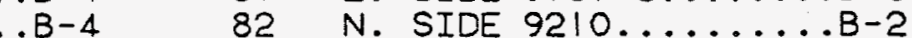
$\ldots A-4 \quad 82 A$ W. SIDE $9210 \ldots . . . . .$.

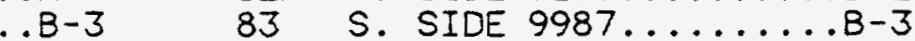
.B-3 85 N. SIDE $9771 \ldots \ldots \ldots \ldots . . . . . . .3$ .8-3 86 N. SIDE 9706-2.......

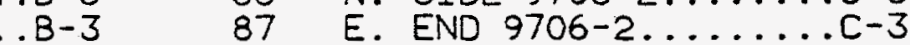
$\ldots 8-3 \quad 88$ S. SIDE $9706-2 \ldots \ldots \ldots . . . . .3$ . B-3 89 W. END $9706-2 \ldots \ldots \ldots . . . . .3$ .B-3 90 S. SIDE $9722-2 \ldots \ldots \ldots . . . .$. ..B-3 91 W. SIDE $9723-1 \ldots . . . . .2-3$ .B-4 92 E. SIDE $9733-4 \ldots \ldots \ldots . . . .3$ ..B-4 93 S. SIDE $9733-4 \ldots \ldots \ldots . . .3-3$ ..C-4 98 S.E. CORNER $9201-1 \ldots . . C-4$ $\ldots B-3 \quad 99$ W. SIDE $9201-1 \ldots \ldots . . .4-4$ .B-3 100 N.W. CORNER $920 i-1 \ldots . . .4$ . C-3 101 E. SIDE $9404-3 \ldots \ldots . . . .4-4$ $\ldots$.. 3 102 S.W. CORNER $9211 \ldots . . .8-3$ $\ldots c-3 \quad 104$ W. END $9404-4 \ldots \ldots . . . .8-4$ $\ldots C-3 \quad 105$ E. END $9404-4 \ldots \ldots \ldots . . . . .4$ 106 N. SIDE $9404-5 \ldots . . . . .8-4$

107 S. SIDE $9220 \ldots \ldots \ldots . . . . . . .3$

108 E. END $9404-5 \ldots \ldots \ldots . . .8-4$

109 N. SIDE $9404-2 \ldots \ldots \ldots . . . . . . .4$

110 W. END $9404-3 \ldots . . . . .4-4$
111 N. SIDE $9404-1 \ldots \ldots . . . .4$

112 E. END $9404-1 \ldots \ldots \ldots . . . .4-4$

113 S. SIDE $9419-1 \ldots \ldots . . . . .4$

114 S. END $9733-3 \ldots \ldots . . . .6-3$

115 S. END $9733-2 \ldots \ldots \ldots \ldots . . .3$

116 S. END $9733-1 \ldots . . . . . . C-3$

117 E. SIDE $9720-i \ldots \ldots \ldots . . .4-4$

118 S. SIDE $9720-1 \ldots \ldots \ldots . .4-4$

120 S.W. CORNER $9204-1 \ldots . . C-4$

121 N. SIDE $9204-1 \ldots \ldots \ldots . . .3$

122 E. END $9204-3 \ldots \ldots \ldots . . . .4$

123 N.E. CORNER $9204-\dot{3} \ldots . . .8-4$

125 E. SIDE $9977-1 \ldots \ldots \ldots . . .10-3$

129 S. SIDE $9766 \ldots \ldots . . . . . .3$

130 E. END $9766 \ldots \ldots \ldots \ldots . . . . . . .3$

131 W. END $9766 \ldots \ldots \ldots \ldots . . . . .3$

132 S. SIDE $9735 \ldots \ldots \ldots \ldots . . . .3$

133 W. SIDE $9735 \ldots \ldots \ldots \ldots . . . .5-3$

134 N. END $9736 \ldots \ldots \ldots \ldots \ldots .3$

135 N. END $9731 \ldots \ldots \ldots \ldots \ldots . . . . . . .3$

137 W. SIDE $973 i \ldots \ldots \ldots \ldots . . . . . . .3$

138 S. END $9731 \ldots \ldots \ldots \ldots . . . . .5$

140 N.E. CORNER $97 i i-5 \ldots . . .3-3$

141 W. END $9711-5 \ldots \ldots \ldots . . . .3$

143 N.E. CORNER $920 . \ldots \ldots . . . . .3-3$

144 S. SIDE $9206 \ldots . . . . . . . D-3$

145 W. SIDE $9206 \ldots \ldots \ldots \ldots . . . . .3-3$

146

E. SIDE $9710-2 \ldots \ldots . . . . .0 .3-3$

\section{8}

150

154

155

156

157

158

159

160

161

162

163

170

171

172

173

174

175

177

179

180

181

182

183

184

186

187
W. $S=$

N. S:I

S.E.

N. SI

N.W.

W. $=$

W.

W. 5

N. SI

N.E.

S. S:

W.

W.

N.

W. $\equiv$

N. $\equiv$

N. $E_{-}^{-}$

N.E.

S.W.

E. S- $^{-}$

N. $S$ :

N. $S$.

E. E

W. E

E.

E. E

H. E

E. E 


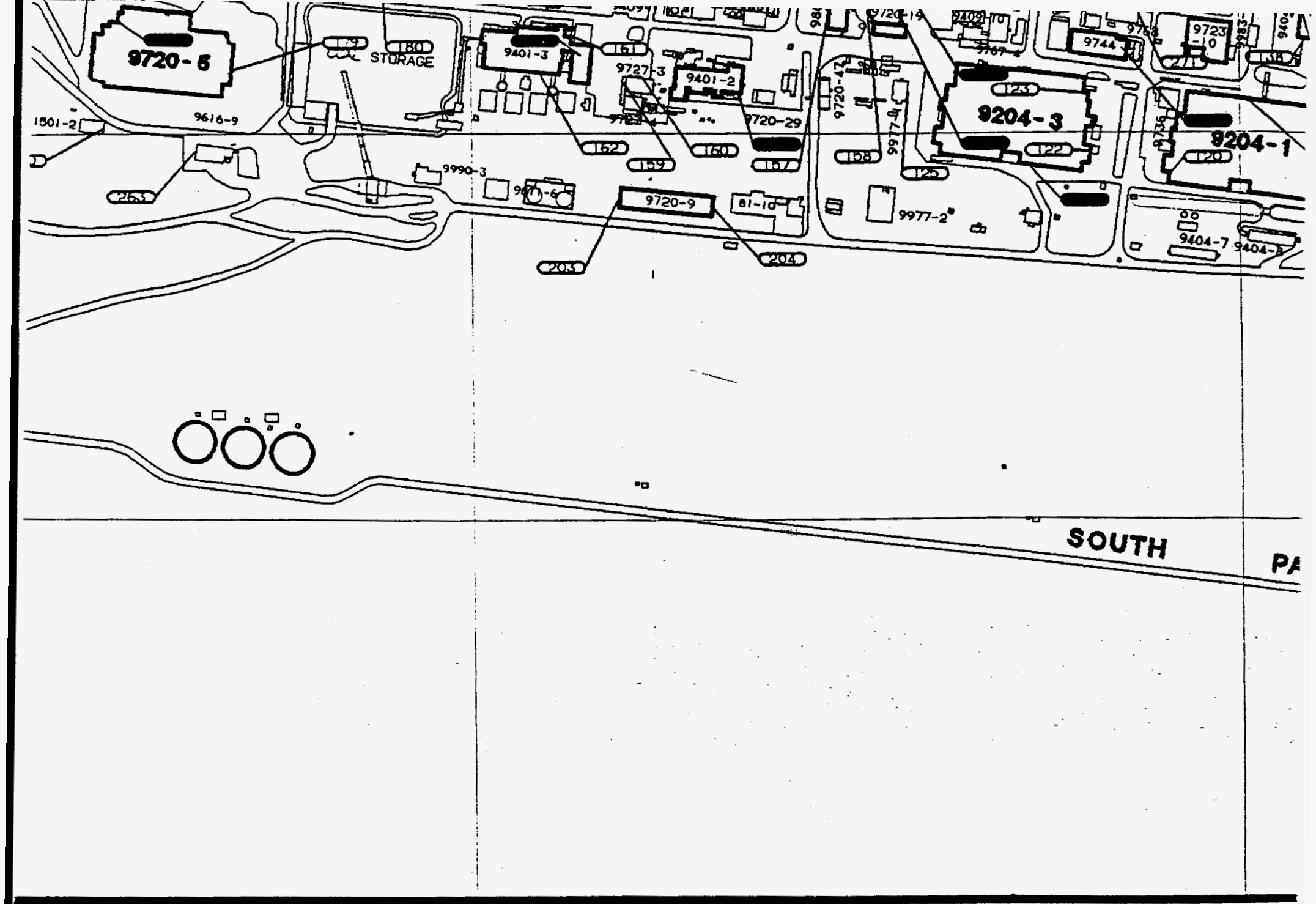

148 W. S-DE 9204-2........D-3

150 N. S_JE $9704-2 \ldots \ldots \ldots . C-3$

154 S.E. CORNER 9201-4...D-3

155 N. SIDE $9201-4 \ldots \ldots . . .3$

156 N.W. CORNER 9201-4...D-3

157 W. SEDE $9805-1 \ldots . . . . D-3$

158 W. $\Xi D D E$ 9720-19.....D-3

159 W. SIDE $9727-3 \ldots \ldots . . . D-3$

160 N. SIDE $9727-3 \ldots \ldots \ldots-3$

161 N.E. CORNER $9401-3 \ldots .0-3$

162 S. SIDE $9401-3 \ldots \ldots . . .10-3$

$163 \quad W . \equiv N 109404-18 \ldots \ldots . . . D-3$

$170 \quad W . \equiv V D$ 9723-19......E-2

171 N. SIDE $9723-19 \ldots \ldots . . . E-2$

172 W. $\equiv 109723-21 \ldots . . . E-2$

173 N. इIDE $9723-21 \ldots . . . E-2$

174 N. SIDE $9204-4 \ldots \ldots . . . E-3$

175 N.E. CORNER 9204-4...E-3

177 S.W. CORNER 9204-4...E-3

179 E. SIDE $9720-5 \ldots . . . . E-3$

180 N. SIDE $9404-13 \ldots \ldots . . . E-3$

181 N. SIDE $9976 \ldots \ldots \ldots . . . .5-3$

182 E. END $9720-12 \ldots \ldots . . . E-3$

183 W. END $9720-12 \ldots \ldots . . . E-3$

184 E. END $9720-13 \ldots \ldots . . . E-3$

$186 \quad E . E_{N D} 9720-18 \ldots \ldots . . . E-3$

187 W. END $9720-18 \ldots \ldots . . . E-3$

188
W. END $9720-18 \ldots \ldots \ldots . E-3$
W. END $9720-14 \ldots \ldots$ E-3

E. END $9720-16 \ldots \ldots . . . E-3$

W. END $9720-16 \ldots . . . . E-3$

E. END $9720-26 \ldots . . . F-3$

W. END $9720-26 \ldots . . . F-3$

E. END $9720-25 \ldots . . . F-3$

W. END $9720-25 \ldots . . . F-3$

S. SIDE $9816 \ldots \ldots \ldots . F-3$

W. END $9817 \ldots \ldots \ldots . . . . . .3$

W. END $9929-1 \ldots \ldots . . . F-3$

E. END $1501-2 \ldots \ldots \ldots . . . .5-3$

W. END $9720-9 \ldots . . . . . D-4$

E. END $9720-9 \ldots \ldots . . . D-4$

W. SIDE $9732-1 \ldots \ldots . . . C-3$

S. SIDE $9706-2 \ldots . . . \mathrm{C}-3$

W. END $9720-4 \ldots . . . . A-4$

S. SIDE $9766 \ldots \ldots \ldots \ldots$. 3

S.W. CORNER $9203 \ldots . .8 .3$

W. SIDE $9616-5 \ldots . . . A 4-4$

S. SIDE $9106 \ldots . . \ldots . . .3$

S. SIDE $9107 \ldots \ldots \ldots . . . . .2$

N. SIDE $9108 \ldots . \ldots \ldots . . . .4$

S. SIDE $9109 \ldots . . . . . C-3$

W. SIDE $9102-1 \ldots . . . . B-4$

S.W.CORNER $9102-2 \ldots . .3-4$

E. SIDE $9104-1 \ldots \ldots . . .4-4$

E. SIDE $9104-2 \ldots . . .0-4$

E. SIDE $9104-3 \ldots . . . .0-4$
239

240

241

242

243

244

245

249

250

251

252

253

257

258

260

263

265

266

267

268

269

270

271

272

275 


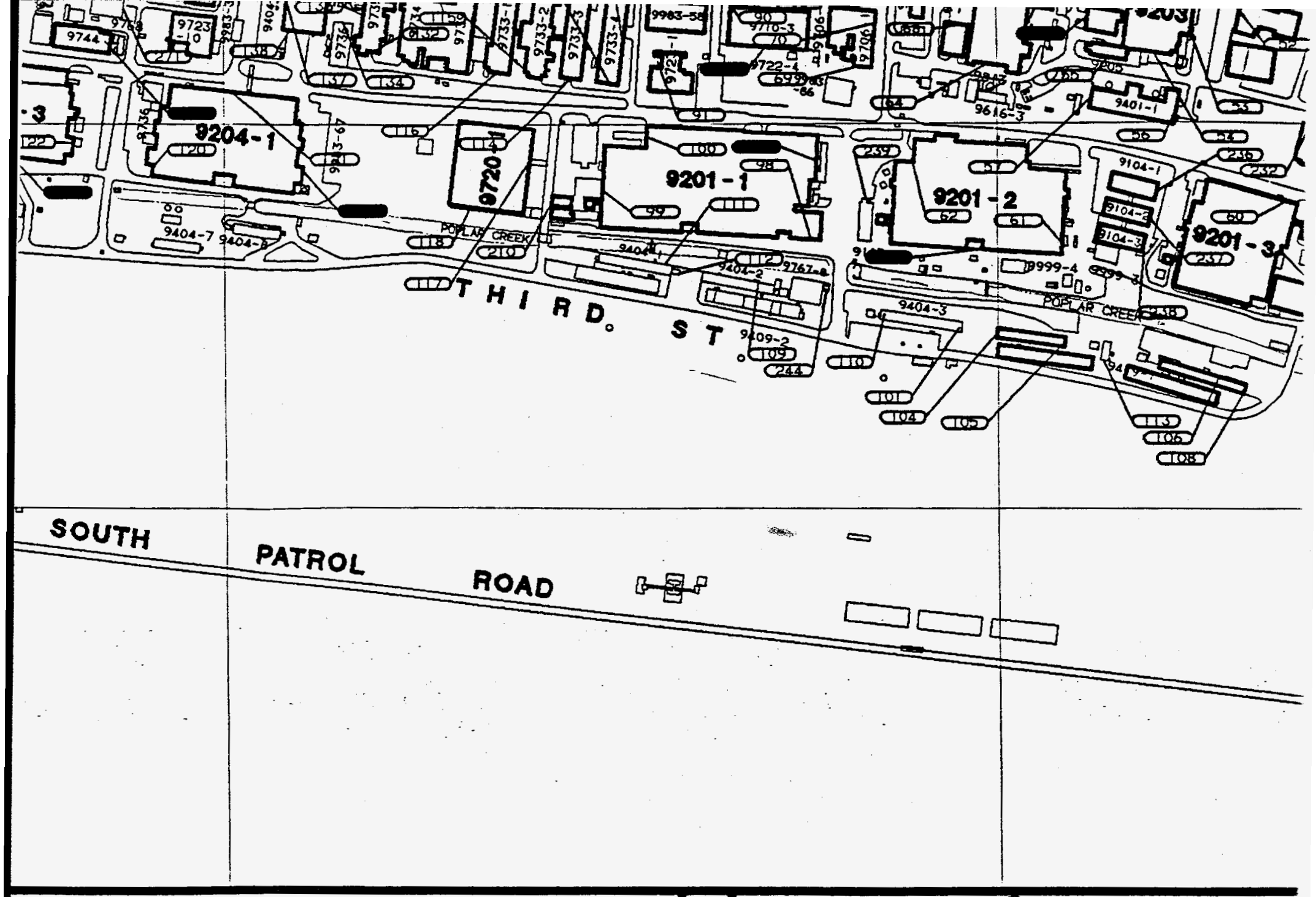

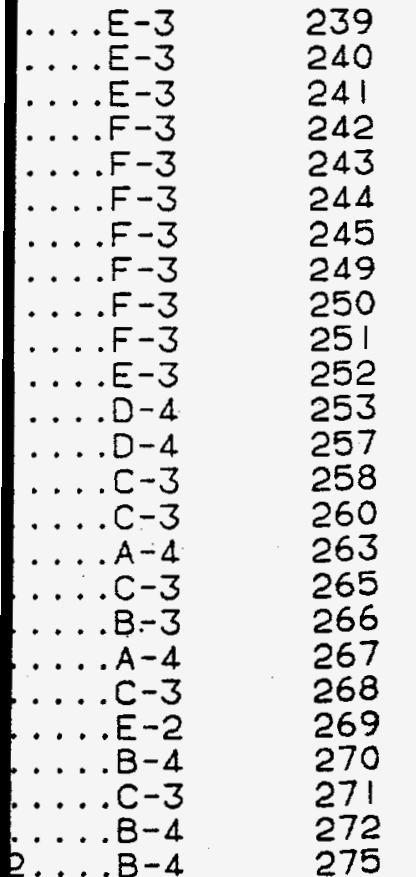

N. SIDE $9105 \ldots \ldots \ldots \ldots$ C-4

S. SIDE $9420 \ldots \ldots \ldots \ldots F-2$

S.E. CORNER $9110 \ldots . D-3$

E. SIDE 9720-39......B-4

S. SIDE $9754-2 \ldots \ldots . .8-3$

E. SIDE $9767-8 \ldots \ldots \ldots$. 4

S.W. CORNER $983 i \ldots . . . F-3$

N. $9201-52 F L \& R P$. .E-2

S. SIDE $9769 \ldots \ldots \ldots$....

W. SIDE $9769 \ldots \ldots \ldots . . . .$.

S.E. CORNER 9983-41 ..E-2

S. $9111,9112 \ldots \ldots \ldots .0-2$

N.BETWN 9983-62 \& 63.E-2

$E$. SIDE $9824-4 \ldots \ldots \ldots E-4$

E. SIDE $9725 \ldots \ldots \ldots \ldots$. 4

W. SIDE $96 \mid 6-9 \ldots \ldots . . . E-3$

N.E. $97.23-18 \ldots \ldots \ldots . . D-3$

W. SIDE 9116 RM. $135 \ldots$. 3

N.SIDE E END 97149 M.I.W Y-12

W. SIDE $9201-5 N \ldots . . . E-2$

S. SIDE 9204-4.......E-3

W. SIDE 9206..........

E. SIDE $9720-17 \ldots \ldots . . .10-3$

E. SIDE $9103 \ldots \ldots \ldots . . .2$

W. SIDE $9983-A H \ldots \ldots . A-4$

\section{ras}

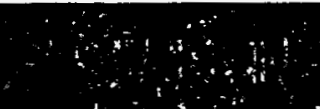

7

4
6

13

16

17

18
19

20

25

36

38

$38 B$

47

50

59

63

66

74

79

84.

119

124

136

139

142

147

149

$150 \mathrm{~A}$
N.W. CORNER $9212 \ldots \ldots . D-2$

W. SIDE $9995 \ldots \ldots \ldots \ldots . . .2$

W. END $9996 \ldots \ldots \ldots \ldots \ldots$. . .

E. SIDE $9998 \ldots \ldots \ldots \ldots . . . .2$

E. SIDE $9215 \ldots \ldots \ldots \ldots$.

S.E. CORNER $9215 \ldots \ldots \ldots$. 2

N.W. CORNER 9998......D-2

W. SIDE $9404-11 \ldots \ldots \ldots$. 3

N. SIDE $9720-6 \ldots \ldots \ldots$. . A 4

W. SIDE $9738 \ldots \ldots \ldots . .8-4$

E. SIDE $9709 \ldots \ldots \ldots . . . . .4$

E. SIDE $9709 \ldots \ldots \ldots . . . .8-4$

S. SIDE $9737 \ldots \ldots \ldots \ldots . .$.

S.E. CORNER 9728......8-3

E. SIDE $9201-3 \ldots \ldots . .8-4$

S. SIDE $9201-2 \ldots \ldots \ldots . C-4$

W. SIDE $9720-20 \ldots \ldots . . .3-3$

N. SIDE $9704-1 \ldots \ldots \ldots . .3$

E. SIDE $9208 \ldots \ldots \ldots \ldots . . .3-3$

E. SIDE $9983 \ldots \ldots \ldots \ldots \ldots$. 3

S.E. SIDE $9204-1 \ldots . . C-4$

S. SIDE 9204-3...... D-4

E. SIDE $9731 \ldots \ldots \ldots \ldots$. 3

S. SIDE $97 \mid 1-5 \ldots \ldots \ldots$ - 3

N.W. CORNER 9720-38..E-3

E. SIDE 9204-2......D-3

S. SIDE $9204-2 \ldots \ldots \ldots$.

E. SIDE $9704-2 \ldots \ldots \ldots$. 


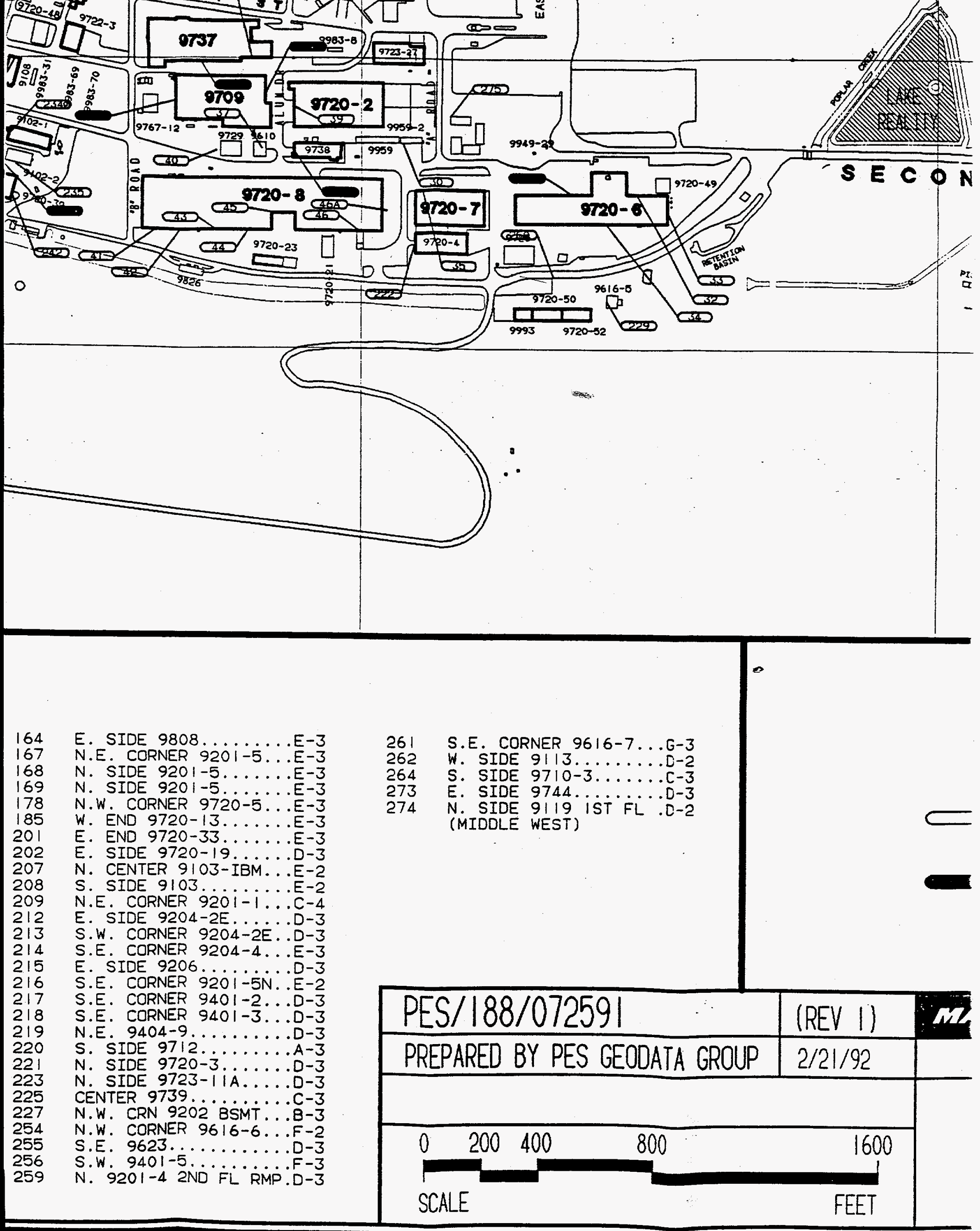
N. $9201-4$ 2ND FL RMP.D-3
261

264

273

274
S.E. CORNER 9616-7...G-3

N. SIDE 9119 IST FL .D-2 (MIDDLE WEST)

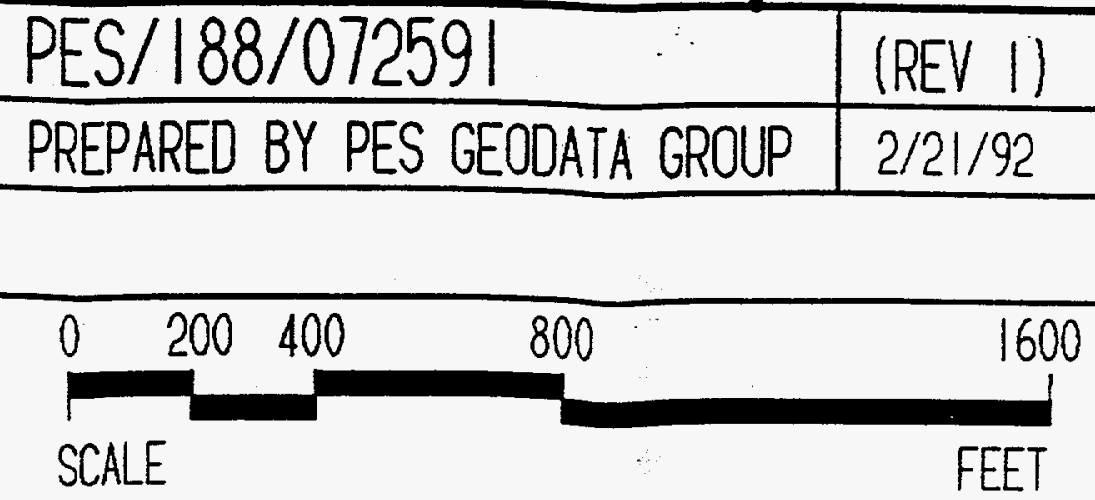




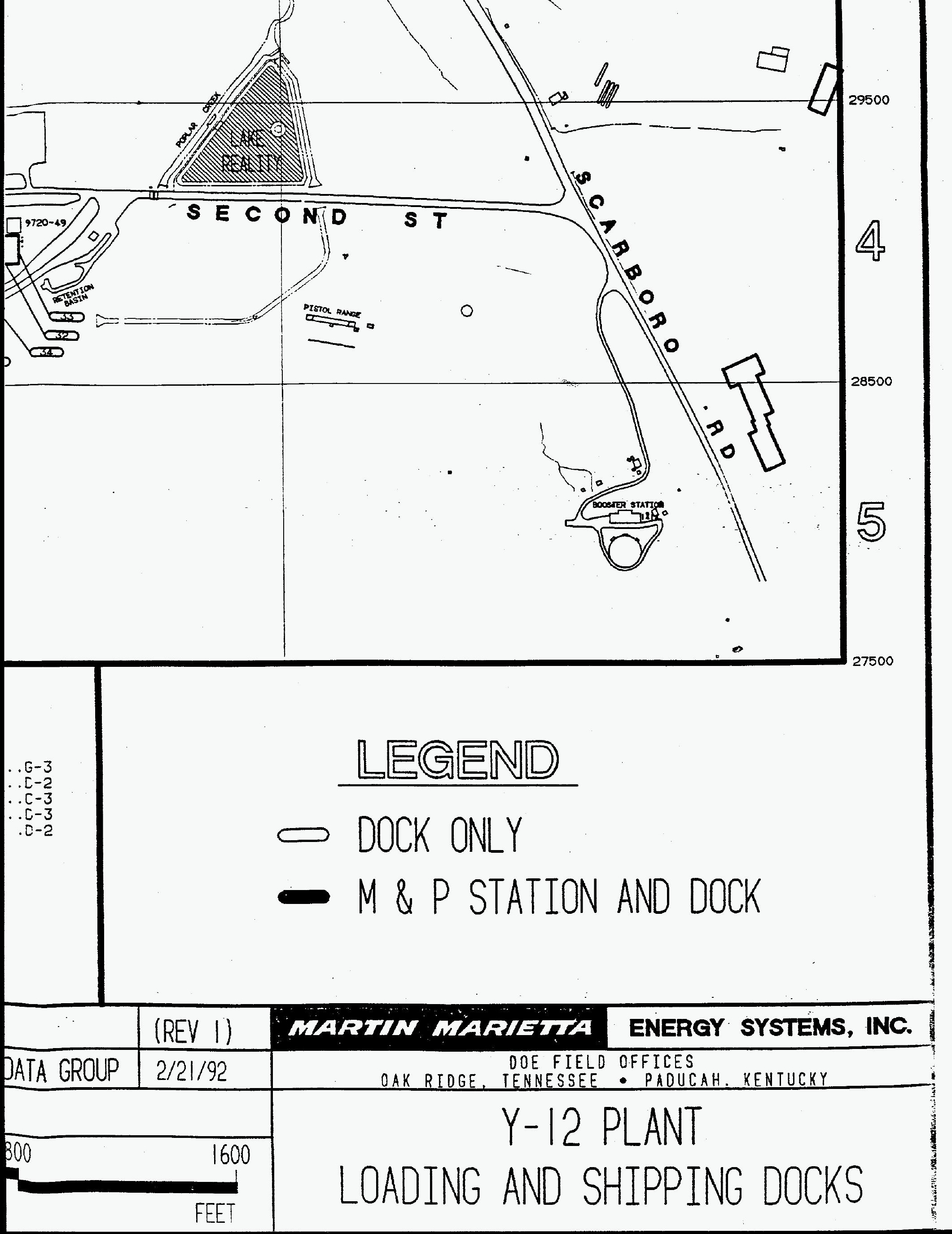



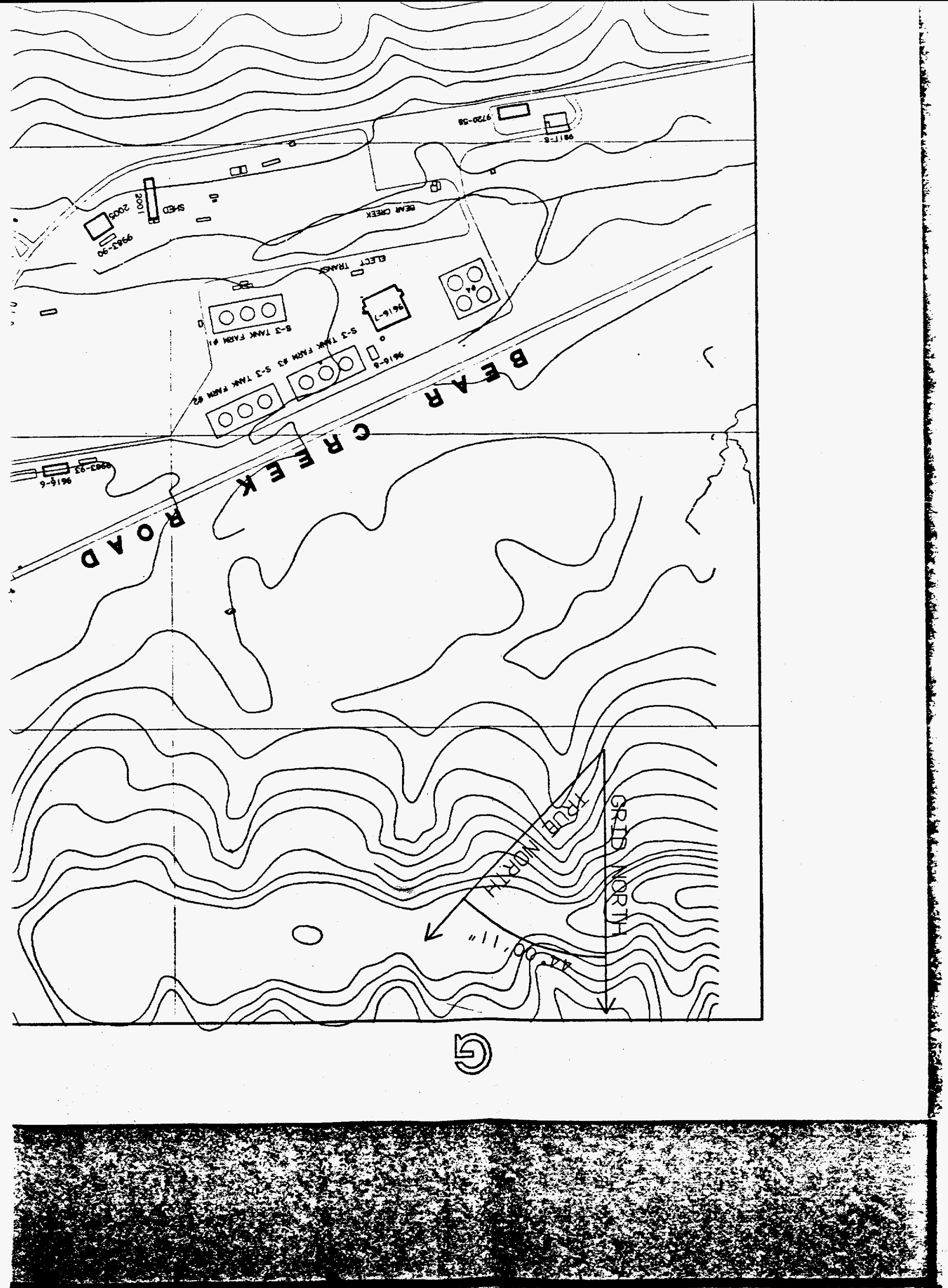

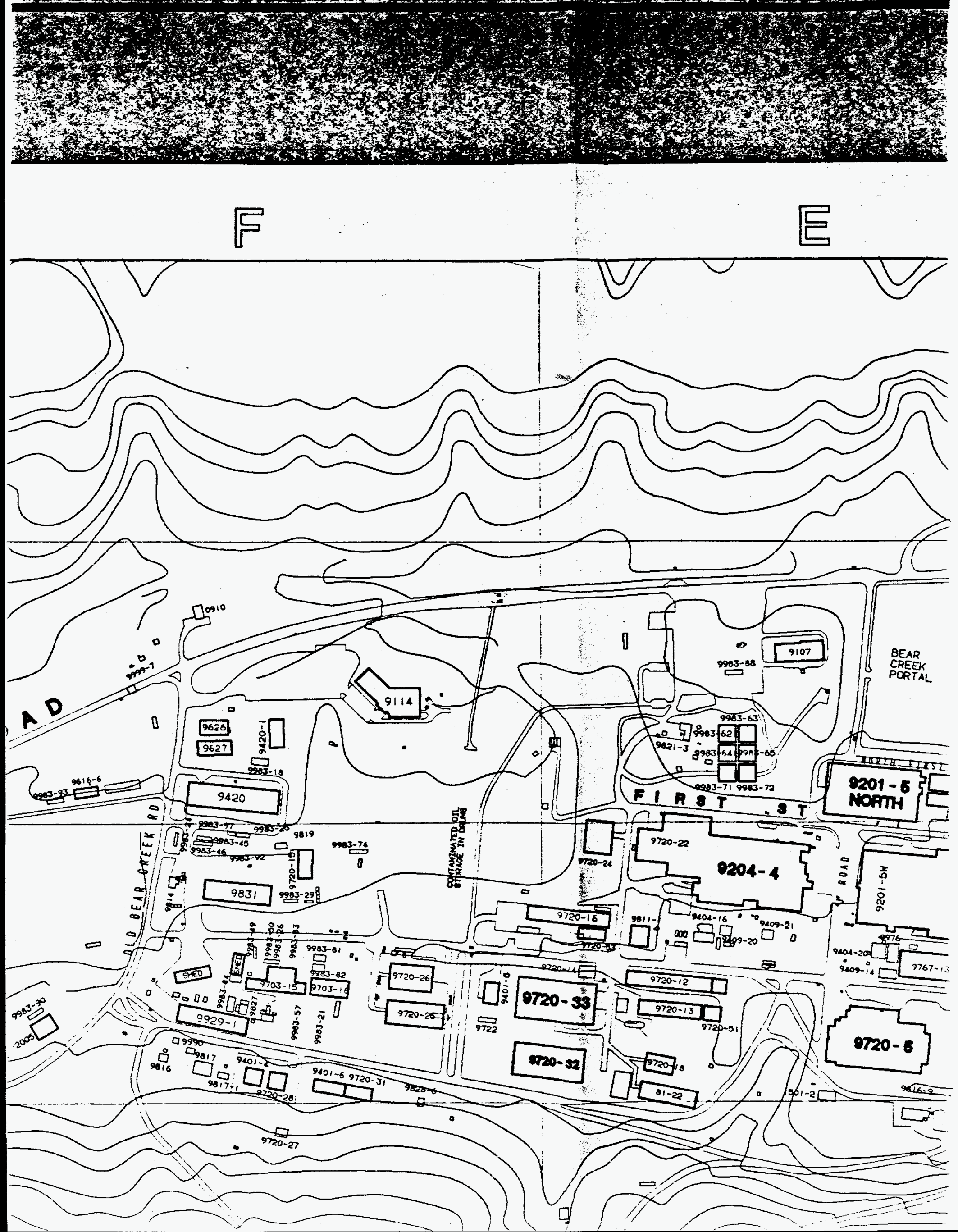


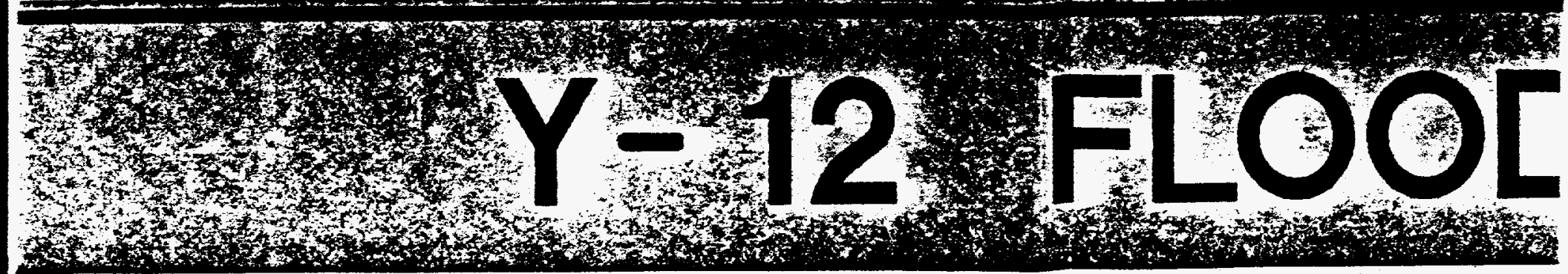

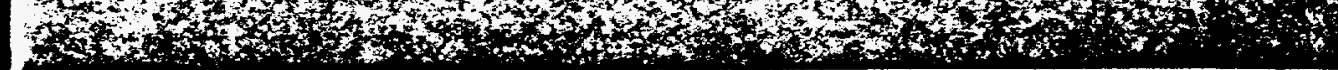

(D)

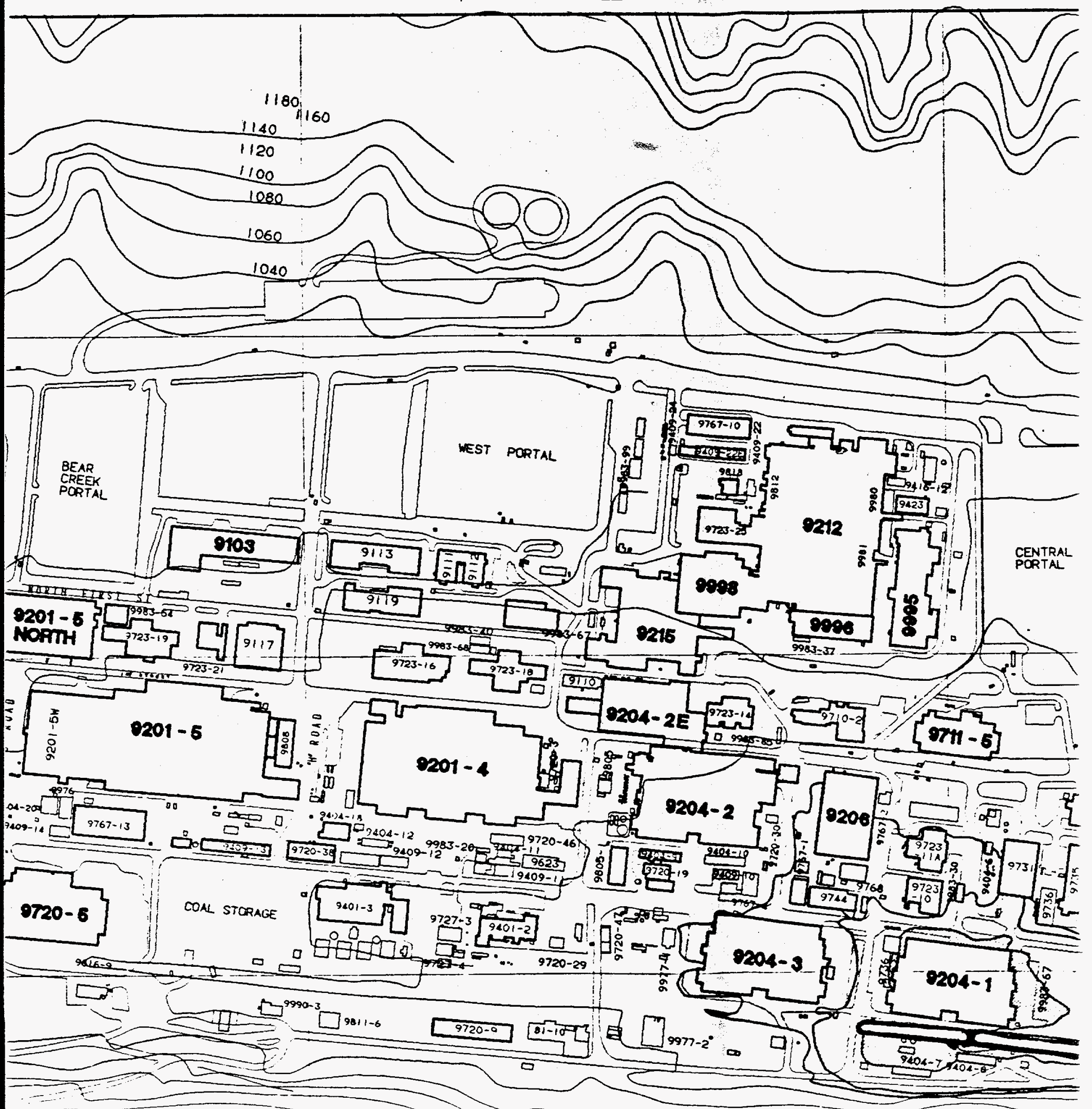




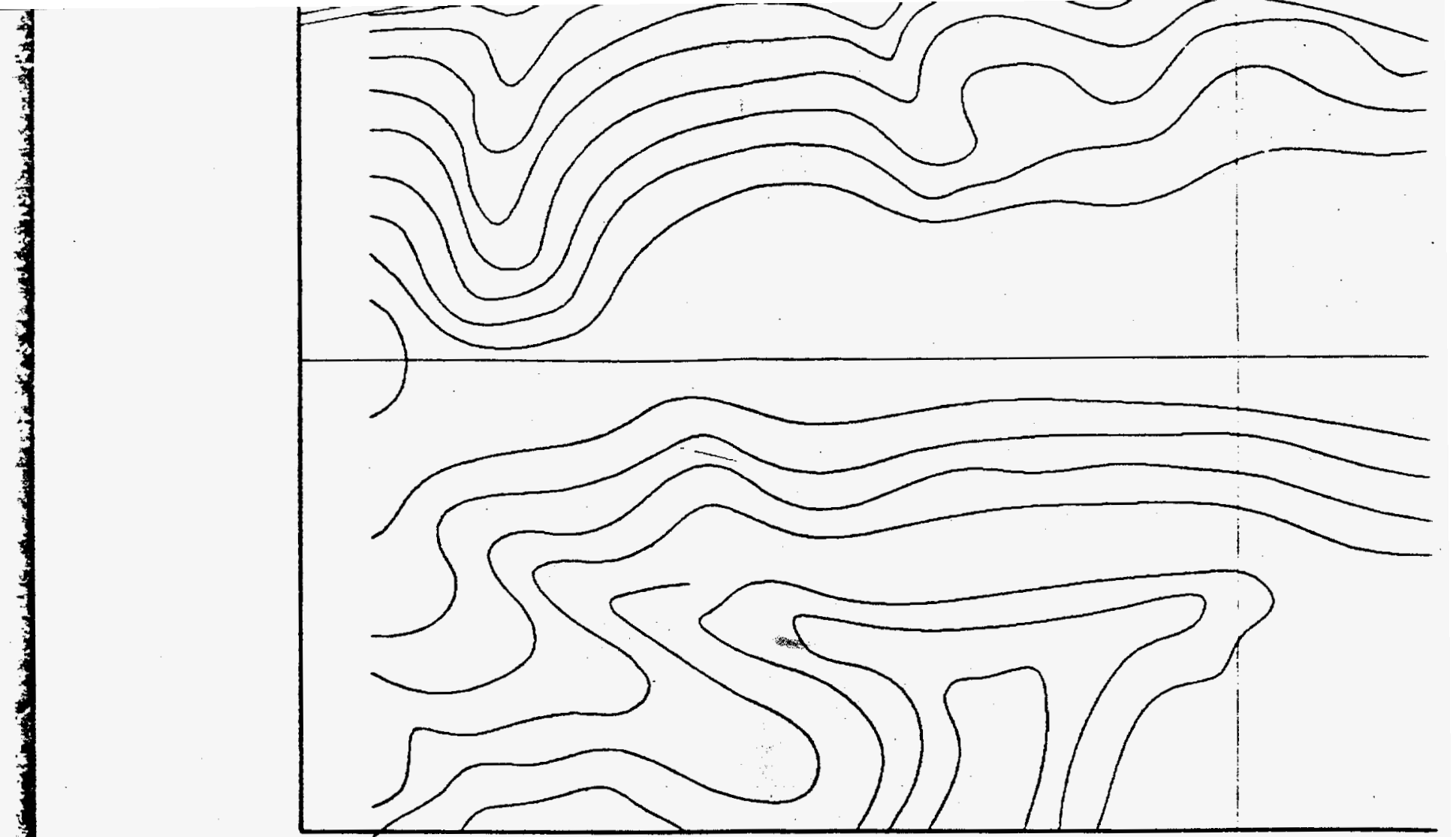

\section{LËGEND}

PROBABLE MAXIMUN

MAXIMUM PROBABLE

500 YEAR FLOOD

100 YEAR FLOOD 


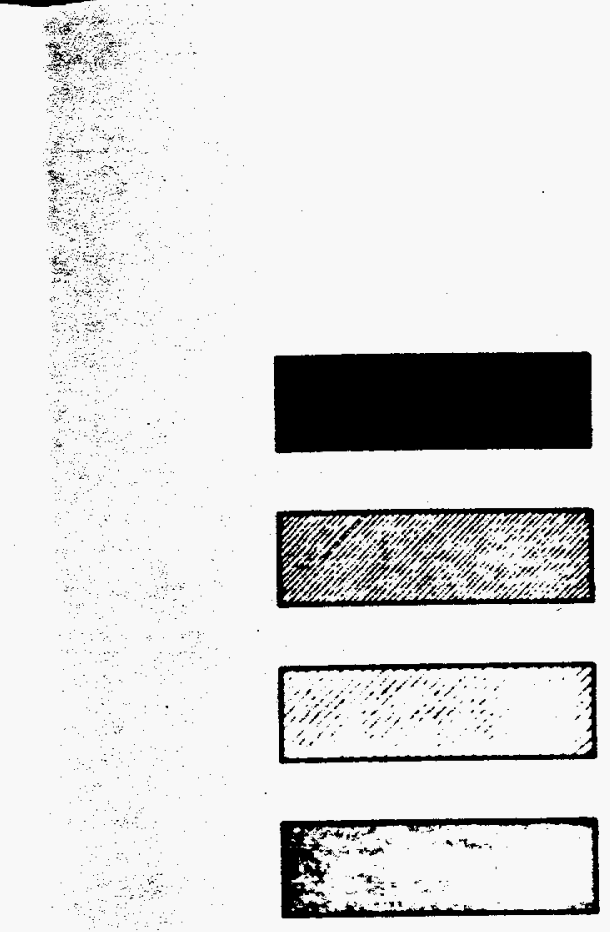




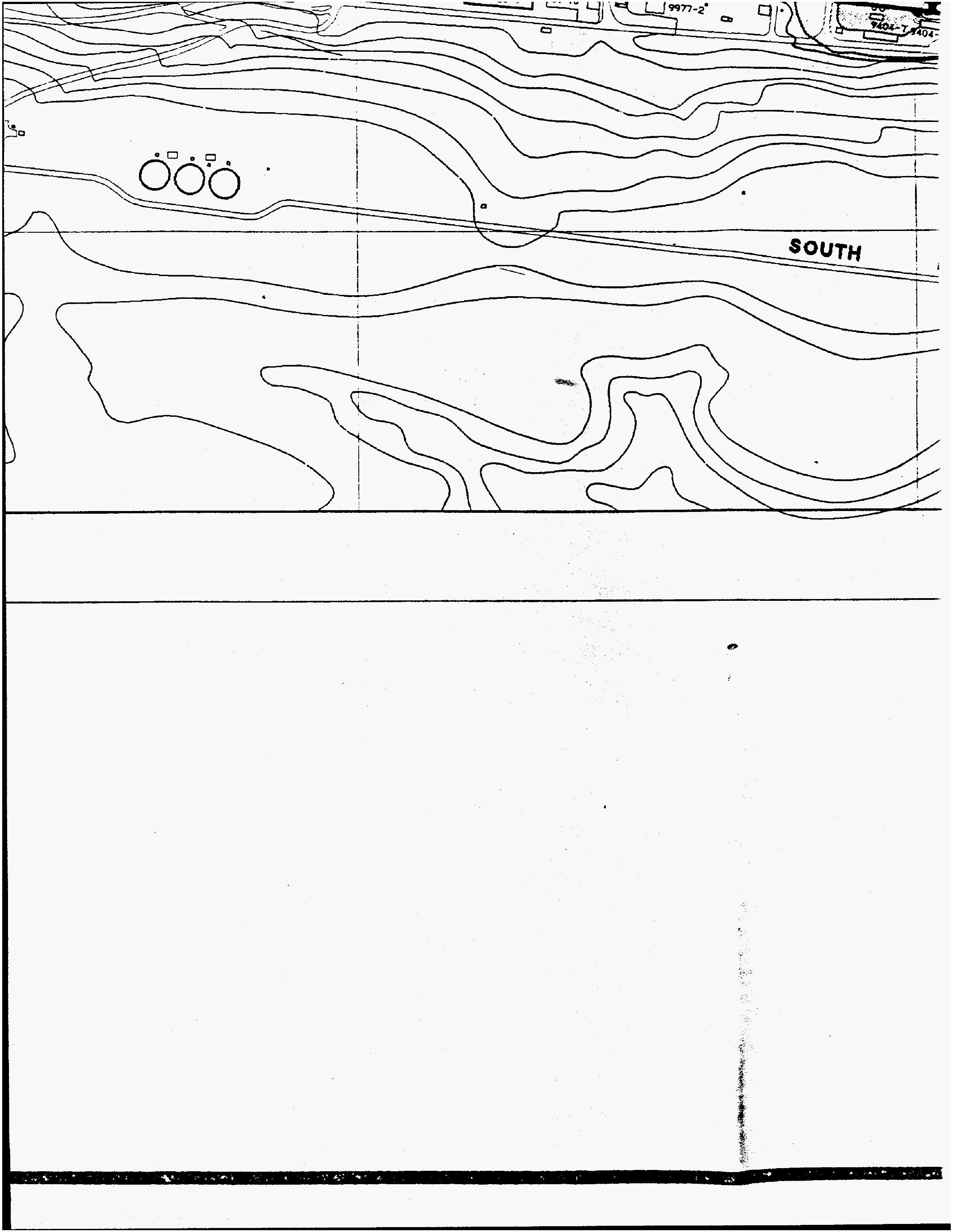




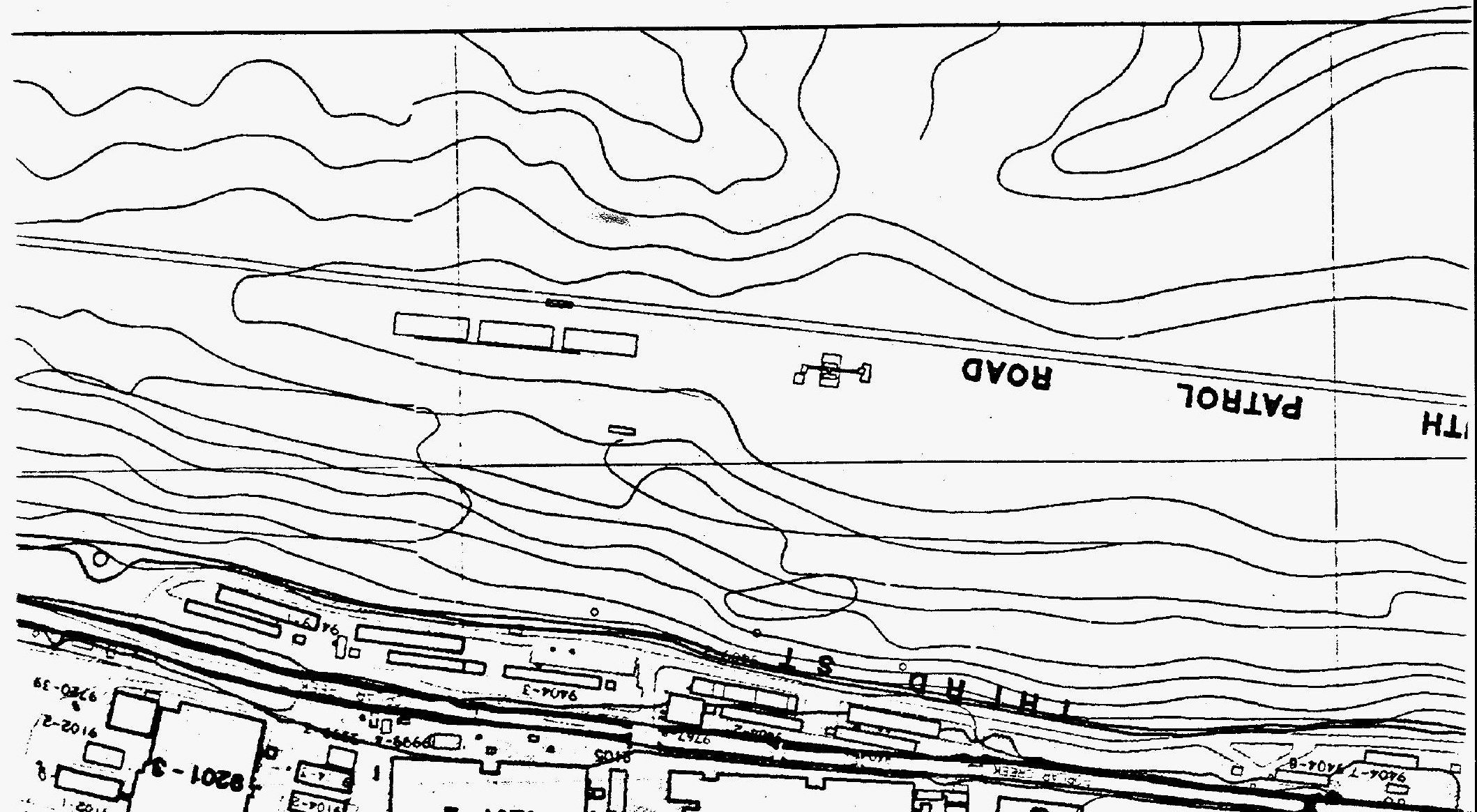




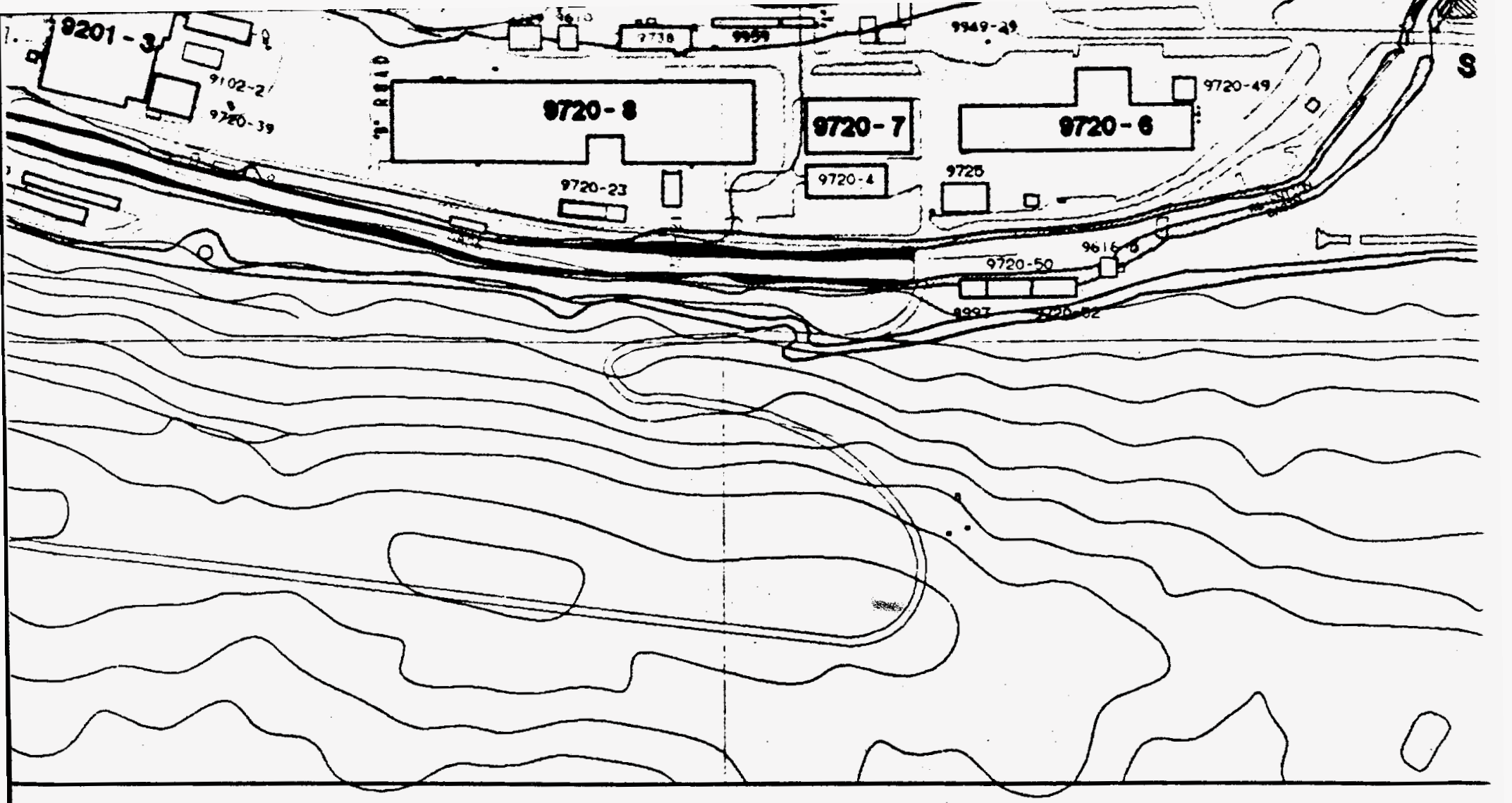


$N-31500$

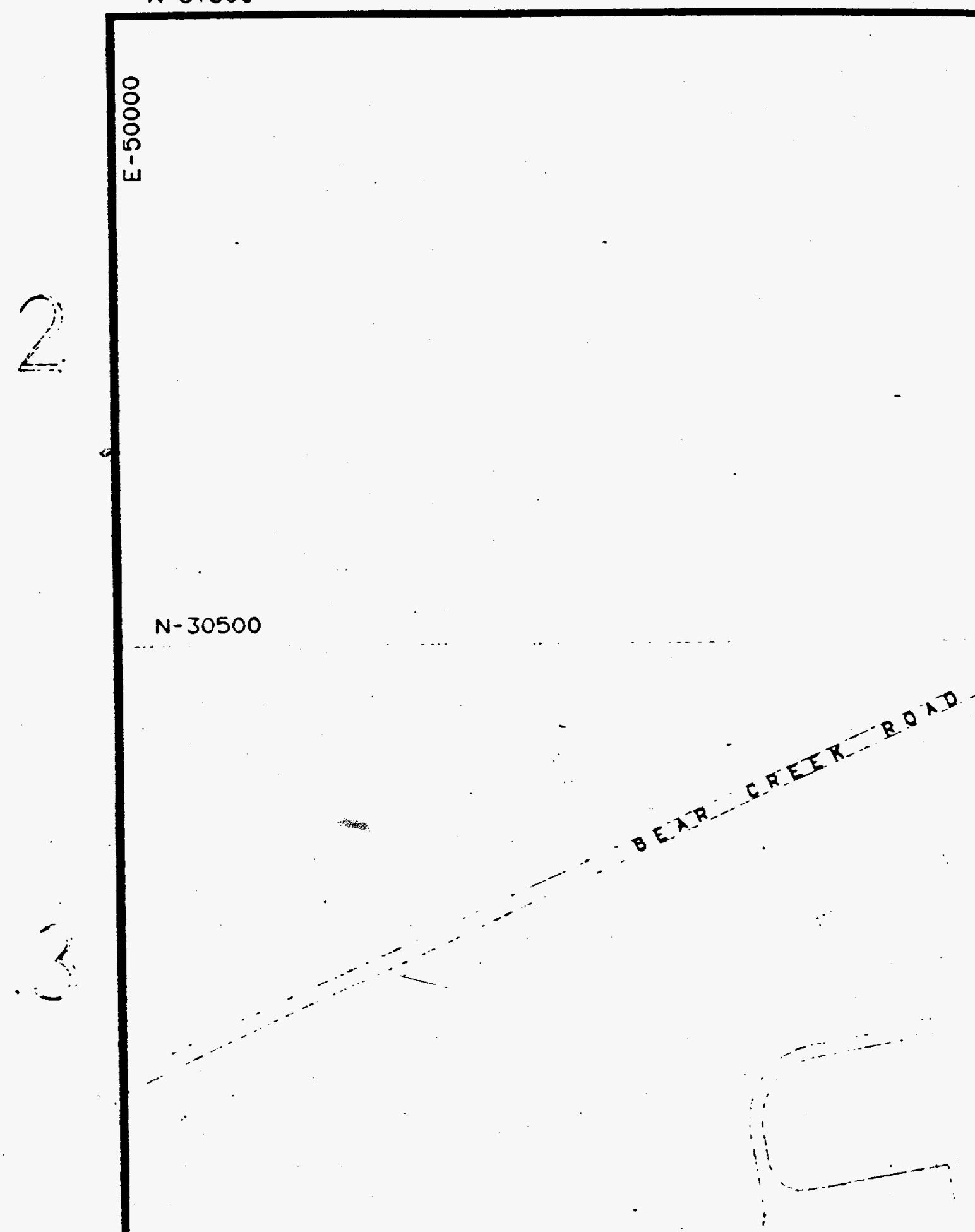

$N-29500$

unte ctones.

,$+\infty 000$ 


\section{F}

8
8
?
!

- PARKING AREA

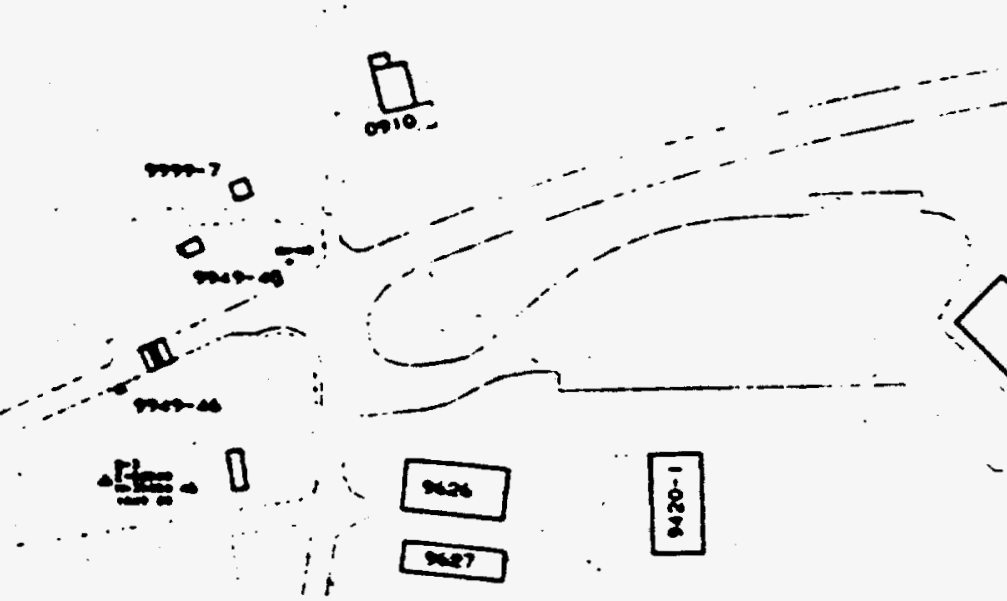

9114

$\infty$

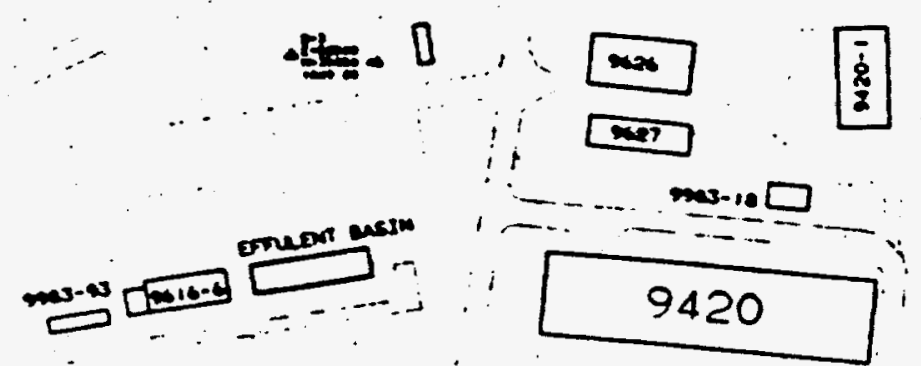

- -

30 is

17s-10
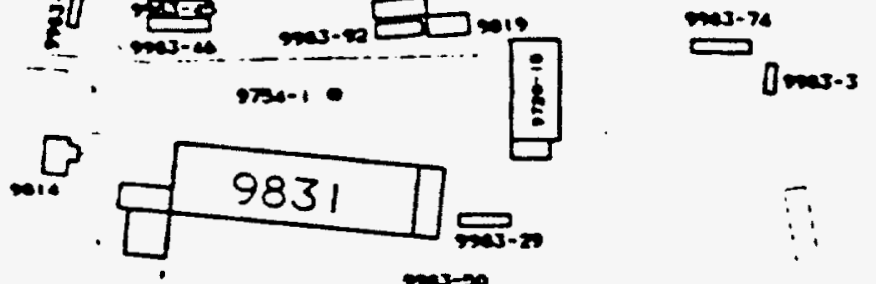

D
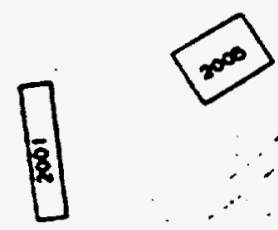

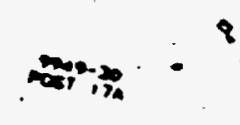

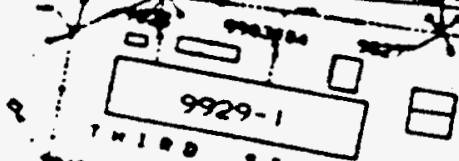

$\underset{\operatorname{mon} 20}{\infty}$

monas
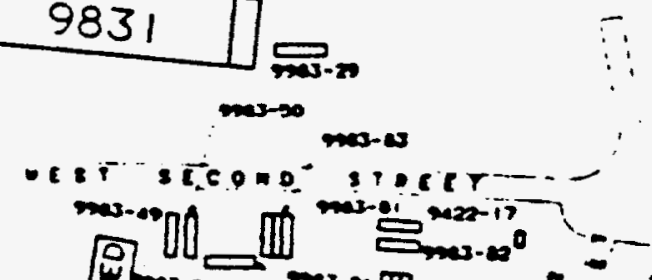


\section{F}

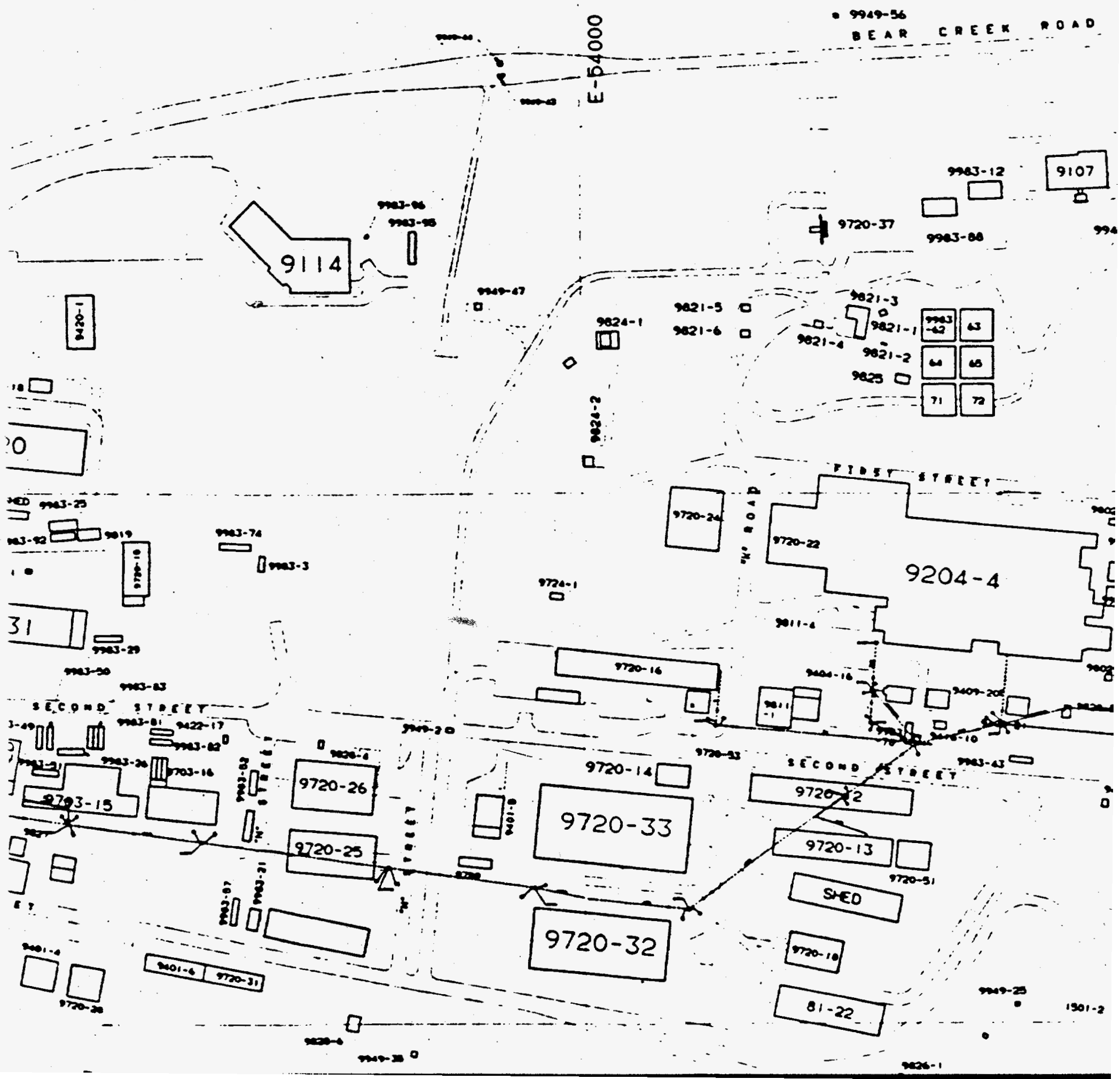




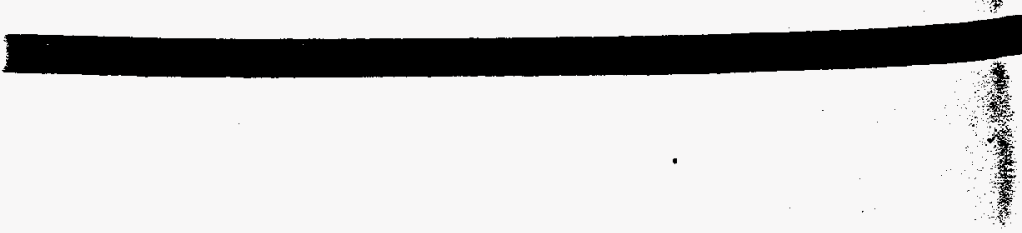

\section{E}

PaAnING area

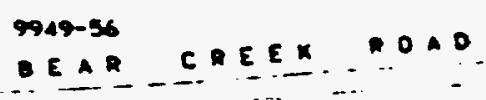
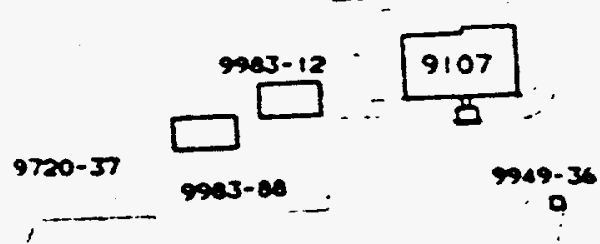

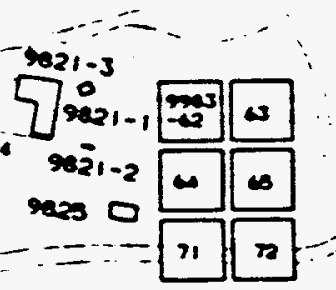

.

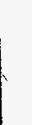

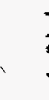




\section{U.}

PARex Ino Maca

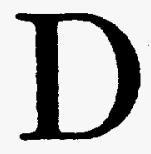

WEST PORTAL

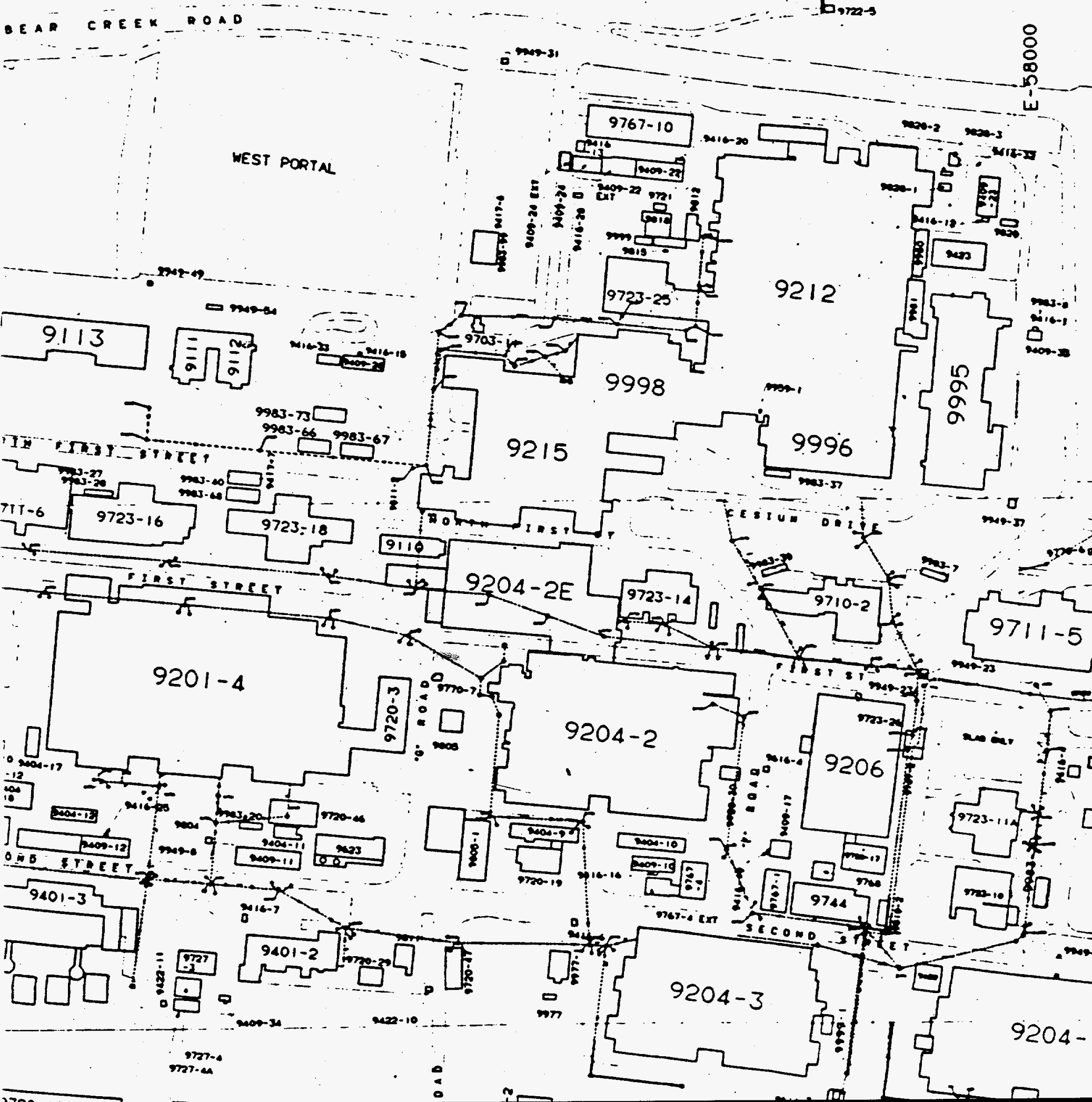




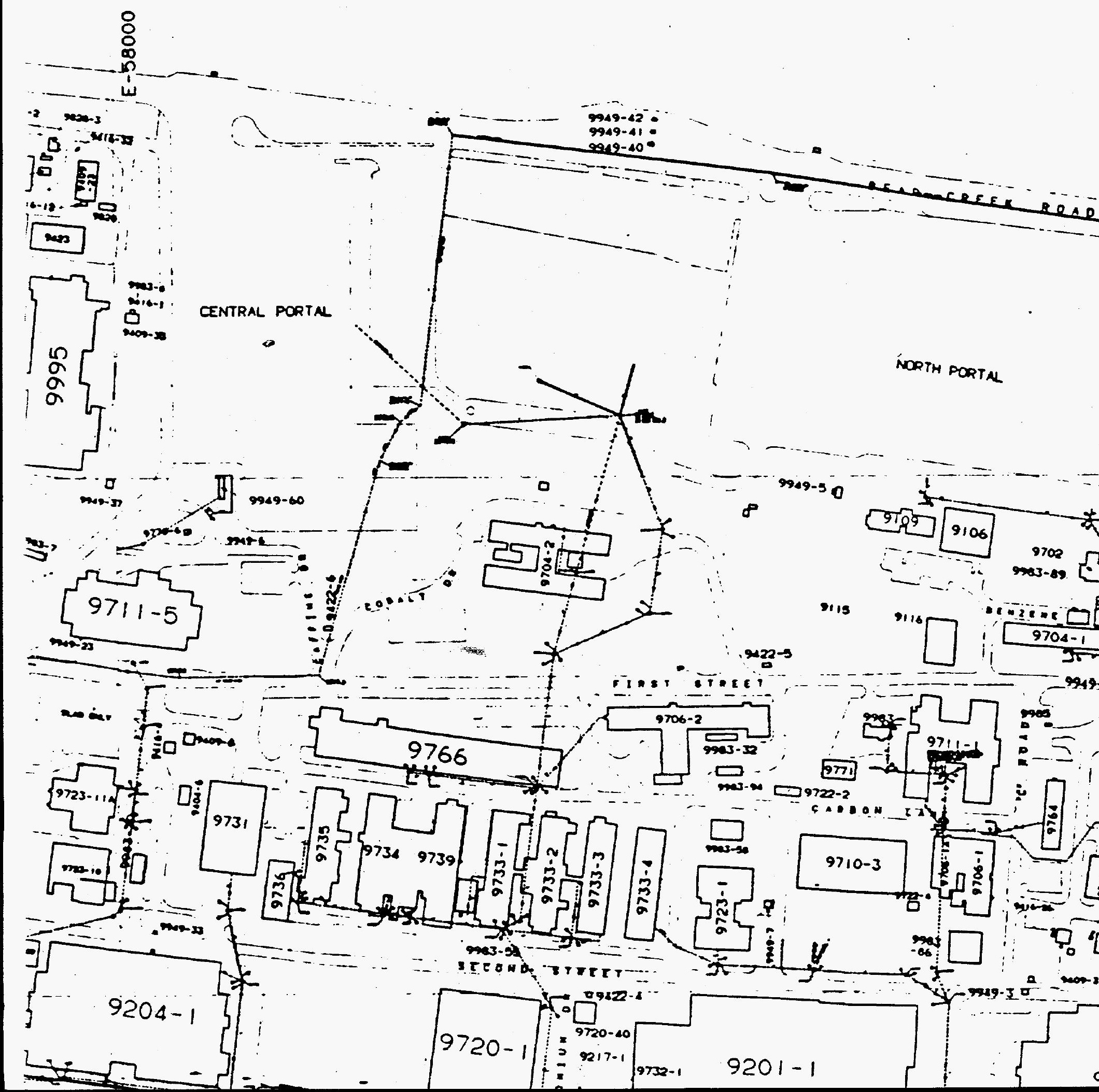




\section{B 。}

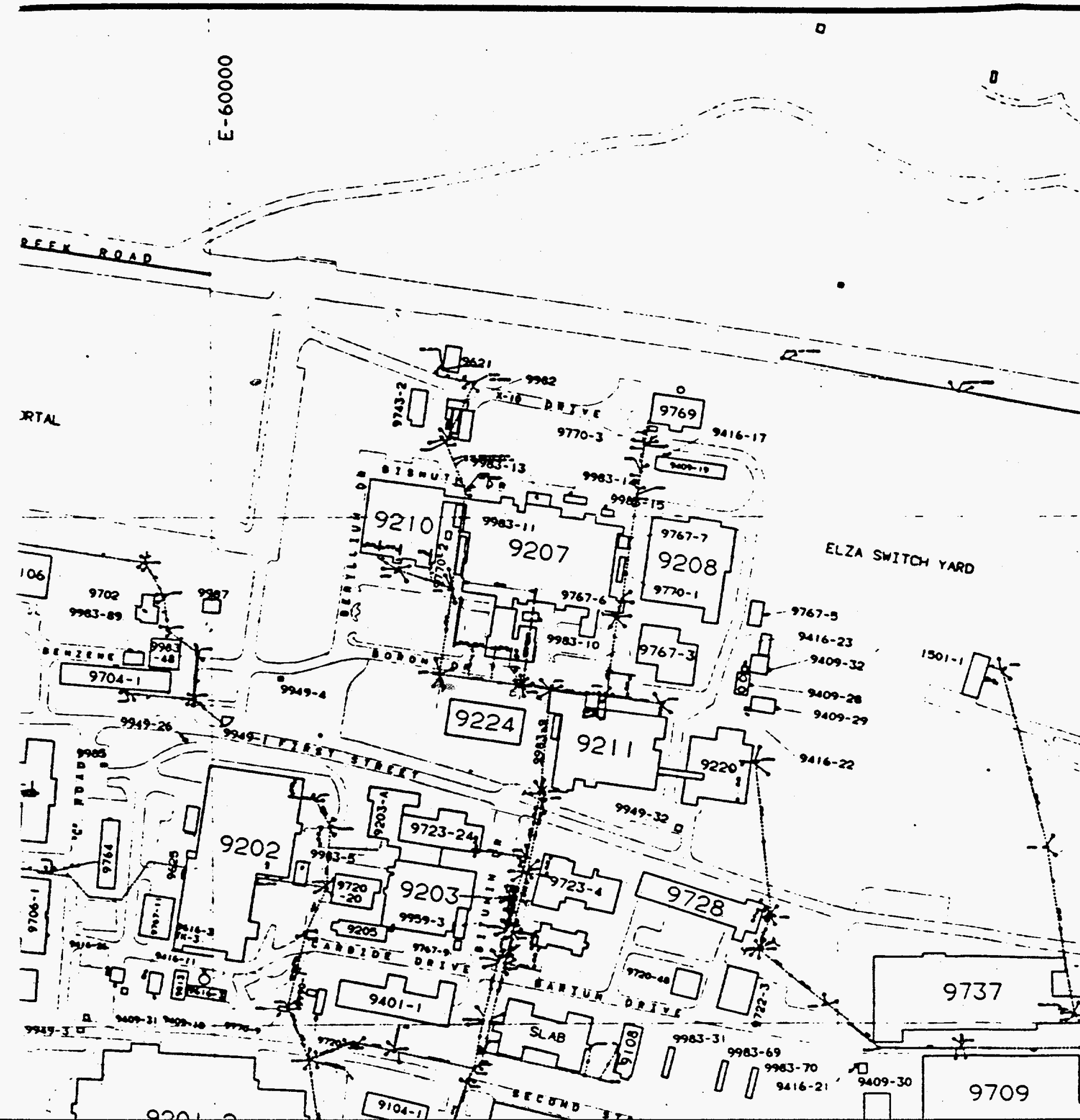




$$
\text { thopt? }
$$

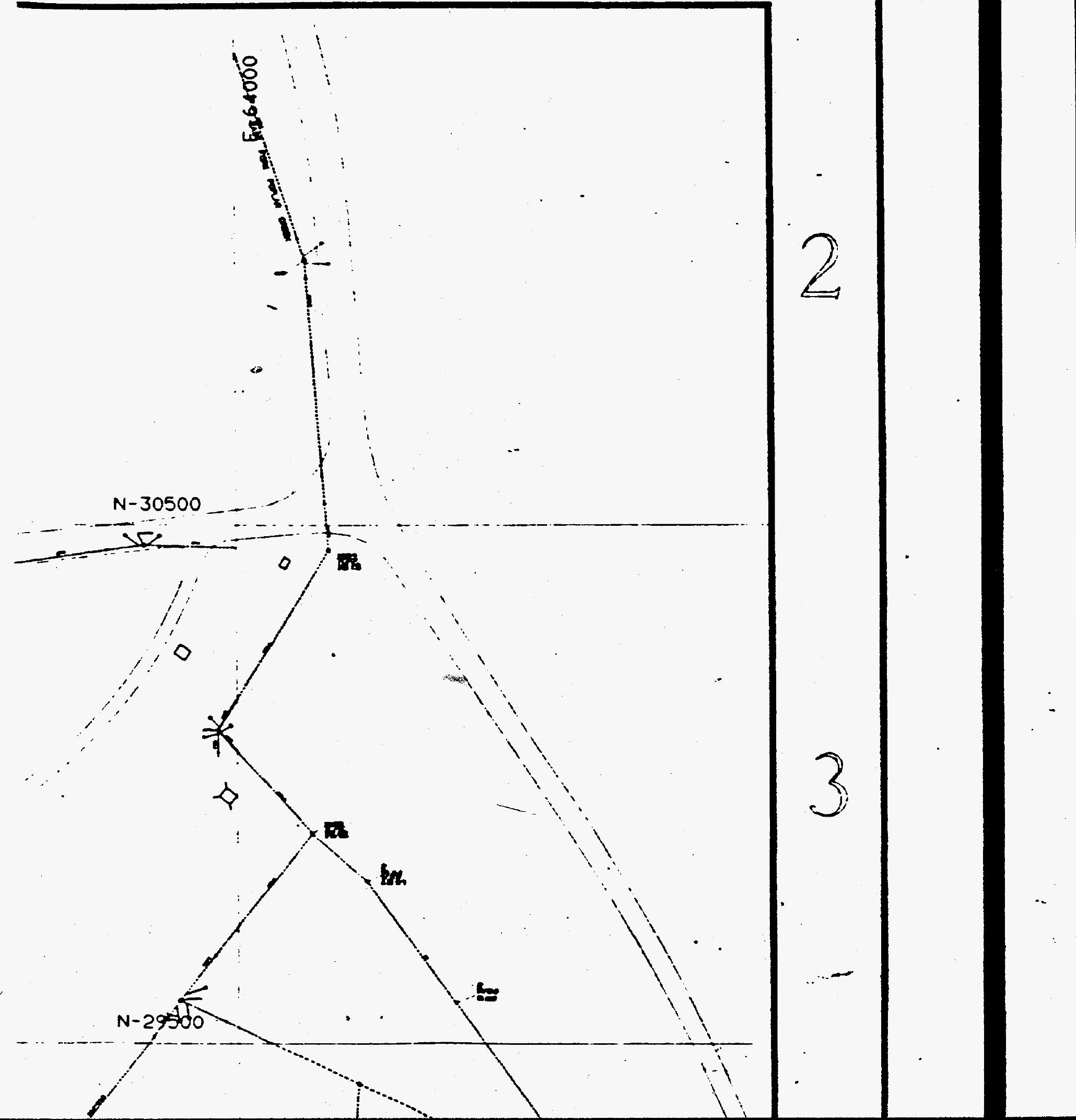


$N-30500$

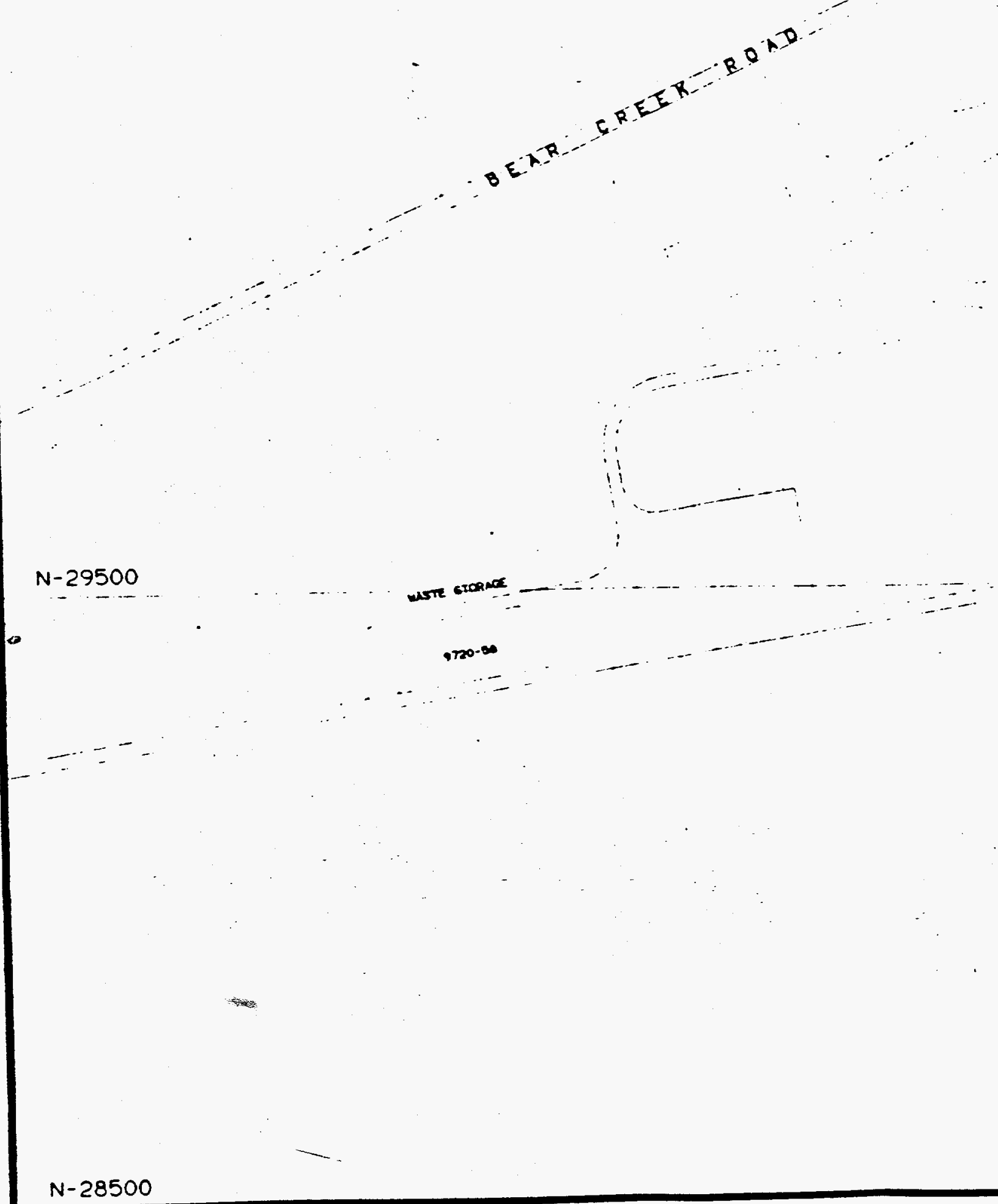



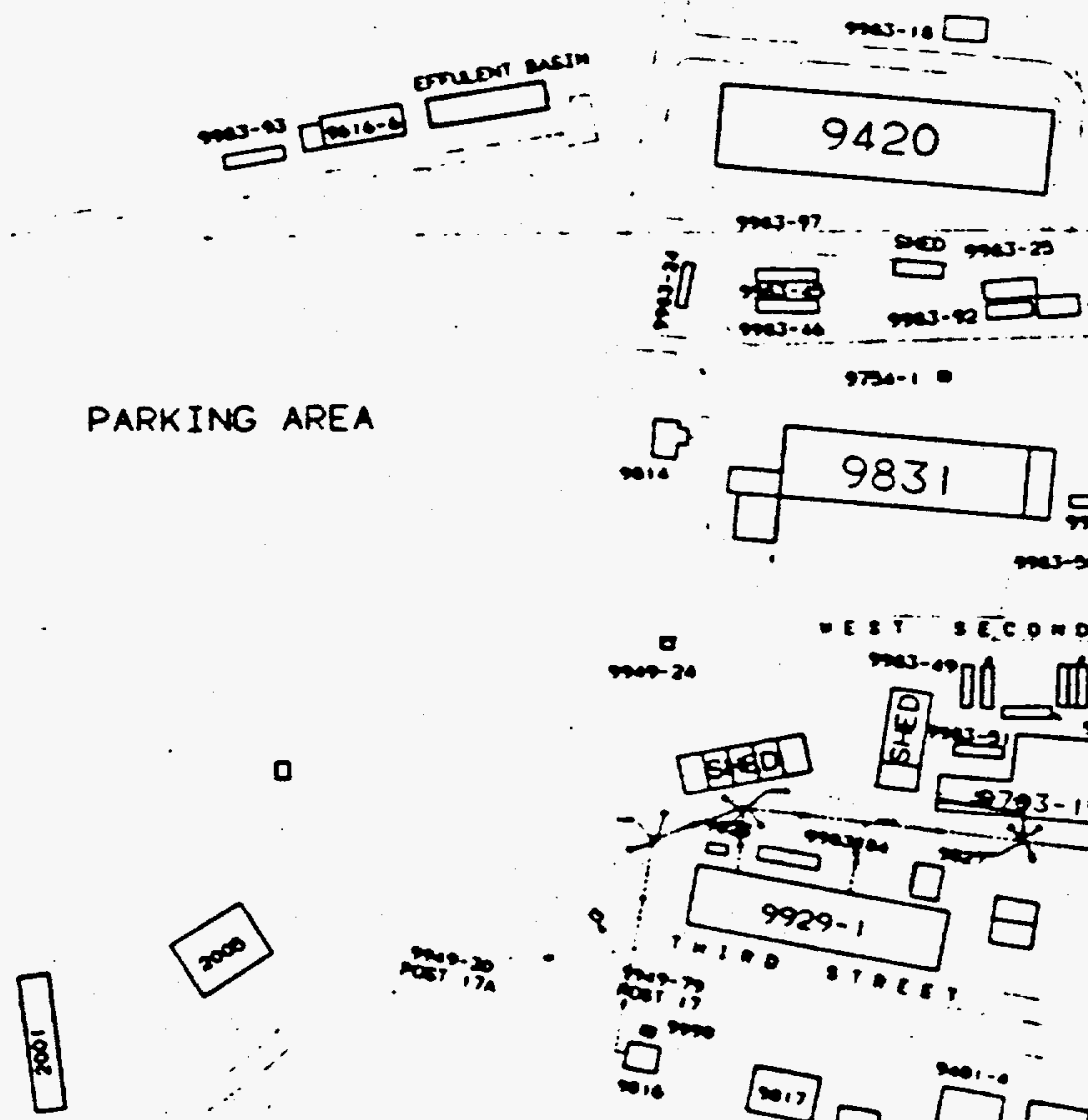

in

PARKING AREA

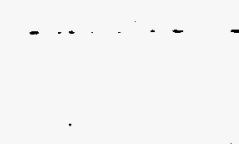

口

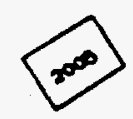

$\lim _{i \infty}^{\infty}$

$\mathrm{B}^{-}$ 97s-1 -

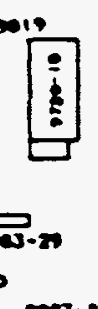

$\sum_{0 \text { mosis-3 }}^{\operatorname{mos}}$

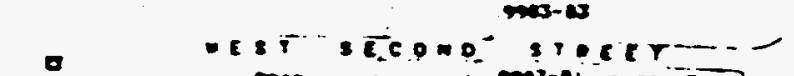

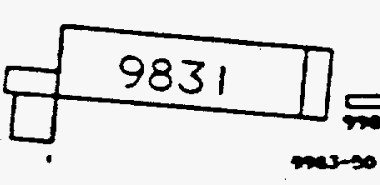

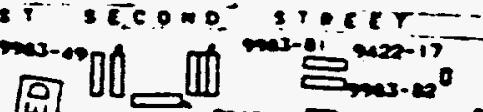

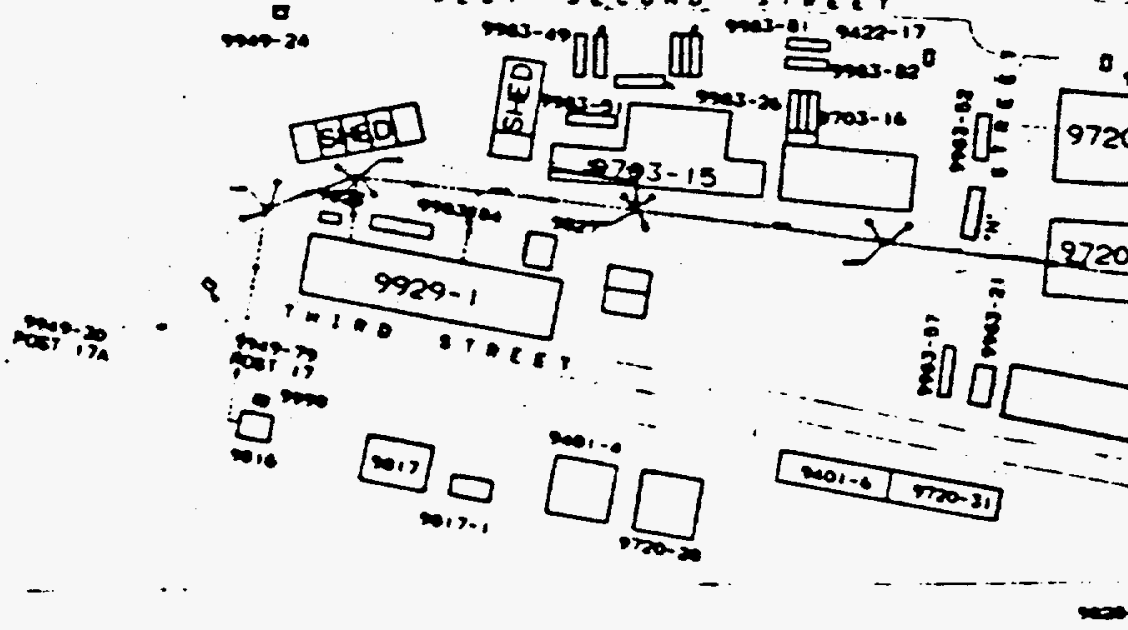

mane

$\square \rightarrow n$

$\bullet$

$\because$

$\because$

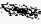

- 949-50 


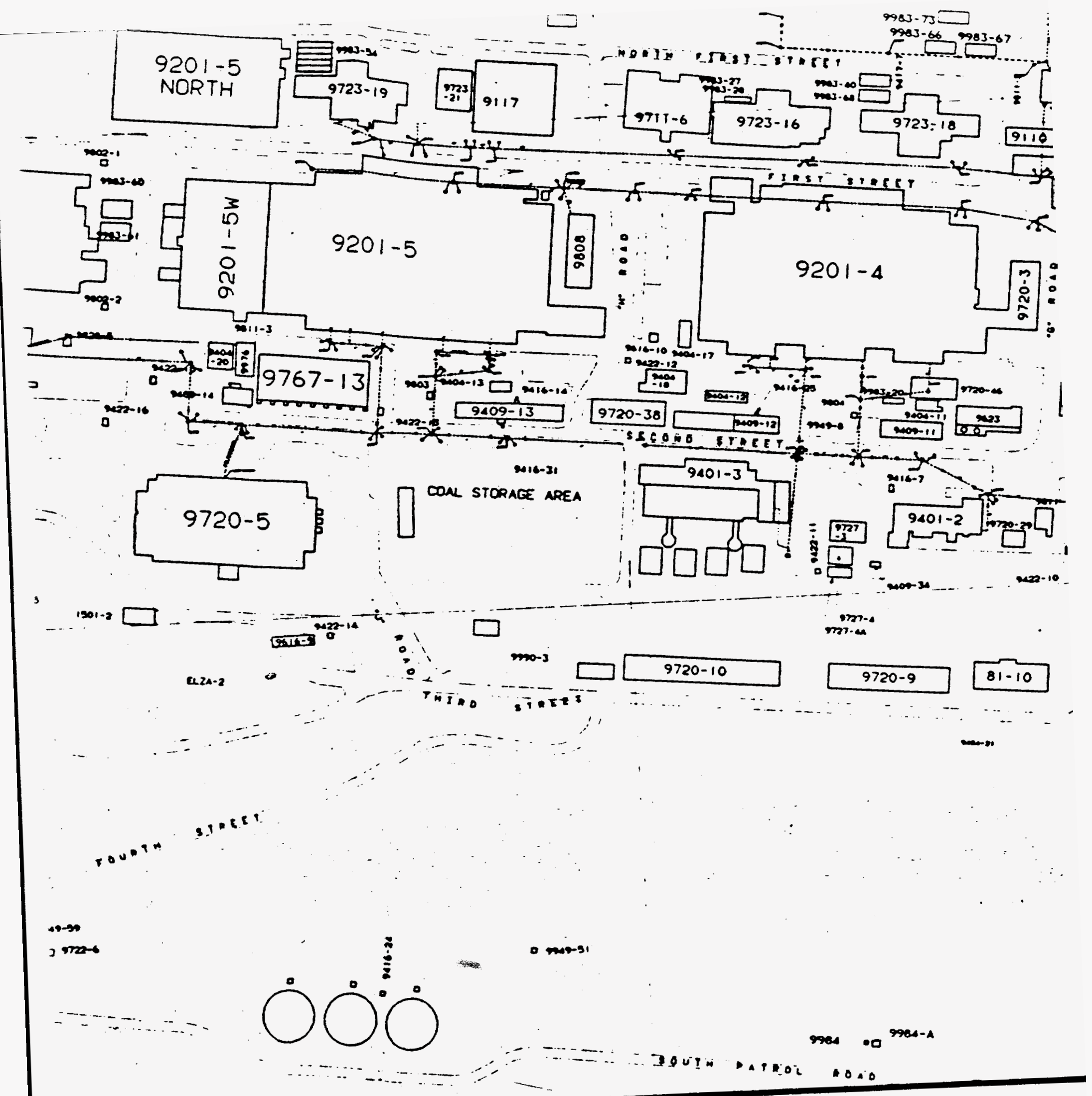




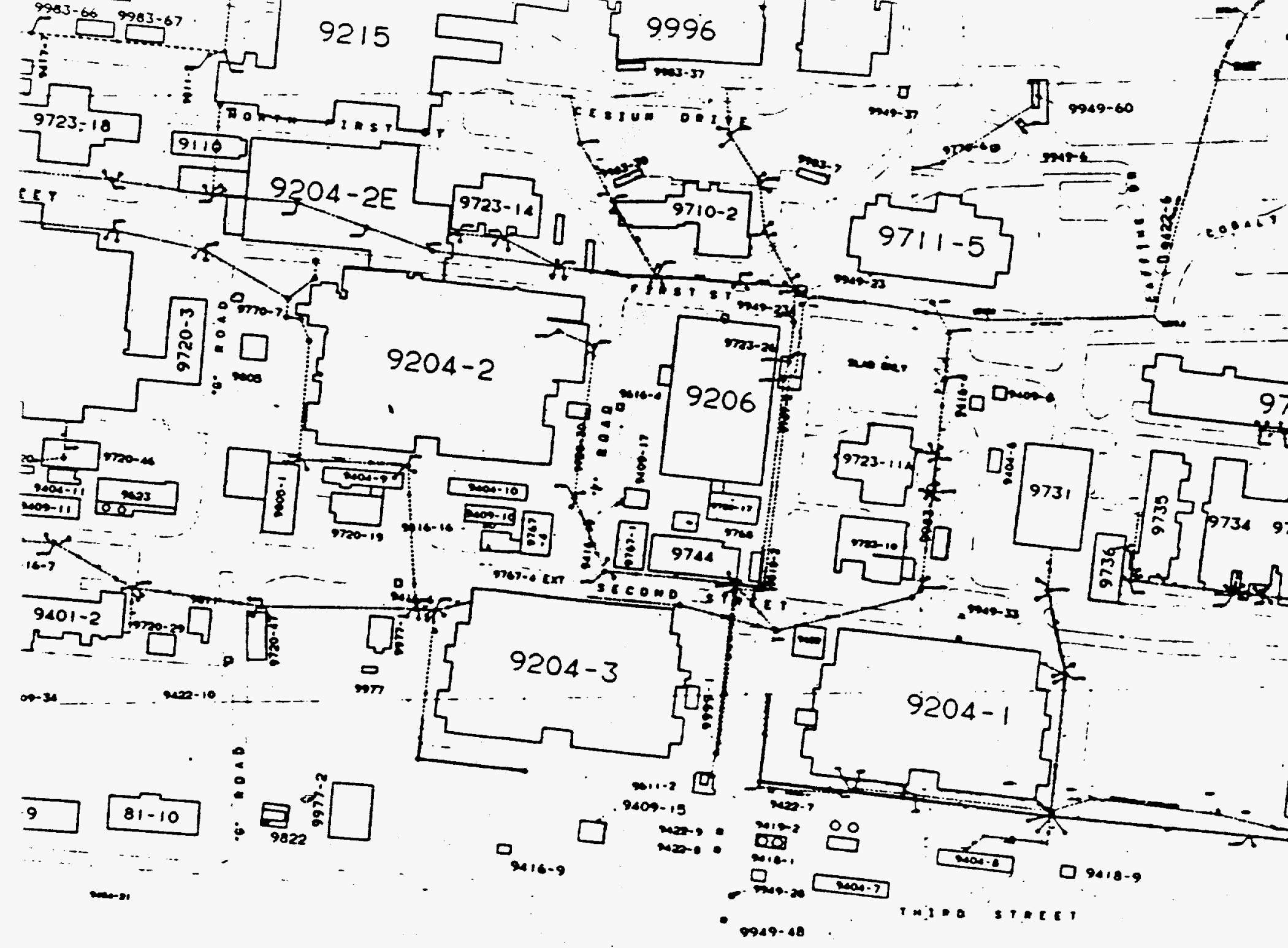




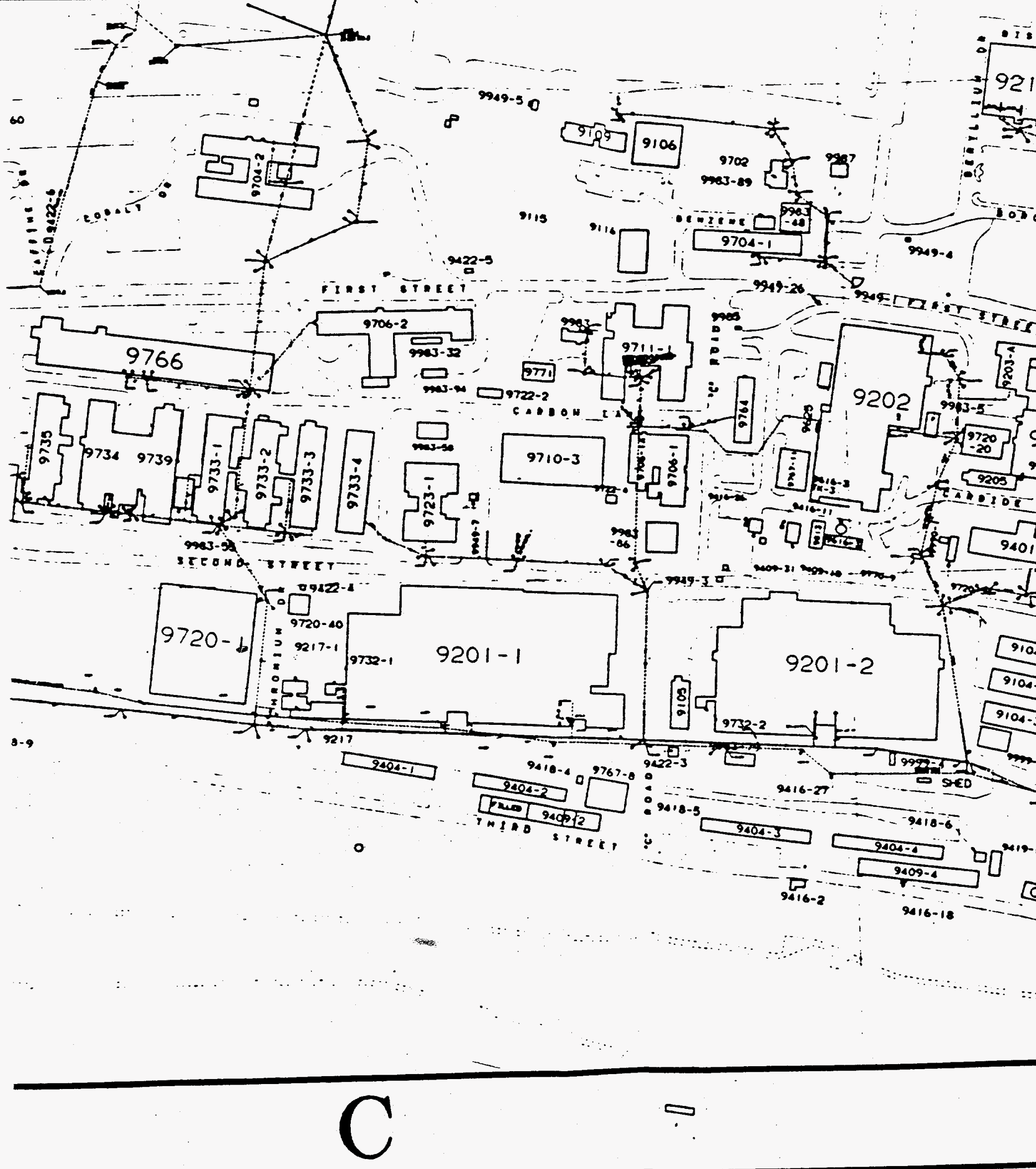




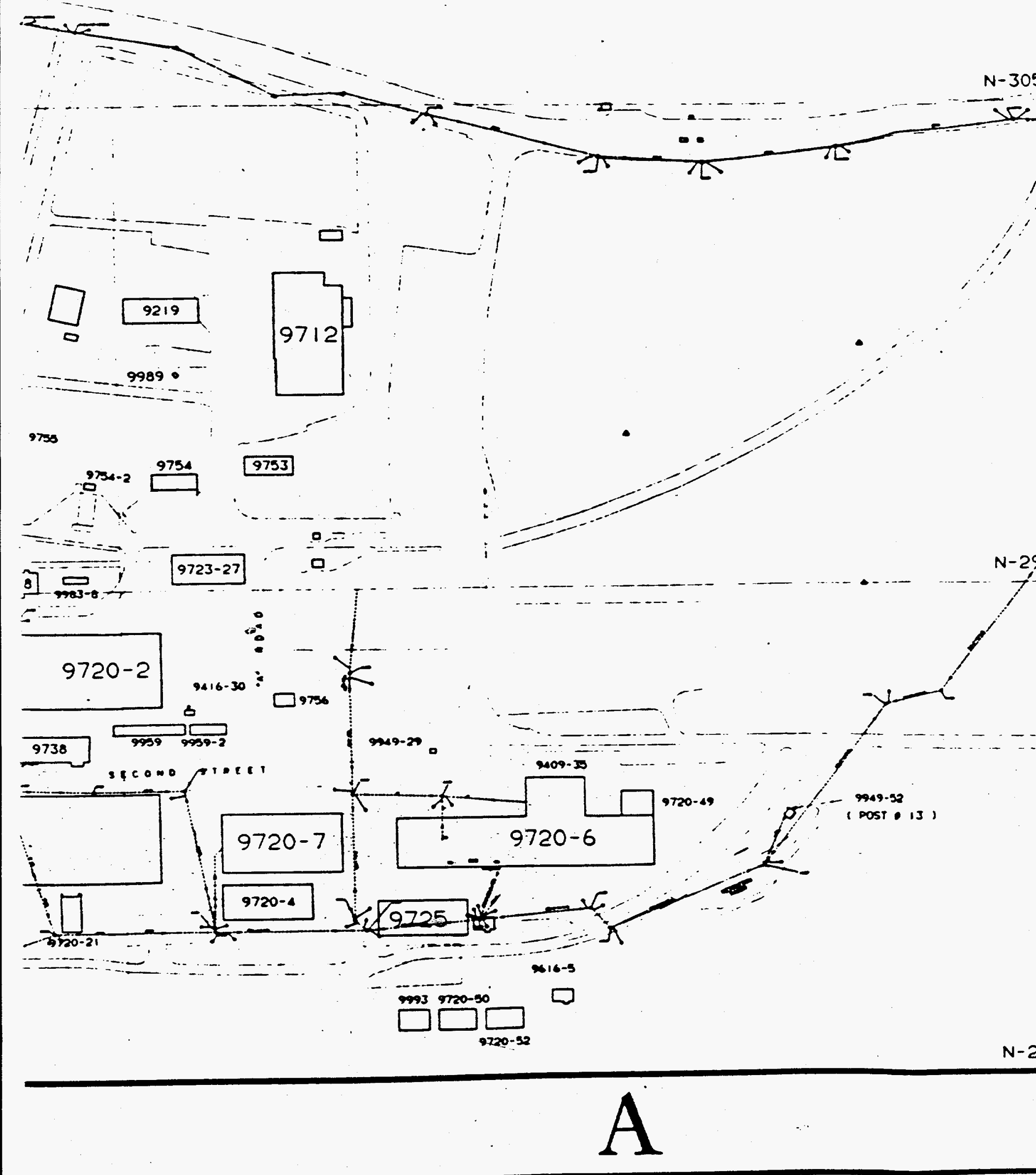




\section{Map 6}

The Y-12 Plant Storm Sewer System Master Plan Map

The Y-12 Plant Storm Sewer System Master Plan Map has been determined by the U.S. Department of Energy to contain UNCLASSIFIED CONTROLLED NUCLEAR INFORMATION (UCNI) and is not to be disseminated to the public. The document must be protected as required in $10 \mathrm{CFR}$ Part 1017 and its implementing orders. Unauthorized dissemination of the material is subject to civil and criminal sanctions under section 148 of the Atomic Energy Act of 1954, as amended (42 U.S.C. 2168).

The Y-12 Plant Storm Sewer System Master Plan Map was submitted as a part of the first revision of this document. If additional copies of this map are needed, please contact B. E. Skaggs at (615) 241-2582. 


\section{tives

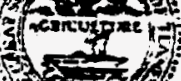 \\ 西

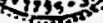 \\ TENNESSEE DEPARTMENT OF CONSERVATION \\ Custors House \\ 701 Broadway \\ Nastrille, IN 37243}

October 24, 1991

Mr. RoberkJ. Spence

Y-12 Site Manager

Department of Energy

P.O. Box 2001

Oak Ridge, IN 37831-8555

RE: Resource Conservation and Recovery Act Part B Permit Maps

Dear Mr. Spence:

The Division of Solid Waste Management is in recelpe of your October 9, 1991, letter requesting a varlance from the mapping scales required in Rule 1200-111-.07(5)(-a) 1.7-of the Tendesse-Hazardous Waste Management Regulations.

Due to the nature of the Department of Energy Reservation at Oak Ridge, tbe Difision of Solld Vaste Management does not foresee any problem with granting this request. You may use the scales that have been requested in your letter.

Please feel free to contact either Bill Krispin or Jackle Okoreeh-Bash if you have any queselons regarding this latter.

Sincerely,

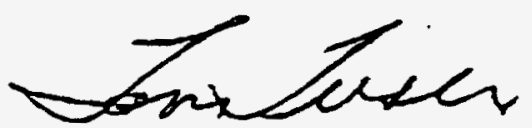

Tom Ifiesler, Direcror

Division of Solid Waste Management

JTF/BK/F1011297

CC: Sherry Lankford, DOE

W111am Brom, MES/Y-12

Gary Bodenstein, DOE

i. G. McYillan, DOE

James Scarbrough, EPA

B111 Krispin; IDEC/SWM

Jackse Okoreeh-Bash, TDEC/SWA

Earl Leming, IDEC 
APPENDIX B-2

WIND ROSES 


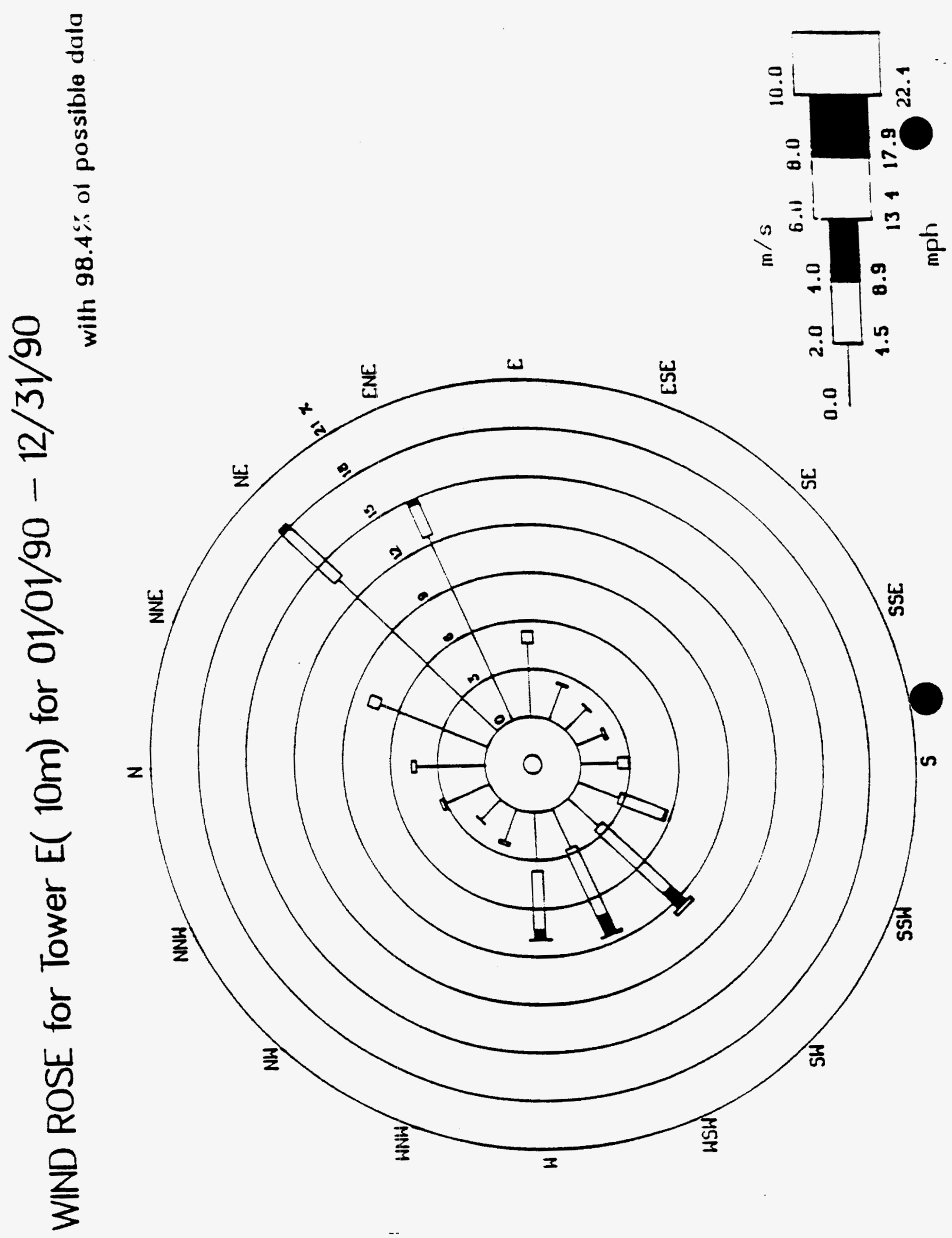


WIND ROSE for Tower E( 30m) for 01/01/90 - 12/31/90

with $\mathbf{9 7 . 8 \%}$ of possible data

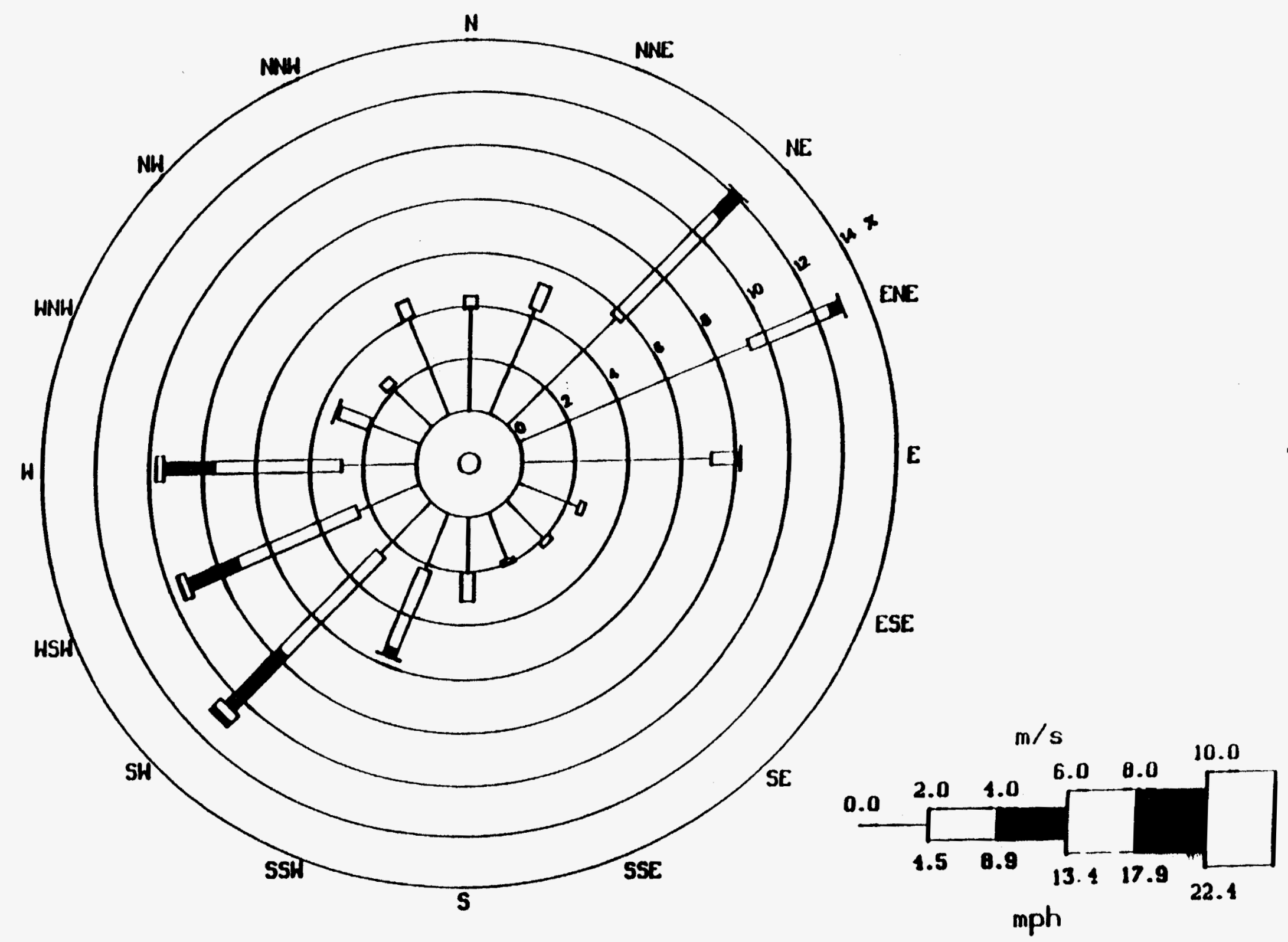




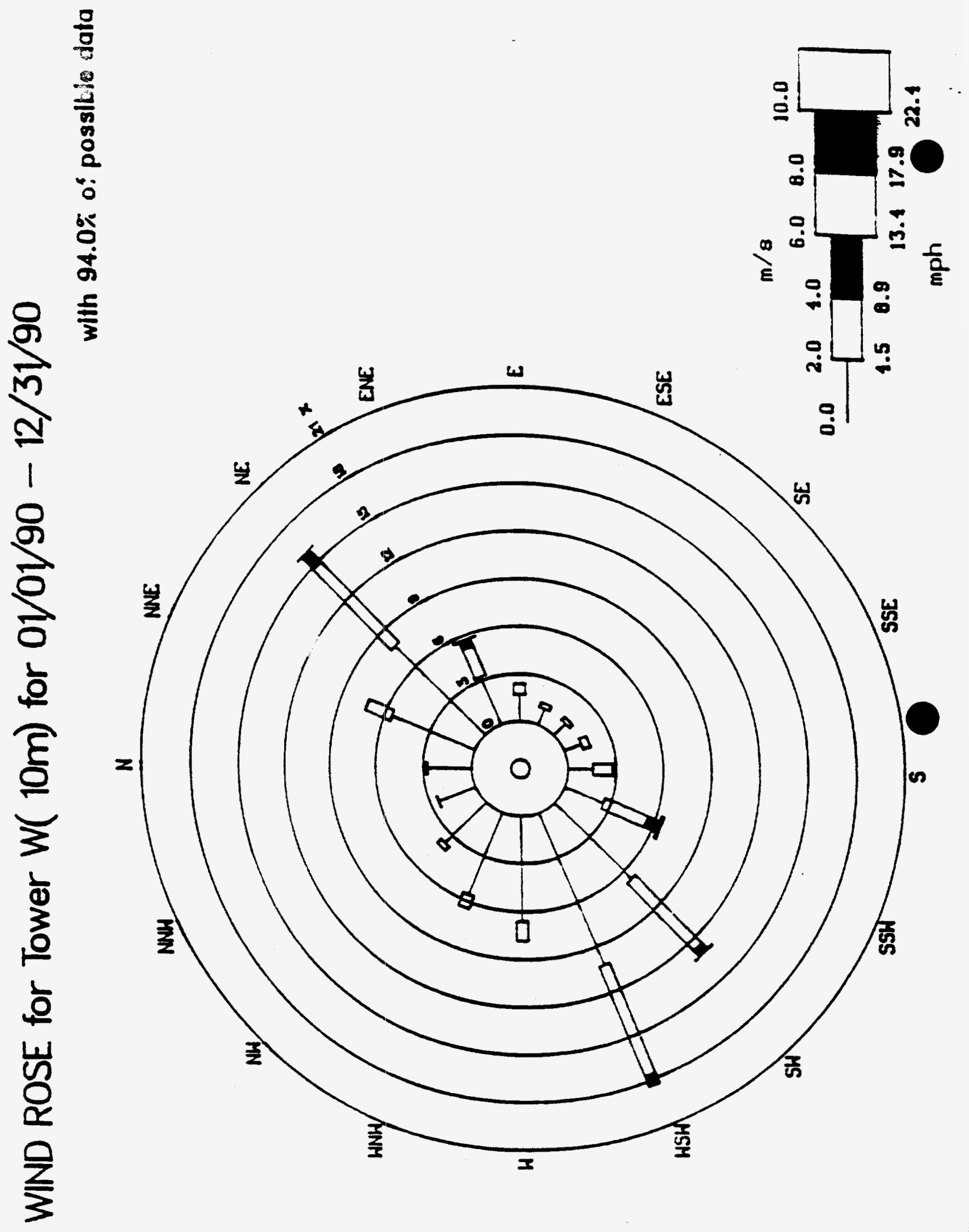




\author{
APPENDIX C-1 \\ WASTE ANALYSES
}


Oak Ridee K-25 site

Anvivtical Chemistry Department

Results of Analyses
Date Printed:

27-ALS-1991 11:

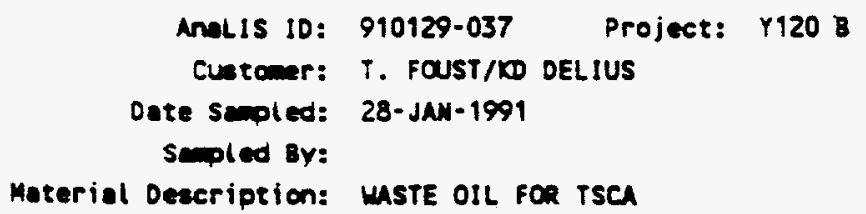

\section{Low}

LaN

TP-0802

Prep (Isotopic, Parr Bonb)

servllius

Thoriun

100014RO

TP-0908

101102 ACD 100014

HPAT 15

$176907 T P-176907$
$T P-176907$

Prep (lsotopic)

Prep (Isotopic)

\$81702 TP- 181702

TP- 181702

Parr Bomb Ureniu

Parr Bam Ureniu

183702 TP- 183702

TP- 183702

Uraniun Fluoranetric

Uraniu Fluorametric

186802 EPA- 1010

Flash Point Closed Cup

$<0.058$

$<38$

$c$

c

C

c

c

$<$

2

$>145$

Archive

R1151

205109 TP-2051

210102 TP-2116

TP-2116

Uranica-235

Uranium-235
Lor $U+1-$

Lor $u+1-$ $\infty / 9$

ML BAIN

$\operatorname{ug} / 9$

ML BAIN a

File Nuber Completed
Dete
onpleted

$6-F E B-199$ 6-FEB-199

20-mar-199

20-MAR-19S

$10320 A$

10307E

19-MRR-19

RM SALIMAS $\quad X X$

30- JAN -

30- JAN-19

$99-30$

$91-30$

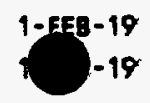

5-FEB-19

5-FEg-19

ug/9 CL NILLIS 91-K27

degrees F

$91-11$

$5-F E B-19$

K10040797

CL MONROE

205109

$4-M A Y-19$

Weight $x$

$x x \times x$

$x \times x x$
6-FEB-15 $6-F E B-15$ 
Anal 1s 10: $910129-037$

Laboratory: Gas / Liquid Chromatogrechy Laboratory

File 10: GC 0449

Instrument 10:

Authorized By: D. S. ZIMCG

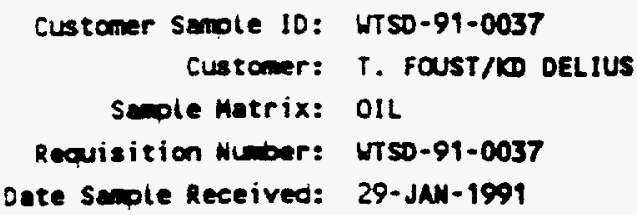

PCE (TCL) OIL

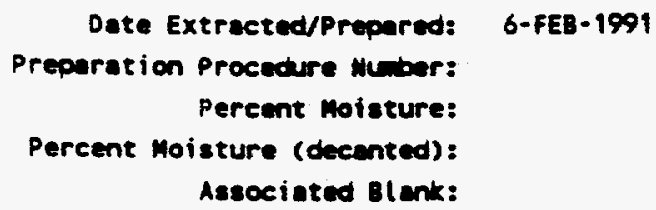

\section{Date Reporting cullifiers:}

U - Compound we envireed for but not detected. The muber is the ettainable detection liait for the saple.

8 - Analvte was found in the reagent blenk as wll as the semple.

$d$ - Indieates en estimeted value.

No - Mot detected.

A - Aldol condeneation product.

D - Secondary dilution.

E - Exceeds initial celibration range. 
APPENDIX C-2

WASTE IDENTIFICATION FORMS 
WASTE ITEM IDENTIFICATION

\begin{tabular}{l|l}
\hline ste Item ID Number & D. Generator's Name (Print
\end{tabular}
I3. Badge No. 14. Generator's Phone No. 15. MS

I11. Origin Roomi Area
16. Charge NumberiWO

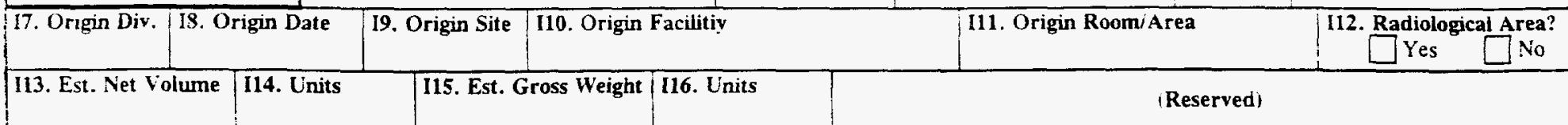

CONTAINER INFORMATION ( 1 of ) If more than one attach Waste Container List (UCN-2109A)

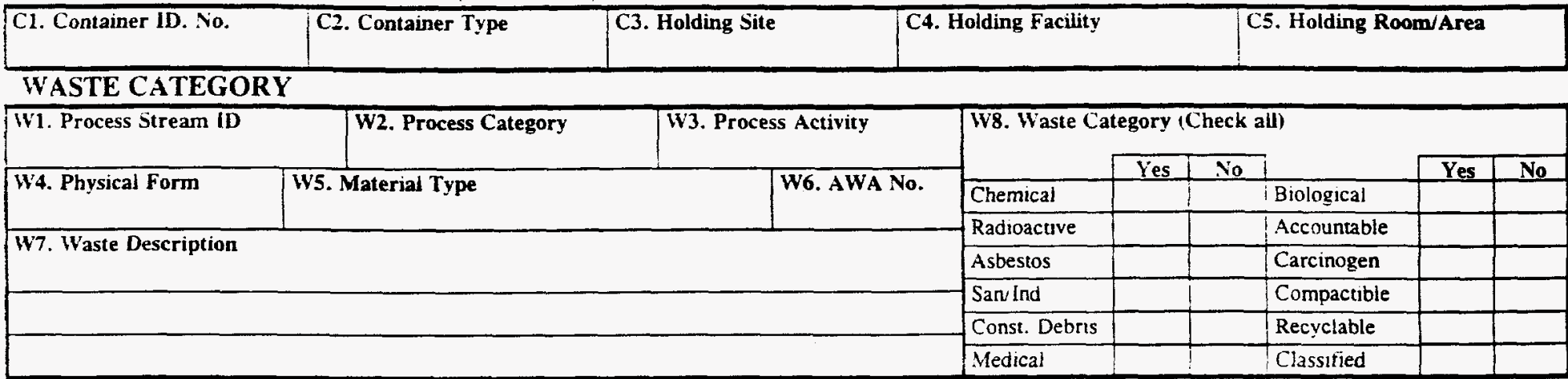

CHEMICAL WASTE
M1. RCRA?
M2. RCRA 90-day Start Date
M3. PCB?
$\square$ Yes $\square$ No
M4. PCB Start Date
M5. PCB Conc. (PPM)
$\square$ Yes $\square$ No
M7. Determination Document Number(s)
M6. Determination Method (Check ONE)
$\square$ Analysis
Process Knowledge
$\square$ Reference
M10. EPA Waste Code Numbers
M8. Flash Pt. M9. pH

*11SUbostance ID

111\%1/1\%

M13. Substance rane

RADIOACTIVE WASTE

R1. RAD Category (Check ONE)

$\square$ TRU $\square$ High-Level

R4. Determination Method

(Check ONE)

$\square$ Analysis

$\square$ Process Knowledge

$\square$ Reference

R6. Chemical Form
R2. RAD Handling Type

$\square$ Contact $\square$ Remote
R3. UCN 2681 No.

\begin{tabular}{|c|c|c|c|c|c|c|c|c|}
\hline R7 Isotope & R8. Est Qty & R9. Units & $\mathrm{ATPLOHan}$ & Ro $\mathrm{Rst} / \mathrm{O}$ & 29. Units & R7 Isotope & R8, Est $\mathbf{Q u}$ & no volls \\
\hline & & & & & & & & \\
\hline & & & & & & & & \\
\hline & & & & & & & & \\
\hline
\end{tabular}

HANDLING INFORMATION

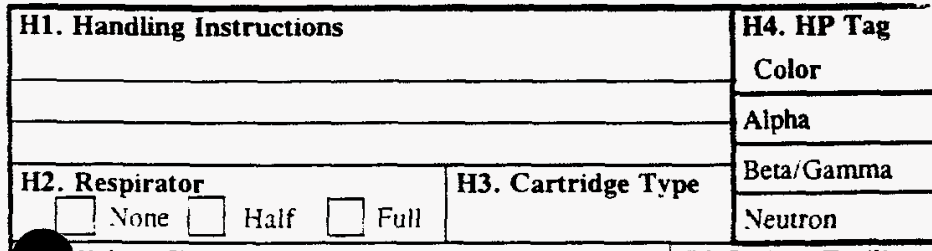

ckup Site

H6. Pickup Facility

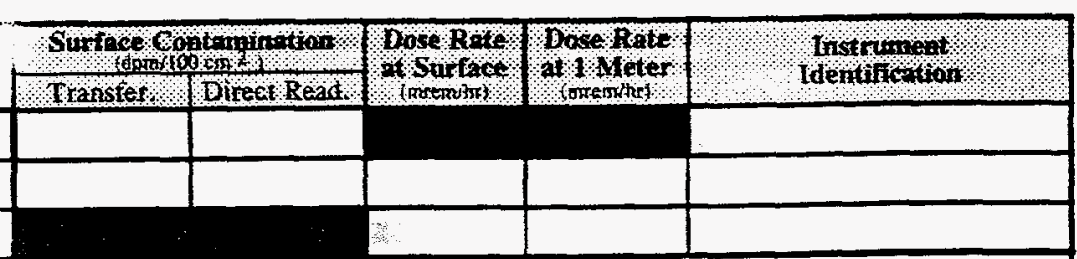

H7. Pickup Area

SIGNATURES and APPROVALS

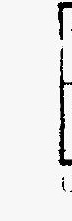

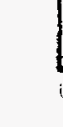

Si. Generator

S3. Verification Officer

Badge

Date

CN-2109 (i23 8-93) 


\section{(Continuation Page of \\ Referenced from WID (UCN-2109)* \\ \begin{tabular}{|l|l}
\hline I1. Waste Item ID Number & C1. Container ID. No.
\end{tabular}}

Jequence
Number
1
*ALL WASTE ITEM/CONTAINERS ON THIS FORM

HAVE THE SAME CHARACTERISTICS AS

ITEM/CONTAINER NUMBER 1

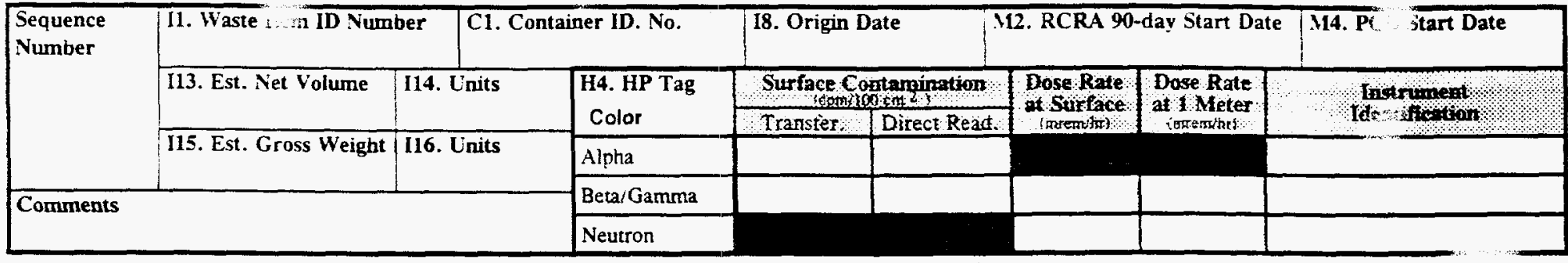

\begin{tabular}{|c|c|c|c|c|c|c|c|c|c|}
\hline \multirow{4}{*}{$\begin{array}{l}\text { Sequence } \\
\text { Number }\end{array}$} & \multicolumn{2}{|c|}{ 11. Waste Item ID Number } & \multicolumn{2}{|c|}{ C1. Container ID. No. } & \multicolumn{2}{|c|}{ 18. Origin Date } & \multicolumn{2}{|c|}{ M2. RCRA 90-day Start Date } & \multirow{3}{*}{ M4. PCB Start Date } \\
\hline & \multirow[t]{2}{*}{ I13. Est. Net Volume } & \multirow{2}{*}{\multicolumn{2}{|c|}{ 114. Units }} & \multirow{2}{*}{$\begin{array}{l}\text { H4. HP Tag } \\
\text { Color }\end{array}$} & \multicolumn{2}{|c|}{ Sur fice Contanimation: } & \multirow{2}{*}{$\begin{array}{l}\text { Dose Rate. } \\
\text { of Surface } \\
\text { (t)rethit) }\end{array}$} & \multirow{2}{*}{$\begin{array}{l}\text { Dose Rate } \\
\text { at I Meter } \\
\text { (Atrenthitf }\end{array}$} & \\
\hline & & & & & Transterto & Direct Read: & & & \\
\hline & 115. Est. Gross Weight & \multicolumn{2}{|c|}{ I16. Units } & Alpha & & & & & \\
\hline Comments & & & & Beta/Gamma & & & & & \\
\hline
\end{tabular}

\begin{tabular}{|c|c|c|c|c|c|c|c|c|}
\hline \multirow{3}{*}{$\begin{array}{l}\text { Sequence } \\
\text { Number }\end{array}$} & \multicolumn{2}{|c|}{ I1. Waste Item ID Number } & C1. Container ID. No. & \multicolumn{2}{|c|}{ 18. Origin Date } & \multicolumn{2}{|c|}{ M2. RCRA 90-day Start Date } & \multirow{2}{*}{$\begin{array}{l}\text { M4. PCB Start Date } \\
\text { Prow }\end{array}$} \\
\hline & 113. Est. Net Volume & I14. Units & $\begin{array}{l}\text { H4. HP Tag } \\
\text { Color }\end{array}$ & Sirface & Them & $\begin{array}{l}\text { Doserate } \\
\text { fonsanht }\end{array}$ & 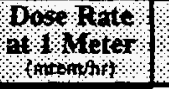 & \\
\hline & 115. Est. Gross Weight & I16. Units & Alpha & & 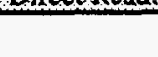 & & & \\
\hline \multirow[t]{2}{*}{ Comments } & & & Beta/Gamma & & & & & \\
\hline & & & Neutron & & & & & \\
\hline
\end{tabular}

\begin{tabular}{|c|c|c|c|c|c|c|c|c|}
\hline \multirow{4}{*}{$\begin{array}{l}\text { Sequence } \\
\text { Number }\end{array}$} & 11. Waste Item ID Number & C1. & C1. Container ID. No. & \multicolumn{2}{|c|}{ 18. Origin Date } & \multicolumn{2}{|c|}{ M2. RCRA 90-day Start Date } & \multirow{3}{*}{\begin{tabular}{|l} 
M4. PCB Start Date \\
14
\end{tabular}} \\
\hline & \multirow[t]{2}{*}{ 113. Est. Net Volume } & \multirow[t]{2}{*}{ I14. Units } & \multirow{2}{*}{$\begin{array}{l}\text { H4. HP Tag } \\
\text { Color }\end{array}$} & \multicolumn{2}{|c|}{ 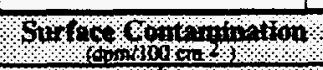 } & \multirow{2}{*}{ 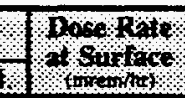 } & \multirow{2}{*}{ Dopterote } & \\
\hline & & & & Transtax & Dited Read & & & \\
\hline & 115. Est. Gross Weight & 116. Units & Alpha & & & & & \\
\hline \multirow{2}{*}{ Cormments } & & & Beta/Gamma & & & & & \\
\hline & & & Neutron & & & & & \\
\hline
\end{tabular}

\begin{tabular}{|c|c|c|c|c|c|c|c|c|}
\hline \multirow{4}{*}{$\begin{array}{l}\text { Sequence } \\
\text { Number }\end{array}$} & I1. Waste Item ID Number & C1. & C1. Container ID. No. & \multicolumn{2}{|c|}{ I8. Origin Date } & \multicolumn{2}{|c|}{ M2. RCRA 90-day Start Date } & \multirow{3}{*}{ 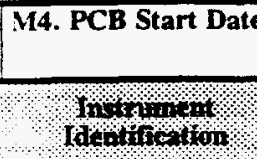 } \\
\hline & \multirow[t]{2}{*}{ 113. Est. Net Volume } & \multirow[t]{2}{*}{ 114. Units } & \multirow{2}{*}{$\begin{array}{l}\text { H4. HP Tag } \\
\text { Color }\end{array}$} & \multicolumn{2}{|c|}{ Surtace Contandination } & \multirow{2}{*}{ 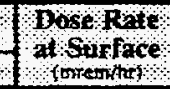 } & \multirow{2}{*}{$\begin{array}{l}\text { Dose Rate: } \\
\text { at I Weter } \\
\text { tmeterums:- }\end{array}$} & \\
\hline & & & & Ttansfet: & Ditect Read & & & \\
\hline & 115. Est. Gross Weight & I16. Units & Alpha & & & & & \\
\hline \multirow{2}{*}{ Comments } & & & Beta/Gamma & & & & & \\
\hline & & & Neutron & & & & & \\
\hline
\end{tabular}

SIGNATURES and APPROVALS

\begin{tabular}{|l|l|l|}
\hline S1. Generator & Badge & Date \\
\hline S3. Verification Officer & Badge & Date \\
\hline
\end{tabular}

\begin{tabular}{|l|l|l|}
\hline S2. HP Technician & Badge & Date \\
\hline S4. Derivative Classifier & Badge & Date \\
\hline
\end{tabular}


Attach Container Packing List and/or Barcode Labeis Here (staple)

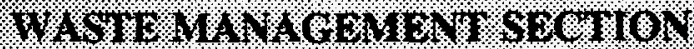

\section{EPA Codes}

DOT Rad $>=2000$

$\square$ Yes $\square$ No

Required Labeis/Markings/Tags Correct
$\square$ Yes $\square$ No

zard Class/Division

DOT ID Number $\quad$ Packing Group

Packing Group

Sample Request Number

Date Sampled

Sampling Code Number

1 Yr. Storage Deadline for RCRA (Date) 9 Month/1 Year PCB Date

Field Review Signature (TSD)

Required Protective Equipment

\begin{tabular}{|l}
\hline Fieid Review Signature (TSD) \\
\hline Onsite TSD Facility \\
\hline
\end{tabular}

Operator's Signature

Date Waste Received

Movement History

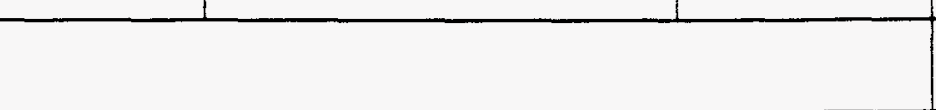

\begin{tabular}{|l|l}
\hline Badge Number & Date \\
\hline
\end{tabular}

\begin{tabular}{|l|l|} 
& Date Moved \\
\hline Operator's Signature to to & to
\end{tabular}

Operator's Signature

Disposal Method/Code

Disposal Facility/Company

\begin{tabular}{|l|l|l}
\hline Shelf & Column \\
\hline
\end{tabular}

Badge Number

Date

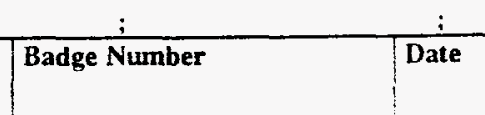

Waste Manifest Number

CD Receipt Date

Shipping Coordinator's Signature

Badge Number

Waste Destination

Disposal Instructions: 


\section{ENERGY SYSTEMS WASTE DISPOSAL REQUEST}

\section{C.N-2:09 Protile Sheer}

\section{WASTE ITEM TENTIFICATION}

Waste item ID Numoer: The unque iD numoer of the waste vem

$\therefore$ Generator s vame: The name of the indiviuuat resporsioic tor the gereration of the waste

13. Budge vis.: The badge number of the waste gentrator.

Gherator \& Phone Yo. Phone number where the waste generator can be reached

U5: Mai Stop

"harge Number WOProject Number lior ER only) A valid work order, account number, or project number inr waste handiing charges

Origin Div.: The division code of the originating division

Origin Date: The date that the waste was generated

Origin Sice: The sice (plani) where the waste was generated

1:0. Orighn Facility: The tacility (building) where the waste was ge: :.ated

111. Origin RoomiArea: The room or area where the waste was gi died

112. Radiological Area: The generation area is a radiological area ives or nol

113. Est. Net Volume: The estunated net volume of the waste material

114. Units: Volume units

1:5. Est. Gross Weight: The estumated gross weight of the waste materiai

1i6. Linis: Weight units

\section{CONTANER DFORMATION}

C1. Cuntaner ID No.: The untque ID number of the sintoping/storage contaner for this waste them

C2. Container Type: The type code for the shipoing/storage container

C3. Holding Site: The sice (plant) where the waste was heid durnng accumuiation

C4. Holding Facility: The facility (building) where the waste was held during accumulation

C5. Holding RoomiArea: The room number or area identufier where the waste was held during accumulation

\section{WASTE CATEGORY}

H. Process Stream ID: The ID number of the orocess stream which generated the waste

W2. Process Category: The category or the process whicn generated this waste

W3. Process Activity: The descriptive name of the generation process

W4. Physicai form: The physical form of the waste materia!

W5. Material Type: The sub-category of the physical form of the waste materal

Wh. AWA Vumber: Asbestos Work Authorization Number

iv 7. Waste Descripuon: Further specincation of the waste. including descripuve intormation

W8. Waste Category: Spectric categories for the waste material (check each one etther "YES" or "YO")

\section{CHEMICAL WASTE}

M1. RCRA (Y/N)?: The waste contains RCRA regulated material

M2. RCRA 90-Day Start Date: The date RCRA waste was placed in a 90 -day storage area

M3. PCB ( $Y / N)$ ?: The waste contains $P C B$ reguiated matertai

144. PCB Start Date: The date PCB waste material was removed from service

M5. PCB Conc.(PPM): The PCB concentration in parts per million (if "less than" nan, enter nnn)

M6. Determination Method: The method used to determine the chemical characteristics

47. Determination Document Number(s): Document numbers that substantiate the determination of the characteristics

18. Flash Potnt: The tlash point of the waste material (degrees C)

19. PH: The relative acidity of the waste material $(\mathrm{oH})$

M10. EPA Waste Code Numbers: The EPA waste code numbers determined from the waste characterisucs

M11. Substance ID: The ID number of a chemical constituent of the waste cetther its CAS number or MSDS record number

MI2. Vol ir: The percent oy volume for the chemical substance

M13. Substance Name: The common name of the chemical substance

\section{RADIOACTIVE WASTE}

R1. Rad Category: The radioactive waste category code (check one)

R2. Rad Handling Type: The radioactive waste handling code

R3. LTV 2081 Number: The ID number of the UCN-2681 "Accountability Transfer" form assoctated with this waste : It unv

R4. Determination Method: The metnod used to determine the radioactive characteristics (check one)

RS. Determination Document Number(s): Document numbers that substantate the determination of the characieristics

R6. Chemical Form: The chemical form of the waste material

R7. Isotope ID: The ID number of a particular radioactiye isotope contained in this waste item

R8. Fst. Quantity: The estumated quantity of this isotope

R9. Quan. Unts: The units ior the isotope quanuty (grams or curies)

\section{HANDI.NG INFORMATION}

H!. Manding Instructions: General handling instructions for the waste

H2. Respirator: Respirator requirements tor handling this waste

H3. Cartridge Type: Respirator cartridge ne to be used (if applicabie)

H4. HP Survey Data (completed by Healis: hysics technician)

HP Tag Color: The color code of the survey tag (G.Y.R.B)

Surface Contamination: The transterrable and Direct Reading count rates $(d p m / 100 \mathrm{~cm} 2)$

Dose Rate at Surtace: The dose rate measured at the surtace (mrem/hr)

Dose Rate at 1 Meter: The dose rate measured at 1 meter (mrernhr)

insurumen ID: The heaith physics instrument ID number (" $M$ " number) Example: $M 123456$

15. Pickup Site: The site (plant) where the waste is to be picked up

46. Pickup Facilty: The facsity (building) where the waste is to be picked up

H7. Pickup Room/Area: The room number or area identifier where the waste is to be picked up

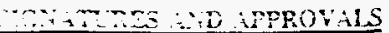

S. Generator: The signature of the waste generator. cerufying that the information on the form is compiete and accurate

: IP Te:inician: The stenature and badge numher of the HP technieian cerufvine that the HP survev information is enrrect

53. Vertication Officer: The signature and badge number of an auchorized person certiving that the form has teen cornpteted properiy

s. Derivative Classifier: Deternines the waste tem security classification and revifof dite form for ciassiñed information 
Waste Stream ID

Date Request Initiated

Pick-Up Facility ID

Contact Name

Material Form (Circle one) SOLID GAS

Waste Stream Description
WTP Request No.

Date Request Rec.

Generator Division/Plant

Phone No.

SLUDGE LIOUID AEROSOL

OIL

Contaminants (Circle one) ASBESTOS/BERYLLIUM/CARCINOGEN/MERCURY/PCB/OTHER

Radioactive [] Yes [1 No If Yes, [] Depleted [0 Enriched

RCRA [] Yes [NNo (If Yes List Codes)

Respirator Required [] Yes [] No If Yes, [] Mask [] Cartridge

H.P. Tag Color _ Total No. of Containers

Charge No.

\section{FIELD REVIEW}

Environmental TC

Badge No.

Date Assigned

Date of Field Review

Hazards

Hazard Class

DOT Name

Request rejected [] Yes [] No If Yes, Reason and Date

\section{SAMPLING HISTORY}

WTP PSM \#

LIMS No.

LIMS No.

LIMS No.

LIMS No.

Code No.

Code No.

Code No.

Code No.

Date

Date

Date

Date

\section{MOVEMENT HISTORY}

WTP Movement No.

Delivery Site

Transporter's Signature

Delivery Date

Transporter's Signature

Badge No.

Environmental TC Signoff

Badge No.

Location

Movement No.

Delivery Site

Transporter's Signature

Delivery Date

Transporter's Signature

Environmental TC Signoff

Badge No.

Badge No.

Location

\section{DISPOSAL INFORMATION}

WTP Movement No.

Disposal Facility

Facility Operator (Signature and Badge No.

Driver's Signature

Driver's Signature

Tank No.

Date

\begin{tabular}{ll}
\hline Badge No. & Date \\
Badge No. Date & \\
\hline
\end{tabular}




\begin{tabular}{|c|c|c|c|c|c|}
\hline \multicolumn{6}{|c|}{ WASTE ITEMS } \\
\hline ITEM NO. & CONTAINER & BARCODE & $\begin{array}{l}\text { ACCUMULATIO } \\
\text { N START DATE }\end{array}$ & $\begin{array}{l}\text { WEIGHT/ } \\
\text { LBS }\end{array}$ & $\begin{array}{l}\text { VOLUM } \\
\text { E/UNITS }\end{array}$ \\
\hline & & & & & \\
\hline & & & & & \\
\hline & & & & & \\
\hline & & & & & \\
\hline & & & & & \\
\hline & & & & & \\
\hline & & & & & \\
\hline & & & & & \\
\hline & & & & & \\
\hline & & & & & \\
\hline & & & & & \\
\hline & & & & & \\
\hline & & & & & \\
\hline & & & & & \\
\hline & & & & & \\
\hline & & & & & \\
\hline & & & & & \\
\hline & & & & & \\
\hline & & & & & \\
\hline & & & & & \\
\hline & & & & & \\
\hline & & & & & \\
\hline & & & & & \\
\hline & & & & & \\
\hline & & & & & \\
\hline & & & & & \\
\hline & & & & & \\
\hline & & & & & \\
\hline & & & & & \\
\hline
\end{tabular}




\section{HAZARDOUS WASTE IDENTIFICATION TAG 2114A AND \\ WASTE IDENTIFICATION TAG 2114B}

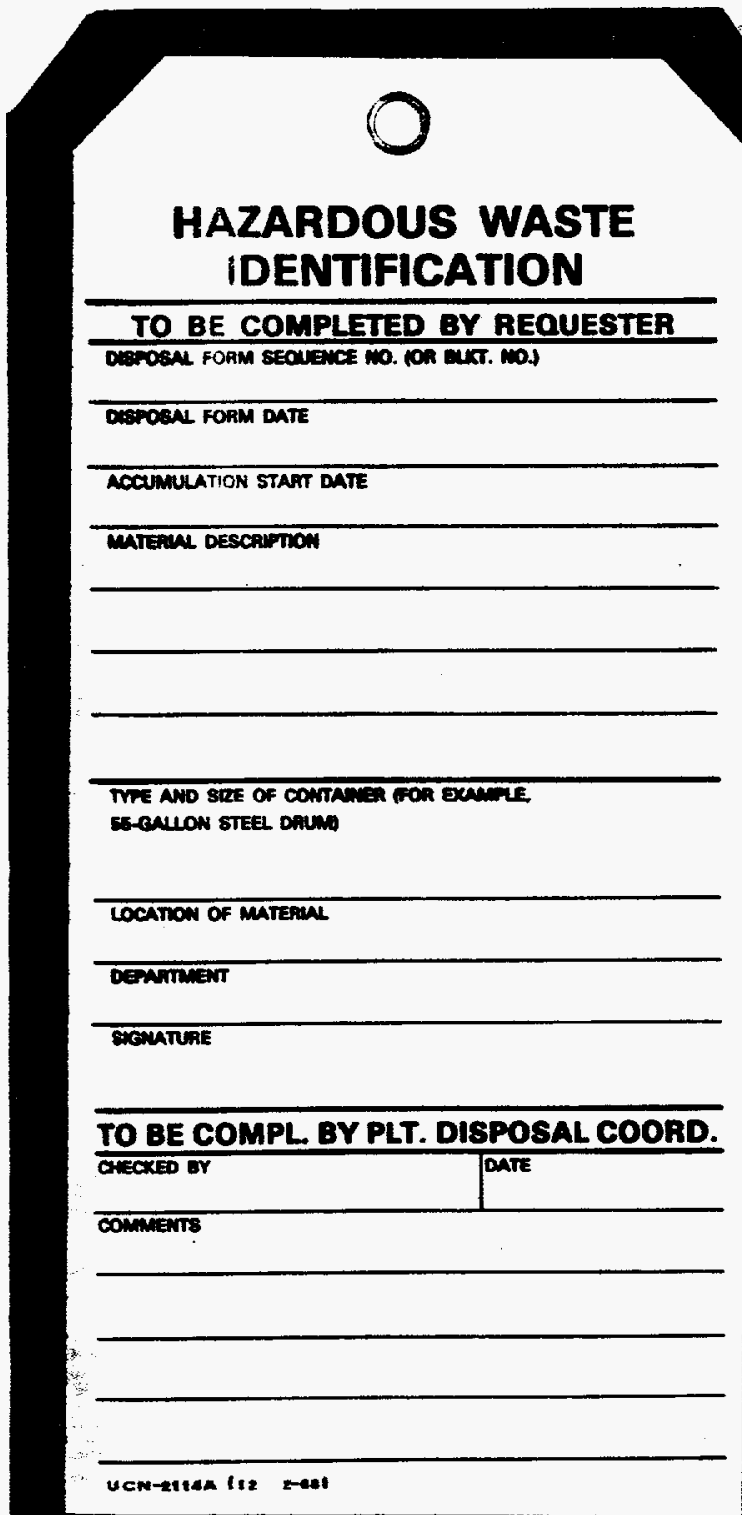

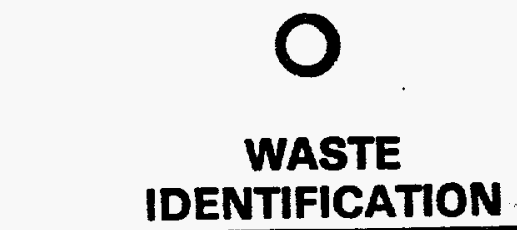

TO BE COMPLETED BY REQUESTEP DISPOSAL FOAA SEOUENCE NO. (OA ELXT. NO.)

DISPOSNL FORM DATE

MATERULL DESCRAPION

TMPE AND SRE OF CONTAMEA GOR EXNWLE S-GULON 8TEE DHUM

COCAIDON OF MATERTLL

DePARTIITT

MEMTURE

TO BE COMPL. BY PLT. DISPOSAL COORD.

CHECKED B

Dan:

CommEats

UCW-21148 (2 2-88) 


\section{SAMPLE REQUISITION REQUEST}

\section{REQUEST OR CONTACT}

REQUESTOR'S I.D. NO. REQUESTOR'S PHONE NO.

MATERIAL DESCRIPTION

PICK-UP BUILDING PICK-UP DOCK

CONTAINER TYPE NO. OF CONTAINERS

SAMPLE REQUISITION NO. (LIMS)

SAMPLE CODE(S) SAMPLE DATE

QC SAMPLE CODE

RESPIRATOR REQUIREMENTS

DATE RESULTS REQUIRED BY

SAMPLING PLAN

C-2-8 


\section{APPENDIX C-3 \\ EXAMPLES OF POTENTIALLY INCOMPATIBLE WASTE}

Many hazardous wastes, when mixed with other waste or materials at a hazardous waste facility, can produce effects which are harmful to human health and the environment, such as (1) heat or pressure, (2) fire or explosion, (3) violent reaction, (4) toxic dusts, mists, fumes, or gases, or (5) flammable fumes or gases.

Below are examples of potentially incompatible wastes, waste components, and materials, along with the harmful consequences which result from mixing materials in one group with materials in another group. The list is intended as a guide to operators of storage facilities and to indicate the need for special precautions when handling and storing potentially incompatible waste materials. This list is not intended to be exhaustive.

In the list below, the mixing of a Group A material with a Group B material my have the potential consequences as noted.

Group 1-A

Acetylene sludge

Alkaline caustic liquids

Alkaline cleaner

Alkaline corrosive liquids

Alkaline corrosive battery fluid

Caustic wastewater

Lime sludge and other corrosive alkalines

Lime wastewater

Lime and water

Spent caustic
Group 1-B

Acid sludge

Acid and water

Battery acid

Chemical cleaners

Electrolyte, acid

Etching acid liquid or solvent

Pickling liquor and other corrosive acids

Spent acid

Spent mixed acid

Spent sulfuric acid

\section{Potential consequences: Heat generation; violent reaction.}




\section{APPENDIX C-3 (Continued) \\ EXAMPLES OF POTENTTALLY INCOMPATIBLE WASTE}

Group 2-A

Aluminum

Beryllium

Calcium

Lithium

Magnesium

Potassium

Sodium

Zinc powder

Other reactive metals and metal hydrides

Potential consequences: Fire, explosion, or heat generation; generation of flammable or toxic gases.

Group 3-A

Alcohols

Water
Group 2-B

Groups 1-A or 1-B waste 
Group 4-A

Alcohols

Aldehydes

Halogenated hydrocarbons

Nitrated hydrocarbons

Unsaturated hydrocarbons

Other reactive organic compounds and solvents
Group 4-B

Concentrated waste

Groups 1-A or 1-B

Group 2-A wastes

Potential consequences: Fire, explosion, or violent reaction.

Group 5-A

Spent cyanide and sulfide solutions
Group 5-B

Group 1-B wastes

Potential consequences: Generation of toxic hydrogen cyanide or hydrogen sulfide gas.

Group 6-A

Chlorates

Chlorine

Chlorites

Chromic acid

Hypochlorides

Nitrates

Nitric acid, fuming

Perchlorates

Permanganates

Peroxides

Other strong oxidizers
Group 6-B

Acetic acid and other organic acids Concentrated mineral acids

Group 2-A wastes

Group 4-A wastes

Other flammable and combustible wastes

Potential consequences: Fire, explosion or violent reaction. 
APPENDIX D-1

FIGURES D-1 through D-6 


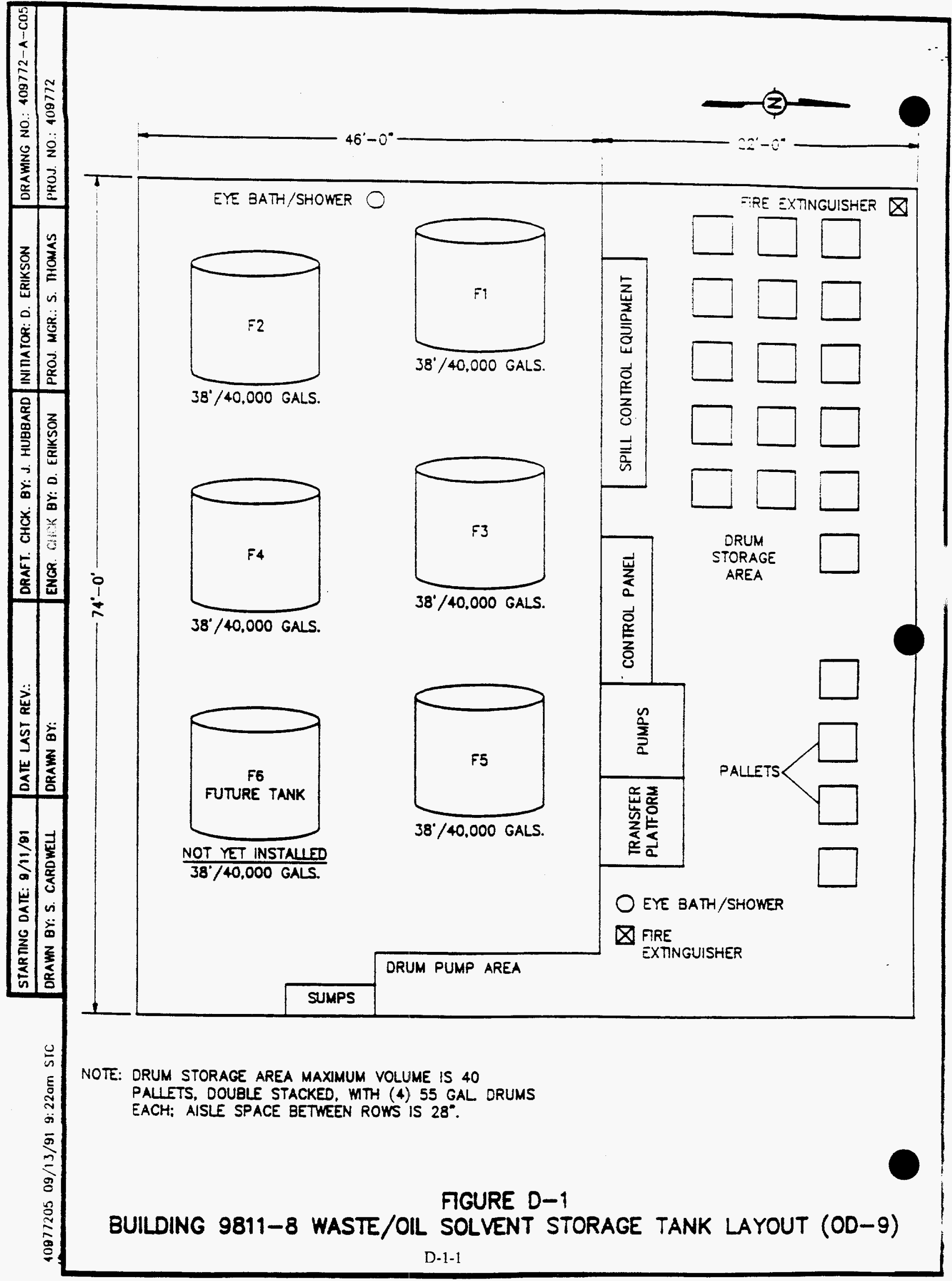


$4097720211 / 06 / 91 \quad 2: 48 \mathrm{pm} \mathrm{JWH}$

\begin{tabular}{l|l|l|l|l|l|l|}
\hline STARTNG DATE: 09/09/91 & DATE LAST REV:: 11/6/91 & DRAFT. CHCK. BY: J. HUBBARO & INITATOR: D. ERIKSON & ORAWNG NO.: 409772 -A -G02 \\
\hline DRAWN BY: S. TOKAY & DRAWN BY: J. HUBBARD & ENGR. CHCK BY: D. ERIKSON & PROJ. MGK.: S. M1OMAS & PROJ. NO.: 409772 \\
\hline
\end{tabular}
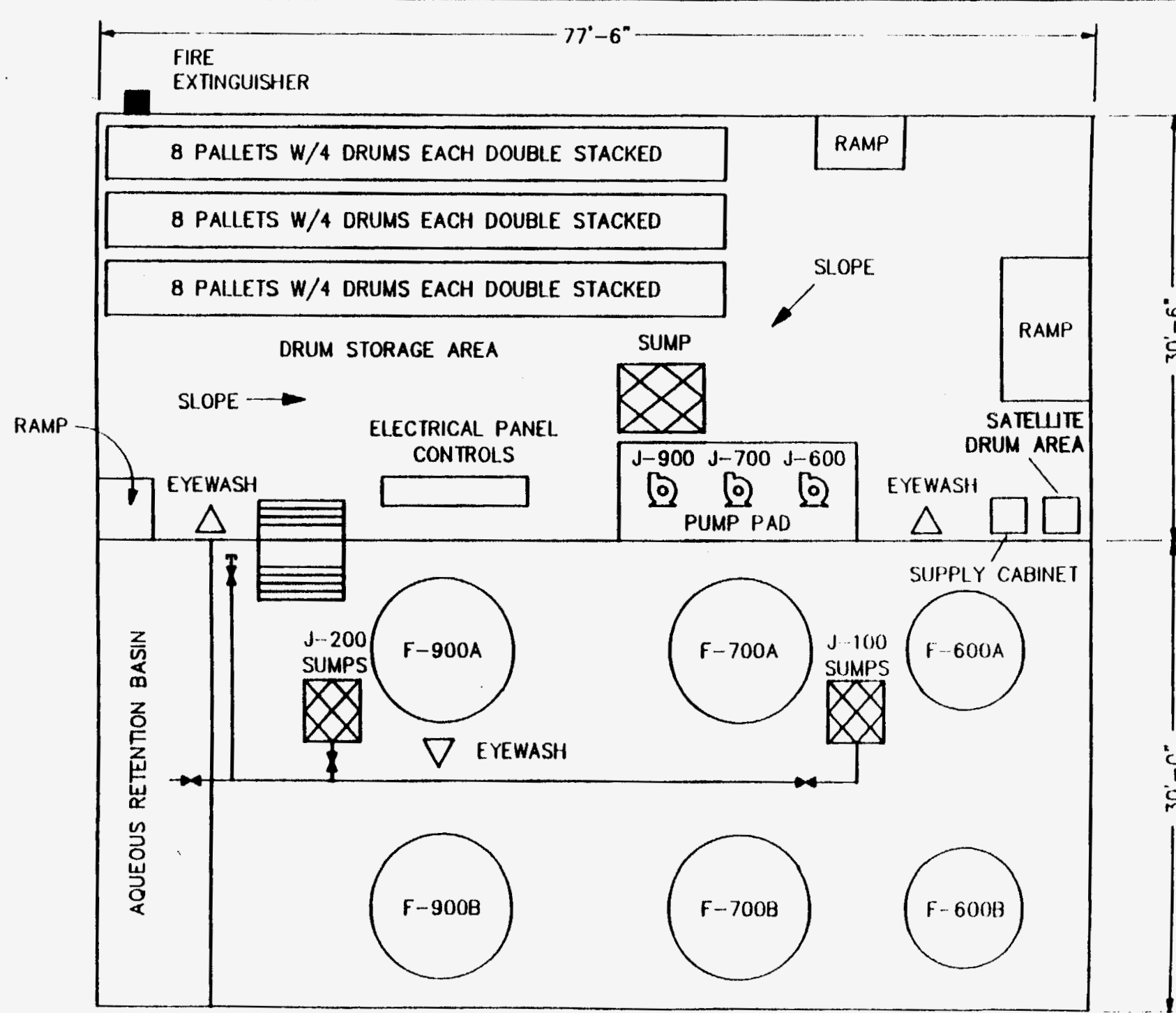

NOTE: MAXIMUM VOLUME TO BE STORED IN CONTAINERS IS 48

PALLETS, DOUBLE STACKED, MTH (4) 55 GAL. DRUMS

EACH: AISLE SPACE BETWEEN ROWS IS $28^{\circ}$.

FIGURE D-2. OIL DIKE-10 STORAGE UNIT PLAN VEW

D-1-2 


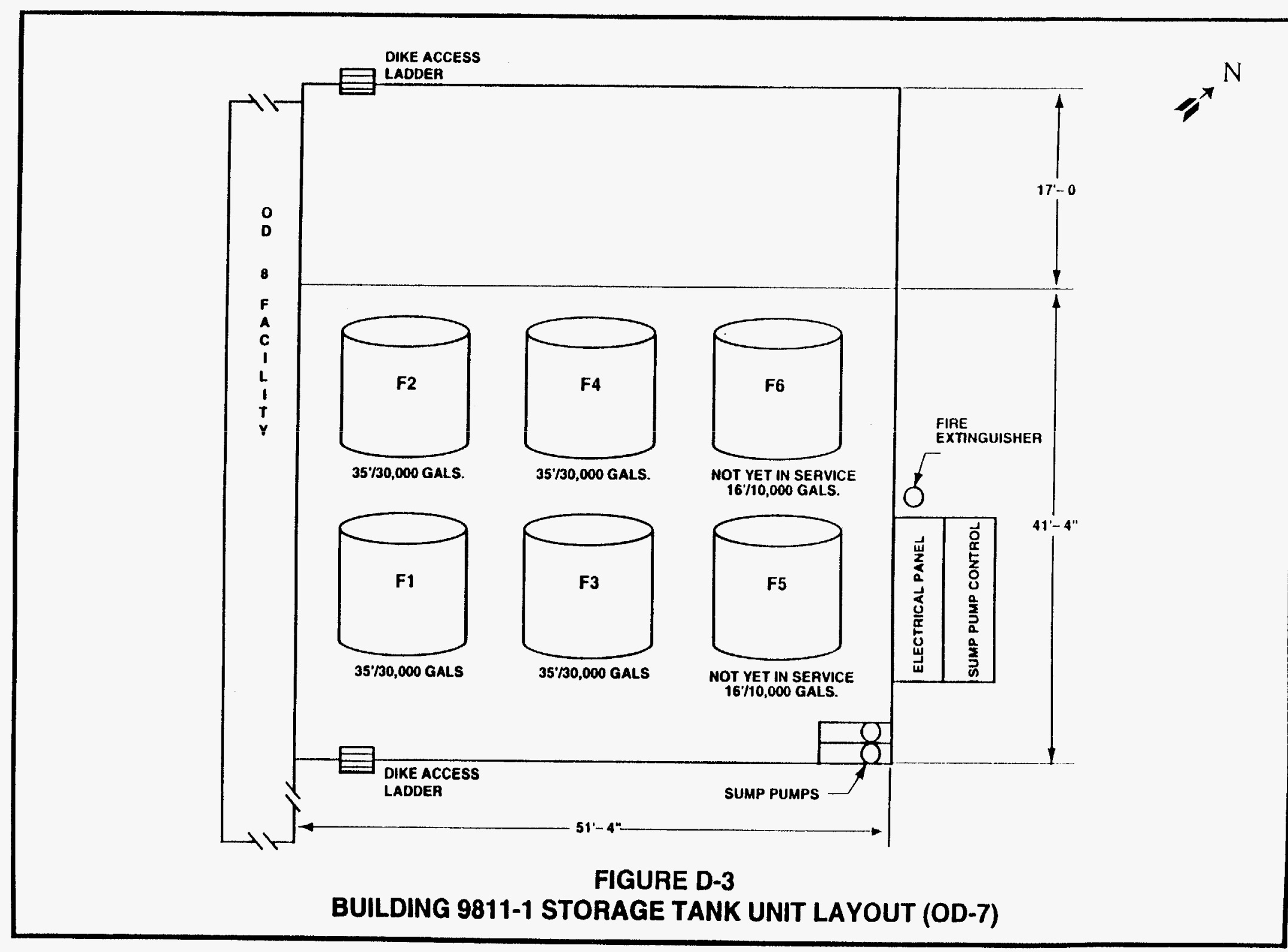




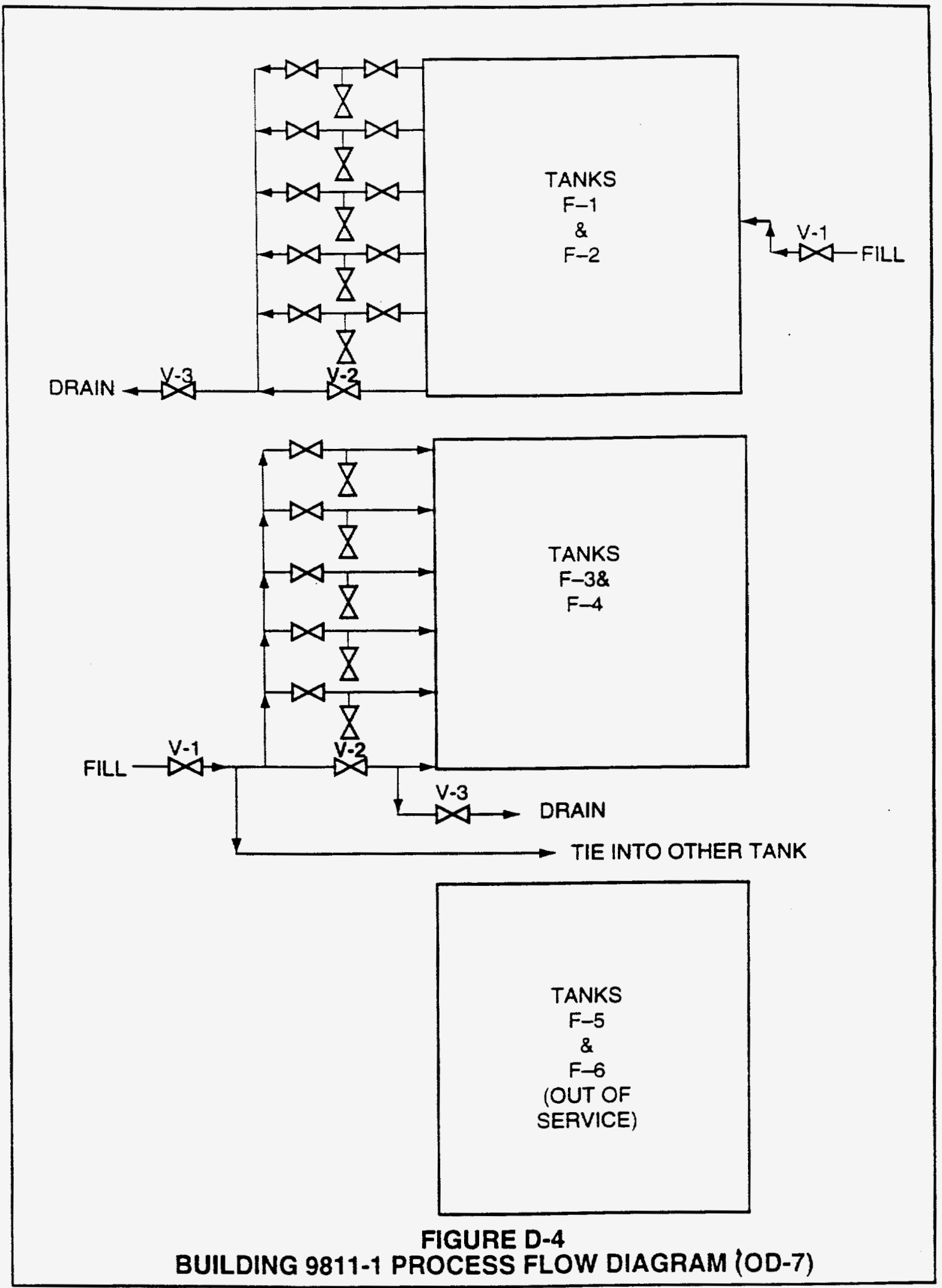




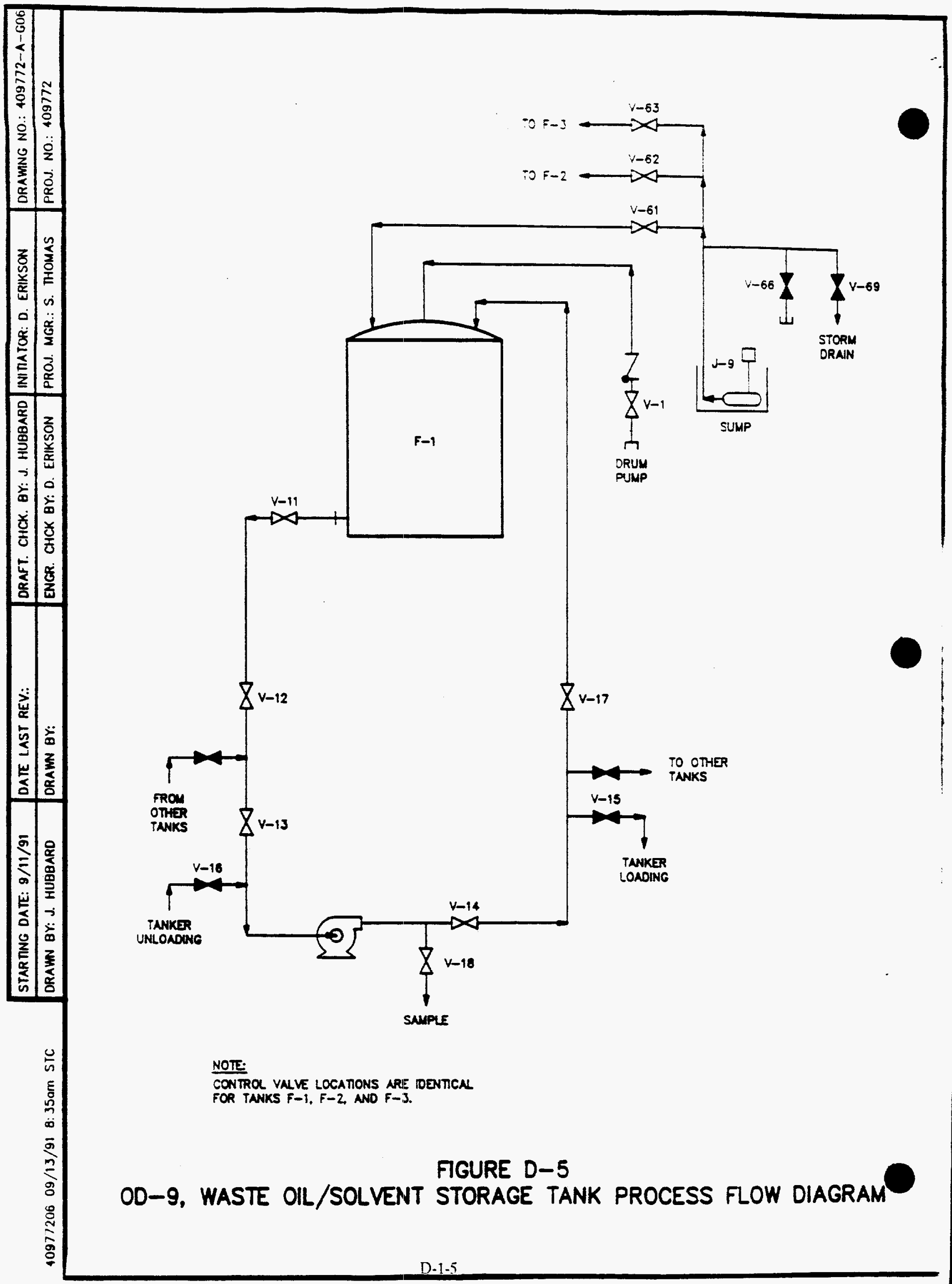




\section{APPENDIX D-2 \\ SECONDARY CONTAINMENT CALCULATIONS}

For OD-7 Tank Storage Area

Total South Dike Capacity:

Dike Capacity $=50.0^{\prime} \times 40.0^{\prime} \times 3.75^{\prime}=7,500 \mathrm{ft}^{3}$

Sump Capacity $=\pi(2 \mathrm{ft})^{2} \times 4.3^{\prime}=54.04 \mathrm{ft}^{3}$

Total $=7,554.0 \mathrm{ft}^{3}$

Minus Volume Impacts:

$$
\begin{aligned}
& \text { 30,000 gal Tanks }=4 \times\left[\pi(6.0 \mathrm{ft})^{2} \times 2.75^{\prime}\right]=1,244.1 \mathrm{ft}^{3} \\
& \begin{aligned}
10,000 \text { gal Tanks } & =2 \times\left[\pi(5.25 \mathrm{ft})^{2} \times 2.75^{\prime}\right]=476.2 \mathrm{ft}^{3}
\end{aligned} \\
& \begin{aligned}
\text { Tank Pads } & =2 \times\left[\pi(6.25 \mathrm{ft})^{2} \times 1.0^{\prime}\right]=245.4 \mathrm{ft}^{3} \\
& =2 \times\left[\pi(7.0 \mathrm{ft})^{2} \times 1.0^{\prime}\right]=307.9 \mathrm{ft}^{3} \\
& =2 \times\left[\pi(6.13 \mathrm{ft})^{2} \times 1.0^{\prime}\right]=235.7 \mathrm{ft}^{3}
\end{aligned} \\
& \text { Total }=2,509.3 \mathrm{ft}^{3}
\end{aligned}
$$

Secondary Containment Capacity $=\left(7,554.0 \mathrm{ft}^{3}-2,509.3 \mathrm{ft}^{3}\right) \times 7.48 \mathrm{gal} / \mathrm{ft}^{3}=37,734 \mathrm{gal}$

$25-$ Year Storm $=5.5^{\prime \prime}$ rainfall

$$
=5.5^{\prime \prime} \times 50.0^{\prime} \times 40^{\prime}=916.7 \mathrm{ft}^{3} \times 7.48 \mathrm{gal} / \mathrm{ft}^{3}=6,857 \mathrm{gal}
$$

Capacity Needed $=$ volume of largest tank +25 year storm

$$
=30,000 \mathrm{gal}+6,857 \mathrm{gal}=36,857 \mathrm{gal}
$$

Excess Capacity $=37,734$ gal $-36,857 \mathrm{gal}=877 \mathrm{gal}$

Total Secondary Containment at OD-7 $=37,734$ gallons 
For OD-9 Tank Storage Area

Total Diked Capacity $=73.5^{\prime} \times 42.0^{\prime} \times 5.6^{\prime}=17,287 \mathrm{ft}^{3}$

Minus Volume Impacts:

Drum Staging Area $=18^{\prime} \times 12^{\prime} \times 5.6^{\prime}=1,210 \mathrm{ft}^{3}$

Tank Pads $=6 \times\left[\pi(8.25 \mathrm{ft})^{2} \times 1^{\prime}\right]=1,283 \mathrm{ft}^{3}$

Tank Displacement $=5 \times\left[\pi(6.75 \mathrm{ft})^{2} \times 4.6^{\prime}\right]=3,292 \mathrm{ft}^{3}$

Total $=5,785 \mathrm{ft}^{3}$

Secondary Containment Capacity $=\left(17,287 \mathrm{ft}^{3}-5,785 \mathrm{ft}^{3}\right) \times 7.48 \mathrm{gal} / \mathrm{ft}^{3}=86,035 \mathrm{gal}$

25 -Year Storm $=5.5^{\prime \prime}$ rainfall

$=5.5^{\prime \prime} \times\left[\left(73.5^{\prime} \times 42^{\prime}\right)-\left(18^{\prime} \times 12^{\prime}\right)\right]$

$=1,316 \mathrm{ft}^{3} \times 7.48 \mathrm{gal} / \mathrm{ft}^{3}=9,843 \mathrm{gal}$

Capacity Needed $=$ volume of largest tank +25 -year storm

$=40,000 \mathrm{gal}+9,843 \mathrm{gal}=49,843 \mathrm{gal}$

Excess Capacity $=86,035$ gal $-49,843$ gal $=36,192$ gal

Total Secondary Containment at OD-9 for Tanks $=86,035$ gallons

For OD-9 Container Storage Area

Total Diked Capacity $=74^{\prime} \times 22^{\prime} \times 5^{\prime \prime} / 12 \mathrm{ft}=678.3 \mathrm{ft}^{3}$

Minus Volume Impacts:

Pump Pad $=0.5 \times 0.2 \mathrm{ft} \times 19 \mathrm{ft} \times 11.5 \mathrm{ft}=21.9 \mathrm{ft}^{3}$

Pallet Displacement $=20 \times 1.6 \mathrm{ft}^{3}=32 \mathrm{ft}^{3}$

Total $=53.9 \mathrm{ft}^{3}$

Secondary Containment Capacity $=\left(678.3 \mathrm{ft}^{3}-53.9 \mathrm{ft}^{3}\right) \times 7.48 \mathrm{gal} / \mathrm{ft}^{3}=4,671 \mathrm{gal}$

Capacity Needed $=10 \%$ of volume of containers

$=0.1 \times 160 \mathrm{drums} \times 55 \mathrm{gal} / \mathrm{drum}=880 \mathrm{gal}$

Excess Capacity $=4,671$ gal -880 gal $=3,791$ gal

Total Secondary Containment at OD-9 for Containers $=4,671$ gallons 


\section{For OD-10 Tank Storage Area}

Total Dike Capacity:

Dike Capacity $=65^{\prime} \times 30.3^{\prime} \times 3^{\prime}=5,908 \mathrm{ft}^{3}$

S. mp Capacity $=2 \times 27 \mathrm{ft}^{3}=54 \mathrm{ft}^{3}$

Total $=5,962 \mathrm{ft}^{3}$

Minus Volume Impacts:

Tank Pads $=8 \times 10^{\prime} \times 10^{\prime} \times 6^{\prime \prime}=400 \mathrm{ft}^{3}$

Secondary Containment Capacity $=\left(5,962 \mathrm{ft}^{3}-400 \mathrm{ft}^{3}\right) \times 7.48 \mathrm{gal} / \mathrm{ft}^{3}=41,604 \mathrm{gal}$

25-Year Storm $=5.5^{\prime \prime}$ rainfall

$=5.5^{\prime \prime} \times 65.0^{\prime} \times 30.3^{\prime}=902.7 \mathrm{ft}^{3} \times 7.48 \mathrm{gal} / \mathrm{ft}^{3}=6,752 \mathrm{gal}$

Capacity Needed $=$ volume of largest tank +25 -year storm

$=6,500 \mathrm{gal}+6,752 \mathrm{gal}=13,252 \mathrm{gal}$

Excess Capacity $=41,604$ gal $-13,252$ gal $=28,352$ gal

Total Secondary Containment at OD-10 for Tanks $=41,604$ gallons

For OD-10 Container Storage Area

Total Diked Capacity $=77.5^{\prime} \times 30.5^{\prime} \times 5 / 12^{\prime \prime}=985 \mathrm{ft}^{3}$

Minus Volume Impacts:

Pump Pad $=6^{\prime} \times 20^{\prime} \times 5^{\prime \prime}=50 \mathrm{ft}^{3}$

Ramps $=2 \times 6^{\prime} \times 6^{\prime} \times 5^{\prime \prime}=30 \mathrm{ft}^{3}$

Ramp $=10^{\prime} \times 10^{\prime} \times 5^{\prime \prime}=41.7 \mathrm{ft}^{3}$

Cabinet/Satellite $=20 \mathrm{ft}^{2} \times 5^{\prime \prime}=8.3 \mathrm{ft}^{3}$

Pallets $=24 \times 1.6 \mathrm{ft}^{3}=38.4 \mathrm{ft}^{3}$

Total $=168.4 \mathrm{ft}^{3}$

Secondary Containment Capacity $=\left(985 \mathrm{ft}^{3}-168.4 \mathrm{ft}^{3}\right) \times 7.48 \mathrm{gal} / \mathrm{ft}^{3}=6,108 \mathrm{gal}$

Capacity Needed $=10 \%$ of volume of containers

$=0.10 \times 192$ drums $\times 55 \mathrm{gal} / \mathrm{drum}=1,056 \mathrm{gal}$

Excess Capacity $=6,108$ gal $-1,056$ gal $=5,052$ gal

Total Secondary Containment at OD-10 for Containers $=6,108$ gallons 


\section{OD-7 \\ STORAGE UNIT}


UNION CARBIOE CORPORATION

NUCLEAR DIVISION

OAK RIOGE. TN PAOUCAM, KY

PROJECT TITLE

WASTE OIL STURAGE FACILITY

JOQ TITLE

$<-4$

TANKS T-3/AND T-4 F-3

Note: Dimengions for Tank T-3 are THE same As T-4 Locarion of Nopzles Differ.
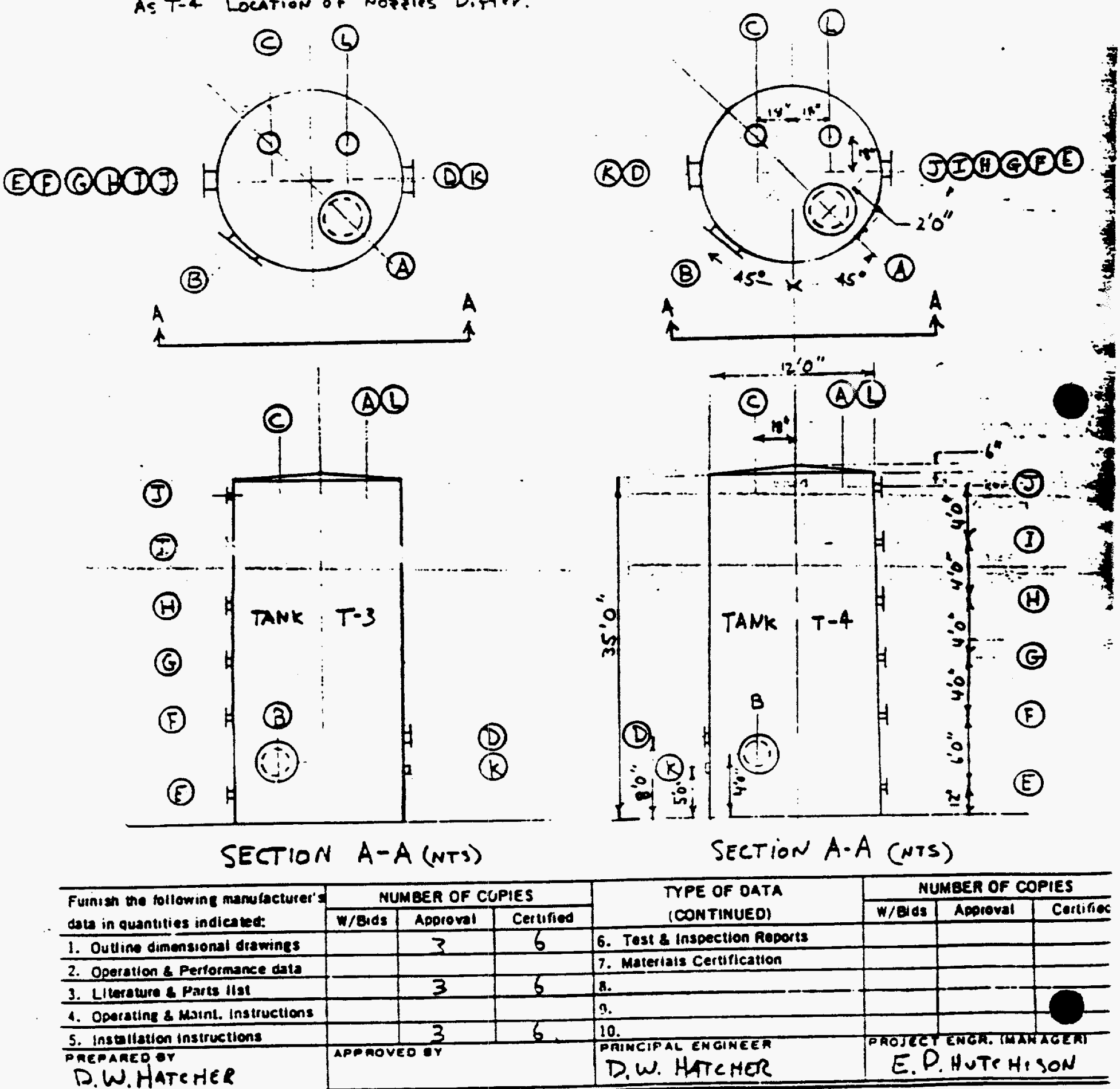

SECTION A-A (NTS)

\begin{tabular}{|c|c|c|c|c|c|c|c|}
\hline \multirow{2}{*}{$\begin{array}{l}\text { Fuinigh the tollowing manulacturet' } \\
\text { dots in quantities indieated: }\end{array}$} & \multicolumn{3}{|c|}{ NUMBER OF CUPIES } & \multirow{2}{*}{$\begin{array}{l}\text { TYPE OF OATA } \\
\text { (CONTINUED) }\end{array}$} & \multicolumn{3}{|c|}{ MUMBER OF COPIES } \\
\hline & w/Buds & Approval & Certified & & w/eids & Appreval & Certifies \\
\hline 1. Oulline dimensional diawines & & 3 & 6 & 6. Tust \& Inspection Roports & & & \\
\hline 2. Operation \& Pertormance data & & & & 7. Materiats Certiflcation & & & \\
\hline 3. Llterature \& Parts IIst & & 3 & 5 & s. & & & \\
\hline 4. Oparating \& Masint. Instructions & & & & 9. & & & \\
\hline 5. Instullation instructions & & 3 & 6 & 10. & & & \\
\hline $\begin{array}{l}\text { PaEpaneo or } \\
\text { D. W. Hatente? }\end{array}$ & APP nOV & over & & $\begin{array}{l}\text { PATINCIFAL ENGIMEER } \\
\text { D.W. HATLHER }\end{array}$ & & CA. In & \\
\hline
\end{tabular}


Y.12 PLANT - OAK RIDGE, TENMESSEE

TANK AND DRUM DATA SHEET

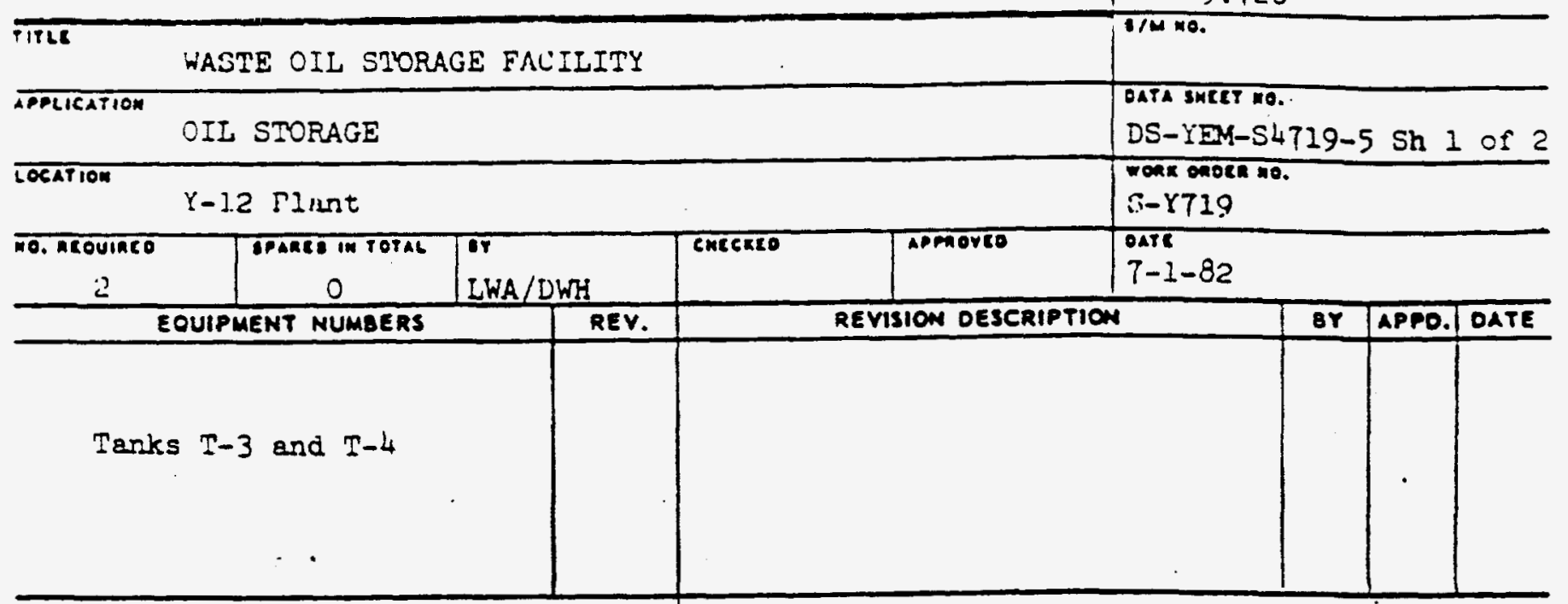

Process Fluid waste oil

SKETCH:

So. G. 0.9 to 1.0 Cons.

Oper. exis atinos Dasion pals

Oper. Tomp. ${ }^{\circ} \mathrm{F} 70$ Desien Tomp. Of

Corrosien Allomenes in. none

Oper. Volum Gol. 30.000

Veseel 0.0. 12'0"

Lempth, Tong. 10 Teno. $35^{\prime} 0^{\prime \prime}$

Heer Transfor none Alionien none

Morprials of Construetion:

Hoods - C.S

$\frac{\text { Hoods }}{\text { Shall }}$ C.S

- Nozzles C.S

Flonges 8 Covers

.5

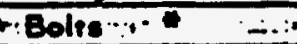

C. $S$

Goskots coing esbestos

Internol Boffles, re.

Intemel Piplen

no

Extornd Luge, te.

no

Supports

C.S.

Veseel Lining

Insulotion

none

Trpe of Hood (10a)

none

Typo of Heod (bolrom)

shallow dighed

Typo of Suppors enciugr boits to concresta Lifsing Lugs as required

Monhole Flo. Raling. \& Foeing

Nozzle Flg. Rating \& focing

Outalde Finish (One coat primer, two cuats

Inside Finish * scid-proof enamel)

Vessel Welght ibs. * 16050 (16

Hydrostorle Tesp pole (fill with water-hold.

Code

UL cor one hr)

Strese Relleved none

Rodlogrophod spot

Stamped

UL

I= Wlimess Test Required

company option

Inspecilon By___ company option

$\dot{z}=$

NOTE: Space merted wish an esterish (') voador to furnish the informatem

NOTLS

1. See sketches on Sheet 2

2. Grounding lugs shell be provided

3. Nozzles to extend 6" minimum from tank surfaces

4. Nozrle schedule:

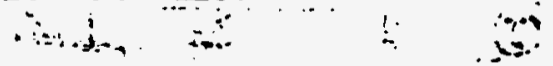

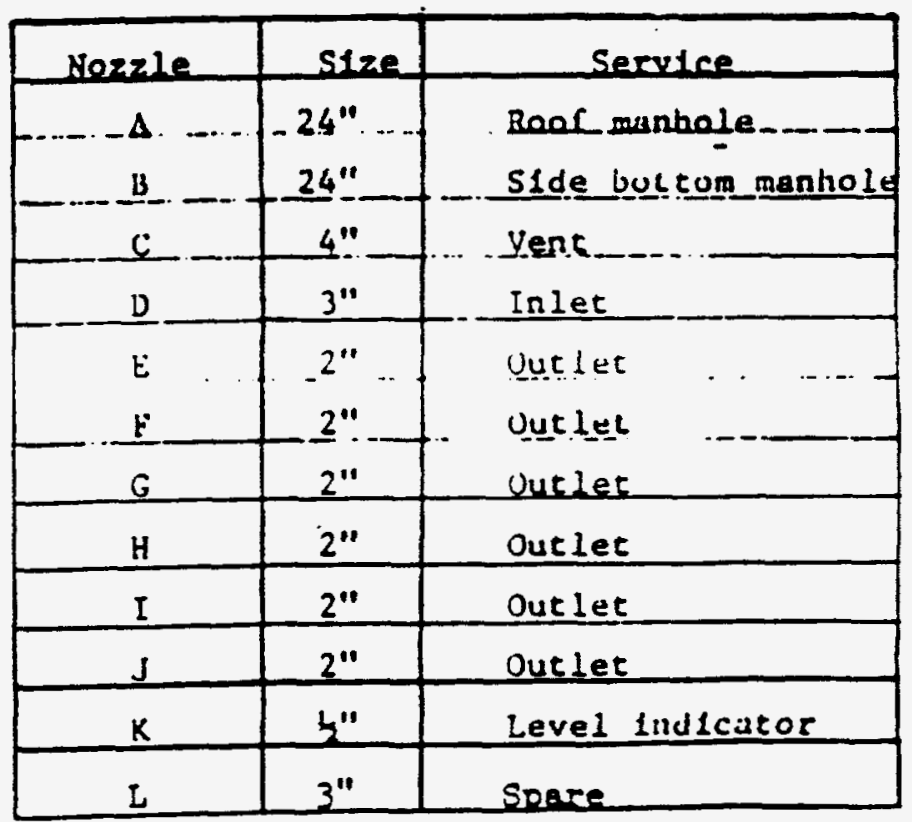




\section{OD-9 \\ STORAGE UNIT}




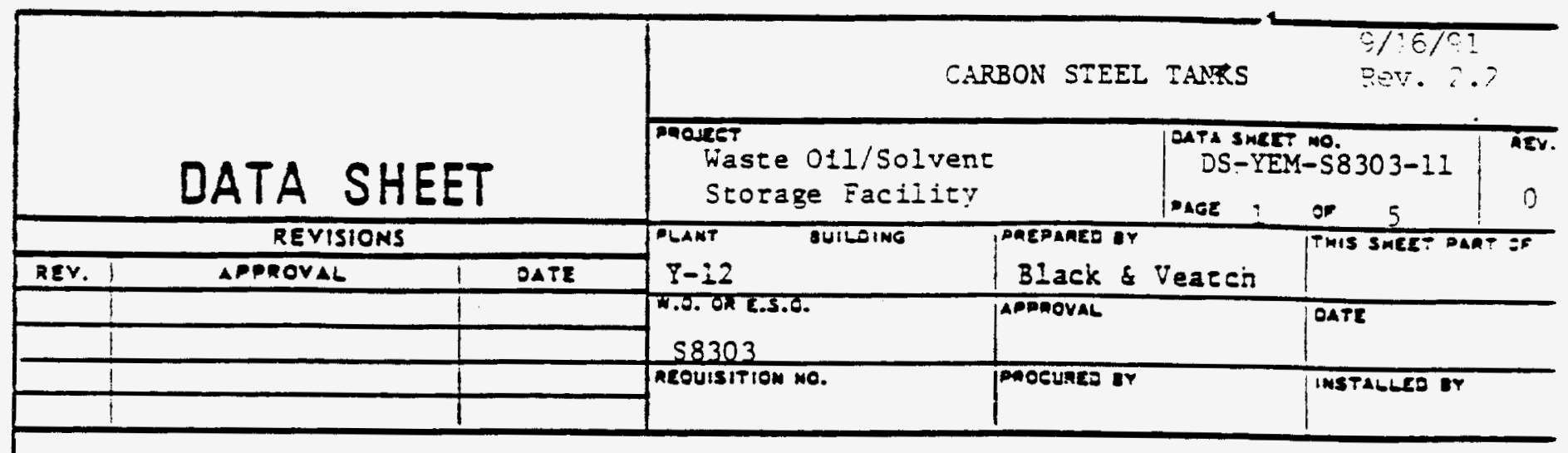

EQUI PMENT NUMBERS: F-1, 2, 3, 4, 5

Type:

Reference Standards:

Process Fluid:

Sp. Gr.:

$\mathrm{pH}$ :

Pressure; Operations/Design, psig:

Temperature; Operating/Design, ${ }^{\circ} \mathrm{F}$ :

Corrosion Allowance, Inch:

Tank Capacity, Gallons:

Tank Dimensions:

Material of Construction She11:

Head:

Internal Baffle:

Supports :

Piping:

Lining:

Insulation:

Type of Heads:

Extermal Finfsh:

Intemal Coating:

Accessories:
Vertical Welded

API 650, ANSI B16.5, ASME Boller and Pressure

Vessel Code, Section IX, ASTM A-516,

ASTM A-36, ASTM A-106, SSPC, UL-142

Waste O11/Solvents (Note 1)

1.62

$-$

Atmosphertc

$80 / 98^{\circ} \mathrm{F}$

None

40,000

13.5 Ft Diameter X 37.5 Ft Height (sidewa11)

ASTM A-516

ASIM A-516

-

ASTM $\cdot A-36$

ASIM A-106

-

$2^{\prime \prime}$ Calcium S111cate

Shallow Dished Top, Flat Bottom

Primer--Per Sect1on 11.430 of these Specificatior

High Temperature Baked Epoxy (Note 1)

(1) 2-24" Flanged Manholes (See Note 3d.)

(2) Caged Ladder \& Platform

(3) Lifting Lugs (Number and Location to be manufacturer's standard)

(4) Insulation Supports (See Specification Subsect1on 12, Engineering Standard ES-4.13-2)

(5) Piping Support Lugs

(6) Handrail

(7) Grounding Lugs (See Specification Subsection 12 , Engineering Standard ES-1.2-9)

(8) Flame Arrestor (See Note 3b.)

(9) Breather Valve (See Note 3c.)

(10) Mechanical Type Level Indicator (See Note 3a.)

(11) Identification Plate (See Note $3 e$. )

\begin{tabular}{|c|c|c|c|c|c|c|c|}
\hline \multirow{2}{*}{ 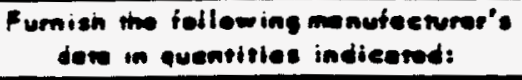 } & \multicolumn{3}{|c|}{ NUMEER OF COPIES } & \multirow{2}{*}{$\begin{array}{l}\text { TPE OF DATA } \\
\text { (EONTINUEO) }\end{array}$} & \multicolumn{3}{|c|}{ NUMBER OF COPIES } \\
\hline & Wridel & Aserenal & Conitied & & W/Bidet & Aberterel & 1 Sertifie \\
\hline ¿. Ourtine dimensucesal orawine & 1 & & & 1. Inseallation instrustions & 1 & & 1 \\
\hline 2 Pertamence dav & & & & & 1 & & $\perp$ \\
\hline 3. Wesint of couromint & & & & & 1 & & 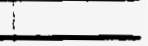 \\
\hline 4. Desernotive tlierabure & & & & & 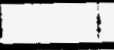 & & 1 \\
\hline
\end{tabular}

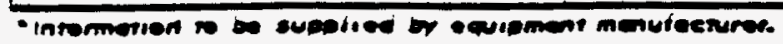




\section{CARBON STEEL TANK DATA SHEET \\ DS-YEM-S8303-11 \\ PAGE 2 OF 5}

NOTES :

1. Process Fluld

Components: Perchlorethylene
Tr1chlorethylene
Freon 113
Toluene
Xylene
Bexane

Yethylene Chloride

PCB's

Waste 011

Water

U-235 (less than 1\% by wt.)

The tank coating shall be sultable for immersion in the above

fluld and shall be in accordance with Subsection 11.450 of

these Specifications. All welding and fabrication shall be

completed prior to the application of the coating.

\section{Construct1on}

a. The tank shall be O.I. 11sted, and shall be supplied with the appropriate U.L. Ilsting mark, and constructed in accordance wth OL-142-1980, Standard of Safety for Steel Aboveground Tanks for Flammable and Combustible L1quids.

b. The tank shall be constructed in strlct accordance with the ASME Boiler and Presare Vessel Code, Section VIII, Division I, and Section IX (Welding Qualifications), 1980 Edition. The ASME code stamp w1ll not be required. The tank supplier shall have his quality control plan, welding procedures, and welder's or operator's qualifications avallable for review prior to start of fabrication. The Contractor officer shall have the option to inspect the vessel prior to, duriag, and upon completion of fabrication. The tank supplier shall not1fy the Contracting offlcer not less than one week before fabrication is complete.

c. After all welding is completed, all welds shall be ground smooth, and all sharf corners or edges on the vessel shall be ground to prevent possible injury to operating personnel. The ressel shall then be cleaned of all foreign matertal, grease, and dirt.

d. After welding, grinding, and cleaning the vessel shall be filled with water and held full for two hours with no leaks. 


\section{CARBON STEEL TANR DAIA SHEE: \\ DS-YEY-S8303-11 \\ PAGE 3 OF 5}

e. Upon complet1on of the job, the tank supplier shall furnish the following laformation to the Contracting officer:

I A notarized U-I form that the tank was fabricated in accordance with the ASME code and the U.L. Standard.

II A notarized statement that a hydrostatic test was performed on the tank and that there were no leaks.

3. Accessories

a. Level Gauge (II-1,2,3,4,5)

Type:

Construction

Float:

Float Cable:

Float Gu1de W1res:

Anchor:

Anchor Weight:

Gauge Board:

Sheares:

Bearings:

Float Dlameter:

Gauge Reading Distance:

Tank Connect 10n:
Mechanical IIquid Level Indicator

316 Stafnless Steel Hollow

Shell Welded

316 Stainless Steel

316 Stainless Steel

Steel

50 Ibs

Steel

316 Stainless Steel

TFE

15 Inches

$40 \mathrm{Ft}$

Threaded

\section{Controls:}

The level gauge shall be provided with two 10 amp, 120 volt SPDT IImit switches, each independently adfustable over the full range of Indication, wth deadband less than $5 \%$ of range, mounted in a NEMA 4 enclosure.

b. Flame Arrestor

$\begin{array}{ll}\text { Installation: } & \text { Vertical } \\ \text { Construct1on: } & \text { Aluminum } \\ \text { Connection: } & 4 " \text { Flanged } \\ \text { Capacity at 10" B 0: } & 40,000 \text { SCFH } \\ \text { Meximum Pressure Orop: } & 1 \text { psig }\end{array}$

The flame arrestors shall be U.L. Histed. 


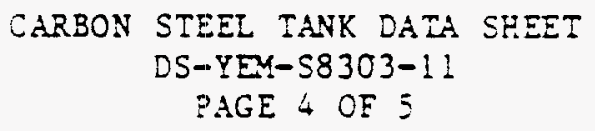

c. Breather Valve

Type:

Capacity at $10^{\prime \prime} \mathrm{H}_{2} \mathrm{O}$ :

Connect10n:

Rellef Set: igs

Press re:

Vacuum:

Construction:
Pressure and Vacuum

40,000 SCFH

4" Flanged

I" $\mathrm{B}_{2} \mathrm{O}$

Alumf num, Statnless Steel

d. Manholes:

The manhole on the top of the tank shall be fumbished with extra long bolts for emergency rellef venting.

e. Ident1ficat1on Plate:

The tank shall be furnished with a stainless steel identification plate that includes the following informat1on:

Tank Manuf acturer

Quotation Number and Date

Tank Type

Des1gn Cond1t1ons

Capac1ty

DImenslons

Materials of Construction

External Fintsh

Accessortes 


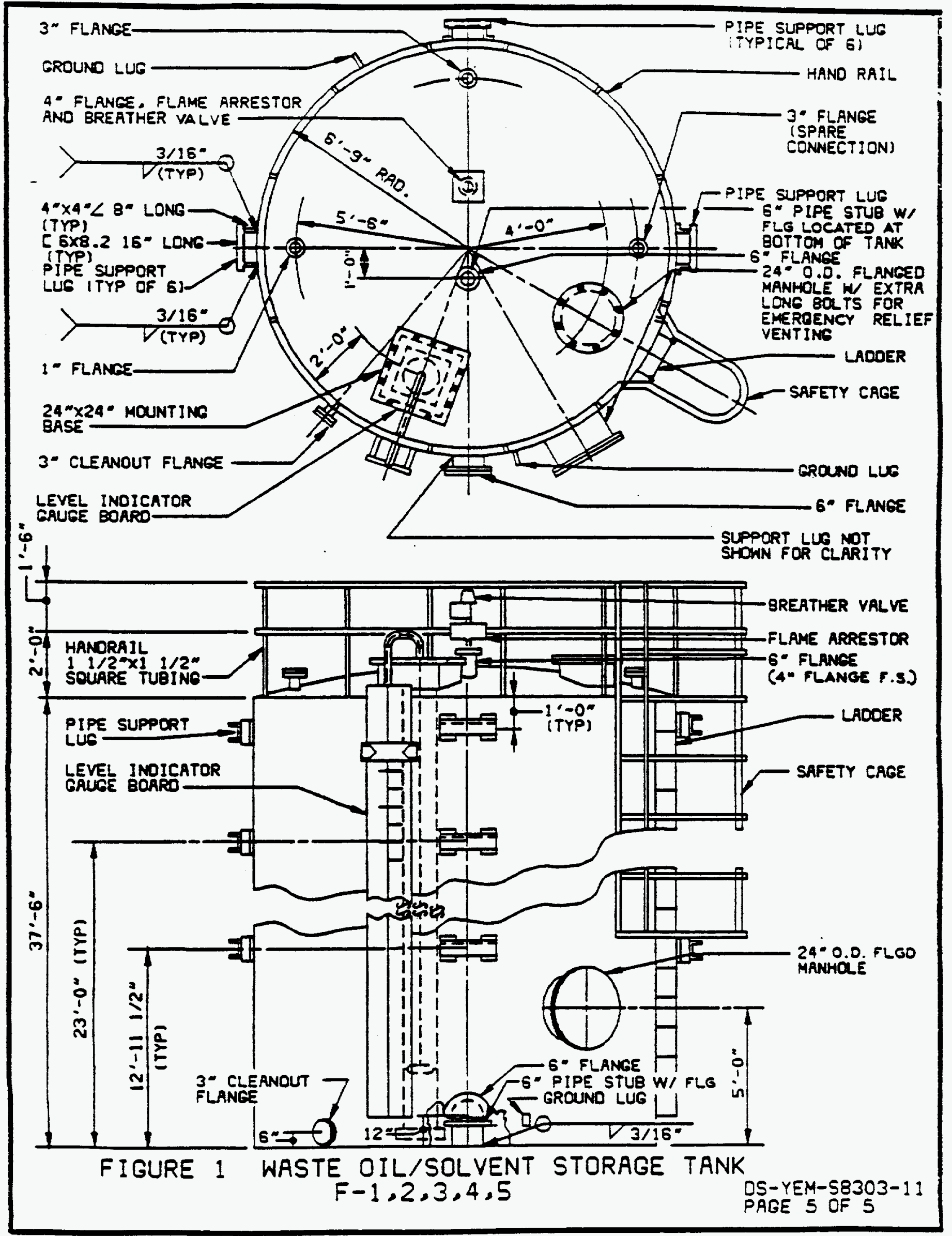




\section{OD-10 STORAGE UNIT}




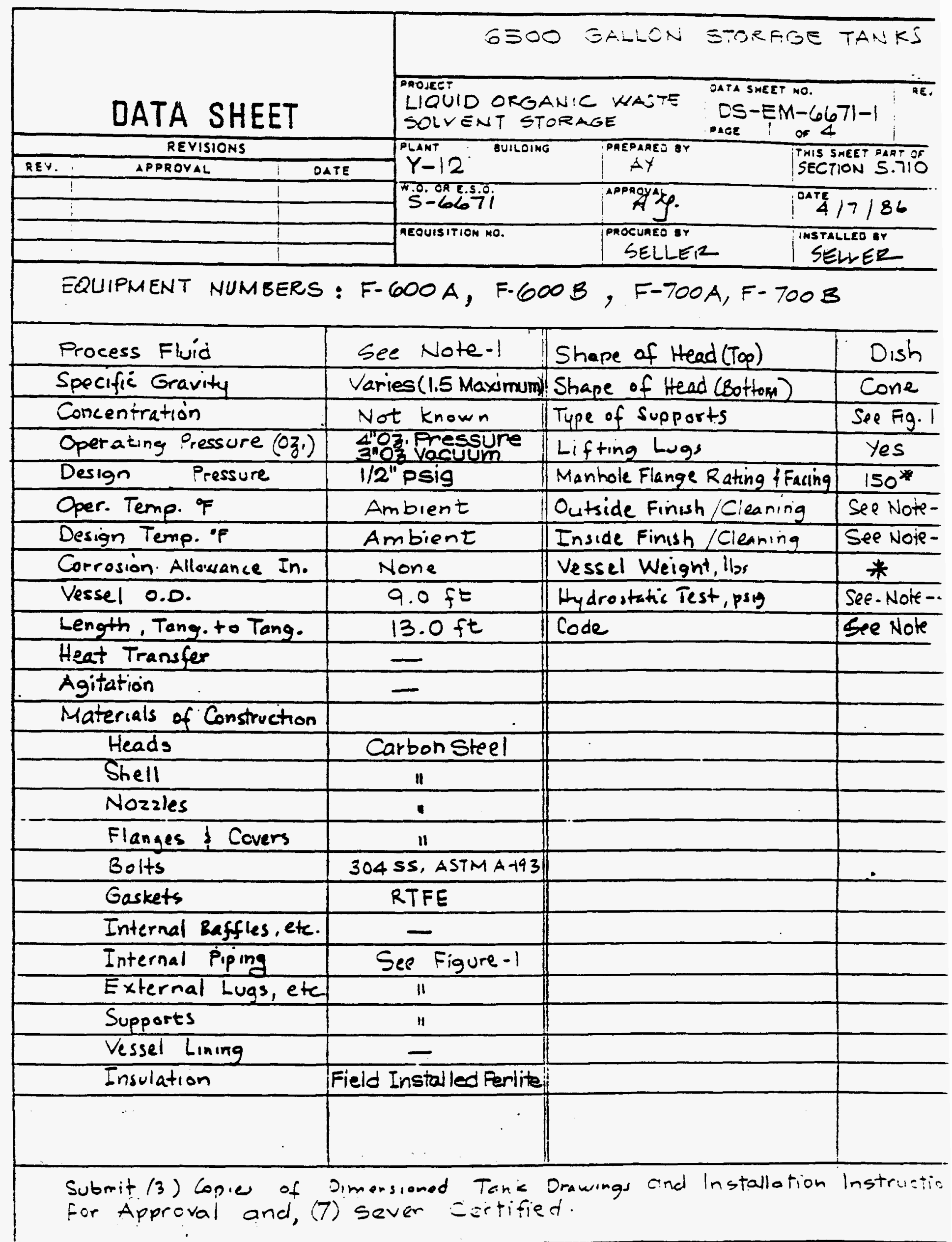




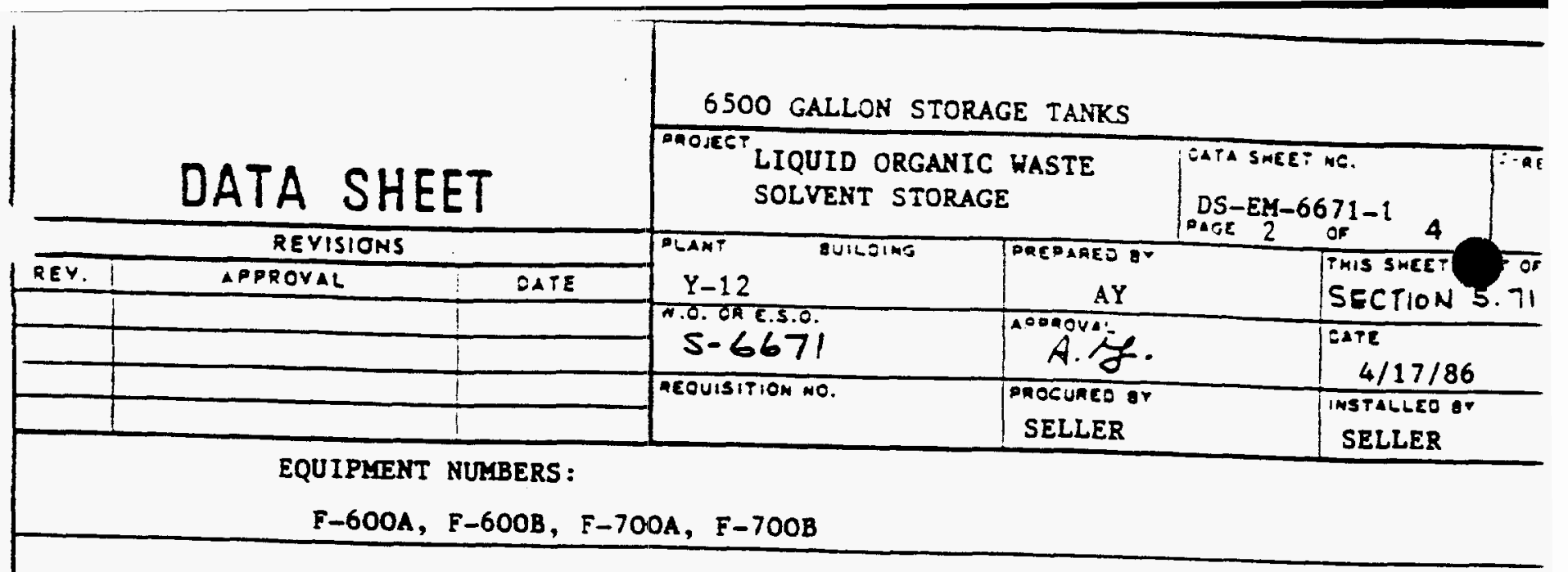

NOTES:

1. The fluid contained by the tanks shall be as follows:

Tank No. Fluid

600 A

$600 \mathrm{~B}$

$700 \mathrm{~A}$

$700 \mathrm{~B}$

Combustible Fluid (Methyl Chloroform)

Combustible Fluid (Methyl Chloroform)

Flammable Liquid

Non-Combustible Liquid (Perchloroethylene)

2. Fabrication:

a) The tank shall be constructed in accordance with UL-142 standards. Tank shall carry the manufacturer's label. Tank shall be clasisified as an atmospheric tank. All welding shall be done in strict accordance with UL-142 standards.

b) The tank supplier shall submit to the Company his quality control plan, welding procedures, welder's or operator's qualifications, and mill test reports of all stainless steel material, including welding rods, prior to the start of fabrication.

Tank components shall be carefully fitted to form joints which are free of voids. Voids at joints filled with weld metal will not be acceptable. Nozzles and/or flange faces shall be square and perpendicular to the centerline of the vessel.

3. Tanks shall be supplied with all items as noted on Figure-1, "6000 Gallon Storage Tank". Tank supplier shall provide identification plates which shall include tank size, manufacturer's name, material of construction and other relevant information.

a) The tank supplier shall have his quality control plan, welding procedures" welder's or operator's qualifications, and mill test reports available for review prior to state of fabrication. The tank supplier shall notify the company when all of the above items are

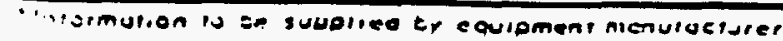


2" NFT-THREADED (COMEINATION CONSERVATION VEUT \& FLAME ARRESTOR)

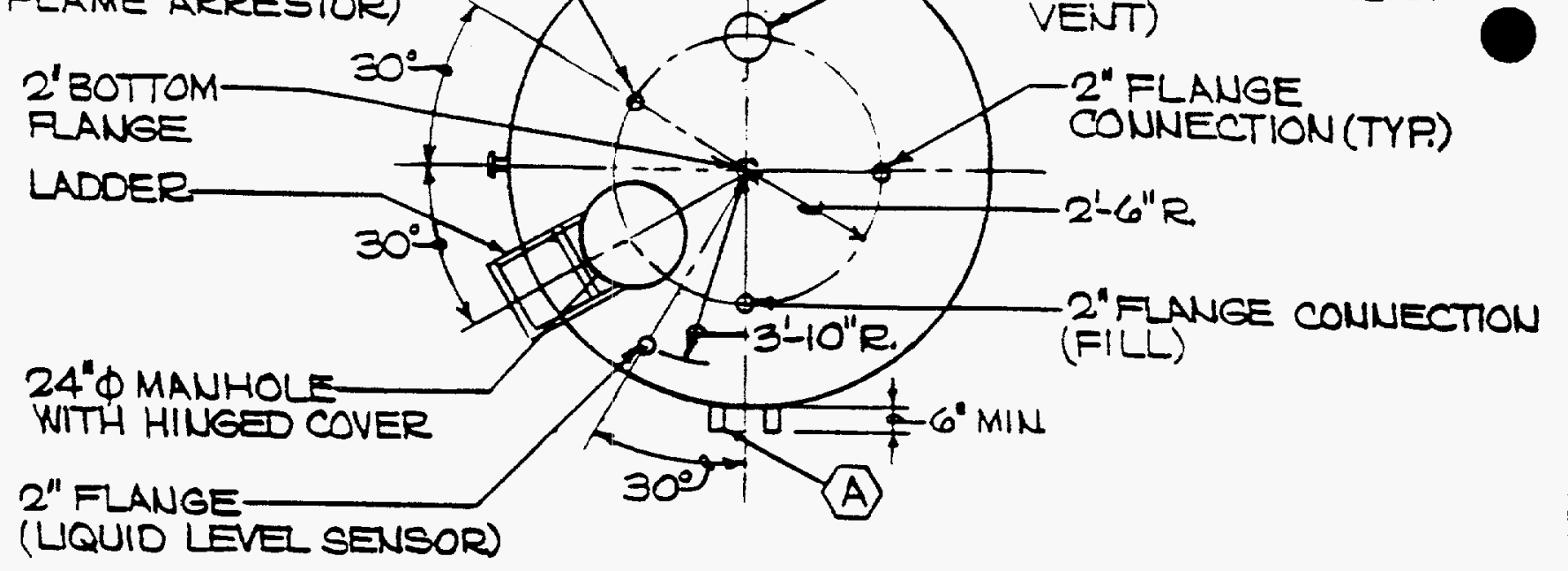

2" FLANGE
(LQUIO LEVE SENSOR)
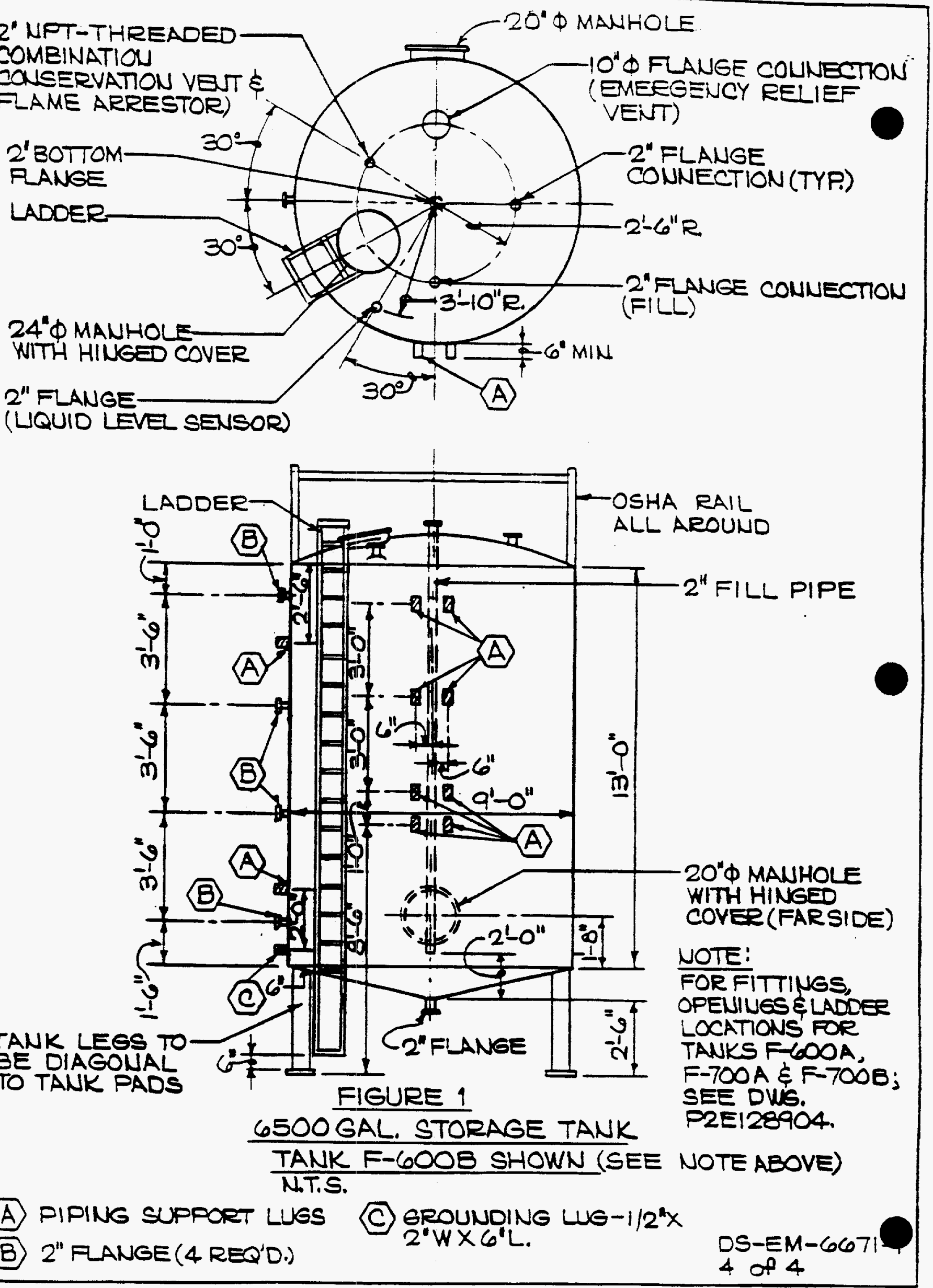

TANK LESS TO BE DIAGONAL

TO TANK PADS

\section{FIGURE 1}

10" $₫$ Flange conNectION (EMEEGENCY RELIEF VENT)

2" FLANGE

2"FLANGE CONNECTION

24"D MANHOLE 
3000 GALLON STORAGE TANKS

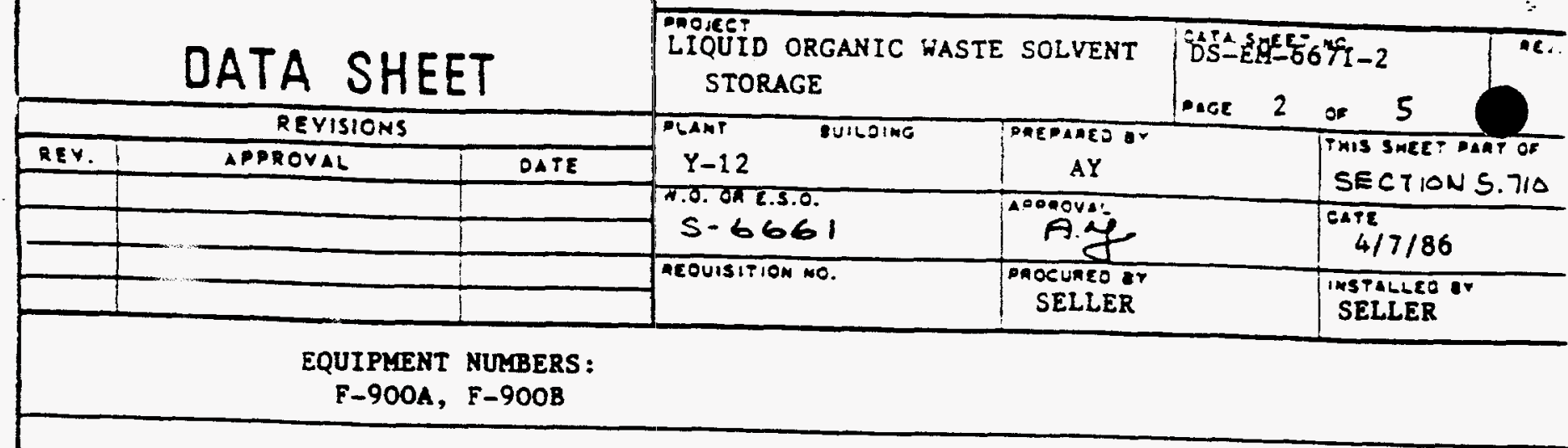

\section{NOTES}

1. The fluid contained by the tanks shall be as follows:

Tank No. Fluid

900 A Miscellaneous Liquids (Methylene Chloride)

$900 \mathrm{~B}$ Non-Combustible Liquid (Freon)

2. Fabrication:

a) The tank shall be constructed in accordance with ASME Boiler and Pressure Vessel Code, Section VIII, Division 1, and Section IX. The ASME code stamp shall not be required.

b) The tank shall be flabricated in accordance with the following comments :

Material Specifications:

Chemical Composition: All stainless steel items furnished shall have a maximum carbon content of 0.308 heat (formerly ladle) analysis.

Buey Test: The tank supplier shall furnish manufacturer's certified reports (Mill Test Reports) that all stainless steel items furnished are capable of passing the luey nitric Acid Test in accordance with ASTM A-262 Practice "C", with a maximum average corrosion rate of 0.0020 inch penetrations per month.

Material Finish: All stainless steel items furnished shall be thoroughly precleaned, descaled (pickled), acid cleaned (passivated), and inspected after cleaning, in accordance with ASTM A-380. Acid cleaning (passivation) shall be the last step in cleaning, and the acid shall be washed from the surface of the material. The surfaces shall not be pitted or intergranularly attacked.

c) All fabrication shall be in strict accordance with the ASME Boiler and Pressure Vessel Code. The first pass weld shall be by the inert gas tungsten arc procedure backed wtin heliut 


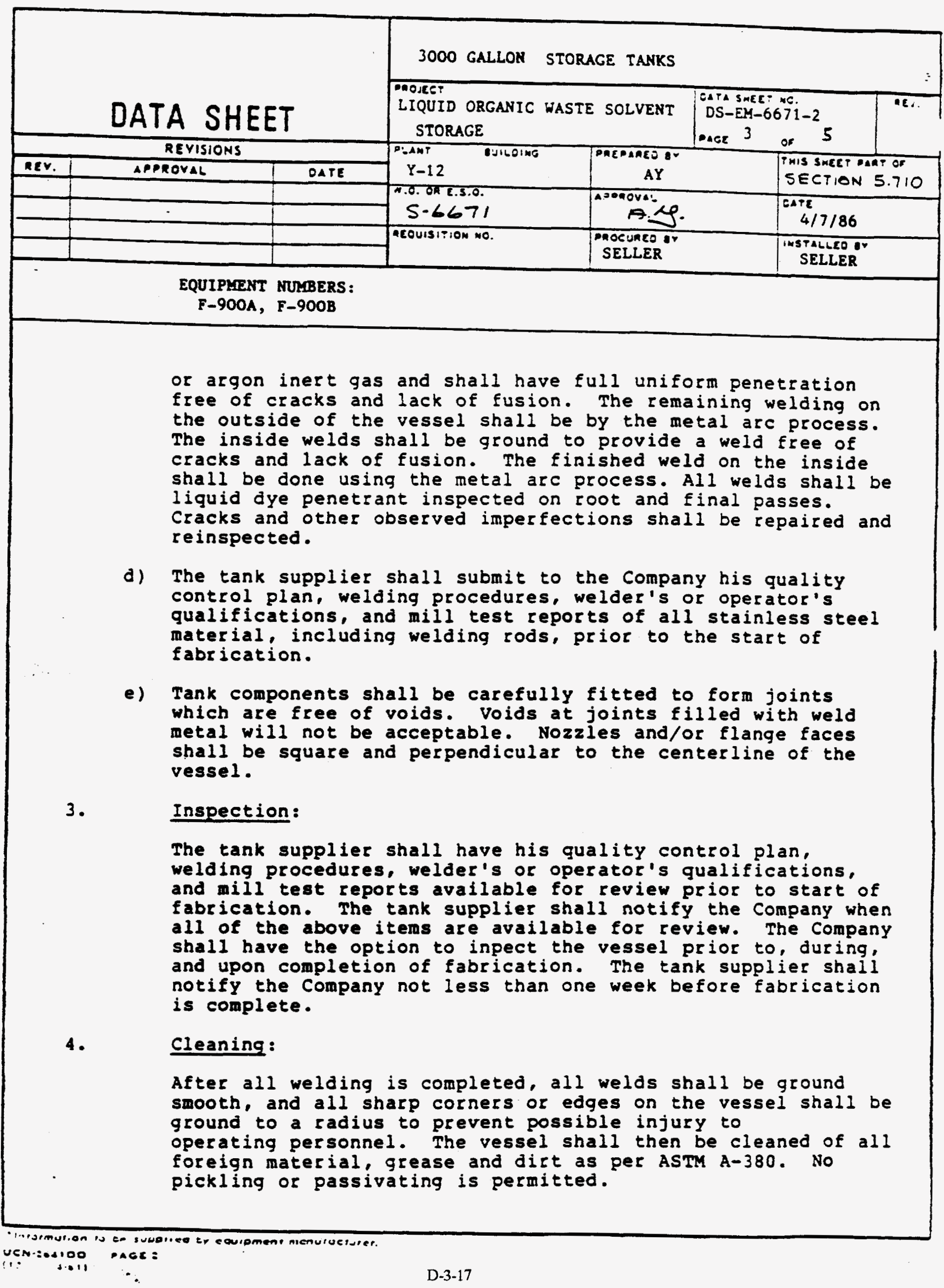


2" NPT-THREADED

(SPRING LOADED

BREATHER VENT है

FLAME ARRESTOR).

2" BOTTOM

FLANGE

LADDER

$24^{\prime \prime} \varnothing$ MANHOLE

WTH HINGED COVER

$2^{\prime \prime}$ FLANGE

(UQUID LEVEL SENSOR)

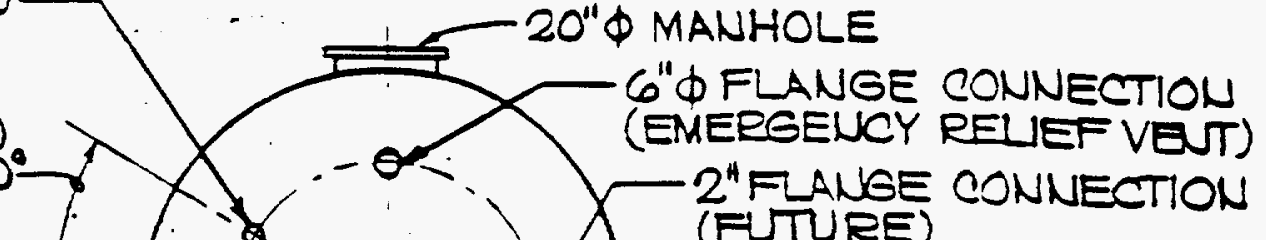

(FUTURE)

TANK LEGS

LADDER

TO BE DIAGONAL

TO TANK PAD

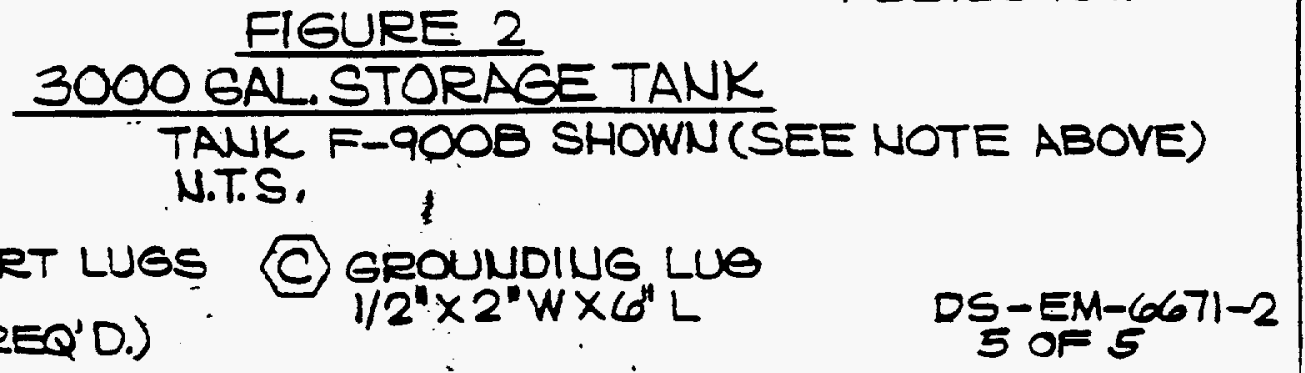

OSHA RAIL ALL AROUND $2^{\prime \prime} F I L L$ DROP PIPE $20^{\circ} \phi$ MANHOLE WTH HINGED COVER (FAR SIDE)

NOTE:

FOR FITTINGS, OPENILSS ELADDER LOCATIONS FOR TANK F-900A; SEE DWG. P2E128904,

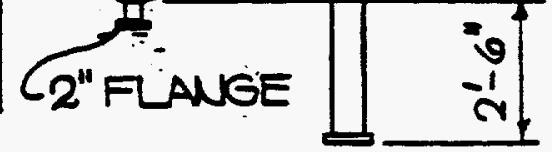

FIGURE 2 5 of 5 


\section{ETE CONSULTING ENGINEERING, INC. \\ P. O. $80 \times 3471$ Oak Ridge, TN 37831 \\ 311 Oak Ridge Turnpike \\ PHONE: 515.482 .4053 or 546.0154}

President

LARRYE. BARNETT.M. B. A.
Sereror. Treaturer PARIS R. WALKER, JP, P. E

July 20,1988

Mr. Mark Burris

Martin Marietta Energy System, Inc.

HSEA

P.O. BOX 2009

BIDG 9116, R00m 108

Mail stop 1

Oak Ridge, IN $\Xi 7830$

RE: RCRA Tank Iategrity Assessment Contract $=32 \mathrm{~K}-\operatorname{CI} 173 \mathrm{~V}$

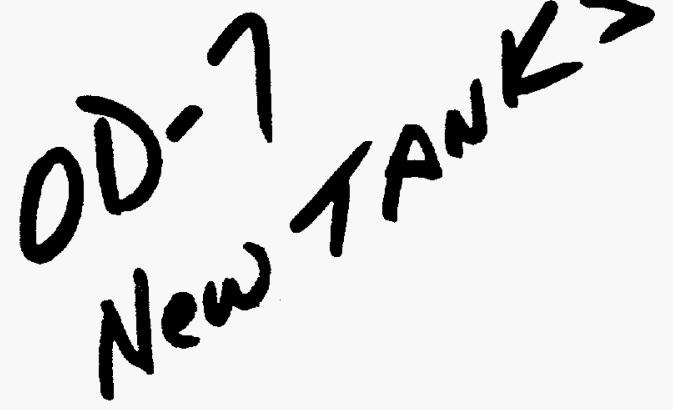

The scope of work under this contract was to perform an Integrity Assessment of eight (8) tanks and one (1) sump. The assessment is to comply with all requirements of the code Federal Regulation, 40CER section 255.191 "Assessmed of Existing Tank Systems Integrity", state, and local regulations. The Federal Register, Volume 51, Number 134 dated Monday July 14, 1986 Subpart J-Tank Systems section 265.191 Assessment of existing tank system's integrity, in summary states: The owner or operator of existing tanks which do not have secondary contaminants sust be inspected to determine that the tank system is not leaking or unfit for use. The assessment must deteraine that the tank system is adequately designed and has sufficient structural strength and compatibility with the waste to be E

Exhibit D-3. Results of Integrity Assessnents for 9409-5 Tanks. 
Mr. Mark Burris

July 20, 1988

Page $\leq ?$

stored or treated to ensure that they will not collapse, rupture, or fail. At a minimut this assessment rust consider the following: "1) Design standards if available accordirg to which the tank and ancillary equiprent were constructed; 2) Hazardous characteristics of waste that have been or will be handled; 3) Existing corrosion frotection; 4) Documented age of tank system if available, (otherwise an estimate of age); and 5 ) Results of a leak test, internal inspection or other tank integrity exarination, such that (i) For pon-enterable underground tanks this assessment wust consist of a leak test that, is capable of taking in to account the effects of temperature variations, tank end deflection, vapor pockets add high water table effects, (ii) for other than non-enterable underground tanks and for anciliary equiprent, this assessment must be either a leak test as described above or an internal inspection andior other tank integrity examination certified by an independent qualified register professional engineer, in accordance to $270.11(d)$ and address cracks, leaks, corrosion, and erosion.

The work location of the tanks and surpare as follows: SITE 1. At this location three underground storage tanks numbr 834-U, 835-U, and 836-U are located behind building 9754 . SITE 12 Four above ground storage tanks number 837-A, 2326-A, 838-A, Exhiblt D-3. Results of Integrity Assessnents for 9409-5 Tanks 
Mr. Mark $\equiv u r j i s$

July 20,: :988

Page $=3$

and 232i-A are located south of bujlding 9404-5. SITE=3 one above graud nitric acid storage tank numer 1300-t is located east of building 9204-4. SITE 4 At this location is a sump pit lesignated as number $2100-U$ and is located south of building $9201-4$

\section{$\underline{\text { SITE }=1}$}

A field iaspection of SITE l tanks was performed on January 15, 1988. information supplied by Mark Burris is as follows: Tank \$834-j ieast $(3 n k)$ is a 10,000 gallon undergrousd unprotected steel tark which is used to store PCB contaminated waste oil and is approximately 11 years old. At the tise of the inspection, the tank was said to be empty. Underground tank $\$ 835-U$ is a 10,000 gallon 24 year old unprotected steel tank containing waste oij contaminated with PCB's and trace solvents and uranium contaminarts with uranium being less than 30 parts per liter. The tank was said to be full. Underground tank $\$ 836-U$ (west tank) is a 20,000 gallon 24 year-old unprotected steel tank containing waste oil contaxinated with FCB's, trace solvent and uranium esatarination with uranium less than 30 parts per liter. The tank was said to have 17,000 gallons. Mr. Burris stated tiat it would not he feasible to conduct hydrostatic test

Exhiblt D-3. Results of Integrity Assessments for 9409-5 Tanks (continued). 
Mr. Mrak Burris

July 20,1988

Page 4

on thesc tasks because of lack of place to temporary store contaminants and lack of proper equiprent. Mr. Burris stated an utrasonic and hydrostatic test was conducted on all three tanks in 1979. It is recommended to refer to report presared by Geotek Engineering Company in latter gart of 1986. This report included investigations of subsurface soil using atrgering borings, field monitoring including ground water level measurements in borings, field testing of soil resistivity, soil mechanics laboratory testing of samples, compliance evaluation of federal, state, and other agencies requirements, desiga' evaluation and assessment of Y-12's UST design standards as compred to EFA's. regulations and guidance documents, and probabilistic assessment including analysis of each tank to evaluate the probability that tank content have been released into the environment. Since these are unprotected steel tanks which do not contain any secondary containment, it is wy recomrendation to empty tanks as soon as permissible and remove in accordance with guidelines. According to Mr. Burris, renoval is the plan of MMEs as soon as waste can be emptied.

\section{$\underline{S I T E}: 2$}

A field inspection of SITE 2 tanks was performed on May 10, 1988. Present at this inspection were Nancy Montgomery of Martin Marietta, Larry Barnett of STE, and two esployees of

Exhibit D-3. Results of Integrity Assessnents for 9409-5 Tanks (continued). 
Mr. Mark Burris

July 20,1988

P3 8 e $: 5$

Martin Marietta Maintenance Department for purpose of removing gianole covers. Tank l designated as $837-1$ (west iank) is a 30,000 gallon above ground storage tank which stores, per information supplied by Mark Burris of MMEs, waste oil and water with solvents and PCB's 5-50 PPM. Also, per Mr. Burris the tank was constructed in 1982 and the construction is mild steel with shell thickness being $3 / 16$ inch to $1 / 4$ inch and head thickness being $3 / 15$ inch to $1 / 4$ inch. At the time of the field inspection the tank had 16 feet of haste liquid (approximately half full). A hydrostatic leak pressure test could not be performed on this tank because of availably of a storage place for the waste material. The visual inspection of the exterior and limited visual inspection of the interior indicated the tank to be in a suitable condition for intended use. Rowever, several places on the exterior shell had rust spots. It was obvious these areas had had the paint skinned off during erection. It is recommended to sandblast or wirebrush rust spots, apply primer and repaint to match. Also, it is recommended yearly to take sample from tank waste material and perform laboratory analysis to determine characteristics of waste to determine if it is compatible with mild steel construction. According to Mechanical Inspection Derartaent Test and Installation Report supplied by Ms. Montgomery, this tank was inspected on June 12, 1987. A hydrostatic test was

Exhibit D-3. Results of Integrity Assessments for 9409-5 Tanks (continued). 
Mr. Mark Burris

July 20, 1988

Page 6

conducted utilizing the waste oil that was in the tank. At the time of this inspection there were no indications of leakage fros the tank and no exterior damage was noted. Also, the report states an ultrasonic thickness test indicated that the shell of the tank was .288 to . 290 jnches thick in the lower two sections, $.215-.230$ thick in the upper three sections and the top head was .218 - .223 thick. Thickness readings included paint thickness.

Next tank inspected is identified as number 2326-A (west tank) and is an above ground tank with 10,000 gallon capacity. Per information supplied by Mr. Burris the tank is used for storage of 1,1,1 trichloroethane, is constructed of mild steel, and is approximately 3 years old. This tank was visually inspected on May 10, 1988 and was found to be in good condition with the exception of a rust ring forming approximately 24 inches down from the top on the inside. The rust condition is winor at this time and it is recommended to saridblast or wire brush, apply primer, and repaint. A hydrostatic test could not be conducted on this tank because of availability of temporary storage for material. The tank was approximately 60: full at time of inspection. Again, it is recommended yearly to obtain chenical sample for compatibility f storage wastewith the mild steel tank. It is iy opinion this tank is suitable for intended use.

Exhibit D-3. Results of Integrity Assessments for 9409-5 Tanks (continued). 
Mr. Mark Burris

July 20, 1988

Page $\neq 7$

Per information supplied the tank was inspected on July 24,1986 and found to be ia very good condition. The tank. was hydrostaticalidy tested on this date by filling to capacity with potable water. No leaks fere found to exist.

Next tank inspected is identified as number 338-A (east tank) and is an above ground tank with capacity of 30,000 gallons. Per isformation supplied by Mr. Burgis the task is constructed of mild steel, installation was 1982 and material stored consist of waste ojl and water with low chlorinate solvents. No uranium or no PCB's are stored. At the time of the inspection on May 10, 1988 this tank contained 18 feet of storage material. This is approximately $1 / 2$ full. No previous inspection report was furnished for this tank. The external and internal inspection of the tank revealed it to be in good condition and suitable for inteoded use. Minor rust spots were appearing on the outside as a result of installation scratches. It is recomended to sandblast or wire brush spots, add pirimer, and repaint. Again, due to the lack of temporary storage place for the waste material in the tank a hydrostatic test was not performed. It is recommended yearly to obtain chemical sample for compatibility of storage waste with oild steel casing construction.

Exhibit D-3. Results of Integrity Assessments for 9409-5 Tanks (contimued). 
Mr. Mark Burris

July 20, is88

Page $\$ 8$

Next tank inspected is identified as number 2327-A (east task) and is an above ground 10,000 gallon tank. Per information from Mr. Buris, the tank is constructed of mild steel, contains stored waste water with no PCB's, and is approximately 3 years old. Also, per supplied inspection report, this tank ias inspected on october 24,1986 and was found to be leaking. The leak was determined by a dye penetrate test on a suspect weld of four feet in length on the bottom head in the southeast quadrant of the tank. At this time the maintenance division ground out the" weld and rewelded. A second hydrostatic test'was performed on this same date and revealed the tank in satisfactory condition. This tank was visually inspected on May 10, 1988 and contained $9 \quad 1 / 2$ feet of waste liquid which is approximately 60x full. The tank showed very slight areas of rust, no leaks were found, and tank was determined to be suitable for intended use. It is recomended to sandblast or wire brush rust areas, apply primer, and repaint. Also, it is recormended yearly to obtain chemical sample to determine compatibility of storage waste with wild steel casing construction.

All four tanks are contained in a concrete sump pit. The pit has capacity to contain storage waste from any one tank. However, the concrete walls have many cracks ond slow seepage would exist. In case of any type of catastrophic failure. the

Exhibit D-3. Results of Integrity Assessnents for 9409-5 Tanks (continued). 
Mr. Mark Burris

July 20, 1988

Page $\neq 9$.

retajning basin woul need to be pugped irrediately to minirize leakage.

\section{SITE $=3$}

This tank is an above ground fiberglass tank with nitric acid stored material. The tank is designated as $1300-A$. The tank at present does not contain secondary containrent. A mechanical inspection report was furnished dated october 10,1985 and at that time the tank was said to be satisfactory for it's present ise. Nio wall thickness weasurements could be taken because of fiberglass construction. During the october 10 , 1985 inspection a boroscope was used to inspect the internal surfaces of this fiberglass constructed nitric tank and no flaws were seen. The appearance of walls and heads of tank were smooth and without appearance of cracks and loose strains of fiberglass. Tank support legs looked as if they were in need of grouting. My field investigation on January 15,1988 indicated the tank to be in good condition. However, a hydrostatic test could not be performed. It is wy recommendations to install a secondary containment around this tank as a safety precaution. Containment can be constructed of concrete blocks but will need to be lined on inside with material such as fiberglass which is compatible with nitric acid.

Exhibit D-3. Results of Integrity Assessments for 9409-5 Tanks (continued). 
Mr. Mark Burris

July 20,1988

Page 110

\section{SITE:4}

This site contains a large underground vault designated as tank 2100-U. At the time of the field inspection the underground vault was completely filled with liquid solution which was assumed to be water. It is recommended to take samples at various depths (approximately 1 foot intervals) of liquid to determine cbemical characteristics. In my opinion, after reviewing the construction drawings of this tank which indicates concrete construction, this tank would not be water tigbt; therefore, having leakage. It should be determined if this tank has any future use and if not it is recommended to remove liquid and eitber remove tank or fill with concrete.' It is my opinion there exist to many leaks in this tank to even to attempt a hydrostatic test. Also, the number of pipe openings is unknown.

If any additional information is needed please feel free to contact our office at 482-4053.

sincerely,

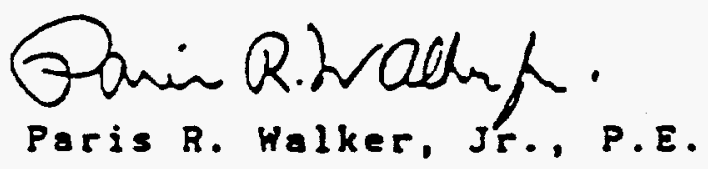

PRWJr/db

CEN : RUSHLTR

Exhibit D-3. Resalts of Integrity Assessnents for 9409-5 Tanks (contimued). 


\section{MECHANICAL INSPECTION DEPARTMENT \\ TEST AND INSPECTION REPORT}

\begin{tabular}{l|l}
\hline MIO.NO. & MAINTENANCE NO. \\
$1122-0252$ & \\
\hline
\end{tabular}

\section{EOFEUUPMENT}

naste Oil Storage iank

LOCATED BUILDING

$\$ 409-5$

SATE INSPECTED

$6-12-87$

INSPECTOA

L. E. Hoover

PROPEATYNo.

Y261440

oremation no.

2363 Ti03 Tank $=006-1$ File $\$ 837$

\begin{tabular}{|l|l|}
\hline YL. & COL \\
SOUth
\end{tabular}

$4-2353$

INSPECTION ANO TEST OF THIS EQUIPMENT INOICATES:

$\begin{array}{lll}\square \text { SATISFACTORY } & \square \text { UNSATISFACTORY } & \square \text { UNSAFE } \\ \square \text { NEEDS REPAIR } & \square \text { TAGGEO OUT } & \square \text { ENGINEERING CHANGE REOUIRED }\end{array}$

ihis 30,000 gal. Waste $0 i l$ tank was visually inspected and a hydrostatic test was conducted utilizing the waste oil that is in the tank. There is no indications or leakage from the tank and no external damage was noted.

Ultrasonic thickness test indicated that the shell of the tank was .288 to .290 thick in the lower two sections, .215 to .230 thick in the upper three sections and the top head is .218 to .223 thick. Thickness readings include the paint thickness.

inis tank is satisfactory for continued service.

\section{ACTION RECOMMENDED}

1.1 Condition contritures orobeble er imminent tellure of eceident ond immodiere correcrion should be mode.

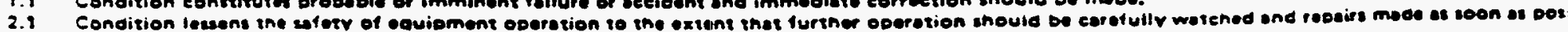

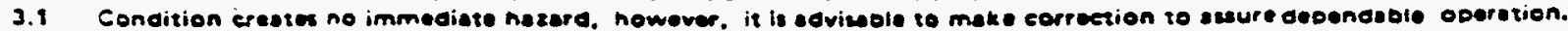

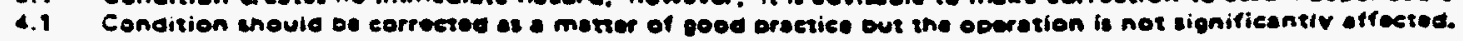

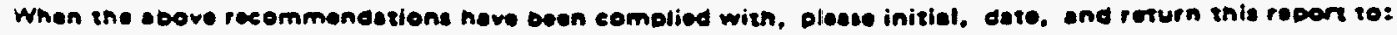

$$
\text { K. D. Calfee }
$$

H. Holden, $9983-48$, MS-001

rlle - NORC

Exhibit D-3. Results of Integrity Assessments for 9409-5 Tanks 


$$
1 / 22-0052
$$

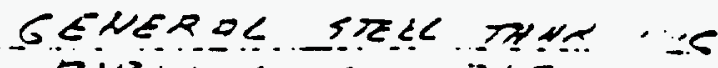
Bipi,i, $=0<$ : $\therefore$

- BuI! 1982

$Y 261440$

$E=5 \pi \operatorname{siot}$

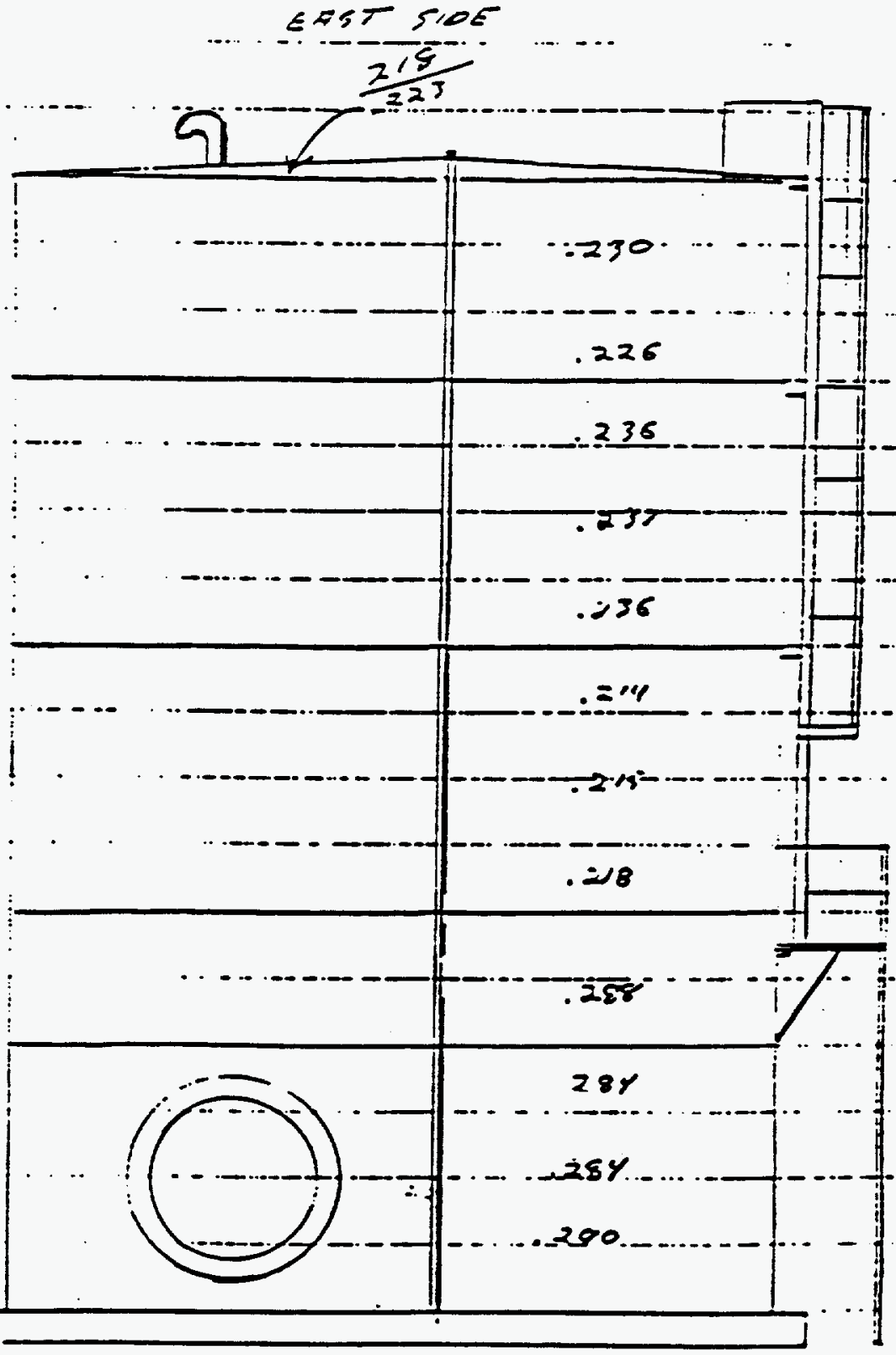

HCIEUT 35 ET

DNA. . . . 38 R

Exhibit D-3. Results of Integrity Assessnents for 9409-5 Tanks (continued). 


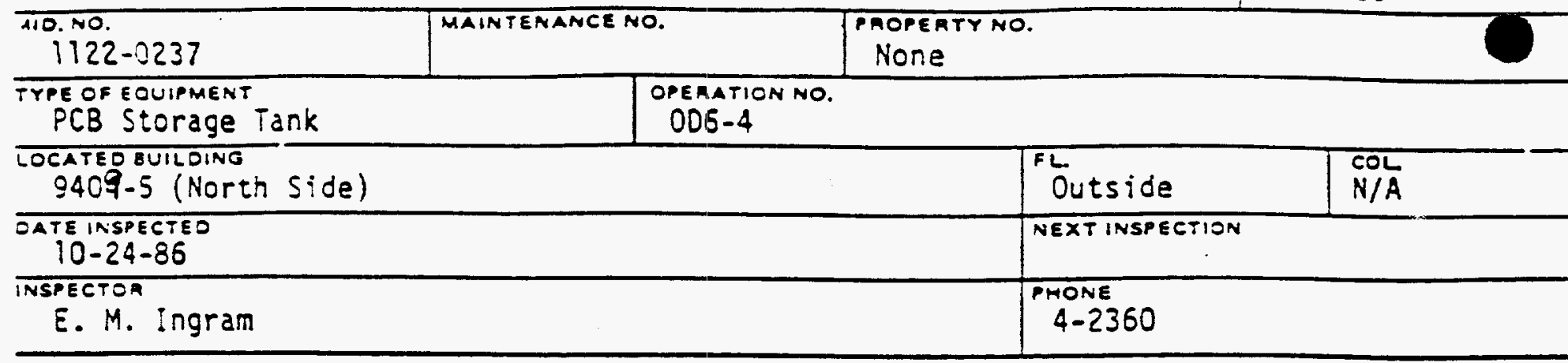

INSPECTION AND TEST OF THIS EQUIPMENT INDICATES:

为 SATISFACTORY

NEEDS REPAIR
UNSATISFACTORY

TAGGED OUT
UNSAFE

ENGINEERING CHANGE REOUIRED

\section{RECOMMENDATIONS}

This 10,000 gallon carbon steel storage tank located in the east end of dike 9500-0025 north of 9404-5 was hydrostatically inspected and was found to be leaking. Further investigation by the use a dye peneirate test on a suspect weld of 4 foot in length on the bottom head in the south east quadrant of tank showed voids in weidment. It was apparent by visual inspection of weld the fit-up was dissimilar when welded. Maintenance Division ground out weld and rewelded.

\section{ACTION RECOMMENDED}

A second hydrostatic test was performed 10-24-86 with tank suspended on cross ties to reveal the bottom of tank. Results of test found tank in satisfactory condition. Plans are to recoat bottom of tank and lower it to concrete pad. Thickness readings were taken with the following results: Heads - .259" to .269"; Shell - .268" to $.277^{\prime \prime}$.

1.1 Condition connitutes probable or imminent failure of eceident and immediete cerrection should be mede.

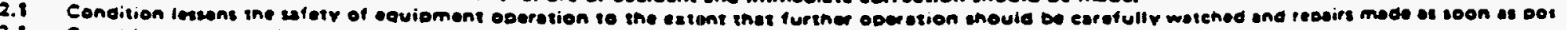

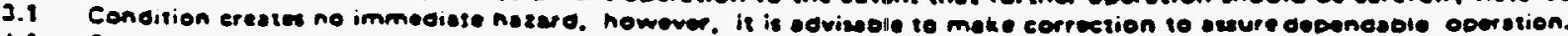

4.1 Condition moula be corrected as a merter of pood orectice but the operation is not sienifleantiy atfected.

Whan the obove recommonestient have opon complied with, pleas initibl, wete, ond roturn this report to:

K. D. Calfee

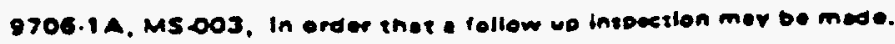

J. Holden, $9983-48$, MS-001

File - NORC Exhibit D-3. Results of Integrity Assessnents for $9409-5$ Tanks D-4-13 (cont 


\section{MECHANICAL INSPECTION DEPARTMENT \\ TEST AND INSPECTION REPORT}

\begin{tabular}{|c|c|c|c|}
\hline 1122-225 & MAINTENANCE NO. & propentrano. & \\
\hline $\begin{array}{l}\text { EOF EQUIPMENT } \\
\text { Atmos. Storage Tank }\end{array}$ & OPERATH & & \\
\hline $\begin{array}{l}\text { OOCATED BUILOING } \\
\text { OD } 6 \text { Facility SO. of }\end{array}$ & $9404-5$ West Tonk & Outside & $\cos$ \\
\hline $\begin{array}{r}\text { SATE INSPECTED } \\
7-24-86\end{array}$ & & $\begin{array}{l}\text { NEXT INSPECTION } \\
7-25-87\end{array}$ & \\
\hline $\begin{array}{l}\text { RSPECTOA } \\
\text { L. E. HoOver }\end{array}$ & & $\begin{array}{l}\text { PMONE } \\
4-2353\end{array}$ & \\
\hline
\end{tabular}

INSPECTION AND TEST OF THIS EOUIPMENT INDICATES:

SATISFACTORY

NEEDS REPAIR
UNSATISFACTORY

TAGGED OUT
UNSAFE

ENGINEERING ChANGE REOUIRED

RECOMMENDATIONS

: The above tank is a 10,000 gal. mild steel storage tank to be used for storage of 1,1,1 trichloroethane. It was inspected externally and found to be in very good condition. The tank was hydrostatically tested by filling to capacity with potable water. No leaks were found to exist. This tank is suitable for intended use.

\section{ACTION RECOMMENDED}

This tank will be added to MID inspection schedule to be inspected externally on a yearly basis and internaliy every five years.

$$
\cdots
$$

1 Condition conmtitutw brobeble or imminent failure or veeident end immediate eerreetion shoule be made.

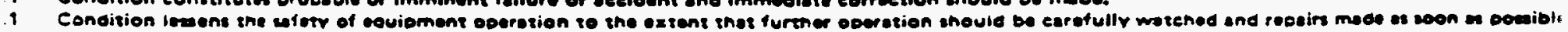

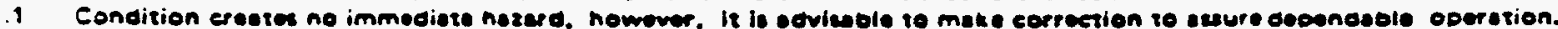

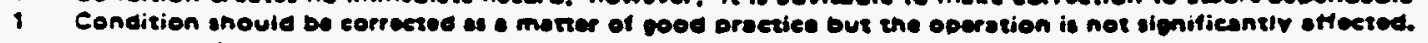

Men the ebove recommandetions hove been complied with, plesse initisl, dete. snd return thls cepont se:

$$
\text { K. D. Calfee }
$$

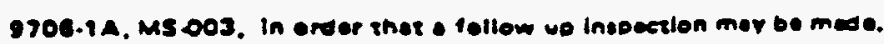

\section{DISTAIOUTION}

J. M. Holden, $9720-6$, MS-001

File - NORC

Exhibit D-3. Results of Integrity Assessnents for 9409-5 Tanks (continued)

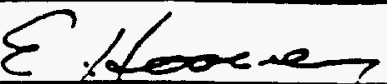

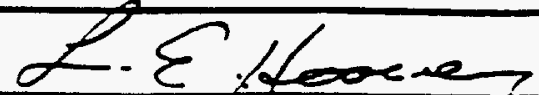

\section{1. a cices}

rioceviene 
RCRA TANK INTEGRITY ASSESSMENT CONTRACT \#32K-CTI73V MODIEICATION A

PFEPARED FOR:

MARTIN MARIETTA ENERGY SYSTEM, INC IIQUID ORGANIC WASTE SOLVENT STORAGE FACIIITY

B Y :

ETE CONSUITING ENGINEERING, INC. P.O. BOX 3471

OAK RIDGE, TENNESSEE ETE IOB NO. $87-391-3$

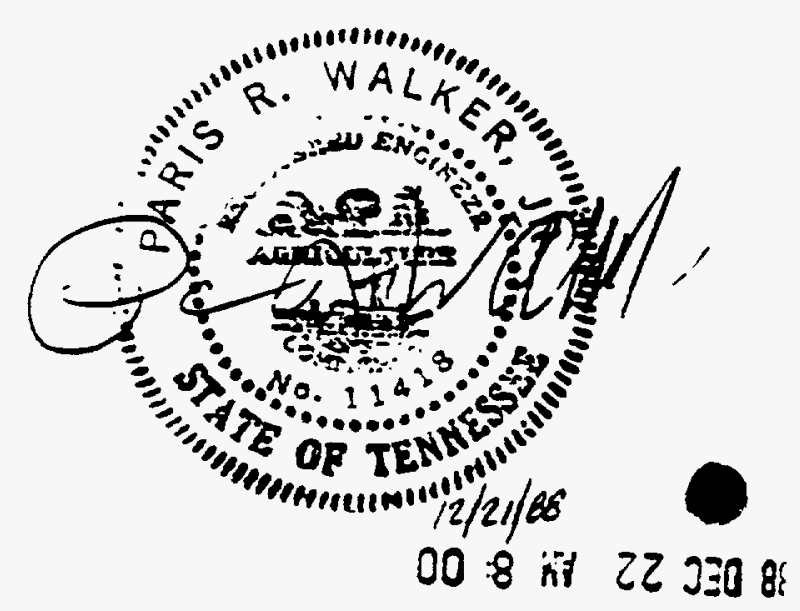


The Liquid Organic Waste Solvent Storage Facility is located in the extreme western end of the Y-12 Plant area and is further located as being contained in dike no. 9500-0101. The facility consists of (4) four 6,500 gallon carbon steel tanks identified in the field by tags reading 1122-0479, 1122-0480, 1122-0481, and 1122-0482 and (2) two 3,000 gallon stainiess steel tanks identified with tags reeding $1132-0255$ and 1132-0256. There was no written document supplied correlating the Equipment Testing and Inspection Report no. noted on each tank and the tank number listed in the RCRA Part B Permit Application and on the hydrostatic test certificates. The (6) six tanks are contained within dike No. 9500-0101. A smaller dike, No. 9500-0103, is attached to the northwestern end of dike No. 9500-0101 but is a totally separate unit designed as an aqueous reteation basin for the collection of rainwater contaminated by operations at this facility.

Information pertinent to the assessment of this facility, supplied by Martin Marietta Energy Systems, Inc., is as follows: 1) Pages from RCRA Part B Permit Application for the Liquid Organic Waste Storage Facility. As a part of this document is page C-l listing the materials to be stored at this facility, page C-2 listing the waste category, storage container (by numer), and waste description, and page D-2 listing the tanks by number (corresponding to page $c-2$ ), materials used in their construction, capacities, and their proposed contents. Pages $\mathrm{C}-1, \mathrm{C}-2$ and $\mathrm{D}-2$ have been photo copied and attached with this document for reference. 2) Equipment Testing and Inspection Reports (ET \& IP), dated August 24, 1988, for tanks 1122-0479, 1122-0480, 1122-0481, 1132-0255 and 1132-0256. No ET \& IR was provided for tank 1122-0482. 3) ET \& IR report for dikes 9500-0101 and 
9500-0103 dated August 24, 1988. 4) Noterized certificate of hydrostatic tests for tanks F-600 A \& B (carbon steei), F-700 A \& B (carbon steel) and F-900 A \& B (stainless steel) as weil as other certificates for additional tests. 5) Miscellaneous Vendor Data, Routing and Analysis Sheets.

A field inspection was made on October 11, 1988 of the liquid Organic Waste Solvent Storage Facility. Present during the inspection was Paris R. Halker, Jr., P.E. and Thomas P. Whitson of ETB Consulting Engineering, Inc.

The site consists of (4) four 6,500 gallon carbon steel taoks and (2) two 3.000 gallon stainless steel tanks. The (6) six tanks are totally contained within the concrete dike area no. 9500-0101.

An Equipment Testing and Inspection Report dated August 24, 1988 indicated that a hydrostatic test was performed on the dike and the facility was found unsetisfactory for its intended use. It was noted repairs were being made during the October 11 th inspection. Cracks in the dike were being sealed using a reinforcing fiberglass cloth and resin compound. After the appropriate curing time for the repair materials it was recomended that another hydrostatic test be conducted to determine success of the repairs.

Within the dike each tank is resting on steel supports which raise the tank bottom approximately 18 to 24 inches off the bottom of the dike floor. A visual inspection of the supports reveaied no problems of cracks 
or stress. The tanks and dike are totally exposed with no overhead or side cover.

Both the 6,500 gallon carbon steel tanks and 3,000 gallon stainiess steel tanixs have been wrapped or coated in a fiberglass cloth and coated with a resin type paint. The top and bottom of the tanks have undergone the same exterior treatment. The exterior coating or shell serves as a barrier to minimize the tanks outer shells exposure to corrosive elements and to act as insulation.

At the time of the October 11 th inspection the tanks were sealed and examination of the interior of the tanks was not possible. During a follow up inspection October 18 th the top portals were opened and a visual inspection of the tank interiors were made. The interior of all (6) six tanks, carbon steel and stainless steel, were unlined with bare metal exposed. The carbon steel tank interiors were coated with iron oxide or rust. The outer coating on each tank makes an exterior inspection impossible at this time. However, notarized Certificates of Compliance from Bendel Corporation indicate hydrostatic testing was performed on each tank with satisfactory results.

The ancillary components of this facility, excluding the dikes, include external piping, pumpa, and a transfer networik designed to off load incoming tanks or load tanks or drums from the main tank system. The piping network consists of steel pipe, attached to the carbon steel tanks, has been painted with no other coating such as insulation. Stainless steel pipe services the (2) two stainiess steel tanks. All electrical 
lines are contained in conduit and each tank is grounded.

On November 3, 1988 Paris R. Halker, jr. and Thomas P. Whitson, both of ETB Consulting Engineering, Inc., returned to the Liquid Organic Waste Solvent to find dike No. 9500-0103 being filled with water in preparation for another hydrostatic test. A visual inspection of the dike exterior revealed several damp areas. These area were pointed out to Mr. B. M. Ingram who was preforwing the hydrostatic check.

On November 4, 1988 Paris R. Walker, Jr. returned to the site and met with Mr. Ingram who indicated despite several damp spots in the dike, the facility has passed its hydrostatic test. At that time ETE requested a copy of the test results. At the date of this report no test results has been received.

Despite its limited corrosion resistance, carbon steel is the most widely used engineering material of construction for tank and pipe service. For example, the containment of chlorinated organic solvents in carbon steel tanks present an area of concern due to potential degradation of the shell by corrosion. However, in certain instances, measures can be taken to mitigate corrosion of carbon steel components. As the carbon steel tanks at the Iiquid Organic Waste Solvent Storage are unlined, the long term life of these tanks will be less than if they were lined. On the other hand 304 stainless steel provides excellent resistance to many corrosive environments, lined or unlined.

Erosion of the carbon steel tank by abrasion should not present a problem 
because the fluids will be essentially static, except during filling and draining of the tanks under low velocity conditions. Also the components will operate at essentially ambient temperature and pressure which greatly reduces the possibility of corrosion failure.

Despite the fact these tanks were designed, built, and tested for their intended service in accordance with ATSM specifications and ASMB Code rules, annual inspections of the shell walls and pipe walls to ascertain the degree of wall thinning, if any, due to corrosive should be incorporated into the $Y-12$ Plant Maintenance Schedule.

Note should be made that dike no. 9500-0101 provides secondary containment for the Liquid Organic Waste Solvent Facility Tanks. RCRA Part B Permit Application for this facility reveals the capacity of the dike to be 39,000 gallons or 10,000 gallons more that the total of the (6) six tanks together. In case of a catastrophic failure, the dike area would need to be pumped to an appropriate container to minimize exposure of the waste and related problems.

In summary, it is wy opinion the above tanks are structurally adequate for their intended use based upon the site inspections, secondary contaiment, and the attached satisfactory hydrostatic tests. It is recommended to reassess the tanks on an annual basis. 


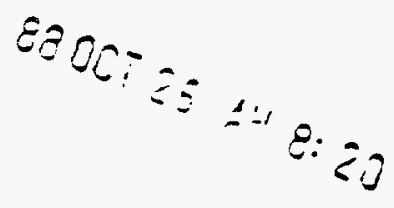

RCRA IANK INTEGRITY ASSESSMENT CONTRACT = $32 K-C T I T 3 V$
MODIEICATION A

PREPARER FOR:

MARTIN MARIETTA ENERGY SYSTEM, IN WASTE OII/SOIVENT FACIIITY

B Y :

ETE CONSUITING ENGINEERING, INC F. O. BOX 3471

OAK RIDGE, TENNESSEE ETE JOB NO. $87-391-3$

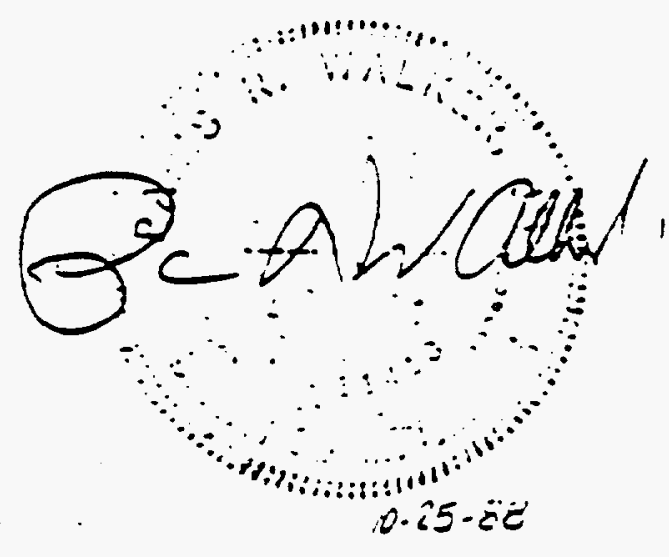


The assessment is to comply with requirements of the Code of Fedari: Regulations, 40 CER section $255.992^{\circ}$ " Vesign and installation of new tann systems or components." The Code of Federal Regulations, Iuly 1, 138: Edition, Subpart J - Tank Systems, section 265.192 in sumary states: The owner or operator of new tank systems or components shall provide a written assessment, reviewed and certified by an independent, qualifier registered professional engineer in accorcance with 40 CFR 2:0.11. Ji, attesting that the tank system has sufficient structural integrity and is acceptable for the storing and treating of hazardous waste.

The assessment will address at a minimum all applicable items and subitems of 265.192 with respect to structural strength, waste compatibility with the tank system, and corrosion protection measures to ensure it will not collapse, rupture, or fail. As this assessment deals with an above ground storage facility items or subitens (3)3(i)A, B, C, D, E, E: (a)4: and (c) will not be included as they deal with underground tank systems.

The waste Oil/Solvent Storage Facility is located southwest of Buildiag 9616-i and consists of (5) five 40,000 gallon carbon steel atmospheric tanks and an attached transfer station. The tanks, Equipment Testing and Inspection (ET \& I) No. 1122-0474, 1122-0475, 1122-0476, 1122-0477, and 1122-0478 were added to ET \& I's schedule August 12, 1988 by a report from L.E. Hoover.

Information pertinent to the assessment of this facility, supplied by Martin Marietta Energy Systens, Ini:., is as follows: 1) RCRA Part B Permit Application for the Waste Oil/Solvent Storage Facility which was initialiy 
prepared by Battelle, Columious Division. Based on this cocument ine waste to be stored at this facility consist of oil wrich may ccrtaln some water and wich may be contaminated with PCBs and uraniun. These wastes may also contain chlorinated organic solvents such as perchloroethylene, trichloroethylene, and Freon 113, as well as trace quantities of toluene. xylene, and methylene chloride. This Part $B$ document also contains general Structural Concrete Specifications noted in Part $B$ as Exhibit D-l. Caulking and Sealing Specifications noted as Exhibit D-2, and Carbon Steei Tank Data Sheets noted as D-3. 2) A letter of certification from $M$ \& Company, Inc., dated June $T$, 1988, specifying the requirements uncer which these tanks were munufactured. 3) Technical Bulletin 9500 containing specification for PLASITE 9500 Hi-Resistant Protective Coating. 4) A notarized letter of certification from Wisconsin Protective Coatings Corporation dated July 15, 1987 indicating when applied in accordance to product specifications, PLASITE 9500 is resistant in either a spill or immersion situation not exceeding $80^{\circ} \mathrm{g}$ to the waste oil mixtures and solvents outlined in RCRA Part B Permit Application for the Waste Oil/Solvent Storage Facidity. The certification from Wisconsin Protective Coatings also included Freon 112. 5) A memo from B.J. Vitatoe dated December 17, 1987 to Charlie Levin indicating the extreme weather conditions prevented hydrostatic testing of the tanks. However preumatic teating with soap and air at 7 psi found (5) five leaks in ( 1 ) one tank. No leaks were found in the other (5) five taniks. 5) A memo from J.M. Carroll of Black \& Veatch dated December 23, 1987 indicated she was present at Tennessee Metal Fabricators on December 17, 1987 and witnessed the hydrostatic testing of the last (2) two tanks. Ms. Carroll also met with Mr. Ron Camphure of Wisconsin Protective Costing Corporation who was 
present to direct the coating of the first ianik. Fi A quality Assurance Checklist complied by J.M. Carroll and dated February 10, 1988 inciudes Affidavits from Tennessee Metal Fabrjcating Corporation. indicating the tanks for the Waste oil/Solvent Storage Facility have been hydrostaticall: tested in accordance with contract specification 9.106 section 11.430 and the tanks protective coating has been tested, using the Holiday Test, is accordance with contract specification section 11.450. Also, attached the Quality Assurance Checklist was a Field Trip Report from ME. Ron Camphure of Wisconsin Protective Coatings. The report outlined his observations of the initial coating of the first tank. 8) Miscellaneous cocuments were provided detailing Liquid Level Indicators, Conservation Vent and Flame Arresters, various transmittals to and from several companies.

A field inspection was made on October 11, 1988 of the Waste Oil/Solvent Storage Facility. Present during the inspection was Paris R. Walker, Ir., P.E. and Thomas $P$. Whitson of ETE Consulting Engineering. Inc.

The site consists of (5) five 40,000 gallon vertical steel tanks setting inside a concreted dike area. An Equipment Test and Inspection Report by L.E. Hoover indicated the dike was hydrostatically tested 12-29-87 and no leaks were noted during a 12 hour hold test. A visual inspection notes the interior of the dike has been painted with an epoxy type paint and there were no visul defects in the dike.

Withis the dike containment each tank is resting on a concrete pedestal which raises the bottom of the tank approximately ( 1 ) one foot above the floor of the dike area. One bare pedestal is available for a future 
tank. A visuaj inspection of the exposed portion of each concreff pedestal revealed no cracks or evidence of siress.

The dike and tanks are totally exposed with no overinad or side cover. The attached transfer station is located under a roofed structure.

Each of the (5) five 40,000 tanks has been wrapped or coated in a fiberglass cloth and coated with an a resin type paint. The top of the tanks is domed and has undergone the same exterior treatment. The Fiberglass and resin outer layer serves as a barrier to minimize the tanks outer shells exposure to corrosive elements.

At the time of the inspection the man ways and inspection portais on all (5) five tanks were seeled and access to the internal portion of the tanks was not possible without breaking the seals integrity. The exterior fiberglass coeting on the tanks makes a visual inspection of the exterior also not possible.

While a visual inspection of the bare steel at this time is not possible. documentation has been provided in the form of certification of tests and fabrication. $M \& W$ Company indicates the tanks provided for the Waste oil/Solvent Storage Facility are according to API 650, ANSI B16.5, ASME Boiler and Pressure Vessel Code, Section IX, ASTM A-516, ASTM A-36, ASTM A-106, SSPC, UT-142. However, this certification has not been notarized.

Notarized certifications have been provided by Tennessee Metal Fabricators Corp. (T.M.E.C.) indicating hydrostatic testios has been performed on 
the tanks :a compilance with contract specification 9.105 and 11.430.

T.M.F.C. also provided notarized certifications indicating the protective coating was tested in compliance with contract specification Section No. 11.450. A pinone call to T.M.F.C. verified the above refered specificaiton sections were from theif contract CE-ACOS-860R21574.

The ancillary components of this facility, excluding the dike, include external piping, pumps, and a transfer network designed to off load incoming tanks or load tanks or druns frum the main tank system. The piping network at this facility has been insulated and wrapped in a thin metal jacket, probably aluminum. In this condition it is not possible to inspect either the pipe, welds, or connections to the tank. One area of concern is the type of materials used in the piping system. As the piping is insulated the actual pipe is not visible and no certififcaitons or specifications were provided for the pipe. The pipe materal should be of a nature and strength to carry or contain the stored liquid. No evidence was provided that the piping was provided with an interior protective coating similar to the type used in the tank. Also, existing could be the possibility of the pipe insulation contributing to corrosive attack via water dripping into pipe insulation, which could contain chloride or flouride salts. A non-halogan bearing insulation should be used or specified. All electrical service is run through conduit and each tank has been grounded.

Despite its limited corrosion resistance, carbon steel is the most widely used encineering material of construction for tank and pipe service. Eowever, in certain isstances, measures must be taken to mitigate 
corrosion of these components. The csatainment ai chiorinated organi soivents in carbon steel tanks, for instance, presents an area ot concern due to potential degradation of the sinell wall by corrosion.

However the use of an internal liner, such as the specified PLASIIE 9500 will provide a protective barrier between the potentiaily corrosiye liquid and the metal wall. If this double-coated liner is continuous, adherent. non-porous, and of uniforn thickness :0.012 - 0.015 itils) it should provide a sufficient barfier for the tanks lntended use.

Erosion of the PLASITE liner on the carbon steel tank by abrasion should not present a problem because the fluids will be essentially static, except during filling and draining of the tanks under low velocity conditions. Also the components will operate at essentially ambier. temperature and pressure which greatly reduces the possibility of corrosion failure.

Despite the fact these tanks were designed, built, and tested for their intended service in accordance with ATSM specifications and ASME Code rules, annual inspections of the shell walls and pipe walls to ascertain the desree of wall thinning, if any, due to corrosive should be incorporated into the $Y-12$ Plant Maintenance Schedule.

Based on the visual inspection of the exposed portions of the tank systea and the satisfactory results of the hydrostatic testing it is deterained the tank system is suitable for its intended use. It should be noted the dike area provides secondary containment in the eveot of leakage or 
spillage. The capacity of the tike area is approximately 7 , $3: T$ gablons. In case of a catastropnic failure, the recention area would need to be pumped immediately to an appropriate container to minimize exposure of the waste and related problems. 

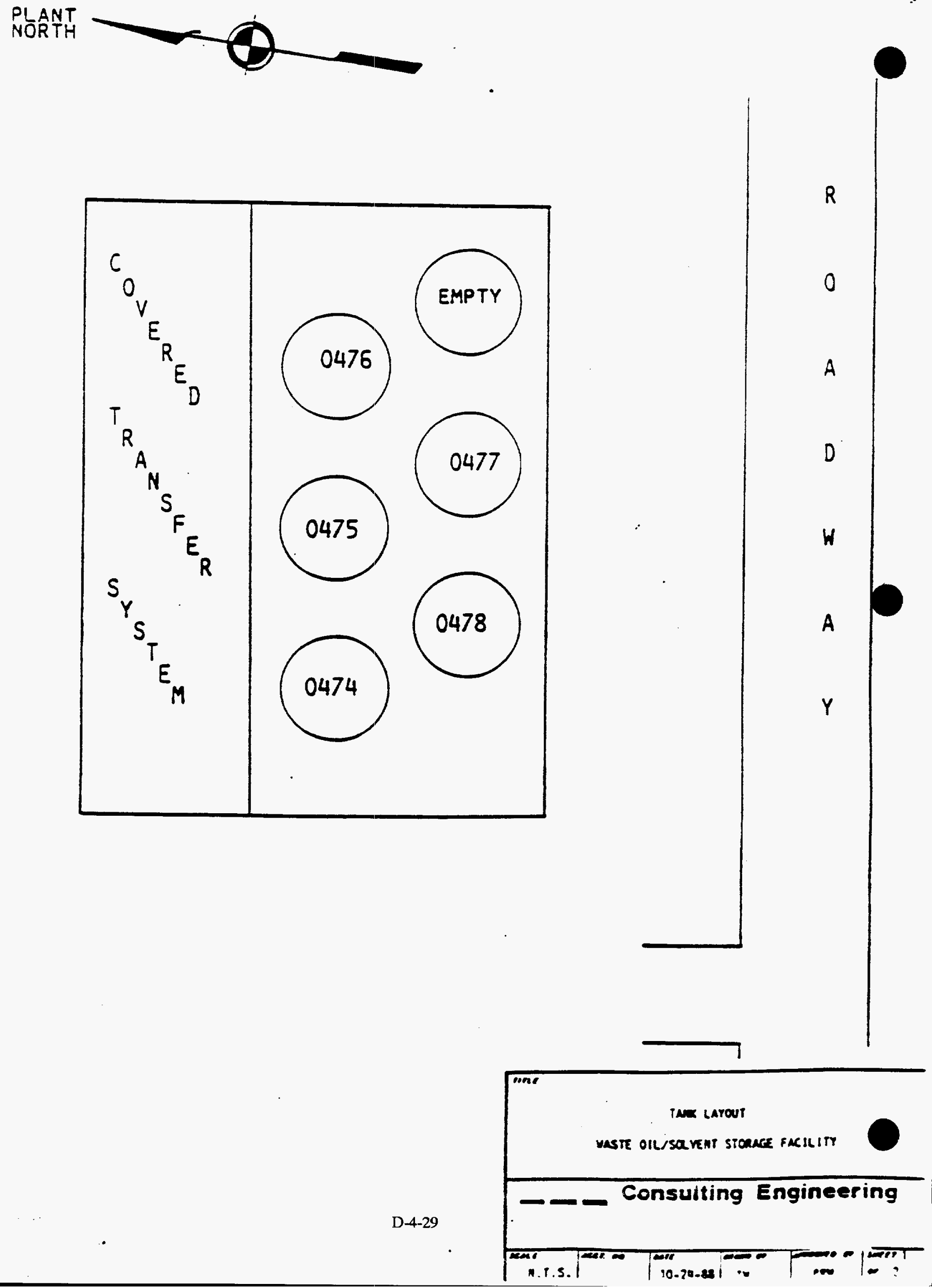
TABLE F-1. GENERAL INSPECTION SCHEDULE

Specific Item

Fire alarm system

Telephone system

Public address (PA) system

Generators

Facility fence

Gates

Two-way radios

Standard industrial absorbents

Absorbal, diaper wipes

Hand pump

Breathing Equipment: disposable respirators, cartridges

Protective Clothing: Tyvek suits, gloves, and booties

Fire extinguishers

Emergency shower and eyewash

Face shields and extra protective eye glasses
Types of Problems

Power failure

Power failure, cut lines

Power failure, speakers

Fuel supply, spark plugs, oil

Corrosion, damage to chainlink fence or barbed wire

Corrosion, damage

Transmitter or receiver, batteries

Out of stock

Out of stock

Clogging

Out of stock, exhausted canisters, leaks, tears, rips

Out of stock, holes, rips, tears

Missing, recharge needed, wrong type

Water pressure, leaking, and drainage

Broken, dirty equipment, out of stock
Frequency of Inspection

Annually

As used

Daily

As used

Daily

Daily

As used

Weekly

Weekly

Weekly

Weekly

Weekly

Weekly

Weekly

Weekly 


\section{TABLE F-2. CONTAINER STORAGE AREA INSPECTION SCHEDULE}

Specific Item

Container placement and stacking

Sealing of containers

Labeling of containers

Container structural integrity

Segregation of incompatible wastes

Pallets

Building integrity

Bases or foundations

Dikes and/or curbing

Sump areas

Debris and refuse

Ramps

Fence and warning signs

Loading and unloading areas

Pumps
Types of Problems

Aisle space, height of stacks

Open lids

Improper identification, date missing

Corrosion, leakage, structural defects

Storage of incompatible wastes in same area

Damage (e.g., broken wood, warping, nails missing)

Damage, sagging, leaking

Cracks, deterioration, spalling in concrete, wet spots

Cracks, deterioration, leakage

Erosion, uneven settlement, cracks and spalling in concrete, wet spots, clogged or inoperable sump pump, accumulated precipitation

Aesthetic, possible reaction with leaks

Erosion, uneven settlement, cracks, and spalling in concrete

Damaged or missing equipment, perimeter fence damaged, illegible signs

Spills and leaks

Leaks at pump seal
Weekly

Frequency of Inspection

Weekly

Weekly

Weekly

Weekly

Weekly

Weekly

Weekly

Weekly

Weekly

Weekly

Weekly

Weekly

Weekly

Weekly 
TABLE F-3. TANK STORAGE INSPECTION SCHEDULE

Specific Item

Dikes

Bases or foundations

Sump areas

Valves

Fittings

Tank level

indicator/level of waste

Debris and Refuse

Ladder

Structural supports

Pipe connections

Protective coating

Tanks shell

Anchor bolts
Types of Problems

Cracks, deterioration, leakage

Erosion; uneven settlement; cracks and spalling in concrete pads, base rings and piers; deterioration of water seal between tank bottom and foundation, wet spots.

Erosion, uneven settlement; cracks and spalling in concrete, wet spots, clogged or inoperable sump pump, accumulated precipitation

Damaged or missing equipment

Daily

Loss or metal thickness, leaks, exterior corrosion, or deterioration

Loss or metal thickness, leaks, exterior corrosion, or deterioration

Leaks, exterior corrosion, or deterioration

Level indication, free movement, operable

Aesthetics, possible reaction with leaks

Damaged, structural stability

Concrete deterioration and cracking, spalling, uneven settlement

External corrosion, cracks, distortion

rust spots, blisters, film lifting

Daily

Corrosion, discoloration, cracks, buckles, bulges

Distortion, corrosion

Daily

Daily

Daily

Daily

Daily

Daily

Daily

Daily

Daily
Frequency of Inspection

Daily

Daily

Daily 
$\underline{\text { Specific Item }}$

Nozzles
Types of Problems

Cracks, corrosion
Frequency of Inspection

Daily 
FIGURE F-4. DAILY INSPECTION LOG SHEET FOR OD-7, OD-9, AND OD-10

\begin{tabular}{|c|c|c|c|}
\hline General Inspection Items & Types of Problems & $\begin{array}{c}\checkmark=\text { Acceptable } \\
\mathbf{X}=\text { Unacceptable } \\
\mathbf{N A}=\text { Not Applicable }\end{array}$ & $\begin{array}{c}\text { Observations, } \\
\text { Date and Nature of Repairs, Remedial } \\
\text { Action }\end{array}$ \\
\hline Telephone system (as used) & Power failure, cut lines & & \\
\hline Public address (PA) system & Power failure, speakers & & \\
\hline Generators (as used) & Fuel supply, spark plugs, oil & & \\
\hline Facility fence (OD-10 only) & $\begin{array}{l}\text { Corrosion, damage to fence or barbed } \\
\text { wire }\end{array}$ & & \\
\hline Gates (OD-10 only) & Corrosion, damage & & \\
\hline Two-way radios (as used) & Transmitter or receiver, batteries & & \\
\hline Tank Inspection Items & Typas of Problems & $\begin{aligned} v & =\text { Acceptable } \\
\mathbf{X} & =\mathbf{U n a c o e p t a b l e} \\
\mathrm{NA} & =\mathrm{Not} \text { Applicable }\end{aligned}$ & $\begin{array}{l}\text { Observations, } \\
\text { Date and Nature of Repairs, Remedial } \\
\text { Action }\end{array}$ \\
\hline Dikes & Cracks, deterioration, leakage & & \\
\hline Bases or foundation & $\begin{array}{l}\text { Cracks and spalling in concrete pads, wet } \\
\text { spots }\end{array}$ & & \\
\hline Sump areas & $\begin{array}{l}\text { Cracks and spalling in concrete, wet } \\
\text { spots, clogged or inoperable sump pump, } \\
\text { accumulated precipitation }\end{array}$ & & \\
\hline Danger signs & Damaged or missing & & \\
\hline Pipes & Leaks, corrosion, deterioration & & \\
\hline Valves & Leaks, corrosion, deterioration & & \\
\hline Fittings & Leaks, corrosion, deterioration & & \\
\hline Tank level indicator & Restricted movement, inoperable & & \\
\hline Debris and refuse & Aesthetics, possible reaction with leaks & & \\
\hline
\end{tabular}




\begin{tabular}{|c|c|c|c|}
\hline Tank Inspection Items & Types of Problems & $\begin{aligned} v & =\text { Acceptable } \\
X & =\text { Unacceptable } \\
\text { NA } & =\text { Not Applicable }\end{aligned}$ & $\begin{array}{c}\text { Observations, } \\
\text { Date and Nature of Repairs, Remedial } \\
\text { Action }\end{array}$ \\
\hline Ladders & Damage, structural instability & & \\
\hline Structural supports & $\begin{array}{l}\text { Concrete deterioration and cracking, } \\
\text { spalling, uneven settlement }\end{array}$ & & \\
\hline Pipe connections & External corrosion, cracks, distortion & & \\
\hline Protective coatings & Rust spots, blisters, film lifting & & \\
\hline Tank shell & $\begin{array}{l}\text { Corrosion, discoloration, cracks, buckles, } \\
\text { bulges }\end{array}$ & & \\
\hline Anchor bolts & Cracks, distortion, corrosion & & \\
\hline Nozzles & Cracks, distortion, corrosion & & \\
\hline \multicolumn{4}{|l|}{ Additional Comments: } \\
\hline
\end{tabular}


FIGURE F-5. WEEKLY INSPECTION LOG SHEET FOR OD-7, OD-9, AND OD-10

\begin{tabular}{|c|c|c|c|}
\hline General Inspection Items & Types of Problems & $\begin{aligned} v & =\text { Acceptable } \\
X & =\text { Unacceptable } \\
N A & =\text { Not Applicable }\end{aligned}$ & $\begin{array}{c}\text { Observations, Date and Nature of Repairs, } \\
\text { Remedial Action }\end{array}$ \\
\hline Standard industrial absorbent & Out of stock & & \\
\hline Absorbal, diaper wipes & Out of stock & & \\
\hline Hand pump & Clogging & & \\
\hline $\begin{array}{l}\text { Breathing equipment: disposable respirators, } \\
\text { cartridges }\end{array}$ & $\begin{array}{l}\text { Out of stock, exhausted canisters, leaks, } \\
\text { tears, rips }\end{array}$ & & \\
\hline Protective clothing: Tyvek suits, gloves, booties & $\begin{array}{l}\text { Out of stock, inoperative, holes, rips, } \\
\text { tears }\end{array}$ & & \\
\hline Fire extinguishers & Missing, recharge needed, wrong type & & \\
\hline Emergency shower, eyewash & Water pressure, leaking, drainage & & \\
\hline Face shields, protective eye glasses & Broken, dirty equipment, out of stock & & \\
\hline Container Inspection liems & Types of Problems & $\begin{aligned} v & =\text { Acceptable } \\
X & =\text { Unacceptable } \\
\mathbf{N A} & =\text { Not Applicable }\end{aligned}$ & $\begin{array}{l}\text { Observations, Date and Nature of Repairs, } \\
\text { Remedial Action }\end{array}$ \\
\hline Container placement and stacking & Aisle space, height of stacks & & \\
\hline Closed containers & Open containers & & \\
\hline Labeling of containers & $\begin{array}{l}\text { Improper identification, storage or } \\
\text { accumulation start date missing }\end{array}$ & & \\
\hline Container integrity & Corrosion, leakage, structural defects & & \\
\hline Segregation of incompatible waste & $\begin{array}{l}\text { Incompatibles not segregated, reactives } \\
\text { not separated from ignition sources }\end{array}$ & & \\
\hline Pallets & Broken wood, warping, nails missing & & \\
\hline Building integrity & Building is damaged, sagging, or leaking & & \\
\hline
\end{tabular}




\begin{tabular}{|c|c|c|c|}
\hline Container Inspection Items & Types of Problems & $\begin{aligned} y & =\text { Acceptable } \\
X & =\text { Unacceptable } \\
N A & =\text { Not Applicable }\end{aligned}$ & $\begin{array}{l}\text { Observations, Date and Nature of Repairs, } \\
\text { Remedial Action }\end{array}$ \\
\hline Bases or foundations & $\begin{array}{l}\text { Cracks and spalling in concrete pads, } \\
\text { base rings and piers; deterioration of } \\
\text { water seal between tank bottom and } \\
\text { foundation, wet spots }\end{array}$ & & \\
\hline Dikes and/or curbing & Cracks, deterioration, leakage & & \\
\hline Sump areas & $\begin{array}{l}\text { Cracks and spalling in concrete, wet } \\
\text { spots, clogged or inoperable sump pump, } \\
\text { accumulated precipitation }\end{array}$ & & \\
\hline Debris and refuse & Aesthetics, possible reaction with leaks & & \\
\hline Ramps & Cracks and spalling in concrete & & \\
\hline Danger signs & Damaged or missing, illegible signs & & \\
\hline Loading and unloading areas & Free from spills and leaks & & \\
\hline Pumps & Pumps are not leaking at pump seal & & \\
\hline Aisle space & $\begin{array}{l}\text { Insufficient for movement of personne? } \\
\text { fire protection equipment, spill control } \\
\text { equipment }\end{array}$ & & \\
\hline Fire alarm system (annually) & Power failure & & \\
\hline \multicolumn{4}{|l|}{ Additional Comments: } \\
\hline
\end{tabular}




\section{APPENDIX G-1 \\ EMERGENCY and SPILL RESPONSE EQUIPMENT}

The Y-12 Spill Response Trailer, maintained by the Fire Department, is located in the Plant and contains supplies and equipment for the response team. An indication of the trailer's typical contents follows:

\section{Spill Response Trailer - Response Team Equipment}

\section{Check List}

Supplies

Respirators

Rubber Boots

Rain Suits

Paper Suits

Gloves, Rubber

Gloves, Acid Type

Acid Suits

Respirator Cartridges (Combination)

Flagging

Stakes

Face Shields (complete)

Chemical Splash Goggles

Flashlights

Extra Batteries

Caution Lights (flashing)

Shovels, Round Point

Shovels, Square Point

Sledgehammer

Broom (street type)

Tape

Clamps, Hose

Plastic Bags (small)

Full Face Respirator
Diapers

Bottles, Sample

Rope, ft.

Twine

Rubber Aprons

Ax

Ladder, 10'

Reflector Vest (orange)

Water (for pump)

Demineralized Water

Pipe Wrench

Pliers

Pliers, Needle Nose

Crescent Wrench (adjustable)

Vise Grips

Screwdriver (flat tip)

Screwdriver (Phillips head)

Channel Lock Pliers

Teflon tape

3" to 2" Pipe Coupling, Stainless

Plastic Bags (large)

3" Threaded Coupling

Fire Extinguisher 
Additional supplies and equipment are located in Buildings $9720-41$ and 9753 as indicated below.

\section{Building 9720-41 \\ Chec List}

\section{$\underline{\text { Supplies }}$}

Pigs

Gas and Air Driven Pumps

Oil Skimmer Boons

Sandbags

Empty Drums

(including overpack drums)
Diapers

Hoses

gloves, Ear Plugs, Safety Glasses

Generators

Lighting Systems

\section{Building 9753 Supplies}

Check List

Supplies

Leather gloves

Rubber gloves

Plastic bags

Flashlights

Flashlight batteries

Barrels

Road cones

Chemical Splash Goggles

Flagging strips, feet

Shovels

Picks

Boots, pairs

Rope, feet

Diapers, rolls

Paper suits

Sand bags

Raincoats

Plastic, 20’ x 100' roll 
The Y-12 Plant Fire Department typically operates the following fire-fighting and medical response vehicles:

Type
Pumper
Pumper
Pumper
Cardox Truck
Emergency Truck
Ram Charger
Van
Van
Pickup
Pickup
Pickup
T-10 Blazer, 4 x 4
Ambulance
Ambulance
Ambulance
Spill Response Truck

\author{
Use \\ Fire pumper No. 1 \\ Fire pumper No. 2 \\ Fire pumper backup \\ Fire fighting \\ Emergency response \\ For fire chief \\ Service van \\ Routine transportation \\ Fire fighting equipment \\ Routine transportation \\ For day shift fire captains \\ Medical and routine transportation \\ Ambulance No. 1 \\ Ambulance backup \\ Beta-4 \\ Emergency spill response
}




\section{APPENDIX G-2 \\ UNIT-SPECIFIC EMERGENCY and WASTE DESCRIPTIONS}

This section summarizes unit-specific contingency and waste description information for the treatment, storage, and disposal units below.

\section{Cvanide Treatment Unit}

The Cyanide Treatment Unit is located in Building 9201-5N. The nearest Gamewell box is located on the south wall outside of Building 9201-5N. This Gamewell box is connected to the existing plant Gamewell Fire Alarm System and Plant Monitoring System. A telephone is available in the room where the unit is located. An eyewash and safety shower station is also available in this room. Two-way radios are available to communicate with the PED office, if emergency assistance is necessary.

The Cyanide Treatment Unit treats cyanide wastes that have been generated in various plant operations.

\section{Kerr Hollow Quarry Treatment Unit}

The Kerr Hollow Quarry Treatment Unit is located 0.4 miles west of the intersection of Scarboro Road and Bethel Valley Road on the north side of Bethel Valley Road. A public address system is installed at this unit, along with closed circuit television. Two-way radios are used, and a telephone is available in the guard shack for communication with the PED office, if emergency assistance is required.

This unit no longer receives hazardous waste. It is currently undergoing closure.

\section{Garage Underground Tanks}

The Garage Underground Tanks are located near Building 9737. A Gamewell box is located nearby at the service station and connected to the existing plant Gamewell Fire Alarm System and Plant Monitoring System. Two-way radios are used by personnel at this site to provide communication with the PED office, if emergency assistance is needed. A phone is available in Building 9712 East End Garage, as well as an eyewash/safety shower station.

This unit no longer receives hazardous waste. It is currently undergoing closure. 


\section{Walk-In Pits}

The Walk-In Pits are located north of Disposal Area Remedial Action (DARA) Solids Storage Unit, in the Bear Creek Burial Grounds. The nearest available phone, Gamewell box, eyewash and safety shower are located at the DARA Liquid Storage and Treatment Unit. The Gamewell box is connected to the existing plant Gamewell Fire Alarm System and Plant Monitoring System. Two-way radios are used for communication with the PED office, if emergency assistance is needed.

This unit is currently undergoing closure.

\section{Interim Drum Yard}

Interim Drum Yard is located near Building 9720-32. The nearest available Gamewell box is located on the east end of Building 9720-32. This Gamewell box is connected to the existing plant Gamewell Fire Alarm System and the Plant Monitoring System. A portable eyewash and safety shower are used by personnel at this unit. Two-way radios are used for communication with the PED if emergency assistance is needed, and a phone is also available nearby in Building 9401-5.

This unit no longer receives hazardous waste and the closure plan has been submitted for this unit. Approval and closure activities are pending.

\section{Building 9720-9, Storage Unit}

Building 9720-9 is located on Third Street. Two Gamewell boxes are located at the east and west sides of the building and connected to the existing plant Gamewell Fire Alarm System and the Plant Monitoring System. Telephones and two-way radios are also used by personnel to provide communication with the PED office, if emergency assistance is needed. Two eyewash/safety showers are provided and located at the west and south sides of the building.

This unit provides storage for hazardous and nonhazardous waste and uranium-contaminated flammable materials. Waste is stored at this unit until waste analysis and appropriate disposal (bulk storage and/or off-site shipment) can be arranged. All classes of RCRA wastes, except for K-listed wastes, and hazardous wastes from specific sources (40 CFR Part 261.32 and Tennessee Rule 1200-1-11.02(4)) are stored in this unit. 


\section{RCRA and Mixed Waste Storage and Staging Unit, Building 9720-31}

Building 9720-31 is located on West Third Street. Two Gamewell boxes are located on the east and west side of the building and connected to the existing plant Gamewell Fire Alarm System and the Plant Monitoring System. Telephones and two-way radios are also used by personnel to provide communication with the PED offices, if emergency assistance is needed.

This unit is used to store solids, rquids, and sludge wastes. It is a one-story structure constructed of light-weight, concree block, masonry valls and partitions. The building is partitioned into fifteen rooms: one supply room, seven staging rooms, and seven storage rooms. Normally, the largest containers in any of the staging or storage rooms are 55-gallon drums, however, 85-gallon overpack containers may be used to store waste. Waste stored in the staging and storage rooms may be in Department of Transportation-specification containers or the original product containers.

\section{Building 9811-1 RCRA Tank Storage Unit (OD-7)}

Building 9811-1 RCRA Tank Storage Unit is located at the intersection of West Second Street and K Road. It is served by an auxiliary fire alarm pull box which is inside the south side of Building 9811-1. Additional alarm boxes are located at Building 9720-16, and at the intersection of Second Street and K Road which is southwest of OD-7. These boxes are connected to the existing plant Gamewell Fire Alarm System and the Plant Monitoring System. Two fire hydrants are located near this unit. One is approximately 20 feet north of the RCRA Storage Unit, and the second hydrant is located approximately 75 feet southwest. Telephones and two-way radios are used by personnel to provide communication with the PED office, if emergency assistance is needed. A telephone is also located in the OD-7 operator trailer for communication with emergency personnel. A safety shower/eyewash assembly is planned for installation at a future date at the drum loading/unloading area and the transfer station as part of an OD-7 upgrade project.

This unit is designated as the primary storage unit for nonignitable- and nonreactiveuranium-contaminated waste oils and solvents. Contaminated oils, nonchlorinated solvents, and some toxicity characteristic wastes, may also be accepted at the unit. The storage tank area of the unit consists of a 51- $\mathrm{x} 58$-foot, concrete, diked area. Positioned within the diked area are four, 30,000-gallon tanks and one, 10,000-gallon tank. Two additional 10,000-gallon tanks will be installed at a future date. 


\section{Building 9811-1 - RCRA Container Storage Unit (OD-8)}

Building 9811-1 is located at the intersection of West Second Street and K Road. A Gamewell box is located on the south side of the building (inside) and connected to the existing plant Gamewell Fire Alarm System and the Plant Monitoring System. A safety shower/eyewash is located at the north side of the building.

This unit is used primarily as a storage area for containerized liquid waste until the waste has been characterized to allow transfer to other treatment, storage, or disposal units. Contaminated liquids with a concentration of greater than $50 \mathrm{ppm}$ PCBs will not be stored at this unit.

\section{Waste Oil/Solvent Storage Unit (OD-9)}

The Waste Oil/Solvent Storage Unit is located on Old Bear Creek Road, and served by an auxiliary fire alarm pull box. The Gamewell box is connected to the existing plant Gamewell Fire Alarm System and the Plant Monitoring System. Two fire hydrants are available for use and are freeze-proof. One hydrant is located along the site access road approximately 60 feet east of the truck entrance to the building. The second hydrant is on the north side of Old Bear Creek Road, near the site egress road, approximately 100 feet southwest of the facility truck exit area. Telephones and two-way radios are used by personnel to provide communication with the PED office, if emergency assistance is needed. Two safety shower/eyewash assemblies, both of which are freeze-proof, are located at the northeast corner of the tank area (in the truck loading pad adjacent to the drum storage area) and on the floor of the containment structure. Potable water is supplied to both units and is identified by green lights installed above each unit. The eye/face units are push bar operated with stay-open valves.

This unit typically receives and stores nonignitable and nonreactive waste oil/solvents that may contain water, be contaminated with PCBs greater than $50 \mathrm{ppm}$ and uranium, and contain chlorinated organic solvents. The liquid wastes are stored here in tanks and drums until sufficient volume is accumulated for transportation to an outside facility for recovery or disposal.

\section{Liquid Organic Solvent Storage Unit (OD-10)}

The Liquid Organic Solvent Storage Unit is located in the Bear Creek Burial Grounds, and served by an auxiliary fire alarm pull box which is located approximately 40 feet south of the unit. An additional Gamewell box is accessible at the intersection of Bear Creek Road and 
the access road to OD-10. This Gamewell box is connected to the existing plant Gamewell Fire Alarm System and Plant Monitoring System. A freeze-proof fire hydrant is located approximately 200 feet south of the unit. Two-way radios provide communication between the unit and the PED office, if emergency assistance is necessary. Three safety shower/eyewash assemblies are provided at OD-10, which includes two located in the staging area (north and south side) and the third located in the tank area. Potable water is supplied to these assemblies, which are push bar operated with stay-open valves. Each unit is identified by a green light installed above each assembly.

This unit receives and stores liquid organic wastes generated in the Y-12 Plant. These wastes typically include waste oil and combustible and flammable waste liquids that may contain trace quantities of uranium. The liquids received at this unit are pumped into the tanks for storage until sufficient quantity is accumulated for final disposal or recovery.

\section{Building 9409-5 Storage Unit}

The Building 9409-5 Storage Unit is located on Third Street. The nearest Gamewell box is located in Building 9409-2. This Gamewell box is connected to the existing plant Gamewell Fire Alarm System and Plant Monitoring System. No phone is available, and this unit is no longer in service. Two-way radios are used to communicate with the PED office, if emergency assistance is needed.

This unit no longer receives hazardous waste. It is currently undergoing closure.

\section{East Chestnut Ridge Waste Pile}

The East Chestnut Ridge Waste Pile is located on South Patrol Road. Two-way radios are used to communicate with the PED office, if emergency assistance is required. The nearest Gamewell box is located southwest of the unit across the street from the Containerized Waste Storage Area. This Gamewell box is connected to the existing plant Gamewell Fire Alarm System and Plant Monitoring System.

This waste pile is used for the storage of soils and spoils contaminated with hazardous and low-level radioactive materials, asbestos, and roofing materials from the closure of RCRA sites at the Y-12 Plant. Additional contaminated soils may be moved to the East Chestnut Ridge Waste Pile if excavation activities continue at the Y-12 Plant. The unit is currently inactive. 


\section{Containerized Waste Storage Area (CWSA)}

The CWSA is located on South Patrol Road. A Gamewell box is located south, directly across the street from the CWSA, and is connected to the existing plant Gamewell Fire Alarm System and the Plant Monitoring System. Two-way radios are also used to provide communication with the PED office, if emergency assistance is needed. A portable safety shower/eyewash is provided during operations.

The CWSA consists of three concrete pads measuring 170 feet long and 50 feet wide. The central and eastern concrete pads are covered by open-sided dome tents and store low-level, radioactive-contaminated, RCRA hazardous waste and/or mixtures of these wastes. The western concrete pad is not covered, and no wastes are stored there. Each pad has a onefoot impermeable dike surrounding it to contain spills. The pads and dikes are sloped toward a 60 -gallon sump located on the southeast corner of the pads to catch spilled material and manage rainwater.

\section{Classified Container Storage Unit, Building 9720-25}

Building 9720-25 is located on $\cdot M$ Street. Two Gamewell boxes are located inside the building and connected to the existing plant Gamewell Fire Alarm System and the Plant Monitoring System. Telephones and two-way radios are also used by personnel to provide communication with the PED office, if emergency assistance is needed.

Building 9720-25 is a storage unit designed for storage of classified wastes generated at the Y-12 Plant. The wastes include materials, fabricated parts, and containers which have been security classified to prevent dissemination of potentially vital information. Storage in one part of this unit of classified waste, contaminated with hazardous constituents, is necessary due to present uncertainties as to final modes of treatment and/or disposal of classified and/or hazardous waste materials. The stored materials include RCRA hazardous, low-level radioactive, and mixed wastes.

\section{Oil Landfarm Soils Containment Pad}

The Oil Landfarm Soils Containment Pad is located west of the main plant area on Bear Creek Road. A telephone is available nearby in the sampling trailer, or two-way radios are used to communicate with the PED office, if emergency assistance is needed. The nearest eyewash/safety shower station is located at the Liquid Organic Solvent Storage Unit, which lies west of this location on Bear Creek Road. 
This unit provides storage for contaminated soils and excavation wastes that were generated during RCRA closure of the Oil Landfarm and Oil Retention Ponds at the Y-12 Plant. These soils were contaminated with hazardous, mixed, or radioactive wastes. Contaminants include organics, heavy metals, pesticides, PCBs, and low levels of depleted uranium. The unit provides interim orage for excavation wastes pending scheduling of the soils for final treatment or disposal. This unit is currently inactive.

\section{DARA Solids Storage Unit}

The DARA Solids Storage Unit is located west of the main plant area on Bear Creek Road. A Gamewell box is located near the unloading pad adjacent to the DARA Solids Storage Unit at the DARA Liquid Storage and Treatment Unit. This Gamewell box is connected to the existing plant Gamewell Fire Alarm System and Plant Monitoring System. A telephone is available in the operator's trailer south of the DARA Liquid Storage and Treatment Unit, and two-way radios are also used to communicate with the PED office, if emergency assistance is needed. Eyewash/safety shower stations are available on the unloading pad at DARA Liquid Storage and Treatment Unit.

The DARA Solids Storage Unit provides storage for contaminated sediments and excavation wastes generated during closure of the Oil Retention Ponds. These sediments are contaminated with PCBs and volatile organic compounds. They will be stored in the unit until they can be scheduled for final treatment or disposal. This unit is currently inactive.

\section{Interim Reactive Waste Treatment Area (IRWTA)}

The IRWTA is located west of the main plant area on Bear Creek Road, and served by an auxiliary fire alarm pull box near the trailers at the closed Sanitary Landfill I. Two-way radios are used to provide communication with the PED office, if emergency assistance is needed. Portable eyewash systems are used during operation. In addition, the Y-12 Fire Department staff is at the unit during the treatment process to assist, if needed.

This interim unit was designed for the treatment of sodium potassium (NaK) generated during maintenance activities at the Y-12 Plant. The unit currently operates in accordance with an open burning permit. The IRWTA is used approximately once per year dependent upon the generation of $\mathrm{NaK}$ wastes. The Fire Department staff are present through the duration of the burn to ensure safe treatment of the $\mathrm{NaK}$, which is water reactive. The Contingency Plan will also be implemented if an emergency arises. The $\mathrm{NaK}$ has a mineral oil layer which takes approximately seven hours to burn. The NaK itself will burn away in 
approximately 45 minutes. All wastes and equipment are removed from the treatment area when the burn is completed.

\section{Building 9201-4, Container Storage Area}

Building 9201-4 is located on First Street. Gamewell boxes are located within Building 92014 and connected to the existing plant Gamewell Fire Alarm System and the Plant Monitoring System. Two-way radios are used, and a telephone is available on the first floor in the southwest corner of the building for communication with the PED office, if emergency assistance is needed.

This unit is located within the exclusion area of the Y-12 Plant and is used to store mercurycontaminated solids such as soil or insulation in containers. The solids may also be contaminated with uranium. Building 9201-4 provides container storage for 55-gallon drums of hazardous and mixed waste resulting from decontamination and decommissioning activities.

\section{Building 9212 Container Storage Area}

The Building 9212 Container Storage Area is located in Building 9212. Telephones are available in nearby supervisors' offices. Eyewash/safety showers are available at each location. Two-way radios are also used to communicate with the PED office, if emergency assistance is needed. Gamewell boxes are located throughout Building 9212. These Gamewell boxes are connected to the existing plant Gamewell Fire Alarm System and Plant Monitoring System.

This area processes organic solutions for recovery of enriched uranium. Process operations within the building generate solid waste contaminated with uranium. The solid waste is burned and the resulting ash stored in galvanized tin cans. The cans are stored on stainless steel racks with criticality spacing.

\section{Building 9206 Container Storage Area}

The Building 9206 Container Storage Area is located in Buildings 9206 and 9720-17. For areas located in Building 9206, Gamewell boxes are located near Rooms 24 and 30. Eyewash and safety shower stations are also located in these rooms. For the area located in Building 9720-17, a Gamewell box and a telephone are located in the corridor outside the area. A telephone is available in Room 18 of Building 9206. Two-way radios are also available in these buildings for communication with the PED office. if emergency assistance 
is needed. Gamewell boxes are connected to the existing plant Gamewell Fire Alarm System and Plant Monitoring System.

Building 9206 is the other building at the Y-12 Plant where organic solutions containing enriched uranium for recovery of the uranium are processed. During the recovery process, solid wastes such as gloves, shoe scuffs, lab coats, etc., are generated that are contaminated with uranium. These wastes are burned, and the resulting ash stored for future recovery of the uranium contained in the ash. The ash is stored in galvanized tin cans, and the cans are stored on stainless steel racks with criticality spacing. Criticality spacing requires the cans to be stored approximately two feet apart.

\section{Uranium Treatment Unit}

The Uranium Treatment Unit is located near Building 9767-2. Eyewash/safety shower stations are available at this unit, and the nearest Gamewell box is located 75 feet north of the area on the East Dock between Doors 4 and 5. This Gamewell box is connected to the existing plant Gamewell Fire Alarm System and Plant Monitoring System. Two-way radios are used and a phone is available nearby in Building 9767-2 to communicate with the PED office, if emergency assistance is needed.

The Uranium Treatment Unit is located on the east side of Building 9206, outside and adjacent to the loading dock. The unit consists of two, 300-gallon polytanks located within a diked drum storage area that stores up to eighteen, 55-gallon drums. This unit treats organic solutions containing uranium.

\section{RCRA and PCB Container Storage Area, Building 9720-58}

Building 9720-58 is located on Old Bear Creek Road. Two Gamewell boxes are provided at the east and west sides of Building 9720-58 and connected to the existing plant Gamewell Fire Alarm System and the Plant Monitoring System. Telephones and two-way radios are also used by personnel to provide communication with the PED office, if emergency assistance is needed. A portable eyewash system is provided in the operation trailer adjacent to the unit. A safety shower/eyewash system is also provided at Unit OD-9 that is lo wed directly west of Building 9720-58.

Building $9720-58$ is utilized as a storage and staging area for PCB-contaminated equipment (e.g., transformer, capacitors, and electrical switch gear). The area is also used to store RCRA hazardous waste and used as a staging area for other waste materials awaiting off-site 
shipment. Waste is consolidated at this area until waste analysis and appropriate disposal arrangements can be initiated.

\section{Building 9720-12 Classified Container Storage Area}

The Building 9720-12 Classified Container Storage Area is located on West Second Street. The nearest Gamewell box is located in the northwest corner of Building 9720-12. This Gamewell box is connected to the existing plant Gamewell Fire Alarm System and Plant Monitoring System. Portable eyewash and safety shower stations are used. Two-way radios are used to communicate with the PED office if emergency assistance is needed.

Building 9720-12 is a storage unit for hazardous and nonhazardous waste and a long-term storage unit for uranium-contaminated, solid combustibles generated from Building 9215 process operations. Waste is stored in 55-gallon drums at this building until waste analysis and appropriate recycling techniques can be arranged. 


\section{APPENDIX H-2}

\section{FACILITY SUPERVISOR JOB DESCRIPTION (For Environmental Activities Only)}

Position Title: Facility Supervisor, Waste Management Division

Basic Function of Position: Provide technical support for waste management operations.

Major Environmental Duties and Responsibilities:

- Supervises technicians and operators in all aspects of operation of the facility, including loading, unloading, sampling, storage, inspections, maintenance, and emergency response.

- Reviews the training program for facility operating personnel.

- Inspects RCRA waste treatment and storage tank areas, tanks, dikes, transfer areas, piping, pumps, valves, and waste handling equipment.

- Inspects emergency response equipment including fire extinguishers, communications and alarm facilities, and spill cleanup equipment.

- Initiates appropriate remedial actions for spills, leaks, or defective equipment and ensures timely completion of remedial actions.

- Responsible for the recording of all inspections, remedial actions and their completion and maintains a file of all inspections, logs, and records.

- Works with technicians to identify, sample, and pack drums.

- Schedules all facility maintenance and oversees maintenance activities to ensure that proper procedures and safety precautions are followed, and no spill, fire, other release, or contamination of the facility, personnel, or the environment occurs.

\section{Formal Education Required:}

- High School diploma and/or equivalent education and/or experience.

Specialized Knowledge or Training:

- 24-hour OSHA/SARA Training -- one time only

- RCRA Annual Training

- Criticality Safety - given initially -- refresher is provided biennially

- Hazard Communication

- Radiation Protection - biennial

- Urinalysis - one time only

- Fire Protection - annual

- Health and Safety - annual

- Security Program - annual

- Emergency Preparedness - annual

- Respiratory Training - annual

- Ingress/Egress - the initial program is one time only -- performance documentation checklists will be provided biennially

- General Employee Training - biennial 


\section{APPENDIX H-2 (Continued) \\ TECHNICIAN JOB DESCRIPTION \\ (For Environmental Activities Only)}

Position Title: Technician, Waste Management $\mathrm{L}$ sion

Basic Function of Position: Provides routine technically related operational support for Waste Management Operations.

Major Environmental Duties and Responsibilities:

- Inspects the containers and containment system for leaks or deterioration caused by corrosion or other factors, and material handling equipment.

- Inspects emergency response equipment including fire extinguishers, communications and alarm equipment, and spill cleanup equipment.

- Records inspection activity on inspection log and maintains a file of logs and records.

- Notifies Facility Supervisor of observed problems at the facility, emergency situations, and the need for contingency and/or remedial action.

- Verifies waste stream identification and documentation.

- Takes sample of waste streams from containers as required for analysis.

- Assures proper handling and storage of wastes, including separation of incompatible wastes, prevention of their contact or mixing, and separate storage of ignitables and reactives.

- Assures proper documentation of waste stream identification and storage location, inventory, inflow and outflow.

- Assists in immediate response to spills and notifies the PSS office and Staff Engineer.

Formal Education Required:

- High School diploma and/or equivalent education and/or experience.

Specialized Knowledge or Training:

- 24-hour OSHA/SARA Training -- one time only

- RCRA Annual Training

- Criticality Safety - given initially -- refresher is provided biennially

- Hazard Communication - one time only

- Radiation Protection - biennial

- Urinalysis - one time only

- Fire Protection - annual

- Health and Safety - annual

- Security Program - annual

- Emergency Preparedness - annual

- Respiratory Training - annual

- Ingress/Egress - the initial program is one time only -- performance documentation checklists will be provided biennially

- General Employee Training - biennial 
APPENDIX H-2 (Continued)

HOURLY WORKER JOB DESCRIPTION

(For Environmental Activities Only)

\section{Position Title: Hourly Worker, Waste Management Division}

Basic Function of Position: Under direct supervision, performs daily operational activities at Waste Management Facilities including the transferring of wastes and handling of waste containers.

Major Environmental Duties and Responsibilities:

- Assists with operations involving hazardous waste treatment and storage.

- Moves full and empty containers as required.

- Assists in emergency spill response and cleanup and fire control, and takes other emergency action in accordance with established procedures.

- Performs duties under the direction of the technician present.

Formal Education Required:

- High School diploma and/or equivalent education and/or experience

Specialized Knowledge or Training:

- Requires completion of waste management training program. Additionally, requires individuals to be designated respirator wearers.

- 24-hour OSHA/SARA Training -- one time only

- RCRA Annual Training

- Criticality Safety - given initially -- refresher is provided biennially

- Hazard Communication - one time only

- Radiation Protection - biennial

- Urinalysis - one time only

- Fire Protection - annual

- Health and Safety - annual

- Security Program - annual

- Emergency Preparedness - annual

- Respiratory Training - annual

- Ingress/Egress - the initial program is one time only -- performance documentation checklists will be provided biennially

- General Employee Training - biennial 


\section{APPENDIX H-2 (Continued) \\ CHEMICAL OPERATOR JOB DESCRIPTION \\ (For Environmental Activities Only)}

\section{Position Title: Chemical Operator, Vaste Management Division}

Basic Function of Position: Follows established methods and techniques in performing a single or sequence of operations required in various waste treatment processes associated with the chemical and physical change of materials. Adjusts, regulates, controls, and operates a wide variety of standard and specialized waste treatment processes and associated equipment. Uses various measuring and recording equipment and devices. Maintains detail records of process parameters.

Major Environmental Duties and Responsibilities:

- Moves full and empty containers as required.

- Performs duties under the direction of the Waste Management Supervisor present.

- Must be able to perform basic arithmetic calculations including fractions and decimals.

- Performs single or sequence of operations required to transfer and/or treat various wastes.

- Monitors controls and processes to assure proper operation, transfer, and/or treatment.

- Maintains necessary operating records.

Formal Education Required:

- High School diploma and/or equivalent education and/or experience

Specialized Knowledge or Training:

- Must have a basic understanding of chemical processes. Additionally, requires individuals to be designated respirator wearers.

- 24-hour OSHA/SARA Training -- one time only

- RCRA Annual Training

- Criticality Safety - given initially -- refresher is provided biennially

- Hazard Communication - one time only

- Radiation Protection - biennial

- Urinalysis - one time only

- Fire Protection - annual

- Health and Safety - annual

- Security Program - annual

- Emergency Preparedness - annual

- Respiratory Training - annual

- Ingress/Egress - the initial program is one time only -- performance documentation checklists will be provided biennially

- General Employee Training - biennial 


\section{APPENDIX H-2 (Continued) \\ TRAINING MANAGER JOB DESCRIPTION \\ (For Environmental Activities Only)}

Position Title: Training Manager, Waste Management Division

Basic Function of Position: Manage the divisional training program and assure that the required training for compliance with RCRA is developed, implemented, and documented.

Major Environmental Duties and Responsibilities:

- Organized and direct the function of training in a cost-effective manner to assure compliance with the training requirements of RCRA.

- Supervise any of the training positions reporting to the training manager. These positions may include training supervisors, instructional technologists, curriculum developers, training coordinators, training administrators, training instructors, on-thejob trainers, and/or subject matter experts.

- Analyze resource needs and create section training budget based on all requirements including RCRA.

- Develop long-range training plans for qualification of personnel in assigned section.

- Interface with management, DOE, and other agencies to determine training requirements including RCRA.

- Ensure all training meets DOE and Y-12 standards as well as RCRA requirements including assuring that the required annual RCRA training is performed and documented.

- Develop long-range training plans for training staff to assure compliance with RCRA.

- As applicable to RCRA compliance, oversee training contracts to ensure deliverables meet DOE and Y-12 standards of training.

Formal Education Required:

- Bachelors degree with formal training in adult learning, training analysis, design, development, implementation, evaluation, or equivalent work experience in a training function which demonstrates skills and knowledge have been acquired and utilized effectively.

Specialized Knowledge or Training:

- Successful completion of the DOE Basic Instructor course (Train-the-Trainer)

- Successful completion of Radiation Protection Instructor's course

- Successful completion of the Supervisor's On-The-Job Training course.

- 24-hour OSHA/SARA Training -- one time only

- Fire Protection - annual

- General Employee Training - biennial

- Security Program - annual

- Emergency Preparedness - annual 
APPENDIX H-2 (Continued)

\section{TRAINING ADMINISTRATOR JOB DESCRIPTION \\ (For Environmental Activities Only)}

Position Title: Training Ad inistrator, Y-12 Technical Training Division(Specific Administrator assigned to support Waste Management Division)

Basic Function of Position: Provide assigned division with plant oversight technical training support to assure that all training requirements are met based on RCRA.

\section{Major Environmental Duties and Responsibilities:}

- Work with other training organizations to ensure that training programs meet DOE and Y-12 standards as well as comply with the RCRA training requirements. Provide written approval of acceptable programs.

- Work with other training organizations to develop long-range training plans for qualification of personnel in assigned section including annual RCRA training for the appropriate personnel.

- Interface with management, DOE, and other agencies to determine training requirements including RCRA.

- Work with other training organizations to develop long-range training plans for training staff.

- Develop training standards which will enhance the quality of training at Y-12 including performing periodic audits to assure compliance.

- Complete any other assignments assigned by their training manager in order to assure compliance with RCRA.

\section{Formal Education Required:}

- Bachelors degree with formal training in training analysis, design, development, implementation, evaluation, or equivalent work experience in a training function which demonstrates these skills and knowledge have been acquired and utilized effectively.

- In lieu of a BS/BA degree, three years of progressively expanding responsibilities in training related work.

Specialized Knowledge or Training:

- Successful completion of the DOE Basic Instructor course (Train-the-Trainer).

- Fire Protection - annual

- Security Program - annual

- Emergency Preparedness - annual

- General Employee Training - biennial 
APPENDIX H-2 (Continued)

\section{TRAINING COORDINATOR JOB DESCRIPTION}

(For Environmental Activities Only)

Position Title: Training Coordinator, Waste Management Division

Basic Function of Position: Develop, facilitate, and implement training activities for the personnel in assigned section of the Waste Management Division.

Major Environmental Duties and Responsibilities:

- In areas of subject matter experience, specifically RCRA, develop training courses using the Instructional System Development design.

- Using developed RCRA course material, instruct personnel in job required curriculum at least annually.

- Evaluate students for successful completion of RCRA training.

- In areas of subject matter experience, specifically RCRA, assist other instructors as required by the training manager in the development and delivery of course material.

- Establish and maintain all documentation of appropriate training files.

- Complete any other assignments assigned by their training manager.

Formal Education Required:

- High school diploma or equivalent.

Specialized Knowledge or Training:

- Successful completion of the DOE Basic Instructor course (Train-the-Trainer).

- Fire Protection - annual

- Security Program - annual

- Emergency Preparedness - annual

- General Employee Training - biennial 


\section{APPENDIX H-2 (Continued) \\ ON-THE-JOB TRAINER JOB DESCRIPTION \\ (For Environmental Activities Only)}

Position Title: On-The-Job Trainer, I ste Management Division

Basic Function of Position: Assist in the development of on-the-job training (OJT)

courses, instruct personnel, evaluate trained personnel, and evaluate training.

Major Environmental Duties and Responsibilities:

- In areas of subject matter experience, specifically RCRA compliance and hazardous waste management, assist in the development of OJT courses.

- Using developed OJT course material, instruct personnel in job required curriculum for RCRA compliance and proper hazardous waste management.

- Evaluate RCRA training to ensure quality of program.

- Complete any other training assignments assigned by training manager.

Formal Education Required:

- High school diploma or equivalent.

Specialized Knowledge or Training:

- Successful completion of the Supervisor's On-The-Job Training course.

- 24-hour OSHA/SARA Training -- one time only

- RCRA Annual Training

- Criticality Safety - given initially -- refresher is provided biennially

- Hazard Communication - one time only

- Radiation Protection - biennial

- Urinalysis - one time only

- Fire Pro ection - annual

- Health and Safety - annual

- Security Program - annual

- Emergency Preparedness - annual

- Respiratory Training - annual

- Ingress/Egress - the initial program is one time only -- performance documentation checklists will be provided biennially

- General Employee Training - biennial 


\section{WASTE MANAGEMENT TRAINING REQUIREMENTS}

\section{COURSE}

Resource Conservation and Recovery Act Training

Hazard Communications

Respiratory Protection

Lock-Out-Tag-Out

Fire Protection

Criticality

Hazardous Waste Operations (24-hour)

Department of Transportation Certification

Job-Specific-Procedural Training

General Employee Training

* Drivers Only
SCHEDULE

Annual

One time only

Annual

Biennial

Annual

biennial

New Employee

New Employee*

Biennial

Biennial 
APPENDIX L-1

SUBPART BB - EQUIPMENT IDENTIFICATION/INFORMATION

OD-7, Building 9811-1 RCRA Tank Storage Unit

\begin{tabular}{|c|c|c|c|}
\hline $\begin{array}{c}\text { EQUIPMENT } \\
\text { ID } \\
\text { NUMBER }\end{array}$ & $\begin{array}{l}\text { EQUIPMENT } \\
\text { LOCATION }\end{array}$ & $\begin{array}{l}\text { EQUIPMENT } \\
\text { TYPE }\end{array}$ & METHOD OF COMPLIANCE \\
\hline $\mathrm{V}-30$ & Tank F-1 & Valve & LDAR Monitoring \& Annual Inspections \\
\hline V-31 & Tank F-1 & Valve & LDAR Monitoring \& Annual Inspections \\
\hline$V-32$ & Tank F-1 & Valve & LDAR Monitoring \& Annual Inspections \\
\hline$V-34$ & Tank F-1 & Valve & LDAR Monitoring \& Annual Inspections \\
\hline$V-35$ & Tank F-1 & Valve & LDAR Monitoring \& Annual Inspections \\
\hline$V-36$ & Tank F-1 & Valve & LDAR Monitoring \& Annual Inspections \\
\hline$V-37$ & Tank F-1 & Valve & LDAR Monitoring \& Annual Inspections \\
\hline $\mathrm{V}-38$ & Tank F-1 & Valve & LDAR Monitoring \& Annual Inspections \\
\hline V-39 & Tank F-1 & Valve & LDAR Monitoring \& Annual Inspections \\
\hline$V-40$ & Tank F-1 & Valve & LDAR Monitoring \& Annual Inspections \\
\hline$V-45$ & Tank F-1 & Valve & LDAR Monitoring \& Annual Inspections \\
\hline$V-46$ & Tank F-1 & Valve & LDAR Monitoring \& Annual Inspections \\
\hline V-1393 & Tank F-1 & Valve & LDAR Monitoring \& Annual Inspections \\
\hline$V-1397$ & Tank F-1 & Valve & LDAR Monitoring \& Annual Inspections \\
\hline V-1398 & Tank F-1 & Valve & LDAR Monitoring \& Annual Inspections \\
\hline V-86 & Tank F-1 & Valve & LDAR Monitoring \& Annual Inspections \\
\hline $\mathrm{V}-87$ & Tank F-1 & Valve & LDAR Monitoring \& Annual Inspections \\
\hline V-88 & Tank F-1 & Valve & LDAR Monitoring \& Annual Inspections \\
\hline V-89 & Tank F-1 & Valve & LDAR Monitoring \& Annual Inspections \\
\hline V-90 & Tank F-1 & Valve & LDAR Monitoring \& Annual Inspections \\
\hline V-91 & Tank F-1 & Valve & LDAR Monitoring \& Annual Inspections \\
\hline V-71 & $\begin{array}{l}\text { Tank F-1 } \\
\text { (DTM) }\end{array}$ & Valve & LDAR Monitoring \& Annual Inspections \\
\hline V-72 & $\begin{array}{c}\text { Tank F-1 } \\
\text { (DTM) }\end{array}$ & Valve & LDAR Monitoring \& Annual Inspections \\
\hline$V-73$ & Tank F-1 & Valve & LDAR Monitoring \& Annual Inspections \\
\hline
\end{tabular}




\begin{tabular}{|c|c|c|c|}
\hline $\begin{array}{c}\text { EQUIPMENT } \\
\text { ID } \\
\text { NUMBER }\end{array}$ & $\begin{array}{l}\text { EQUIPMENT } \\
\text { LOCATION }\end{array}$ & $\begin{array}{c}\text { EQUIPMENT } \\
\text { TYPE }\end{array}$ & METHOD OF COMPLIANCE \\
\hline$V-74$ & $\begin{array}{c}\text { Tank F-1 } \\
\text { (DTM) }\end{array}$ & Valve & LDAR Monitoring \& Annual Inspections \\
\hline$V-75$ & $\begin{array}{l}\text { Tank F-1 } \\
\text { (DTM) }\end{array}$ & Valve & LDAR Monitoring \& Annual Inspections \\
\hline V-76 & $\begin{array}{c}\text { Tank F-1 } \\
\text { (DTM) }\end{array}$ & Valve & LDAR Monitoring \& Annual Inspections \\
\hline V-77 & $\begin{array}{c}\text { Tank F-1 } \\
\text { (DTM) }\end{array}$ & Valve & LDAR Monitoring \& Annual Inspections \\
\hline V-78 & $\begin{array}{c}\text { Tank F-1 } \\
\text { (DTM) }\end{array}$ & Valve & LDAR Monitoring \& Annual Inspections \\
\hline V-79 & $\begin{array}{l}\text { Tank F-1 } \\
\text { (DTM) }\end{array}$ & Valve & LDAR Monitoring \& Annual Inspections \\
\hline$V-21$ & Tank F-2 & Valve & LDAR Monitoring \& Annual Inspections \\
\hline $\mathrm{V}-22$ & Tank F-2 & Valve & LDAR Monitoring \& Annual Inspections \\
\hline V-23 & Tank F-2 & Valve & LDAR Monitoring \& Annual Inspections \\
\hline V-24 & Tank F-2 & Valve & LDAR Monitoring \& Annual Inspections \\
\hline $\mathrm{V}-25$ & Tank F-2 & Valve & LDAR Monitoring \& Annual Inspections \\
\hline$V-26$ & Tank F-2 & Valve & LDAR Monitoring \& Annual Inspections \\
\hline$V-27$ & Tank F-2 & Valve & LDAR Monitoring \& Annual Inspections \\
\hline $\mathrm{V}-28$ & Tank F-2 & Valve & LDAR Monitoring \& Annual Inspections \\
\hline$V-29$ & Tank F-2 & Valve & LDAR Monitoring \& Annual Inspections \\
\hline$V-33$ & Tank F-2 & Valve & LDAR Monitoring \& Annual Inspections \\
\hline$V-43$ & Tank F-2 & Valve & LDAR Monitoring \& Annual Inspections \\
\hline$V-44$ & Tank F-2 & Valve & LDAR Monitoring \& Annual Inspections \\
\hline$V-47$ & Tank F-2 & Valve & LDAR Monitoring \& Annual Inspections \\
\hline V-48 & Tank F-2 & Valve & LDAR Monitoring \& Annual Inspections \\
\hline$V-49$ & Tank F-2 & Valve & LDAR Monitoring \& Annual Inspections \\
\hline V-1394 & Tank F-2 & Valve & LDAR Monitoring \& Annual Inspections \\
\hline$V-1395$ & Tank F-2 & Valve & LDAR Monitoring \& Annual Inspections \\
\hline$V-1396$ & Tank F-2 & Valve & LDAR Monitoring \& Annual Inspections \\
\hline V-92 & Tank F-2 & Valve & LDAR Monitoring \& Annual Inspections \\
\hline V-93 & Tank F-2 & Valve & LDAR Monitoring \& Annual Inspections \\
\hline
\end{tabular}




\begin{tabular}{|c|c|c|c|}
\hline $\begin{array}{c}\text { EQUIPMENT } \\
\text { ID } \\
\text { NUMBER } \\
\end{array}$ & $\begin{array}{l}\text { EQUIPMENT } \\
\text { LOCATION }\end{array}$ & $\begin{array}{l}\text { EQUIPMENT } \\
\text { TYPE }\end{array}$ & METHOD OF COMPLIANCE \\
\hline V-94 & Tank F-2 & Valve & LDAR Monitoring \& Annual Inspections \\
\hline V-95 & Tank F-2 & Valve & LDAR Monitoring \& Annual Inspections \\
\hline V-96 & Tank F-2 & Valve & LDAR Monitoring \& Annual Inspections \\
\hline V-97 & Tank F-2 & Valve & LDAR Monitoring \& Annual Inspections \\
\hline V-80 & $\begin{array}{l}\text { Tank F-2 } \\
\text { (DTM) }\end{array}$ & Valve & LDAR Monitoring \& Annual Inspections \\
\hline V-81 & $\begin{array}{c}\text { Tank F-2 } \\
\text { (DTM) }\end{array}$ & Valve & LDAR Monitoring \& Annual Inspections \\
\hline$V-82$ & $\begin{array}{c}\text { Tank F-2 } \\
\text { (DTM) }\end{array}$ & Valve & LDAR Monitoring \& Annual Inspections \\
\hline V-83 & $\begin{array}{l}\text { Tank F-2 } \\
\text { (DTM) }\end{array}$ & Valve & LDAR Monitoring \& Annual Inspections \\
\hline V-84 & $\begin{array}{l}\text { Tank F-2 } \\
\text { (DTM) }\end{array}$ & Valve & LDAR Monitoring \& Annual Inspections \\
\hline V-85 & $\begin{array}{l}\text { Tank F-2 } \\
\text { (DTM) }\end{array}$ & Valve & LDAR Monitoring \& Annual Inspections \\
\hline $\mathrm{V}-1$ & Tank F-3 & Valve & LDAR Monitoring \& Annual Inspections \\
\hline $\mathrm{V}-2$ & Tank F-3 & Valve & LDAR Monitoring \& Annual Inspections \\
\hline$V-3$ & Tank F-3 & Valve & LDAR Monitoring \& Annual Inspections \\
\hline V-4 & Tank F-3 & Valve & LDAR Monitoring \& Annual Inspections \\
\hline V-5 & Tank F-3 & Valve & LDAR Monitoring \& Annual Inspections \\
\hline V-6 & Tank F-3 & Valve & LDAR Monitoring \& Annual Inspections \\
\hline V-7 & Tank F-3 & Valve & LDAR Monitoring \& Annual Inspections \\
\hline $\mathrm{V}-8$ & Tank F-3 & Valve & LDAR Monitoring \& Annual Inspections \\
\hline V-9 & Tank F-3 & Valve & LDAR Monitoring \& Annual Inspections \\
\hline$V-10$ & Tank F-3 & Valve & LDAR Monitoring \& Annual Inspections \\
\hline $\mathrm{V}-11$ & Tank F-3 & Valve & LDAR Monitoring \& Annual Inspections \\
\hline V-41 & Tank F-3 & Valve & LDAR Monitoring \& Annual Inspections \\
\hline V-98 & Tank F-3 & Valve & LDAR Monitoring \& Annual Inspections \\
\hline V-99 & Tank F-3 & Valve & LDAR Monitoring \& Annual Inspections \\
\hline V-51 & $\begin{array}{l}\text { Tank F-3 } \\
\text { (DTM) }\end{array}$ & Valve & LDAR Monitoring \& Annual Inspections \\
\hline
\end{tabular}




\section{EQUIPMENT}

ID NUMBER
EQUIPMENT EQUTPIMENT

LOCATION

Tank F-3

(DTM)

V-53 Tank F-3

(DTM)

V-54 Tank F-3

(DTM)

V-55 Tank F-3

(DTM)

V-56 Tank F-3

(DTM)

V-57

Tank F-3

(DTM)

V-58 Tank F-3

(DTM)

V-12

$\mathrm{V}-13$

$\mathrm{V}-14$

V-15

V-16

V-17

V-18

V-19

V-20

$\mathrm{V}-42$

V-100

V-101

$\mathrm{V}-63$

V-64

V-65

V-66
Tank F-4

Tank F-4

Tank F-4

Tank F-4

Tank F-4

Tank F-4

Tank F-4

Tank F-4

Tank F-4

Tank F-4

Tank F-4

Tank F-4

Tank F-4

(DTM)

Tank F-4

(DTM)

Tank F-4

(DTM)

Tank F-4

(DTM)
TYPE

Valve

Valve

Valve

Valve

Valve

Valve

Valve

Valve

Valve

Valve

Valve

Valve

Valve

Valve

Valve

Valve

Valve

Valve

Valve

Valve

Valve

Valve

Valve
METHOD OF COMPLIANCE

LDAR Monitoring \& Annual Inspections

LDAR Monitoring \& Annual Inspections

LDAR Monitoring \& Annual Inspections

LDAR Monitoring \& Annual Inspections

LDAR Monitoring \& Annual Inspections

LDAR Monitoring \& Annual Inspections

LDAR Monitoring \& Annual Inspections

LDAR Monitoring \& Annual Inspections

LDAR Monitoring \& Annual Inspections

LDAR Monitoring \& Annual Inspections

LDAR Monitoring \& Annual Inspections

LDAR Monitoring \& Annual Inspections

LDAR Monitoring \& Annual Inspections

LDAR Monitoring \& Annual Inspections

LDAR Monitoring \& Annual Inspections

LDAR Monitoring \& Annual Inspections

LDAR Monitoring \& Annual Inspections

LDAR Monitoring \& Annual Inspections

LDAR Monitoring \& Annual Inspections

LDAR Monitoring \& Annual Inspections

LDAR Monitoring \& Annual Inspections

LDAR Monitoring \& Annual Inspections

LDAR Monitoring \& Annual Inspections 


\begin{tabular}{cccc}
$\begin{array}{c}\text { EQUIPMENT } \\
\text { ID } \\
\text { NUMBER }\end{array}$ & $\begin{array}{c}\text { EQUIPMENT } \\
\text { LOCATION }\end{array}$ & $\begin{array}{c}\text { EQUIPMENT } \\
\text { TYPE }\end{array}$ & METHOD OF COMPLIANCE \\
\hline V-67 & $\begin{array}{c}\text { Tank F-4 } \\
\text { (DTM) }\end{array}$ & Valve & LDAR Monitoring \& Annual Inspections \\
V-68 & $\begin{array}{c}\text { Tank F-4 } \\
\text { (DTM) }\end{array}$ & Valve & LDAR Monitoring \& Annual Inspections \\
V-69 & $\begin{array}{c}\text { Tank F-4 } \\
\text { (DTM) }\end{array}$ & Valve & LDAR Monitoring \& Annual Inspections \\
V-70 & $\begin{array}{c}\text { Tank F-4 } \\
\text { (DTM) }\end{array}$ & Valve & LDAR Monitoring \& Annual Inspections \\
V-59 & $\begin{array}{c}\text { Tank F-7 } \\
\text { V-60 }\end{array}$ & Valve & LDAR Monitoring \& Annual Inspections \\
V-61 & Tank F-7 & Valve & LDAR Monitoring \& Annual Inspections \\
V-62 & Tank F-7 & Valve & LDAR Monitoring \& Annual Inspections
\end{tabular}




\section{SUBPART BB - EQUIPMENT IDENTIFICATION/INFORMATION OD-9, Waste Oil/Solvent Storage Unit}

\begin{tabular}{|c|c|c|c|}
\hline $\begin{array}{c}\text { EQUIPMENT } \\
\text { ID } \\
\text { NUMBE }\end{array}$ & $\begin{array}{l}\text { EQUIPMENT } \\
\text { LOCATION }\end{array}$ & $\begin{array}{c}\text { EQUIPMENT } \\
\text { TYPE }\end{array}$ & METHOD OF COMPLIANCE \\
\hline V-11 & Tank F-1 & Valve & LDAR Monitoring \& Annual Inspections \\
\hline $\mathrm{V}-12$ & Tank F-1 & Valve & LDAR Monitoring \& Annual Inspections \\
\hline $\mathrm{V}-13$ & Pump J-1 & Valve & LDAR Monitoring \& Annual Inspections \\
\hline $\mathrm{V}-14$ & Pump J-1 & Valve & LDAR Monitoring \& Annual Inspections \\
\hline $\mathrm{V}-15$ & Pump J-1 & Valve & LDAR Monitoring \& Annual Inspections \\
\hline$V-16$ & Pump J-1 & Valve & LDAR Monitoring \& Annual Inspections \\
\hline $\mathrm{V}-17$ & Pump J-1 & Valve & LDAR Monitoring \& Annual Inspections \\
\hline $\mathrm{V}-18$ & $\begin{array}{c}\text { J-1 Sample } \\
\text { Valve }\end{array}$ & Valve & LDAR Monitoring \& Annual Inspections \\
\hline V-71 & Near V-18 & Valve & LDAR Monitoring \& Annual Inspections \\
\hline V-75 & Drain Valve $\mathrm{J}-1$ & Valve & LDAR Monitoring \& Annual Inspections \\
\hline V-77 & Near V-18 & Valve & LDAR Monitoring \& Annual Inspections \\
\hline$V-21$ & Tank F-2 & Valve & LDAR Monitoring \& Annual Inspections \\
\hline $\mathrm{V}-22$ & Tank F-2 & Valve & LDAR Monitoring \& Annual Inspections \\
\hline$V-23$ & Pump J-2 & Valve & LDAR Monitoring \& Annual Inspections \\
\hline $\mathrm{V}-24$ & Pump J-2 & Valve & LDAR Monitoring \& Annual Inspections \\
\hline$V-25$ & Pump J-2 & Val.ve & LDAR Monitoring \& Annual Inspections \\
\hline$V-26$ & Pump J-2 & Valve & LDAR Monitoring \& Annual Inspections \\
\hline $\mathrm{V}-27$ & Tank F-2 & Valve & LDAR Monitoring \& Annual Inspections \\
\hline $\mathrm{V}-28$ & Pump J-2 & Valve & LDAR Monitoring \& Annual Inspections \\
\hline V-76 & Drain Valve $\mathrm{J}-2$ & Valve & LDAR Monitoring \& Annual Inspections \\
\hline V-78 & Near V-28 & Valve & LDAR Monitoring \& Annual Inspections \\
\hline V-79 & Near V-28 & Valve & LDAR Monitoring \& Annual Inspections \\
\hline V-31 & Tank F-3 & Valve & LDAR Monitoring \& Annual Inspections \\
\hline $\mathrm{V}-32$ & Tank F-3 & Valve & LDAR Monitoring \& Annual Inspections \\
\hline$V-33$ & Pump J-3 & Valve & LDAR Monitoring \& Annual Inspections \\
\hline$V-34$ & Pump J-3 & Valve & LDAR Monitoring \& Annual Inspections \\
\hline$V-35$ & Pump J-3 & Valve & LDAR Monitoring \& Annual Inspections \\
\hline
\end{tabular}




\begin{tabular}{|c|c|c|c|}
\hline $\begin{array}{c}\text { EQUIPMENT } \\
\text { ID } \\
\text { NUMBER }\end{array}$ & $\begin{array}{l}\text { EQUTPMENT } \\
\text { LOCATION }\end{array}$ & $\begin{array}{c}\text { EQUIPMENT } \\
\text { TYPE }\end{array}$ & METHOD OF COMPLIANCE \\
\hline$V-36$ & Pump J-3 & Valve & LDAR Monitoring \& Annual Inspections \\
\hline$V-37$ & Tank F-3 & Valve & LDAR Monitoring \& Annual Inspections \\
\hline V-38 & Pump J-3 & Valve & LDAR Monitoring \& Annual Inspections \\
\hline V-74 & Drain Valve $\mathrm{J}-3$ & Valve & LDAR Monitoring \& Annual Inspections \\
\hline V-80 & Near V-38 & Valve & LDAR Monitoring \& Annual Inspections \\
\hline V-81 & Near V-38 & Valve & LDAR Monitoring \& Annual Inspections \\
\hline$V-41$ & Tank F-4 & Valve & LDAR Monitoring \& Annual Inspections \\
\hline $\mathrm{V}-42$ & Tank F-4 & Valve & LDAR Monitoring \& Annual Inspections \\
\hline$V-43$ & Pump J-4 & Valve & LDAR Monitoring \& Annual Inspections \\
\hline V-44 & Pump J-4 & Valve & LDAR Monitoring \& Annual Inspections \\
\hline$V-45$ & Pump J-4 & Valve & LDAR Monitoring \& Annual Inspections \\
\hline$V-46$ & Pump J-4 & Valve & LDAR Monitoring \& Annual Inspections \\
\hline$V-47$ & Tank F-4 & Valve & LDAR Monitoring \& Annual Inspections \\
\hline$V-48$ & Pump J-4 & Valve & LDAR Monitoring \& Annual Inspections \\
\hline $\mathrm{V}-73$ & Drain Valve J-4 & Valve & LDAR Monitoring \& Annual Inspections \\
\hline $\mathrm{V}-82$ & Near V-48 & Valve & LDAR Monitoring \& Annual Inspections \\
\hline V-83 & Near V-48 & Valve & LDAR Monitoring \& Annual Inspections \\
\hline V-51 & Tank F-5 & Valve & LDAR Monitoring \& Annual Inspections \\
\hline V-52 & Tank F-5 & Valve & LDAR Monitoring \& Annual Inspections \\
\hline V-53 & Pump J-5 & Valve & LDAR Monitoring \& Annual Inspections \\
\hline V-54 & Pump J-5 & Valve & LDAR Monitoring \& Annual Inspections \\
\hline V-55 & Pump J-5 & Valve & LDAR Monitoring \& Annual Inspections \\
\hline V-56 & Pump J-5 & Valve & LDAR Monitoring \& Annual Inspections \\
\hline$V-57$ & Tank F-5 & Valve & LDAR Monitoring \& Annual Inspections \\
\hline $\mathrm{V}-58$ & Pump J-5 & Valve & LDAR Monitoring \& Annual Inspections \\
\hline V-72 & Drain Valve $\mathrm{J}-5$ & Valve & LDAR Monitoring \& Annual Inspections \\
\hline V-84 & Near V-58 & Valve & LDAR Monitoring \& Annual Inspections \\
\hline$V-85$ & Near V-58 & Valve & LDAR Monitoring \& Annual Inspections \\
\hline V-61 & Tank F-1 Sump & Valve & LDAR Monitoring \& Annual Inspections \\
\hline$V-62$ & Tank F-2 Sump & Valve & LDAR Monitoring \& Annual Inspections \\
\hline
\end{tabular}




\begin{tabular}{|c|c|c|c|}
\hline $\begin{array}{c}\text { EQUIPMENT } \\
\text { ID } \\
\text { NUMBER }\end{array}$ & $\begin{array}{l}\text { EQUIPMENT } \\
\text { LOCATION }\end{array}$ & $\begin{array}{c}\text { EQUTPMENT } \\
\text { TYPE }\end{array}$ & METHOD OF COMPLIANCE \\
\hline$V-63$ & Tank F-3 sump & Valve & LDAR Monitoring \& Annual Inspections \\
\hline$V-64$ & Tank F-4 Sump & Valve & LDAR Monitoring \& Annual Inspections \\
\hline$V-65$ & Tank F-5 Sump & Valve & LDAR Monitoring \& Annual Inspections \\
\hline$V-66$ & $\begin{array}{c}\text { Pump J-8 } \\
\text { Sample Valve }\end{array}$ & Valve & LDAR Monitoring \& Annual Inspections \\
\hline$V-67$ & $\begin{array}{c}\text { Pump J-9 } \\
\text { Polytank Valve }\end{array}$ & Valve & LDAR Monitoring \& Annual Inspections \\
\hline$V-68$ & $\begin{array}{c}\text { Pump J-8 } \\
\text { Polytank Valve }\end{array}$ & Valve & LDAR Monitoring \& Annual Inspections \\
\hline$V-69$ & $\begin{array}{c}\text { Storm Sewer } \\
\text { Valve }\end{array}$ & Valve & LDAR Monitoring \& Annual Inspections \\
\hline $\mathrm{V}-86$ & $\begin{array}{c}\text { Pump J-8 Sump } \\
\text { Valve, Tanks } \\
\text { F-4 and F-5 }\end{array}$ & Valve & LDAR Monitoring \& Annual Inspections \\
\hline V-87 & $\begin{array}{c}\text { Pump J-9 Sump } \\
\text { Valve, Tanks } \\
\text { F-1, F-2, and } \\
\text { F-3 }\end{array}$ & Valve & LDAR Monitoring \& Annual Inspections \\
\hline V-102 & $\begin{array}{l}\text { Crossover } \\
\text { Valve to F-2 }\end{array}$ & Valve & LDAR Monitoring \& Annual Inspections \\
\hline V-201 & $\begin{array}{l}\text { Crossover } \\
\text { Valve to } F-1\end{array}$ & Valve & LDAR Monitoring \& Annual Inspections \\
\hline V-203 & $\begin{array}{l}\text { Crossover } \\
\text { Valve to F-3 }\end{array}$ & Valve & LDAR Monitoring \& Annual Inspections \\
\hline V-302 & $\begin{array}{c}\text { Crossover } \\
\text { Valve from F-3 }\end{array}$ & Valve & LDAR Monitoring \& Annual Inspections \\
\hline V-402 & $\begin{array}{c}\text { Crossover } \\
\text { Valve from F-4 }\end{array}$ & Valve & LDAR Monitoring \& Annual Inspections \\
\hline V-504 & $\begin{array}{c}\text { Crossover } \\
\text { Valve from F-5 }\end{array}$ & Valve & LDAR Monitoring \& Annual Inspections \\
\hline $\mathrm{V}-1$ & $\begin{array}{l}\text { Drum Pump to } \\
\text { F-1 }\end{array}$ & Valve & LDAR Monitoring \& Annual Inspections \\
\hline $\mathrm{V}-2$ & $\begin{array}{l}\text { Drum Pump to } \\
\text { F-2 }\end{array}$ & Valve & LDAR Monitoring \& Annual Inspections \\
\hline$V-3$ & $\begin{array}{c}\text { Drum Pump to } \\
\text { F-3 }\end{array}$ & Valve & LDAR Monitoring \& Annual Inspections \\
\hline
\end{tabular}




\begin{tabular}{|c|c|c|c|}
\hline $\begin{array}{c}\text { EQUIPMENT } \\
\text { ID } \\
\text { NUMBER }\end{array}$ & $\begin{array}{l}\text { EQUIPMENT } \\
\text { LOCATION }\end{array}$ & $\begin{array}{l}\text { EQUIPMENT } \\
\text { TYPE }\end{array}$ & METHOD OF COMPLIANCE \\
\hline$V-4$ & $\begin{array}{c}\text { Drum Pump to } \\
\text { F-4 }\end{array}$ & Valve & LDAR Monitoring \& Annual Inspections \\
\hline V-5 & $\begin{array}{l}\text { Drum Pump to } \\
\text { F-5 }\end{array}$ & Valve & LDAR Monitoring \& Annual Inspections \\
\hline BPR-1 & $\begin{array}{c}\text { Near Valve } \\
\text { V-15 }\end{array}$ & Valve & LDAR Monitoring \& Annual Inspections \\
\hline BPR-2 & $\begin{array}{c}\text { Near Valve } \\
\text { V-25 }\end{array}$ & Valve & LDAR Monitoring \& Annual Inspections \\
\hline BPR-3 & $\begin{array}{c}\text { Near Valve } \\
\text { V-35 }\end{array}$ & Valve & LDAR Monitoring \& Annual Inspections \\
\hline BPR-4 & $\begin{array}{c}\text { Near Valve } \\
\text { V-45 }\end{array}$ & Valve & LDAR Monitoring \& Annual Inspections \\
\hline BPR-5 & $\begin{array}{c}\text { Near Valve } \\
\text { V-55 }\end{array}$ & Valve & LDAR Monitoring \& Annual Inspections \\
\hline $\mathrm{J}-1$ & & Pump & LDAR Monitoring \& Annual Inspections \\
\hline $\mathrm{J}-2$ & & Pump & LDAR Monitoring \& Annual Inspections \\
\hline $\mathrm{J}-3$ & & Pump & LDAR Monitoring \& Annual Inspections \\
\hline $\mathrm{J}-4$ & & Pump & LDAR Monitoring \& Annual Inspections \\
\hline $\mathrm{J}-5$ & & Pump & LDAR Monitoring \& Annual Inspections \\
\hline
\end{tabular}




\section{SUBPART BB - EQUTPMENT IDENTIFICATION/INFORMATION}

OD-10, Liquid Organic Solvent Storage Unit

\begin{tabular}{|c|c|c|c|}
\hline $\begin{array}{c}\text { EQUIPMENT } \\
\text { ID } \\
\text { NUMBER }\end{array}$ & $\begin{array}{l}\text { EQUIPMENT } \\
\text { LOCA } \mathrm{ON}\end{array}$ & $\begin{array}{c}\text { EQUTPMENT } \\
\text { TYPE }\end{array}$ & METHOD OF COMPLIANCE \\
\hline V-PLTFRM & $\begin{array}{l}\text { Valve on } \\
\text { platform }\end{array}$ & Valve & LDAR Monitoring \& Annual Inspections \\
\hline FV $-1-900$ & $\begin{array}{c}\text { Tanks } 900 \mathrm{~A} \\
\text { and } 900 \mathrm{~B}\end{array}$ & Valve & LDAR Monitoring \& Annual Inspections \\
\hline FV-2-900 & $\begin{array}{c}\text { Tanks } 900 \mathrm{~A} \\
\text { and } 900 \mathrm{~B}\end{array}$ & Valve & LDAR Monitoring \& Annual Inspections \\
\hline FV $-1-700$ & $\begin{array}{c}\text { Tanks } 700 \mathrm{~A} \\
\text { and } 700 \mathrm{~B}\end{array}$ & Valve & LDAR Monitoring \& Annual Inspections \\
\hline FV $-2-700$ & $\begin{array}{c}\text { Tanks } 700 \mathrm{~A} \\
\text { and } 700 \mathrm{~B}\end{array}$ & Valve & LDAR Monitoring \& Annual Inspections \\
\hline FV $-1-600$ & $\begin{array}{c}\text { Tanks } 600 \mathrm{~A} \\
\text { and } 600 \mathrm{~B}\end{array}$ & Valve & LDAR Monitoring \& Annual Inspections \\
\hline FV $-2-600$ & $\begin{array}{c}\text { Tanks } 600 \mathrm{~A} \\
\text { and } 600 \mathrm{~B}\end{array}$ & Valve & LDAR Monitoring \& Annual Inspections \\
\hline FV-7-900 & $\begin{array}{c}\text { Tanks } 900 \mathrm{~A} \\
\text { and } 900 \mathrm{~B}\end{array}$ & Valve & LDAR Monitoring \& Annual Inspections \\
\hline FV $-3-900$ & $\begin{array}{c}\text { Tanks } 900 \mathrm{~A} \\
\text { and } 900 \mathrm{~B}\end{array}$ & Valve & LDAR Monitoring \& Annual Inspections \\
\hline DV $-10-900$ & $\begin{array}{c}\text { Tanks } 900 \mathrm{~A} \\
\text { and } 900 \mathrm{~B}\end{array}$ & Valve & LDAR Monitoring \& Annual Inspections \\
\hline DV $-11-900$ & $\begin{array}{c}\text { Tanks } 900 \mathrm{~A} \\
\text { and } 900 \mathrm{~B}\end{array}$ & Valve & LDAR Monitoring \& Annual Inspections \\
\hline PCV-1-900 & $\begin{array}{c}\text { Tanks } 900 \mathrm{~A} \\
\text { and } 900 \mathrm{~B}\end{array}$ & Valve & LDAR Monitoring \& Annual Inspections \\
\hline DV-12-900 & $\begin{array}{c}\text { Tanks } 900 \mathrm{~A} \\
\text { and } 900 \mathrm{~B}\end{array}$ & Valve & LDAR Monitoring \& Annual Inspections \\
\hline PCV-2-900 & $\begin{array}{c}\text { Tanks } 900 \mathrm{~A} \\
\text { and } 900 \mathrm{~B}\end{array}$ & Valve & LDAR Monitoring \& Annual Inspections \\
\hline Pump J-900 & $\begin{array}{c}\text { Tanks } 900 \mathrm{~A} \\
\text { and } 900 \mathrm{~B}\end{array}$ & Pump & LDAR Monitoring \& Annual Inspections \\
\hline PCV $-3-900$ & $\begin{array}{c}\text { Tanks } 900 \mathrm{~A} \\
\text { and } 900 \mathrm{~B}\end{array}$ & Valve & LDAR Monitoring \& Annual Inspections \\
\hline
\end{tabular}




\begin{tabular}{|c|c|c|c|}
\hline $\begin{array}{c}\text { EQUIPMENT } \\
\text { ID } \\
\text { NUMBER } \\
\end{array}$ & $\begin{array}{l}\text { EQUIPMENT } \\
\text { LOCATION }\end{array}$ & $\begin{array}{c}\text { EQUIPMENT } \\
\text { TYPE }\end{array}$ & METHOD OF COMPLIANCE \\
\hline FV-4-900 & $\begin{array}{l}\text { Tanks } 900 \mathrm{~A} \\
\text { and } 900 \mathrm{~B}\end{array}$ & Valve & LDAR Monitoring \& Annual Inspections \\
\hline FV-5-900 & $\begin{array}{l}\text { Tanks } 900 \mathrm{~A} \\
\text { and } 900 \mathrm{~B}\end{array}$ & Valve & LDAR Monitoring \& Annual Inspections \\
\hline FV-6-900 & $\begin{array}{l}\text { Tanks 900A } \\
\text { and 900B }\end{array}$ & Valve & LDAR Monitoring \& Annual Inspections \\
\hline FV-7-700 & $\begin{array}{c}\text { Tanks 700A } \\
\text { and 700B }\end{array}$ & Valve & LDAR Monitoring \& Annual Inspections \\
\hline FV-3-700 & $\begin{array}{c}\text { Tanks } 700 \mathrm{~A} \\
\text { and } 700 \mathrm{~B}\end{array}$ & Valve & LDAR Monitoring \& Annual Inspections \\
\hline DV $-10-700$ & $\begin{array}{c}\text { Tanks } 700 \mathrm{~A} \\
\text { and } 700 \mathrm{~B}\end{array}$ & Valve & LDAR Monitoring \& Annual Inspections \\
\hline DV $-11-700$ & $\begin{array}{l}\text { Tanks 700A } \\
\text { and 700B }\end{array}$ & Valve & LDAR Monitoring \& Annual Inspections \\
\hline PCV-1-700 & $\begin{array}{l}\text { Tanks 700A } \\
\text { and 700B }\end{array}$ & Valve & LDAR Monitoring \& Annual Inspections \\
\hline DV-12-700 & $\begin{array}{c}\text { Tanks } 700 \mathrm{~A} \\
\text { and } 700 \mathrm{~B}\end{array}$ & Valve & LDAR Monitoring \& Annual Inspections \\
\hline PCV-2-700 & $\begin{array}{c}\text { Tanks } 700 \mathrm{~A} \\
\text { and } 700 \mathrm{~B}\end{array}$ & Valve & LDAR Monitoring \& Annual Inspections \\
\hline Pump J-700 & $\begin{array}{c}\text { Tanks } 700 \mathrm{~A} \\
\text { and } 700 \mathrm{~B}\end{array}$ & Pump & LDAR Monitoring \& Annual Inspections \\
\hline PCV-3-700 & $\begin{array}{c}\text { Tanks 700A } \\
\text { and } 700 \mathrm{~B}\end{array}$ & Valve & LDAR Monitoring \& Annual Inspections \\
\hline FV-4-700 & $\begin{array}{c}\text { Tanks } 700 \mathrm{~A} \\
\text { and } 700 \mathrm{~B}\end{array}$ & Valve & LDAR Monitoring \& Annual Inspections \\
\hline FV-5-700 & $\begin{array}{c}\text { Tanks } 700 \mathrm{~A} \\
\text { and } 700 \mathrm{~B}\end{array}$ & Valve & LDAR Monitoring \& Annual Inspections \\
\hline FV-6-700 & $\begin{array}{c}\text { Tanks } 700 \mathrm{~A} \\
\text { and } 700 \mathrm{~B}\end{array}$ & Valve & LDAR Monitoring \& Annual Inspections \\
\hline FV-7-600 & $\begin{array}{l}\text { Tanks 600A } \\
\text { and } 600 \mathrm{~B}\end{array}$ & Valve & LDAR Monitoring \& Annual Inspections \\
\hline FV $-3-600$ & $\begin{array}{l}\text { Tanks } 600 \mathrm{~A} \\
\text { and } 600 \mathrm{~B}\end{array}$ & Valve & LDAR Monitoring \& Annual Inspections \\
\hline DV $-10-600$ & $\begin{array}{c}\text { Tanks 600A } \\
\text { and } 600 \mathrm{~B}\end{array}$ & Valve & LDAR Monitoring \& Annual Inspections \\
\hline
\end{tabular}




\begin{tabular}{|c|c|c|c|}
\hline $\begin{array}{c}\text { EQUIPMENT } \\
\text { ID } \\
\text { NUMBER } \\
\end{array}$ & $\begin{array}{l}\text { EQUIPMENT } \\
\text { LOCATION }\end{array}$ & $\begin{array}{c}\text { EQUIPMENT } \\
\text { TYPE }\end{array}$ & METHOD OF COMPLIANCE \\
\hline DV $-11-600$ & $\begin{array}{c}\text { Tanks } 600 \mathrm{~A} \\
\text { and } 600 \mathrm{~B}\end{array}$ & Valve & LDAR Monitoring \& Annual Inspections \\
\hline PCV-1-600 & $\begin{array}{c}\text { Tanks } 600 \mathrm{~A} \\
\text { and } 600 \mathrm{~B}\end{array}$ & Valve & LDAR Monitoring \& Annual Inspections \\
\hline DV $-12-600$ & $\begin{array}{c}\text { Tanks } 600 \mathrm{~A} \\
\text { and } 600 \mathrm{~B}\end{array}$ & Valve & LDAR Monitoring \& Annual Inspections \\
\hline PCV-2-600 & $\begin{array}{c}\text { Tanks } 600 \mathrm{~A} \\
\text { and } 600 \mathrm{~B}\end{array}$ & Valve & LDAR Monitoring \& Annual Inspections \\
\hline Pump J-600 & $\begin{array}{c}\text { Tanks } 600 \mathrm{~A} \\
\text { and } 600 \mathrm{~B}\end{array}$ & Pump & LDAR Monitoring \& Annual Inspections \\
\hline PCV-3-600 & $\begin{array}{c}\text { Tanks } 600 \mathrm{~A} \\
\text { and } 600 \mathrm{~B}\end{array}$ & Valve & LDAR Monitoring \& Annual Inspections \\
\hline FV-4-600 & $\begin{array}{c}\text { Tanks } 600 \mathrm{~A} \\
\text { and } 600 \mathrm{~B}\end{array}$ & Valve & LDAR Monitoring \& Annual Inspections \\
\hline FV $-5-600$ & $\begin{array}{c}\text { Tanks } 600 \mathrm{~A} \\
\text { and } 600 \mathrm{~B}\end{array}$ & Valve & LDAR Monitoring \& Annual Inspections \\
\hline FV-6-600 & $\begin{array}{c}\text { Tanks } 600 \mathrm{~A} \\
\text { and } 600 \mathrm{~B}\end{array}$ & Valve & LDAR Monitoring \& Annual Inspections \\
\hline DV-1-900A & Tank $900 \mathrm{~A}$ & Valve & LDAR Monitoring \& Annual Inspections \\
\hline DV-2-900A & Tank $900 \mathrm{~A}$ & Valve & LDAR Monitoring \& Annual Inspections \\
\hline DV-7-900A & Tank 900A & Valve & LDAR Monitoring \& Annual Inspections \\
\hline DV-8-900A & Tank $900 \mathrm{~A}$ & Valve & LDAR Monitoring \& Annual Inspections \\
\hline DV-9-900A & Tank $900 \mathrm{~A}$ & Valve & LDAR Monitoring \& Annual Inspections \\
\hline D-EOV-900A & Tank $900 \mathrm{~A}$ & Valve & LDAR Monitoring \& Annual Inspections \\
\hline DV-6-900A & Tank 900A & Valve & LDAR Monitoring \& Annual Inspections \\
\hline SV-7-900A & Tank 900A & Valve & LDAR Monitoring \& Annual Inspections \\
\hline DV-5-900A & Tank 900A & Valve & LDAR Monitoring \& Annual Inspections \\
\hline SV-5-900A & Tank 900A & Valve & LDAR Monitoring \& Annual Inspections \\
\hline DV-4-900A & Tank 900A & Valve & LDAR Monitoring \& Annual Inspections \\
\hline SV-3-900A & Tank $900 \mathrm{~A}$ & Valve & LDAR Monitoring \& Annual Inspections \\
\hline DV $-3-900 A$ & Tank $900 \mathrm{~A}$ & Valve & LDAR Monitoring \& Annual Inspections \\
\hline SV-1-900A & Tank $900 \mathrm{~A}$ & Valve & LDAR Monitoring \& Annual Inspections \\
\hline SV-2-900A & Tank $900 \mathrm{~A}$ & Valve & LDAR Monitoring \& Annual Inspections \\
\hline
\end{tabular}




\begin{tabular}{|c|c|c|c|}
\hline $\begin{array}{c}\text { EQUIPMENT } \\
\text { ID } \\
\text { NUMBER } \\
\end{array}$ & $\begin{array}{l}\text { EQUIPMENT } \\
\text { LOCATION }\end{array}$ & $\begin{array}{l}\text { EQUIPMENT } \\
\text { TYPE }\end{array}$ & METHOD OF COMPLIANCE \\
\hline SV-4-900A & Tank $900 \mathrm{~A}$ & Valve & LDAR Monitoring \& Annual Inspections \\
\hline SV-6-900A & Tank $900 \mathrm{~A}$ & Valve & LDAR Monitoring \& Annual Inspections \\
\hline SV-8-900A & Tank $900 \mathrm{~A}$ & Valve & LDAR Monitoring \& Annual Inspections \\
\hline F-EOV-900A & $\begin{array}{c}\text { Tank } 900 \mathrm{~A} \\
\text { (on top) }\end{array}$ & Valve & LDAR Monitoring \& Annual Inspections \\
\hline DV-1-900B & Tank $900 \mathrm{~B}$ & Valve & LDAR Monitoring \& Annual Inspections \\
\hline DV-2-900B & Tank 900B & Valve & LDAR Monitoring \& Annual Inspections \\
\hline DV-7-900B & Tank 900B & Valve & LDAR Monitoring \& Annual Inspections \\
\hline DV-8-900B & Tank 900B & Valve & LDAR Monitoring \& Annual Inspections \\
\hline DV $-9-900 B$ & Tank 900B & Valve & LDAR Monitoring \& Annual Inspections \\
\hline D-EOV-900B & Tank 900B & Valve & LDAR Monitoring \& Annual Inspections \\
\hline DV-6-900B & Tank 900B & Valve & LDAR Monitoring \& Annual Inspections \\
\hline SV-7-900B & Tank 900B & Valve & LDAR Monitoring \& Annual Inspections \\
\hline DV-5-900B & Tank 900B & Valve & LDAR Monitoring \& Annual Inspections \\
\hline SV-5-900B & Tank 900B & Valve & LDAR Monitoring \& Annual Inspections \\
\hline DV-4-900B & Tank $900 \mathrm{~B}$ & Valve & LDAR Monitoring \& Annual Inspections \\
\hline SV-3-900B & Tank 900B & Valve & LDAR Monitoring \& Annual Inspections \\
\hline DV $-3-900 B$ & Tank 900B & Valve & LDAR Monitoring \& Annual Inspections \\
\hline SV-1-900B & Tank 900B & Valve & LDAR Monitoring \& Annual Inspections \\
\hline SV-2-900B & Tank 900B & Valve & LDAR Monitoring \& Annual Inspections \\
\hline SV-4-900B & Tank 900B & Valve & LDAR Monitoring \& Annual Inspections \\
\hline SV-6-900B & Tank 900B & Valve & LDAR Monitoring \& Annual Inspections \\
\hline SV-8-900B & Tank 900B & Valve & LDAR Monitoring \& Annual Inspections \\
\hline SV-9-900B & Tank 900B & Valve & LDAR Monitoring \& Annual Inspections \\
\hline F-EOV-900B & $\begin{array}{c}\text { Tank } 900 \mathrm{~B} \\
\text { (on top) }\end{array}$ & Valve & LDAR Monitoring \& Annual Inspections \\
\hline DV-1-700A & Tank 700A & Valve & LDAR Monitoring \& Annual Inspections \\
\hline DV-2-700A & Tank 700A & Valve & LDAR Monitoring \& Annual Inspections \\
\hline DV-7-700A & Tank $700 \mathrm{~A}$ & Valve & LDAR Monitoring \& Annual Inspections \\
\hline DV $-8-700 \mathrm{~A}$ & Tank $700 \mathrm{~A}$ & Valve & LDAR Monitoring \& Annual Inspections \\
\hline
\end{tabular}




\begin{tabular}{|c|c|c|c|}
\hline $\begin{array}{c}\text { EQUIPMENT } \\
\text { ID } \\
\text { NUMBER } \\
\end{array}$ & $\begin{array}{l}\text { EQUIPMENT } \\
\text { LOCATION }\end{array}$ & $\begin{array}{c}\text { EQUIPMENT } \\
\text { TYPE }\end{array}$ & METHOD OF COMPLIANCE \\
\hline DV-9-700A & Tank 700A & Valve & LDAR Monitoring \& Annual Inspections \\
\hline D-EOV-700A & Tank 700A & Valve & LDAR Monitoring \& Annual Inspections \\
\hline DV-6-700A & Tank 700A & Valve & LDAR Monitoring \& Annual Inspections \\
\hline SV-7-700A & Tank 700A & Valve & LDAR Monitoring \& Annual Inspe rions \\
\hline DV-5-700A & Tank 700A & Valve & LDAR Monitoring \& Annual Inspections \\
\hline SV-5-700A & Tank 700A & Valve & LDAR Monitoring \& Annual Inspections \\
\hline DV-4-700A & Tank 700A & Valve & LDAR Monitoring \& Annual Inspections \\
\hline SV-3-700A & Tank 700A & Valve & LDAR Monitoring \& Annual Inspections \\
\hline DV-3-700A & Tank $700 \mathrm{~A}$ & alve & LDAR Monitoring \& Annual Inspections \\
\hline SV-1-700A & Tank 700A & Valve & LDAR Monitoring \& Annual Inspections \\
\hline SV-2-700A & Tank 700A & Valve & LDAR Monitoring \& Annual Inspections \\
\hline SV-4-700A & Tank $700 \mathrm{~A}$ & Valve & LDAR Monitoring \& Annual Inspections \\
\hline SV-6-700A & Tank $700 \mathrm{~A}$ & Valve & LDAR Monitoring \& Annual Inspections \\
\hline SV-8-700A & Tank $700 \mathrm{~A}$ & Valve & LDAR Monitoring \& Annual Inspections \\
\hline SV-9-700A & Tank 700A & Valve & LDAR Monitoring \& Annual Inspections \\
\hline F-EOV-700A & $\begin{array}{c}\text { Tank 700A } \\
\text { (on top) }\end{array}$ & Valve & LDAR Monitoring \& Annual Inspections \\
\hline DV-1-700B & Tank 700B & Valve & LDAR Monitoring \& Annual Inspections \\
\hline DV-2-700B & Tank 700B & Valve & LDAR Monitoring \& Annual Inspections \\
\hline DV-7-700B & Tank $700 \mathrm{~B}$ & Valve & LDAR Monitoring \& Annual Inspections \\
\hline DV-8-700B & Tank $700 \mathrm{~B}$ & Valve & LDAR Monitoring \& Annual Inspections \\
\hline DV-9-700B & Tank $700 \mathrm{~B}$ & Valve & LDAR Monitoring \& Annual Inspections \\
\hline D-EOV-700B & Tank $700 \mathrm{~B}$ & Valve & LDAR Monitoring \& Annual Inspections \\
\hline DV-6-700B & Tank $700 \mathrm{~B}$ & Valve & LDAR Monitoring \& Annual Inspections \\
\hline SV-7-700B & Tank $700 \mathrm{~B}$ & Valve & LDAR Monitoring \& Annual Inspections \\
\hline DV-5-700B & Tank 700B & Valve & LDAR Monitoring \& Annual Inspections \\
\hline SV-5-700B & Tank 700B & Valve & LDAR Monitoring \& Annual Inspections \\
\hline DV-4-700B & Tank 700B & Valve & LDAR Monitoring \& Annual Inspections \\
\hline SV $-3-700 B$ & Tank $700 \mathrm{~B}$ & Valve & LDAR Monitoring \& Annual Inspections \\
\hline DV $-3-700 B$ & Tank 700B & Valve & LDAR Monitoring \& Annual Inspections \\
\hline
\end{tabular}




\begin{tabular}{|c|c|c|c|}
\hline $\begin{array}{c}\text { EQUIPMENT } \\
\text { ID } \\
\text { NUMBER } \\
\end{array}$ & $\begin{array}{l}\text { EQUIPMENT } \\
\text { LOCATION }\end{array}$ & $\begin{array}{l}\text { EQUIPMENT } \\
\text { TYPE }\end{array}$ & METHOD OF COMPLIANCE \\
\hline SV-1-700B & Tank $700 \mathrm{~B}$ & Valve & LDAR Monitoring \& Annual Inspections \\
\hline SV-2-700B & Tank 700B & Valve & LDAR Monitoring \& Annual Inspections \\
\hline SV-4-700B & Tank $700 \mathrm{~B}$ & Valve & LDAR Monitoring \& Annual Inspections \\
\hline SV-6-700B & Tank $700 \mathrm{~B}$ & Valve & LDAR Monitoring \& Annual Inspections \\
\hline SV-8-700B & Tank $700 \mathrm{~B}$ & Valve & LDAR Monitoring \& Annual Inspections \\
\hline SV-9-700B & Tank 700B & Valve & LDAR Monitoring \& Annual Inspections \\
\hline F-EOV-700B & $\begin{array}{c}\text { Tank } 700 \mathrm{~B} \\
\text { (on top) }\end{array}$ & Valve & LDAR Monitoring \& Annual Inspections \\
\hline DV $-1-600 \mathrm{~A}$ & Tank 600A & Valve & LDAR Monitoring \& Annual Inspections \\
\hline DV-2-600A & Tank 600A & Valve & LDAR Monitoring \& Annual Inspections \\
\hline DV-7-600A & Tank 600A & Valve & LDAR Monitoring \& Annual Inspections \\
\hline DV-8-600A & Tank 600A & Valve & LDAR Monitoring \& Annual Inspections \\
\hline DV-9-600A & Tank 600A & Valve & LDAR Monitoring \& Annual Inspections \\
\hline D-EOV-600A & Tank 600A & Valve & LDAR Monitoring \& Annual Inspections \\
\hline DV $-6-600 A$ & Tank 600A & Valve & LDAR Monitoring \& Annual Inspections \\
\hline SV-7-600A & Tank 600A & Valve & LDAR Monitoring \& Annual Inspections \\
\hline DV-5-600A & Tank 600A & Valve & LDAR Monitoring \& Annual Inspections \\
\hline SV-5-600A & Tank 600A & Valve & LDAR Monitoring \& Annual Inspections \\
\hline DV $-4-600 A$ & Tank 600A & Valve & LDAR Monitoring \& Annual Inspections \\
\hline SV-3-600A & Tank 600A & Valve & LDAR Monitoring \& Annual Inspections \\
\hline DV $-3-600 A$ & Tank 600A & Valve & LDAR Monitoring \& Annual Inspections \\
\hline SV-1-600A & Tank 600A & Valve & LDAR Monitoring \& Annual Inspections \\
\hline SV-2-600A & Tank $600 \mathrm{~A}$ & Valve & LDAR Monitoring \& Annual Inspections \\
\hline SV-4-600A & Tank $600 \mathrm{~A}$ & Valve & LDAR Monitoring \& Annual Inspections \\
\hline SV-6-600A & Tank 600A & Valve & LDAR Monitoring \& Annual Inspections \\
\hline SV-9-600A & Tank 600A & Valve & LDAR Monitoring \& Annual Inspections \\
\hline F-EOV-600A & $\begin{array}{c}\text { Tank } 600 \mathrm{~A} \\
\text { (on top) }\end{array}$ & Valve & LDAR Monitoring \& Annual Inspections \\
\hline DV $-1-600 B$ & Tank 600B & Valve & LDAR Monitoring \& Annual Inspections \\
\hline DV $-2-600 B$ & Tank 600B & Valve & LDAR Monitoring \& Annual Inspections \\
\hline
\end{tabular}




\begin{tabular}{cccl}
$\begin{array}{c}\text { EQUIPMENT } \\
\text { ID } \\
\text { NUMBER }\end{array}$ & $\begin{array}{c}\text { EQUIPMENT } \\
\text { LOCATION }\end{array}$ & $\begin{array}{c}\text { EQUIPMENT } \\
\text { TYPE }\end{array}$ & METHOD OF COMPLIANCE \\
\hline DV-7-600B & Tank 600B & Valve & LDAR Monitoring \& Annual Inspections \\
DV-8-600B & Tank 600B & Valve & LDAR Monitoring \& Annual Inspections \\
DV-9-600B & Tank 600B & Valve & LDAR Monitoring \& Annual Inspections \\
D-EOV-600B & Tank 600B & Valve & LDAR Monitoring \& Annual Inspections \\
DV-6-600B & Tank 600B & Valve & LDAR Monitoring \& Annual Inspections \\
SV-7-600B & Tank 600B & Valve & LDAR Monitoring \& Annual Inspections \\
DV-5-600B & Tank 600B & Valve & LDAR Monitoring \& Annual Inspections \\
SV-5-600B & Tank 600B & Valve & LDAR Monitoring \& Annual Inspections \\
DV-4-600B & Tank 600B & Valve & LDAR Monitoring \& Annual Inspections \\
SV-3-600B & Tank 600B & Valve & LDAR Monitoring \& Annual Inspections \\
DV-3-600B & Tank 600B & Valve & LDAR Monitoring \& Annual Inspections \\
SV-1-600B & Tank 600B & Valve & LDAR Monitoring \& Annual Inspections \\
SV-2-600B & Tank 600B & Valve & LDAR Monitoring \& Annual Inspections \\
SV-4-600B & Tank 600B & Valve & LDAR Monitoring \& Annual Inspections \\
SV-6-600B & Tank 600B & Valve & LDAR Monitoring \& Annual Inspections \\
SV-9-600B & Tank 600B & Valve & LDAR Monitoring \& Annual Inspections \\
F-EOV-600B & Tank 600B & Valve & LDAR Monitoring \& Annual Inspections \\
& (on top) & &
\end{tabular}

